\title{
EVALUATION OF THE EFFECTS OF IN-PLANE LATERAL RESTRAINT AND REINFORCEMENT RATIO ON THE PUNCHING CAPACITY OF FLAT SLAB COLUMN SPECIMENS
}

\author{
A Thesis presented \\ To the Faculty of \\ The Graduate School of the \\ University of Missouri - Columbia
}

In Partial Fulfillments of the Requirements

for Degree

Masters of Science

By

CHRISTOPHER ROBERT HENQUINET

Dr. Sarah L. Orton, Thesis Supervisor

July 2013 
The undersigned, appointed by the dean of the Graduate School, have examined the thesis entitled

EVALUATION OF THE EFFECTS OF IN-PLANE LATERAL RESTRAINT AND REINFORCEMENT RATIO ON THE PUNCHING CAPACITY OF FLAT SLAB COLUMN SPECIMENS

Presented by Christopher Robert Henquinet

A candidate for the degree Masters of Science in Civil Engineering

And herby certify that, in their opinion, it is worthy of acceptance.

Professor Sarah Orton

Professor Glenn Washer

Professor Ye Duan 


\section{ACKNOWLEDGEMENTS}

I would like to thank the entire faculty and staff in the Civil and Environmental Engineering Department at the University of Missouri - Columbia. I would like to extend special thanks to my graduate advisor Dr. Sarah Orton for helping me along during my graduate career. I would also like to thank Dr. Ying Tian from the University of Nevada - Las Vegas for sharing his expertise in this research.

This work was supported by The National Science Foundation under Grant No. 1100146. This support is gratefully acknowledged.

I would also like to express my gratitude to Rex Gish, Brian Samuels and Rich Oberto of Engineering Technical Services for their sharing their time, effort and experience. I would like to thank fellow graduate students Zhonghua Peng, Garrett Havens, Matthew Muenks and Aaron Saucier for assisting me in my research studies. Finally I would like to thank the undergraduate research assistants Zach Treece, Zack Fallert, Spencer Bearden, Scott Hamilton, Austin Stake and Matt Jackson for their time and efforts. 


\section{TABLE OF CONTENTS}

Acknowledgements $\quad$ ii

Table of Contents

Table of Figures $\quad v$

Table of Tables $\quad$ ix

Abstract $\quad x$

$\begin{array}{lr}\text { Chapter } 1 \text { - Introduction } & 1\end{array}$

$1.1-$ Problem 2

1.2 - Objective and Research Plan 2

1.3 - Scope 4

Chapter 2 - Literature Review 5

2.1 - Introduction to Punching Shear 5

2.1.1 - Compressive Membrane Action $\quad 7$

2.1.2 - Tensile Membrane Action $\quad 8$

2.2 - Existing Design Standards

2.3 - Past Punching Failures 13

2.4 - Past Research 16

2.4.1 - Elstner and Hognestad 16

$\begin{array}{ll}2.4 .2 \text { - Kinnunen and Nylander } & 17\end{array}$

$\begin{array}{ll}2.4 .3-\text { Muttoni } & 19\end{array}$

$\begin{array}{ll}2.4 .4-\text { Alam } & 20\end{array}$

$\begin{array}{ll}2.4 .5 \text { - Guice and Rhomberg } & 21\end{array}$

2.4.6 - Habibi et al. 22

Chapter 3 - Experimental Setup 26

3.1 - Prototype Structure Design 26 
3.3 - Slab Specimen Construction 25

3.4 - Test Setup Design $\quad 40$

3.5 - Instrumentation 47

3.6 - Material Properties $\quad 59$

$\begin{array}{lr}\text { Chapter } 4 \text { - Results } & 61\end{array}$

4.1 -Unrestrained Slab Testing $\quad 62$

4.1.1 - 0.5\% Unrestrained Pre-Punching 62

4.1.2-0.5\% Unrestrained Post-Punching 72

4.1.3 - 1\% Unrestrained Pre-Punching 75

4.1.4 - 1.0\% Unrestrained Post-Punching $\quad 85$

$\begin{array}{ll}4.2 \text { - Restrained Slab Testing } & 87\end{array}$

$\begin{array}{ll}\text { 4.2.1 - 0.5\% Restrained Pre-Punching } & 87\end{array}$

4.2.2 - 0.5\% Restrained Post-Punching 101

4.2.3 - 1.0\% Restrained Pre-Punching 103

$\begin{array}{ll}4.2 .4-1.0 \% \text { Restrained Post-Punching } & 117\end{array}$

$\begin{array}{ll}4.3 \text { - Comparison of Results } & 119\end{array}$

$\begin{array}{lr}\text { 4.3.1 -Unrestrained Slab Tests } & 119\end{array}$

$\begin{array}{ll}\text { 4.3.2 - Restrained Slab Tests } & 122\end{array}$

$\begin{array}{ll}4.3 .3-0.5 \% \text { Reinforcement Tests } & 124\end{array}$

$\begin{array}{ll}4.3 .4-1.0 \% \text { Reinforcement Tests } & 126\end{array}$

$\begin{array}{lr}\text { Chapter 5 - Summary and Conclusions } & 129\end{array}$

$\begin{array}{ll}\text { References } & 135\end{array}$

$\begin{array}{ll}\text { Appendix } & 137\end{array}$ 


\section{TABLE OF FIGURES}

Figure 2.1.1 - Diagonal cracks resulting from shear (Harris 2004) 6

Figure 2.1.2 - Illustration of moment couple resisting shear forces (Broms 1990) 6

Figure 2.1.1.1 - Net tensile stress at the center of the slab (Vecchio and Tang, 1989) 7

Figure 2.1.1.2 - Illustration of compressive membrane action (Vecchio and Tang, 1989) 8

Figure 2.1.2.1 - Tensile membrane in a simply supported slab (Dat and Hai 2011) 9

Figure 2.3.1 - Collapsed structure in Jackson, Michigan (Aberdeen Group 1956) 14

Figure 2.3.2 - Photo of the progressive collapse of the Skyline Tower (Crowder 2005) 15

Figure 2.3.3 - Collapsed Sampoong Department Store Building (Gardner et al 2002) 16

Figure 2.4.1 - Sketch of slab specimens tested by Elstner and Hognestad (1956) 17

Figure 2.4.2 - Plot of load vs. slab rotation for slabs (Kinnunen and Nylander 1960) 19

Figure 2.4.3 - Relationship between slab thickness, strength and ductility (Muttoni 2008) 20

Figure 2.4.4 - Load vs. displacement for various restraints (Guice and Rhomberg 1988) 22

Figure 2.4.6.1 -Layout of integrity reinforcement (Habibi et al. 2012) 23

Figure 2.4.6.2 - Effects of increased slab thickness (Habibi et al. 2012) 24

Figure 2.4.6.3 - Photo of slab specimen tested (Habibi et al 2012) 25

Figure 3.1.1 - Plan view of prototype structure 27

Figure 3.1.2 - Sketch of slab top reinforcement layout 28

Figure 3.1.3 - Sketch of slab bottom reinforcement layout 29

Figure 3.2.1 - Isolated slab column specimen in relation to overall prototype structure $\quad 30$

Figure 3.2.2 - Tension reinforcement layout for 1\% reinforcement ratio slabs 31

Figure 3.2.3 - Compression reinforcement layout for 1\% reinforcement ratio slabs 31

Figure 2.3.4 - Tension reinforcement layout for the $0.5 \%$ reinforcement ratio slabs 32

Figure 3.2.5 - Compression reinforcement layout for the $0.5 \%$ reinforcement ratio slabs 33

Figure 3.2.6 - Elevation view of slab column specimens 34

Figure 3.2.7 - Cross section view of column section 34

Figure 3.3.1 - Formwork for the slab specimens 36 
Figure 3.3.2 - Picture of slab formwork showing slab depth and reinforcement depths 38

Figure 3.3.3 - Slab specimen ready to pour $\quad 39$

Figure 3.3.4 - Slab specimen just after pouring was completed $\quad 40$

Figure 3.4.1 - Unrestrained test setup with slab specimen ready for testing 41

Figure 3.4.2 - Picture of one of the eight adjustable vertical supports 42

Figure 3.4.3 - Detail of anchorage design 43

Figure 3.4.4 - Anchorage area prior to casting slab 44

Figure 3.4.5 - Bracing to prevent columns from sliding 46

Figure 3.4.6 - Compression brace to stiffen the flanges 47

Figure 3.5.1 - Layout of tension reinforcement strain gages for 0.5\% slabs 49

Figure 3.5.2 - Layout of compression reinforcement strain gages for $0.5 \%$ slabs $\quad 50$

Figure 3.5.3 - Tension reinforcement strain gage layout for 1\% slabs 52

Figure 3.5.4 - Compression reinforcement strain gage layout for 1\% 53

Figure 3.5.5 - Concrete gages in position $\quad 54$

Figure 3.5.6 - Horizontal measurement locations $\quad 54$

Figure 3.5.7 - Horizontal LVDT in position $\quad 55$

Figure 3.5.8 - Center string pot in position for testing 56

Figure 3.5.10 - Center load cell in position $\quad 57$

Figure 3.5.11 - Horizontal Tension and Compression load cells 58

Figure 4.1 - Top view of slab specimen prior to testing 61

Figure 4.2 - Underside of slab prior to testing $\quad 62$

Figure 4.1.1.1 - Pre-punching load vs. center displacement $0.5 \%$ unrestrained 63

Figure 4.1.1.2 - Underside of the 0.5\% unrestrained slab after failure 64

Figure 4.1.1.3 - Load vs. vertical displacements 0.5\% unrestrained 65

Figure 4.1.1.4 - Horizontal expansions 0.5\% unrestrained 66

Figure 4.1.1.5 - Concrete Strains 0.5\% unrestrained 67

Figure 4.1.1.6 - Tension reinforcement strains 0.5\% unrestrained 68 
Figure 4.1.1.7 - Tension reinforcement strains $0.5 \%$ unrestrained

Figure 4.1.1.8 - Compression reinforcement strains 0.5\% unrestrained $\quad 70$

Figure 4.1.1.9 - Tension reinforcement strains $0.5 \%$ unrestrained 71

Figure 4.1.1.10 - Compression reinforcement strains 0.5\% unrestrained 72

Figure 4.1.2.1 - Post-punching load deflection 0.5\% unrestrained 73

Figure 4.1.2.2 - Top view after testing 0.5\% unrestrained $\quad 74$

Figure 4.1.2.3 - Underside after testing 0.5\% unrestrained 75

Figure 4.1.3.1 - Center load deflection pre-punching 1.0\% unrestrained 76

Figure 4.1.3.2 - Load vs. vertical displacements 1.0\% unrestrained 77

Figure 4.1.3.3 - Concrete strains 1.0\% unrestrained 79

Figure 4.1.3.4 - Tension reinforcement strains 1.0\% unrestrained 80

Figure 4.1.3.5 - Tension reinforcement strains 1.0\% unrestrained 81

Figure 4.1.3.6 - Compression reinforcement strains 1.0\% unrestrained 82

Figure 4.1.3.7 - Tension reinforcement strains 1.0\% unrestrained 83

Figure 4.1.3.8 - Compression reinforcement strains 1.0\% unrestrained 84

Figure 4.1.3.9 - Underside of slab after punching 1.0\% unrestrained 85

Figure 4.1.4.1 - Post-punching load deflection 86

Figure 4.1.4.2 - Underside of slab after testing $\quad 87$

Figure 4.2.1.1 - Center load deflection pre-punching 0.5\% restrained 88

Figure 4.2.1.2 - Load vs. vertical displacements 0.5\% restrained $\quad 89$

Figure 4.2.1.3 - Horizontal expansion 0.5\% restrained 90

Figure 4.2.1.4 - Horizontal load cell data $0.5 \%$ restrained 91

Figure 4.2.1.5 - Horizontal compressive loads from strain gages 0.5\% restrained 92

Figure 4.2.1.6 - Concrete strains 0.5\% restrained 94

Figure 4.2.1.7 - Tension reinforcement strains $0.5 \%$ restrained 95

Figure 4.2.1.8 - Tension reinforcement strains 0.5\% restrained 196

Figure 4.2.1.9 - Compression reinforcement strains 0.5\% restrained 98 
Figure 4.2.1.10 - Tension reinforcement strains $0.5 \%$ restrained

Figure 4.2.1.11 - Compression reinforcement strains 0.5\% restrained 100

Figure 4.2.1.12 - Underside of slab after punching 0.5\% restrained 101

Figure 4.2.2.1 - Post punching load deflection 0.5\% restrained 102

Figure 4.2.2.2 - Underside of slab after testing 103

Figure 4.2.3.1 - Center load deflection pre-punching 1.0\% restrained 104

Figure 4.2.3.2 - load vs. vertical displacements 1.0\% restrained 105

Figure 4.2.3.3 - Horizontal expansion 1.0\% restrained 106

Figure 4.2.3.4 - Horizontal load cell data 1.0\% restrained 107

Figure 4.2.3.5 - Horizontal loads from strain gages 1.0\% restrained 108

Figure 4.2.3.6 - Concrete strains 1.0\% restrained 110

Figure 4.2.3.7 - Tension reinforcement strains 1.0\% restrained 111

Figure 4.2.3.8 - Tension reinforcement strains 1.0\% restrained 112

Figure 4.2.3.9 - Compression reinforcement strains 1.0\% restrained 114

Figure 4.2.3.10 - Maximum tension reinforcement strains 1.0\% restrained 115

Figure 4.2.3.11 - Maximum compression reinforcement strains 1.0\% restrained 116

Figure 4.2.3.12 - Underside of slab after punching 1.0\% restrained 117

Figure 4.2.4.1 - Post-punching load deflection 1.0\% restrained 118

Figure 4.2.4.2 - Underside of slab after testing 1.0\% restrained 119

$\begin{array}{ll}\text { Figure 4.3.1.1 - Load deflection pre-punching unrestrained tests } & 121\end{array}$

Figure 4.3.2.1 - Normalized load deflection pre-punching restrained tests 123

Figure 4.3.3.1 - Normalized load deflection pre-punching 0.5\% tests 125

Figure 4.3.4.1 - Normalized load deflection pre-punching 1.0\% tests 127 


\section{TABLE OF TABLES}

Table 1.2.1 - Test matrix for research plan $\quad 4$

Table 3.6.1 - Summary of concrete compressive strengths 59

$\begin{array}{lr}\text { Table 5.1 - Punching loads and residual capacities } & 130\end{array}$

Table 5.2 - Slab rotations prior to failure $\quad 132$

Table 5.3 - Concrete strains prior to failure 132

Table 5.4 - Horizontal expansions and horizontal loads 133 


\begin{abstract}
Localized damage to certain structural members in a building can trigger a chain reaction which results in a partial or complete collapse of the building. A collapse of this nature is called a progressive collapse and has the potential to cause significantly more damage than would be expected from the failure of the first member. This research project is particularly concerned with the potential of progressive collapses in older flat plate reinforced concrete structures. The nature of the design of these structures puts them at risk for progressive collapses normally resulting from punching shear failures at the slab column connections.

The goal of this research is to investigate the behavior of slab column specimens in a setup that more closely resembles a complete structure by applying in-plane lateral restraints. In a structure compressive membrane action can help to increase the capacity of the connection prior to a failure occurring and tensile membrane action can increase the residual capacity of a connection after it has failed. Specifically the experimental tests examine the effects of in plane lateral restraint on the punching shear capacity of the slabs prior to failure and the effects of reinforcement ratio before and after the failure occurs. Better estimation of the punching shear capacity will lead to better prediction if the punching shear failure will cause a progressive collapse.
\end{abstract}

Isolated slab column specimens were constructed with two different reinforcement ratios $(0.5 \%$ and $1.0 \%)$ and tested in two different test setups (without lateral restraint and with lateral restraint). The slab column specimens were constructed following the provisions in the 1971 American Concrete Institute design code. The goal of the testing was to simulate a progressive collapse scenario where a nearby supporting column had been damaged. 
Slabs tested with the higher reinforcement ratio had punching shear capacities that were at least $130 \%$ of the capacities of the specimens with lower reinforcement ratios. It was found that the unrestrained slab with the $1.0 \%$ reinforcement ratio had a punching capacity just over 69 kips which is very close to the ACI equations capacity estimation (70 kip) while the unrestrained slab with the $0.5 \%$ reinforcement ratio had a punching capacity of just under 52 kips.

The effects of the addition of in-plane lateral restraint were not as well defined. The restrained slab with the $1 \%$ reinforcement ratio had a punching capacity of 74 kips and the retrained slab with $0.5 \%$ reinforcement had a capacity of 54 kips. The restrained slabs showed little to no increase in punching shear capacity due to the in-plane lateral restraint. However, the actual stiffness of the test setup (500 kip/in) was much lower than the designed stiffness (1600 kip/in) therefore the full benefits of the in-plane restraint may not have be realized.

The post punching capacity of the slab column specimens was also investigated. All four of the specimens tested had peak residual capacities of more than $70 \%$ of the punching capacity. This residual capacity may be capable of arresting the progression of collapse. These residual capacities are higher than the estimated residual capacities based on previous research work possibly the result of the reinforcement being hooked at the edges of the slab specimens. 


\section{Chapter 1 - Introduction}

A progressive collapse is a structural failure resulting from the loss of one primary structural member such as a column or girder. The initial loss of a structural member can lead to failures of the surrounding members which creates a domino effect style collapse of some or all of the structure. Failures of this type can result in large losses of life as was evident in previous collapses including the World Trade Center in 2001 and the Oklahoma City bombing in 1995.

Flat plate reinforced concrete structures are particularly vulnerable to progressive collapses. Flat plate structures are a common design option because of their ease of construction and reduced cost. A flat plate structure consists of reinforced slabs supported directly by the columns, with no beams, girders and or column capitals present. Due to this style of design flat plate structures are vulnerable to punching shear failures at the slab column connections. When one of the connections becomes overloaded and fails the load previously carried through that connection must now be redistributed to the surrounding connections, which can in turn overload those connections causing them to fail as well, this pattern leads to a progressive collapse.

Punching shear failures are the result of high localized stresses at the connection between the slab and the column. If the connection is not strong enough to resist the applied forces a punching failure could occur. Current design codes such as the ones produced by American Concrete Institute (ACI) and the American Society of Civil Engineers (ASCE) seek to prevent such failures through their design procedures. Most of the design code equations are formulated based on testing of slab column specimens isolated from the surrounding structure without lateral restraints. The goal of this research is to investigate the behavior of slab column specimens in a setup that more closely resembles a complete structure by applying in-plane lateral restraints. In a structure compressive membrane action can help to increase the capacity of the connection 
prior to a failure occurring and tensile membrane action can increase the residual capacity of a connection after it has failed. If better predictions of the capacity of slab column connections are made, then analysis for the possibility of progressive punching shear failures can be improved..

\section{1 - Problem}

There has been little research on the punching behavior of flat plate slabs tested with the effects of lateral restraint, also much of the testing that has been done has been stopped just after the punching failure occurs which does not allow the residual capacity to be investigated. This

research hopes to collect experimental data on the behavior of slab column connections subjected to punching shear failures. Specifically the effects of in plane lateral restraint on the punching shear capacity of the slabs prior to failure and the effects of reinforcement ratio before and after the failure occurs. This research is being conducted in the hope that at its conclusion mitigation strategies can be put in place to aid in the design of safer structures.

\section{2 - Objective and Research Plan}

The primary objectives of this research were to analyze the punching shear capacity of slab column connections subjected to the loss of a surrounding column as well as determine the residual capacity of such failed connections. Evidence has shown that the presence of in plane lateral restraint can increase the punching capacity of slab column connections this research hopes to further investigate its effectiveness along with the effects of the reinforcement ratio of the slab.

This phase of the research project included the construction and testing of four isolated slab column specimens, two of which were constructed with a reinforcement ratio (volume of steel reinforcement in comparison to volume of slab) of $1.0 \%$ while the other two were 
constructed with a reinforcement ratio of $0.5 \%$. One slab constructed at each reinforcement ratio was tested without lateral restraint applied while the other was tested with lateral restraint present to allow its effects to be evaluated. The slab column specimens were constructed at a scale of 0.73 in order to test them within the constraints of the testing facility. The slab was supported vertically along all four sides with connections to a reaction frame added to simulate the effects of in plane lateral restraint. A hydraulic ram was used to load the slab column specimens statically and allow the punching failure to be analyzed.

The tests and results that are presented in this thesis are a portion of a larger research project. The four slab column specimens that were tested and the results that are reported account for half of the eight total isolated specimen tests planned for the duration of the project. Future tests are designed to determine the effects of the anchorage of the reinforcement as well as the effects of dynamic loading on the performance of the isolated slab column specimens. The full test matrix can be seen in Table 1.2.1, the four tests discussed in this thesis are tests numbers $1-4$ in the matrix. 
Table 1.2.1 - Test matrix for research plan.

\begin{tabular}{|c|c|c|c|c|}
\hline Test \# & Loading Rate & Slab Reinf. Ratio & In-Plane & Slab Bending \\
& & & Restraint & \\
\hline Test \# 1 & Static & $1.0 \%$ & Unrestrained & Negative \\
\hline Test \# 2 & Static & $0.5 \%$ & Unrestrained & Negative \\
\hline Test \# 3 & Static & $1.0 \%$ & Restrained & Negative \\
\hline Test \# 4 & Static & $0.5 \%$ & Restrained & Negative \\
\hline Test \# 5 & Static & $0.5 \%$ & Restrained & Positive \\
\hline Test \# 6 & Static & $0.5 \%$ & Restrained & Negative \\
\hline Test \# 7 & Dynamic & $0.5 \%$ & Restrained & Negative \\
\hline Test \# 8 & Dynamic & $0.5 \%$ & Restrained & Negative \\
\hline
\end{tabular}

\section{3 - Scope}

This thesis is organized into five chapters. Chapter 2 provides a literature review on past research in the area of punching shear including the effects of reinforcement ratio and lateral restraint as well as case studies on past structural failures resulting from progressive collapses. Chapter 3 details the design and construction of the isolated slab column specimens as well as the design and construction of the test setups used. Chapter 4 presents the data collected from the testing and makes comparisons between the tests that were conducted. Chapter 5 summarizes the results and presents conclusions that can be drawn from them. Lastly an appendix section and list of references concludes this thesis. 


\section{Chapter 2 - Literature Review}

This chapter will detail how punching shear occurs as well as well as structural failures resulting from punching shear failures. Also, current design code procedures and past research in the area of punching shear capacity of flat plate reinforced concrete slabs will be discussed.

\section{1 - Introduction to Punching Shear}

Structural failures occurring at the slab column connection in reinforced concrete structures are typically referred to as punching shear failures, or two way shear failures. They are the result of high stresses building up around the slab column connection, resulting from the gravity loading over the tributary area of the slab. When these stresses reach high enough levels at the connection they cause a failure which is typically dominated by shear.

In a continuous framing system there are large negative moments that occur at the column connections while the largest positive moments occur at the midspan. In a flat plate system these forces are required to be transferred by the slab into the column. When the moment increases to a certain level it causes flexural cracks in the concrete. These cracks begin to form in circular pattern in the slab around the column. Since the slab is also transferring shear forces into the column at the same location shear cracks also start to develop around the column if the shear forces become large enough, this can be seen in Figure 2.1.1. As the shear cracks begin to form the shear forces are resisted by a moment couple formed by a conical shell at the bottom of the slab next to the column which is in compression and a tension tie provided by the top reinforcement. This couple resisting the shear forces is illustrated by Broms (1990) in Figure 2.1.2. This moment couple resist shear forces until the concrete in the conical shell crushes at which point a punching failure occurs. 


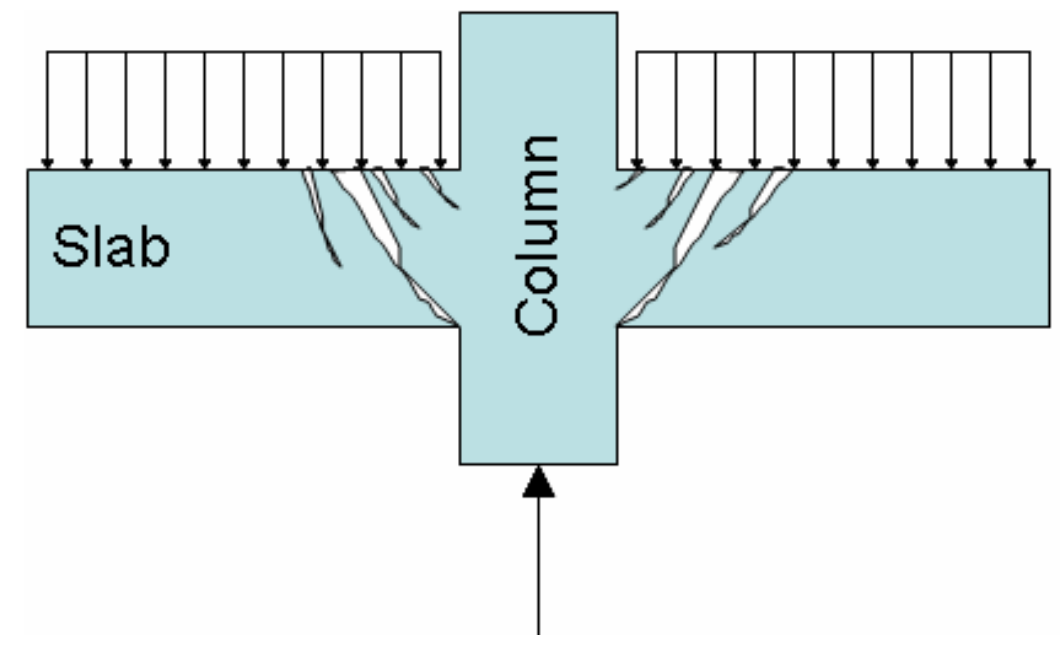

Figure 2.1.1 - Diagonal cracks resulting from shear (Harris 2004 ).

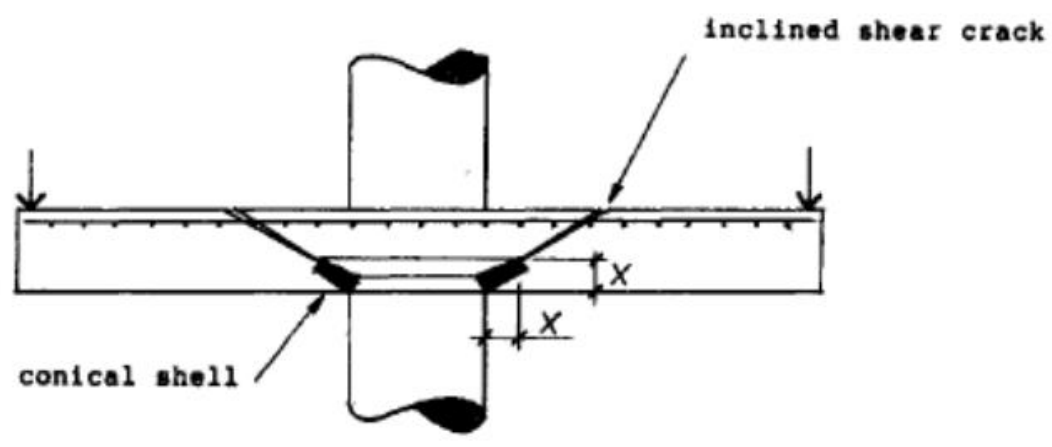

Figure 2.1.2 - Illustration of moment couple resisting shear forces (Broms 1990).

Punching shear failures are brittle failures, which means that they can occur without warning as opposed to flexural failures, which are ductile and have well defined warning signs. Once a punching failure has occurred the load capacity of that connection is reduced which means that a portion of the forces that used to be transferred through that connection must be carried by other connections. This can lead to overloading those connections which can cause them to have a punching failure which leads to a potential progressive collapse. 


\subsection{1 - Compressive Membrane Action}

Compressive membrane action can lead to increased flexural capacity of slabs due to inplane lateral compressive forces. When reinforced concrete slabs are subjected to gravity loads the extreme tensile fiber of the concrete cracks as it reaches its modulus of rupture $\left(f_{r}\right)$. After the concrete cracks the bottom reinforcement goes into tension because it is now required to carry the load that the cracked concrete cannot. As the loading increases the overall tensile stress at the bottom face of the slab is greater than the compressive stress at the top of the slab which results in a net tensile stress at the centerline of the slab (Vecchio and Tang 1989). These effects are illustrated in Figure 2.1.1.1.

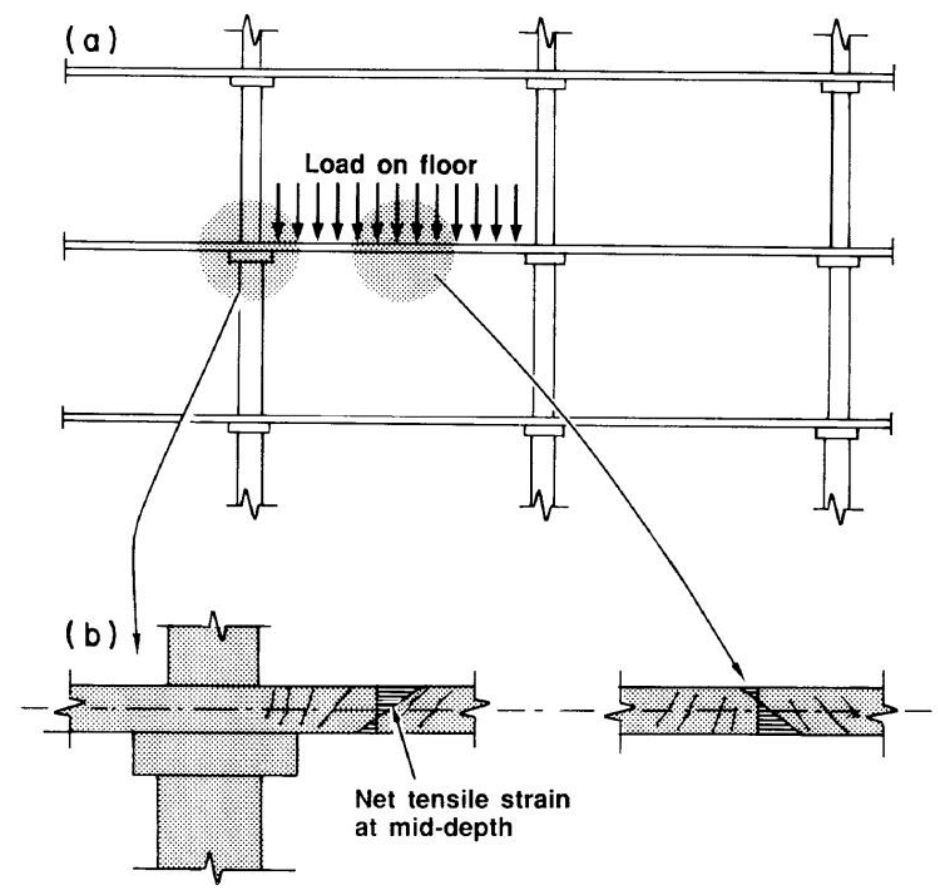

Figure 2.1.1.1 - Picture demonstrating the net tensile stress at the center of the slab (Vecchio and Tang, 1989). 
The net tensile stress results in the slab attempting to expand outwards, this expansion is restricted by the connection between the slab and the surrounding columns. This restriction induces lateral compressive forces in the slab, which allow for increased flexural capacity. The increased capacity of the slab is illustrated in Figure 2.1.1.2.
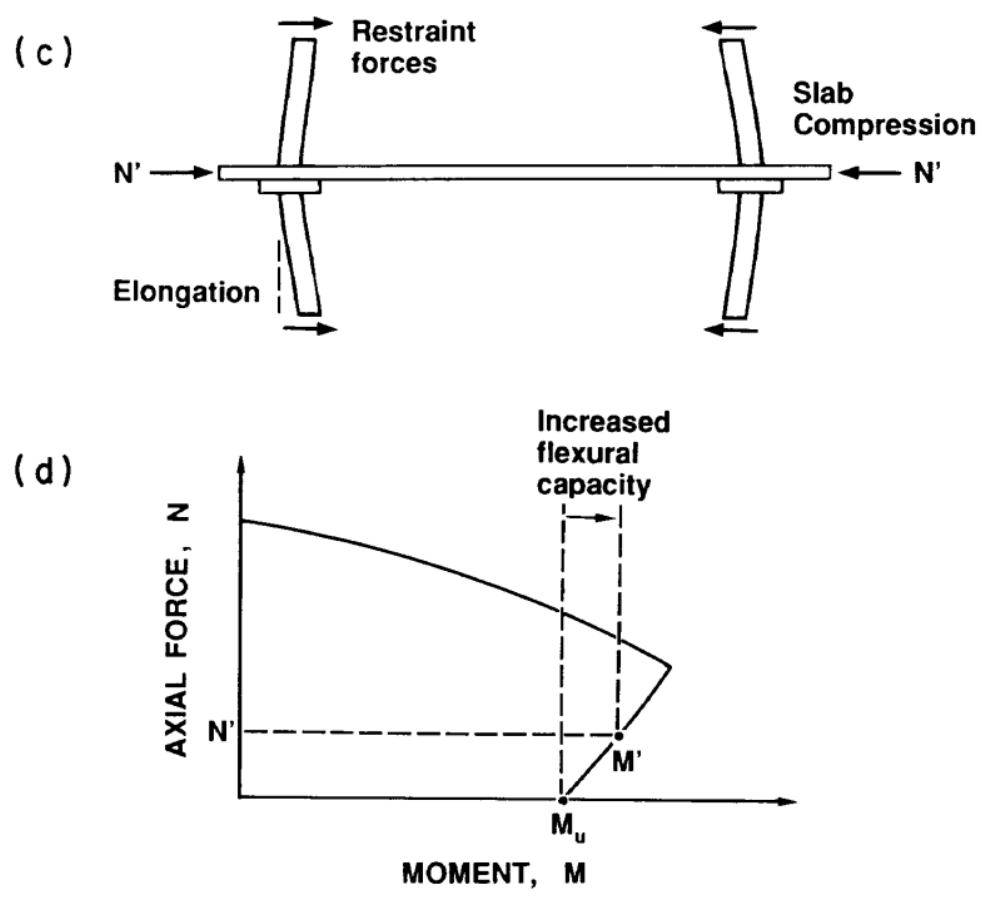

Figure 2.1.1.2 - Figure to illustrate the increased capacity of the slab due to compressive membrane action (Vecchio and Tang, 1989).

\subsection{2 - Tensile Membrane Action}

In slabs even when no lateral restraint is present the possibility of increased load carrying capacity through tensile membrane action exists. After a punching failure when continuous reinforcement is present load can still be carried by the slab specimen because of tensile capacity of the reinforcement. Once large deformations have occurred a compressive ring in the exterior 
of the slab develops, this compression zone provides restraint for the tensile forces in the center of the slab. The restrained tensile forces acting at large deflections work like a catenary and are able to support the vertical loads. Therefore the overall capacity of the slab is a combination of the tensile membrane action in the center of the slab and the increased flexural capacity in the exterior of the slab due to the in-plane compressive forces that are present (Dat and Hai 2011). This is illustrated in Figure 2.1.2.1 (Dat and Hai 2011).
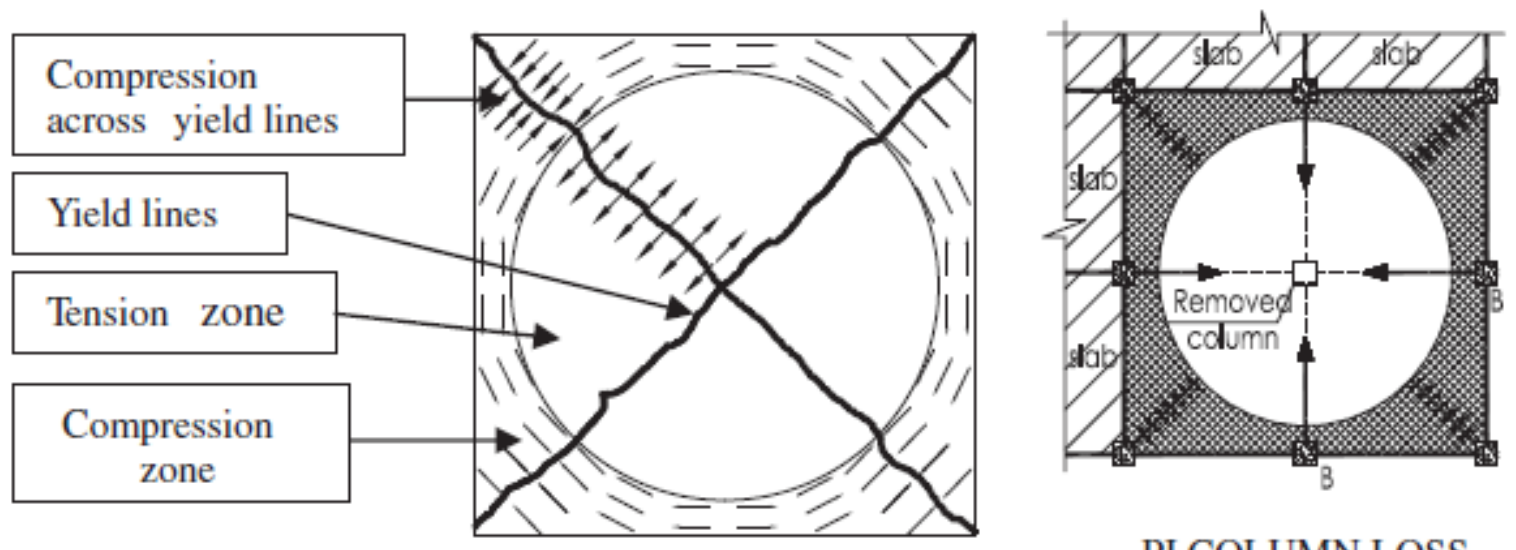

PI COLUMN LOSS

Figure 2.1.2.1 - Tensile membrane in a simply supported slab (Dat and Hai 2011).

\section{2 - Existing Design Standards}

Currently there are design standards that seek to prevent punching shear failures in structures, however these standards vary greatly depending on the design code being used. Also, many of the current design procedures may not account for all of the strength that exists within the slab column connection. This section will explore the existing design procedures in the area of shear at slab column connections.

There are many different equations that can be used to calculate the punching shear capacity of a concrete slab. The equations that are discussed were provided by ACI, Eurocode 2 
and Model Code 90 as well as technical papers on prior research in the area of punching shear failures. Most equations yield different capacities for the same slab as a result of the variables that are used in the equation. One of the most common differences in the equations is the definition of the critical section. The critical section is defined as the area around the column where the failure crack is expected to occur.

ACI defines the critical section for shear at a distance of $d / 2$ from the faces of the column (American Concrete Institute 2008). Also, ACI has defined the critical section as a rectangle for rectangular columns and a circle for circular columns, whereas Eurocode and Model Code define it with rounded corners for rectangular and circular columns. Of the three codes that are being examined ACI uses the smallest definition of the critical section. Eurocode 2 defines the critical section at a distance $1.5 \mathrm{~d}$ from the face of the column (Eurocode 1998) which gives a significantly larger area than that defined by ACI. Also, the corners of the critical section are rounded for circular and rectangular columns. Model code 90 defines the critical section at a distance of $2 \mathrm{~d}$ from the faces of the column (Model Code 1999) which gives the largest critical section out of the three codes that have been discussed. Model Code 90 uses rounded corners for its definition of the critical section which is similar to Eurocode 2. In addition to the different definitions of the critical section that are used, many equations take into account different factors that affect the predicted capacity of the slab.

ACI provides three equations that can be used to calculate the capacity of a slab, the lesser of the three solutions is the one that should be used as the expected capacity. All of the ACI equations take in to account the compressive strength of the concrete but there are other factors in the equations that are different. The ACI equations are given in Equations 1-3, where $V_{c}$ is the shear strength of the slab, $d$ is the effective slab depth, $b_{o}$ is defined as the perimeter of 
the critical section (at a distance of $\mathrm{d} / 2$ from the face of the column), $\mathrm{a}_{\mathrm{s}}$ is an empirical factor based on column location (interior, edge of structure or corner of structure), $\beta$ is the ratio of the long side of the column to the short side of the column and $\mathrm{f}_{\mathrm{c}}$ is the compressive strength of the concrete. Equation 1 controls for rectangular columns, Equation 2 controls for exterior or corner columns and Equation 3 controls for interior square columns.

$$
\begin{array}{ll}
V_{c}=\left(2+\frac{4}{\beta}\right) \lambda \sqrt{f^{\prime} c} b_{o} d & \text { Equation 1 (ACI 1999) } \\
V_{c}=\left(\frac{\alpha_{s} d}{b_{o}}+2\right) \lambda \sqrt{f^{\prime} c} b_{o} d & \text { Equation 2 (ACI 1999) } \\
V_{c}=4 \lambda \sqrt{f^{\prime} c} b_{o} d & \text { Equation 3 (ACI 1999) }
\end{array}
$$

Completing calculations using the correct ACI equation for the slabs constructed for this research it was found that the punching shear capacity should have been about 70,000 pounds, since the ACI equations do not take into account reinforcement ratio all of the slabs constructed have the same expected punching shear strength.

Another equation that was used to calculate an anticipated capacity for the slab was generated by Tian et al. (2008). The equation used included the yield strength of the reinforcement as well as the reinforcement ratio in addition to the compressive strength of the concrete, the column size and the slab depth. The equation used the same definition of the critical section as ACI. Tian's equation for punching shear capacity is shown as Equation 4 where, $V_{n}$ is the shear strength of the slab, $\mathrm{f}_{c}$ is the compressive strength of the concrete, $\mathrm{f}_{\mathrm{y}}$ is the yield strength of the reinforcement, $\rho$ is the reinforcement ratio, $\mathrm{A}_{\mathrm{c}}$ is defined as $\left(A_{c}=4(c+d) d\right)$ where $\mathrm{c}$ is the width of the column and $\mathrm{d}$ is the effective slab depth and $\xi$ is defined as $(\xi=$ $(\mathrm{c} / \mathrm{d})^{1 / 2}$. 


$$
\mathrm{V}_{\mathrm{n}}=2.3 \xi \mathrm{A}_{\mathrm{c}}\left(\rho \mathrm{f}_{\mathrm{y}} \sqrt{f^{\prime} c}\right)^{1 / 2}
$$

Equation 4 (Tian 2008)

Using Equation 4 (Tian 2008) the capacity of the slab with the $0.5 \%$ reinforcement ratio was estimated to be about 81,800 pounds and the capacity of the slab with the $1.0 \%$ reinforcement ratio was estimated to be 115,700 pounds.

Model Code (1990) uses an equation that takes into account the concrete compressive strength $f_{c}$, reinforcement ratio $\rho$, effective slab depth $d$ and critical section perimeter $b_{w}($ defined at a distance of $2 \mathrm{~d}$ from the face of the column) to predict the punching shear strength of flat slabs. The shear strength equation from Model Code (1990) can be seen as Equation 5.

$$
V_{c}=\left[0.12\left(1+(200 / d)^{1 / 2}\right)\left(100 * \rho^{*} f_{c}\right)^{1 / 3}\right] b_{w} * d \quad \text { Equation } 5(\text { Model Code 1990) }
$$

Using Equation 5 the estimated capacity of the slabs constructed with the reinforcement ratio of $0.5 \%$ was 50,400 pounds, while the estimated capacity of the slabs with the reinforcement ratio of $1.0 \%$ was 63,500 pounds.

Eurocode 2 uses an equation that takes into account the compressive strength of the concrete $\mathrm{f}_{\mathrm{c}}$, the reinforcement ratio $\rho$, the effective slab depth $\mathrm{d}$ and the critical section perimeter $b_{w}$ (defined at a distance of $1.5 \mathrm{~d}$ from the face of the column) to predict the shear strength of flat slabs. The equation published by the Eurocode is presented as Equation 6 .

$$
V_{c}=\left[0.167(1.6-d) f_{c}(1.2+40 * \rho)\right] b_{w}^{*} d \quad \text { Equation } 6 \text { (Eurocode 2, 1998) }
$$

Using Equation 6 the estimated capacity of the slabs constructed with the reinforcement ratio of $0.5 \%$ was 55,500 pounds, and the capacity of the slabs with the $1.0 \%$ reinforcement ratio was 70,000 pounds. 
The equations that can be used to estimate the punching capacity of a slab column connection can vary significantly. There can be many differences in the variables that are used in the equations as well as differences in the way that some of the variables are defined. This leads to many different predicted capacities of the same slab which can create issues when trying to ensure the slab column connection that you have designed will be adequate.

\section{3 - Past Punching Failures}

Punching shear failures have occurred in the past in flat plate reinforced concrete structures. Although, an isolated punching failure in a structure does not guarantee a total structural collapse there have been some cases where the failure of one connection has led to the surrounding connections being overloaded in turn causing them to fail. A failure of this type is described as a "progressive collapse" where one failure causes the next (similar to a domino effect). Considering that there are many structures that have been constructed using a flat plate framing system there has been a considerable amount of research done in the area of punching shear in the hope that future failures can be prevented. Before looking into the past research it is important to examine some of the past failures to fully understand the consequences associated with failures of this type.

One structural failure attributed to punching shear occurred in an office building in Jackson, Michigan in 1956. The structure was still under construction when the flat plate slabs failed due to shear at the column connections. It was speculated that the failure occurred because the area of the slab around some of the interior columns was reduced by the addition of holes to allow the instillation of pipes and duct work (Aberdeen Group 1956). It can be seen in Figure 
2.3.1 that most of the structure that had already been constructed collapsed as a result of the punching failures at the connections.

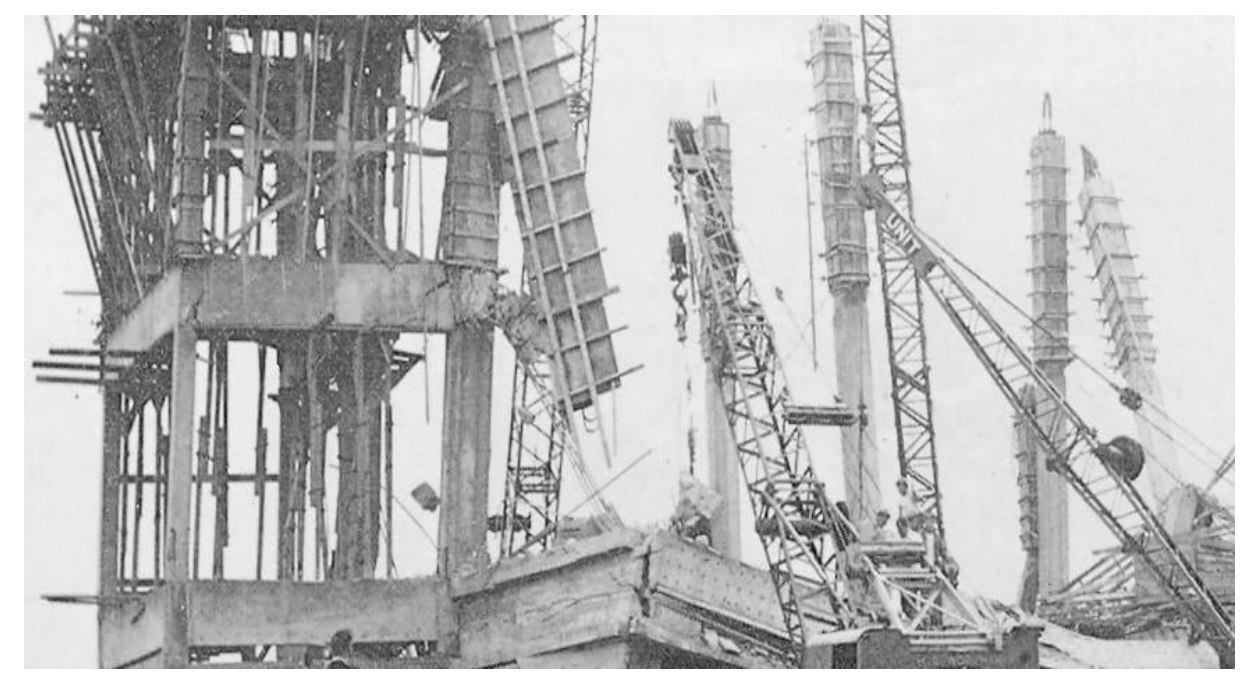

Figure 2.3.1 - Photo of collapsed structure in Jackson, Michigan (Aberdeen Group 1956).

Another instance of failure during construction occurred in Boston, Massachusetts in 1971, this failure resulted in the deaths of four men. The structure was nearing completion when a slab connection at the roof failed, this initial failure caused a progressive collapse in the structure that propagated all the way down to the ground level. The root cause of this failure was inadequate concrete strength that resulted from poor protection from cold weather during the curing process (King and Delatte, 2004). A third case where a punching shear failure has occurred in a structure during construction happened in 1973, the Skyline Plaza Tower collapsed resulting in 48 casualties. After the completion of one of the stories in the tower the construction shoring below was removed prior to the scheduled date which resulted in punching shear failures around multiple slab column connections above (Crowder, 2005). These failures resulted in the slabs below being overloaded which caused them to fail as well, this progressive collapse propagated all the way down to the ground as can be seen in Figure 2.3.2. 


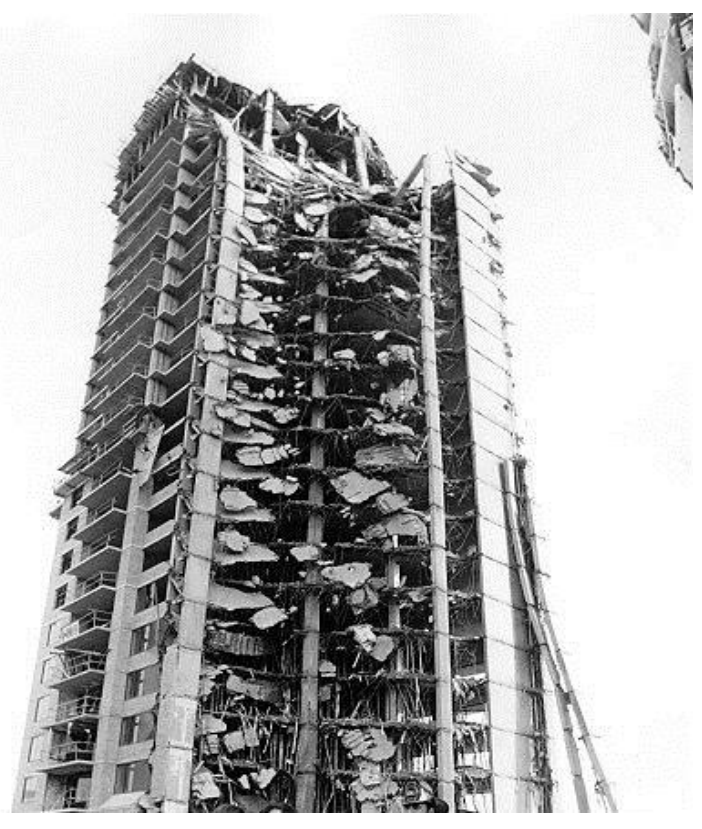

Figure 2.3.2 - Photo of the results of the progressive collapse of a portion of the Skyline Tower (Crowder 2005).

A fourth example of structural failure due to punching shear occurred in South Korea in 1995, a five story department store collapsed while it was in use resulting in the deaths of 501 people. The structure was not initially a department store, in order to convert the existing structure columns were removed to provide space for escalators to be installed. However this was not the only issue, the fifth floor was also renovated to accommodate a restaurant which increased the dead load on that floor by over 30\% (Gardner et al, 2002). The remaining slab column connections were not adequate to resist the increased loading, this ultimately resulted in a punching shear driven progressive collapse of a large portion of the structure. The loss of life associated with this collapse increased the need for research in the area of punching shear failures as well as progressive collapse. The collapsed structure can be seen in Figure 2.3.3. 


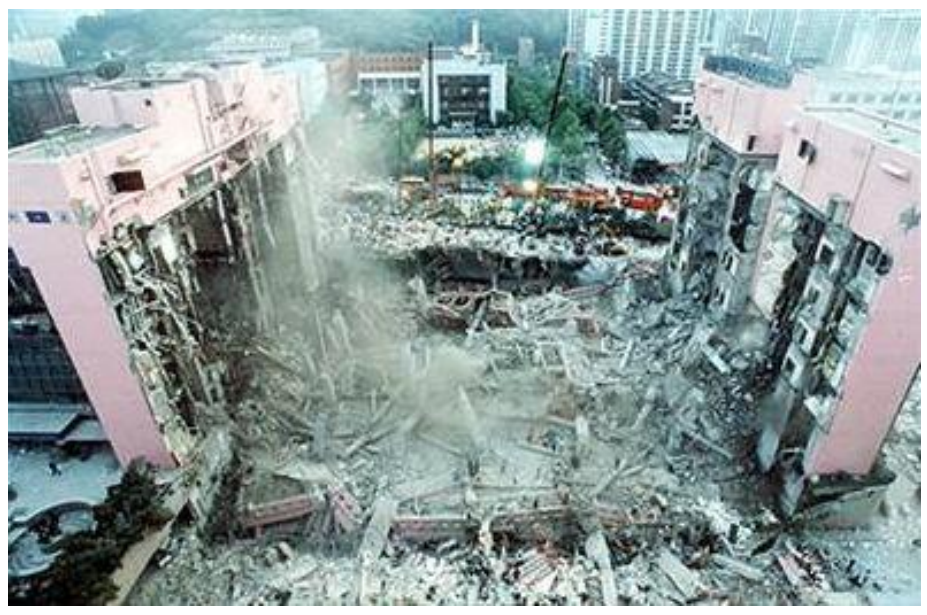

Figure 2.3.3 - Photo of the collapsed Sampoong Department Store Building (Gardner et al 2002).

\section{4 - Past Research}

Since the 1950's there has been an increasing amount of research in the area of punching shear failures of flat plate reinforced concrete slabs. A brief overview of some of the past research work that relates to this project will be presented in this section.

\subsection{1 - Elstner and Hognestad}

Some of the earliest work done in the area of punching shear was conducted in 1956 by Elstner and Hognestad (1956). They tested 39 flat plate reinforced concrete slabs loaded from above through a column stud. All of the slabs tested were 6 feet square with a thickness of 6 inches. Variables that changed within the tests included concrete 
compressive strength, volume of tension and or compression reinforcement, addition of shear reinforcement as well as the boundary support conditions. At the conclusion of the testing it was determined that $85 \%$ of the slabs tested failed in shear due to punching. Also, it was determined that the ultimate failure of the slab occurred after yielding of the reinforcement in the vicinity of the column, thus yielding of reinforcement can be used as an obvious indicator of the presence of punching shear (Elstner and Hognestad, 1956). The tested slab specimens were loaded from a top column stud however no bottom column stud was present which may have prevented the researchers from obtaining a completely accurate stress distribution within the specimens. A sketch of the test specimens can be seen in Figure 2.4.1.

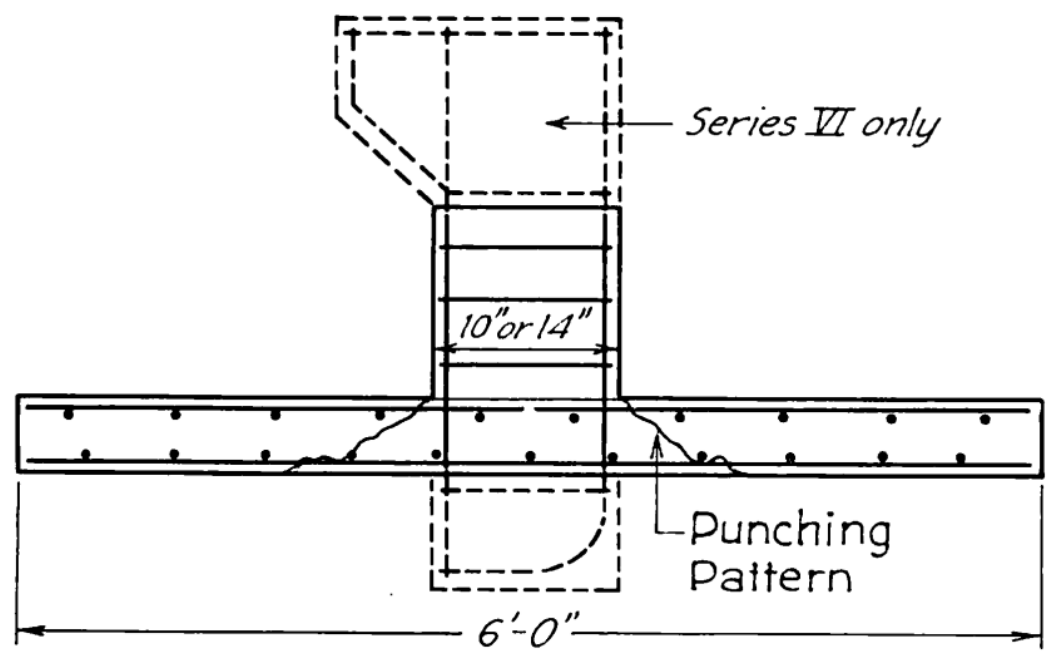

Figure 2.4.1 - Sketch of slab specimens tested by Elstner and Hognestad (1956).

\subsection{2 - Kinnunen and Nylander}

Kinnunen and Nylander (1960) conducted testing on flat plate reinforced concrete slabs in the 1960's. The primary variable that they tested was the flexural reinforcement ratio of the slabs. 
Their testing was designed to determine the effects of the reinforcement ratio on the punching shear capacity of the slabs. Their findings showed that slabs tested with low reinforcement ratios (around $0.5 \%$ ) failed in a significantly more ductile manner in comparison to slabs tested with a high reinforcement ratio (about $2 \%$ ) which failed in a brittle manner. The ultimate capacity of the slabs tested with the lower reinforcement ratio was dependent on the flexural strength of the slabs thus the punching failure did not occur until after large plastic deformations. However the slabs with higher reinforcement ratios which failed in a brittle manner failed before yielding of the reinforcement. Kinnunen and Nylander were able to conclude that the failure of the slabs was related to not only the reinforcement ratio but also the angle of rotation of the slab (Kinnunen and Nylander, 1960). A plot displaying results can be seen in Figure 2.4.2. Overall, the slabs with lower reinforcement ratios failed at lower ultimate loads but were much more ductile then the slabs with higher reinforcement ratios which failed at higher loads. 


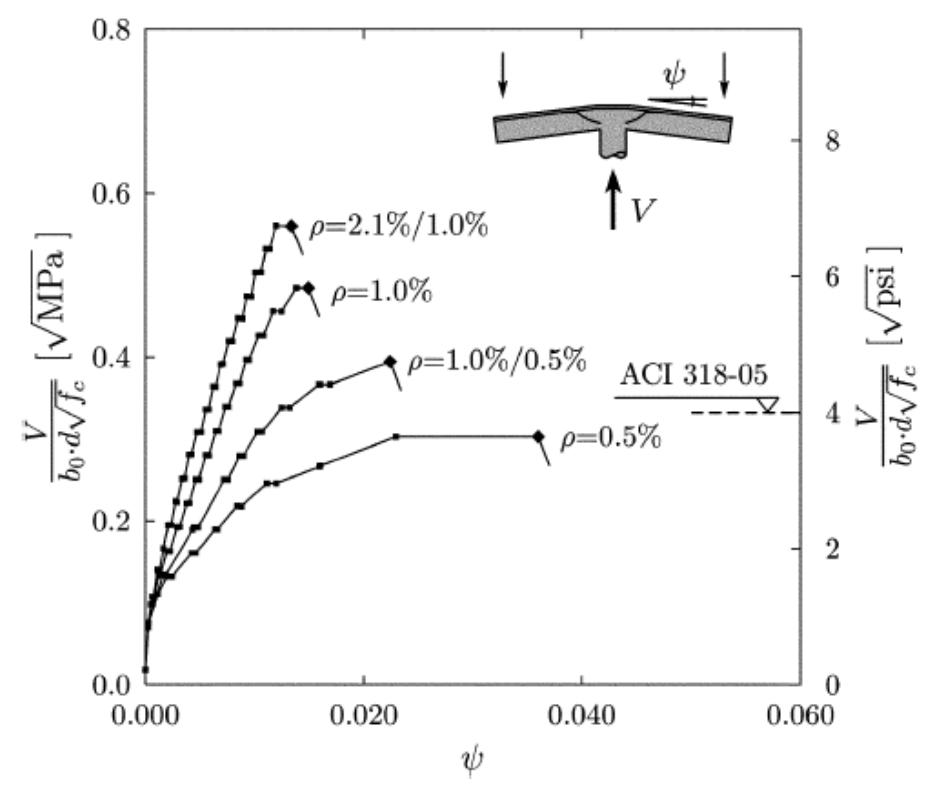

Figure 2.4.2 - Plot of load vs. slab rotation for slabs tested at various reinforcement ratios (Kinnunen and Nylander 1960).

\subsection{3 - Muttoni}

Muttoni's (2008) research focused on testing slab specimens of different thicknesses as opposed to the work done by Kinnunen and Nylander (1960) as well as Elstner and Hogenstad (1956). Overall it was determined that there were large differences in the performance of the slabs based on size. Muttoni determined that punching capacity for thick slabs with low reinforcement ratios were lower than may have been anticipated in comparison to thinner slabs with similar reinforcement. Also, the thick slabs did not show much ductility prior to failure which Muttoni (2008) determined was undesirable. A plot comparing the thickness, strength and ductility of slabs tested can be seen in Figure 2.4.3. 


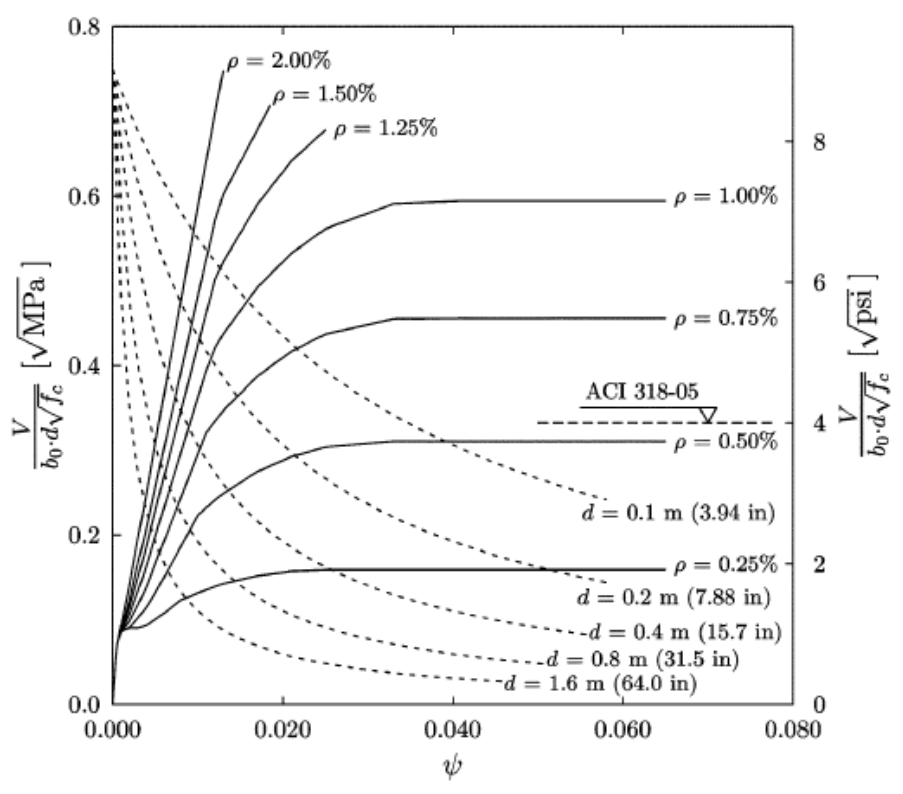

Figure 2.4.3 - Plot displaying relationship between slab thickness, strength and ductility (Muttoni 2008).

Muttoni (2008) suggested that the solution to this was to use thinner slabs with additional shear reinforcement included to increase the capacity while still providing adequate levels of ductility. However the addition of shear reinforcement at the slab column connections would complicate the normally simple construction process which is one of the main factors that makes flat plate construction a popular option. This research will look into the effects of in-plane forces in the hope that they can negate the need for additional shear reinforcement.

\subsection{4 - Alam}

Testing of simply supported isolated slab column specimens can provide some insight into the behavior of these types of connections but to gain a better understanding of their performance in a structural system more realistic boundary conditions need to be simulated. Alam (2008) tested 16 slab column specimens to determine their punching shear capacity. Of the 16 specimens 13 were cast integrally with edge beams designed to provide lateral stiffness as 
well as prevent translation and rotation of the slabs. The stiffness of the beams was altered for different test by casting a thicker or thinner beam, also the reinforcement ratio of the slabs were changed during the series of test. Altering the stiffness of the edge beams changes the boundary conditions imposed on the slab creating either a higher or lower level of restraint. Alam (2008) concluded that the greater the restraint at the edges of the slab the greater the punching capacity of that particular slab (Alam 2008). It was also noted that all of the slabs that he tested with edge restraint provided failed at a higher load than was predicted by current design codes. This is a result of code previsions being designed based on test of simply supported slabs with their edges unrestrained. The work done by Alam (2008) differs from this project in that casting the slabs with edge beams provides rotational restraint as well as lateral restraint. In the testing for this project there is no rotational restraint provided, therefore the results of the testing will not follow the same trends. For example in Alam's (2008) testing the slabs with the largest edge beams failed at the highest loads but at smaller deflections, preventing the slab from rotating is a main cause for these effects.

\subsection{5 - Guice and Rhomberg}

Another study that focused on the effects of various levels of edge restraint was performed by Guice and Rhomberg (1988). Their testing sought to determine the optimal level of edge restraint required in order to maximize the effects of compressive and tensile membrane action. They constructed a test setup that allowed the slab only specimens, not slab column specimens, to be partially restrained against lateral movement as well as rotation. Guice and Rhomberg (1988) tested 16 slab specimens of various thicknesses and reinforcement ratios to determine the effects of various edge restraint in different situations. Guice and Rhomberg (1988) were able to conclude that some rotational freedom was necessary to develop the full 
benefit of compressive membrane action. Small rotational freedoms also increased the effects of tensile membrane action after the punching failure had occurred. Figure 2.4.4 shows that the slabs with lesser rotational freedoms benefited more from compressive membrane action while the slabs with greater rotational freedoms saw greater benefits once tensile membrane action took over after the punching failure occurred.

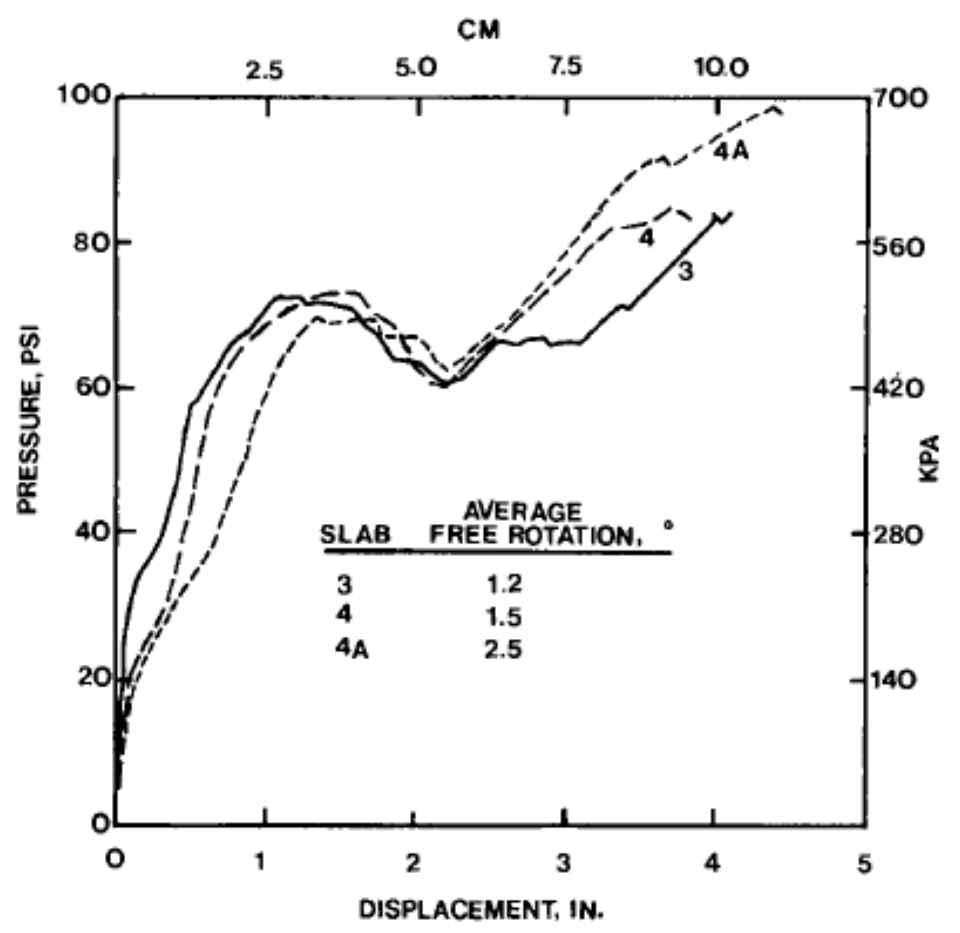

Figure 2.4.4 - Plot of load vs. displacement for slabs with various restraints (Guice and Rhomberg 1988).

\subsection{6 - Habibi et al.}

There has been less research done in the area of post-punching capacity of flat plates as compared to the pre punching capacity. One study that dealt with the post punching capacity of 
slabs was completed by Habibi et al. in 2012. Slab column specimens were constructed with the goal of evaluating the effectiveness of structural integrity reinforcement in increasing the postpunching capacity of flat slabs. The slabs tested for the research project were constructed corresponding to the Canadian CSA A23.3 Standard. Slabs tested without integrity reinforcement failed in a brittle manner immediately after a punching failure. It was determined that the presence of structural integrity reinforcement through the core of the column could significantly increase the post-punching load carrying capacity of slabs (Habibi et al. 2012). The slab specimens tested continued to carry load until either the integrity reinforcement fractured or ripped out of the slab. The layout of the integrity reinforcement can be seen in Figure 2.4.6.1.

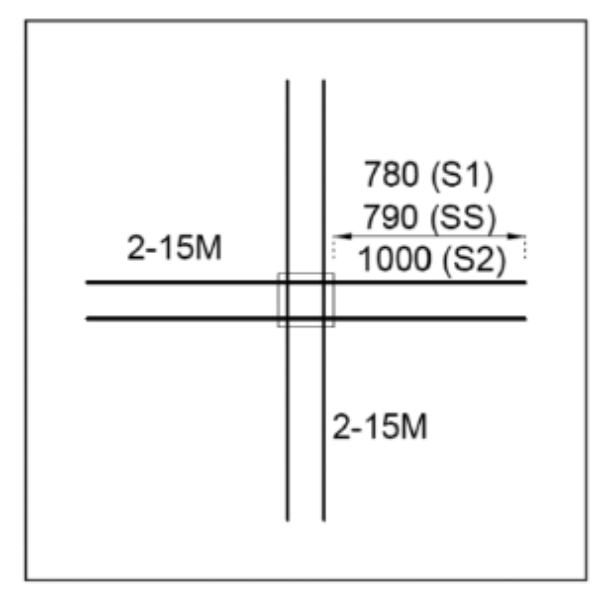

Figure 2.4.6.1 -Layout of integrity reinforcement (Habibi et al. 2012).

It was shown that increasing the slab thickness and therefore the depth of the reinforcement, provided an increase in post-punching capacity as more force was required to rip the reinforcement out of the concrete (Habibi et al. 2012), these effects can be seen in Figure 2.4.6.2. 


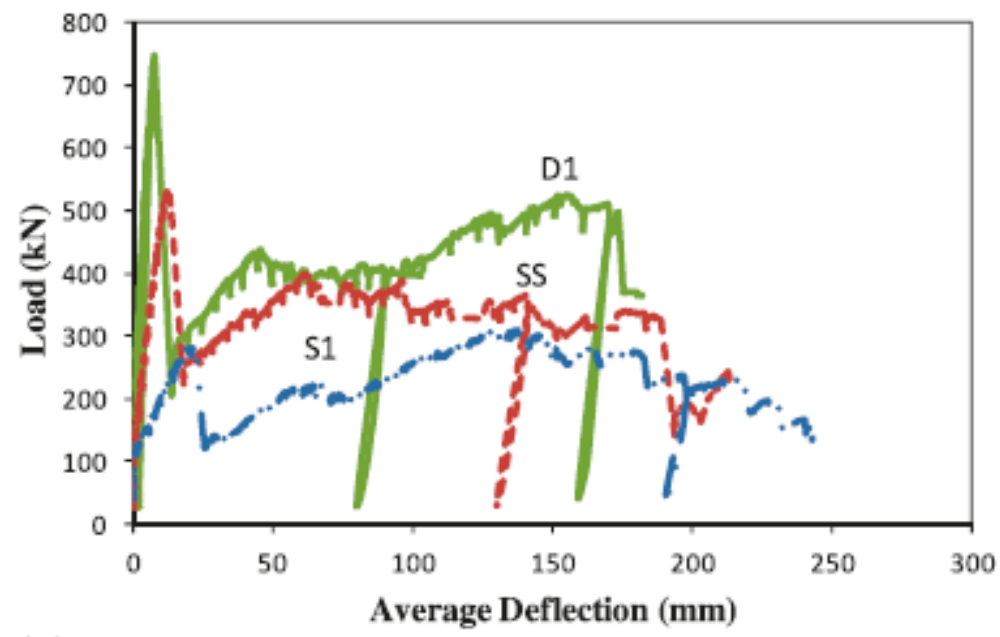

Figure 2.4.6.2 - Plot showing the effects of increased slab thickness and reinforcement depth on the pre and post punching capacity of flat slabs (Habibi et al. 2012).

It should also be noted that thicker slabs continued to carry load until the integrity reinforcement fractured while thinner slabs typically failed with the reinforcement ripping out of the concrete prior to fracture (Habibi et al. 2012). An equation was also generated to predict the post punching capacity of the slab specimens. This equation is presented as Equation 7, where $V_{s e}$ is the post-punching resistance, $A_{s b}$ is the total area of integrity reinforcement and $f_{y}$ is the yield strength of the reinforcement.

$$
\mathrm{V}_{\mathrm{se}}=0.5 * \Sigma\left(\mathrm{A}_{\mathrm{sb}} * \mathrm{f}_{\mathrm{y}}\right) \quad \text { Equation } 7 \text { (Habibi et al. 2012) }
$$

Figure 2.4.6.3 shows the slabs tested by Habibi et al (2012) as well as a plot of postpunching results from two tests. 


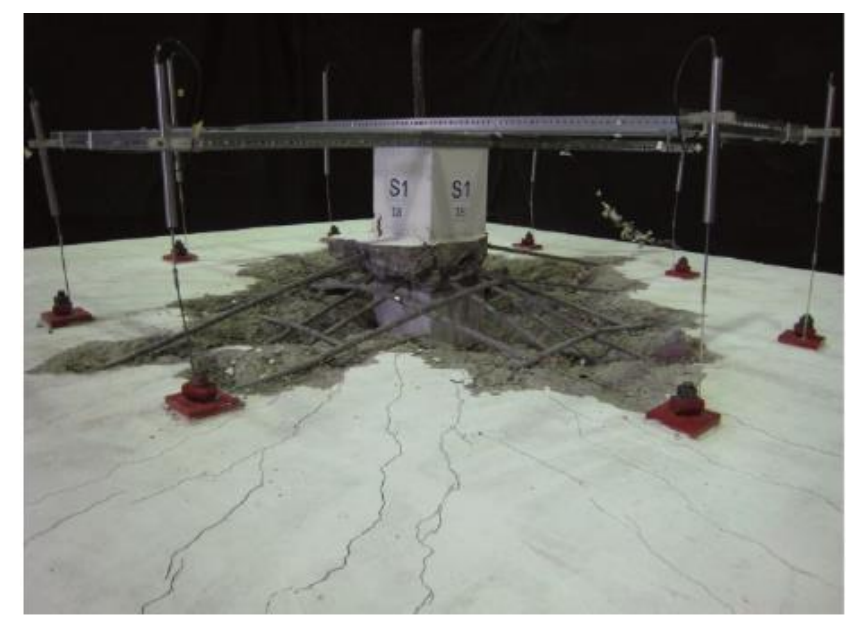

Figure 2.4.6.3 - Photo of slab specimen tested (Habibi et al 2012).

Using Equation 7 the predicted post punching capacity of the slabs constructed for this research project is 22.8 kips. 


\section{Chapter 3 - Experimental Setup}

For this portion of the research four slabs were designed, constructed and tested. Of the four slabs two were constructed with a reinforcement ratio of $1 \%$ whereas the other two slabs were constructed with a reinforcement ratio of $0.5 \%$. The slabs were tested in two different configurations, one with lateral restraint applied and one without any lateral restraint applied.

Two of the slabs, one slab with a $1 \%$ reinforcement ratio and one slab with a $0.5 \%$ reinforcement ratio were tested in each test setup configuration.

This chapter will detail the design of the prototype structure, the slab specimens and the test setup configurations as well as the punching shear capacity predictions of the specimens based on equations derived from previous research.

\section{1 - Prototype Structure Design}

The prototype structure that our slab column specimens are designed to replicate is an older flat plate reinforced concrete structure designed following the 1971 ACI concrete design provisions. The prototype structure is five stories tall and has a square layout consisting of 4 bays in each direction. Columns are spaced such that the spans are 20 feet in each direction. Material properties of the concrete are assumed to be a unit weight of $150 \mathrm{pcf}$ and a 28 day compressive strength of $4000 \mathrm{psi}$, the steel reinforcement is assumed to have a yield strength of $60 \mathrm{ksi}$. The assumed loadings on the structure were a superimposed dead load of $20 \mathrm{psf}$ and a live load of $50 \mathrm{psf}$ and the self-weight of the slab. The structure was designed with a minimum concrete cover of 0.75 inches, using these properties the minimum slab thickness was calculated to be 6.875 inches. A design thickness of 7.5 inches was selected to satisfy this minimum thickness, the column was designed to be a square with sides measuring 15 inches. The tensile 
and compressive reinforcement in the slabs was designed by calculating a bending moment in the slabs and using the direct design procedure. However, the focus of this research is on the punching strength of the slab column connection which is dependent on the reinforcement ratio, therefore we selected two different reinforcement ratios to test one higher than the design ratio $(1.0 \%)$ and one lower than the design ratio $(0.5 \%)$. A plan view of the prototype structure can be seen in Figure 3.1.1.

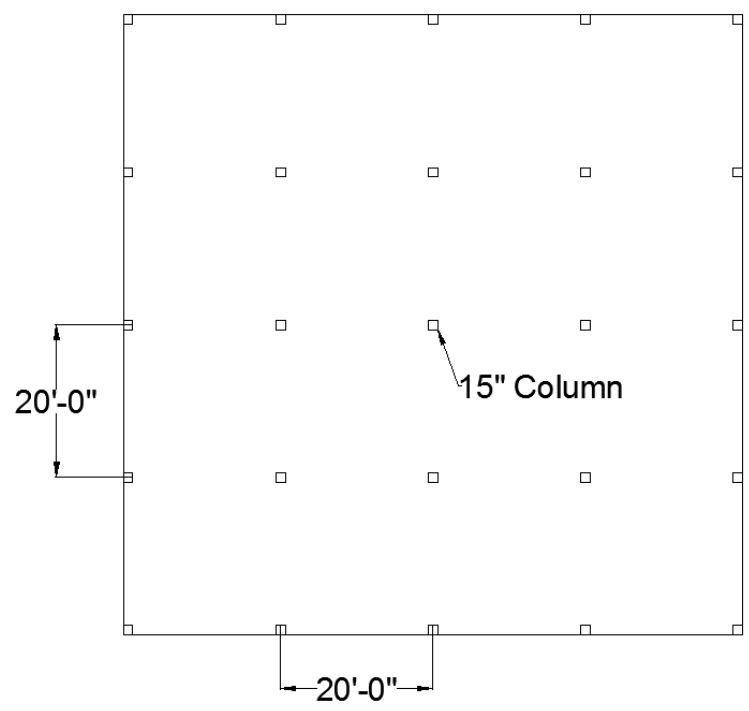

Figure 3.1.1 - Plan view of prototype structure.

Near the column in a continuous framing system large negative moments are present with the largest positive moments being present at the mid-span. Because of this moment distribution the slab bottom bars are discontinuous through the column as they are not needed to resist the negative moments. Sketches of the slab top and bottom reinforcement can be seen in Figures 3.1.2 and 3.1.3 respectively. Since the prototype structure was designed following the procedures of ACI 1971 this discontinuous reinforcement is acceptable. If the structure had been designed following a more recent version of the code some of the slab bottom reinforcement 
would have to be continuous to comply with the code regulations which require structural integrity reinforcement (American Concrete Institute).

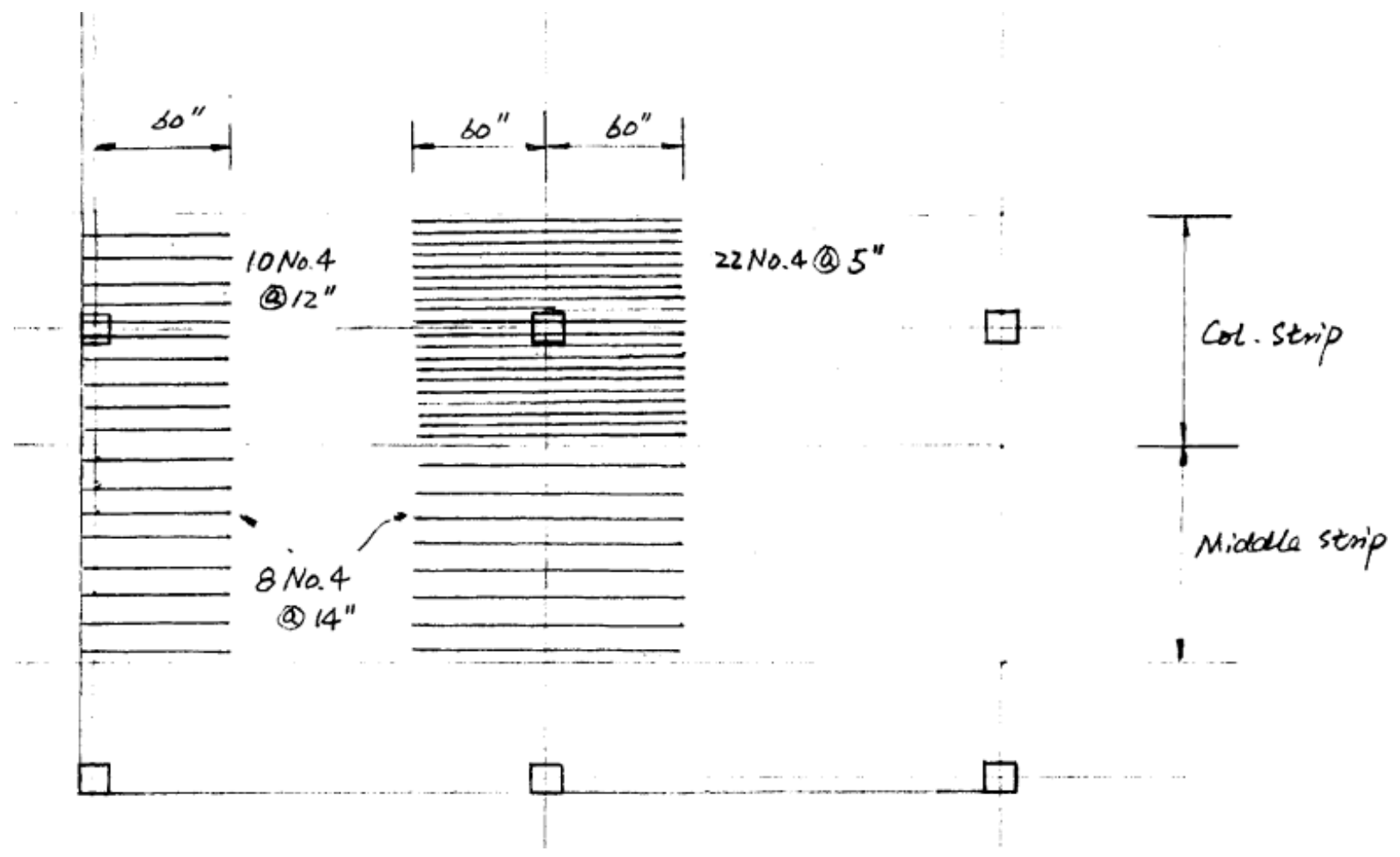

Figure 3.1.2 - Sketch of slab top reinforcement layout. 


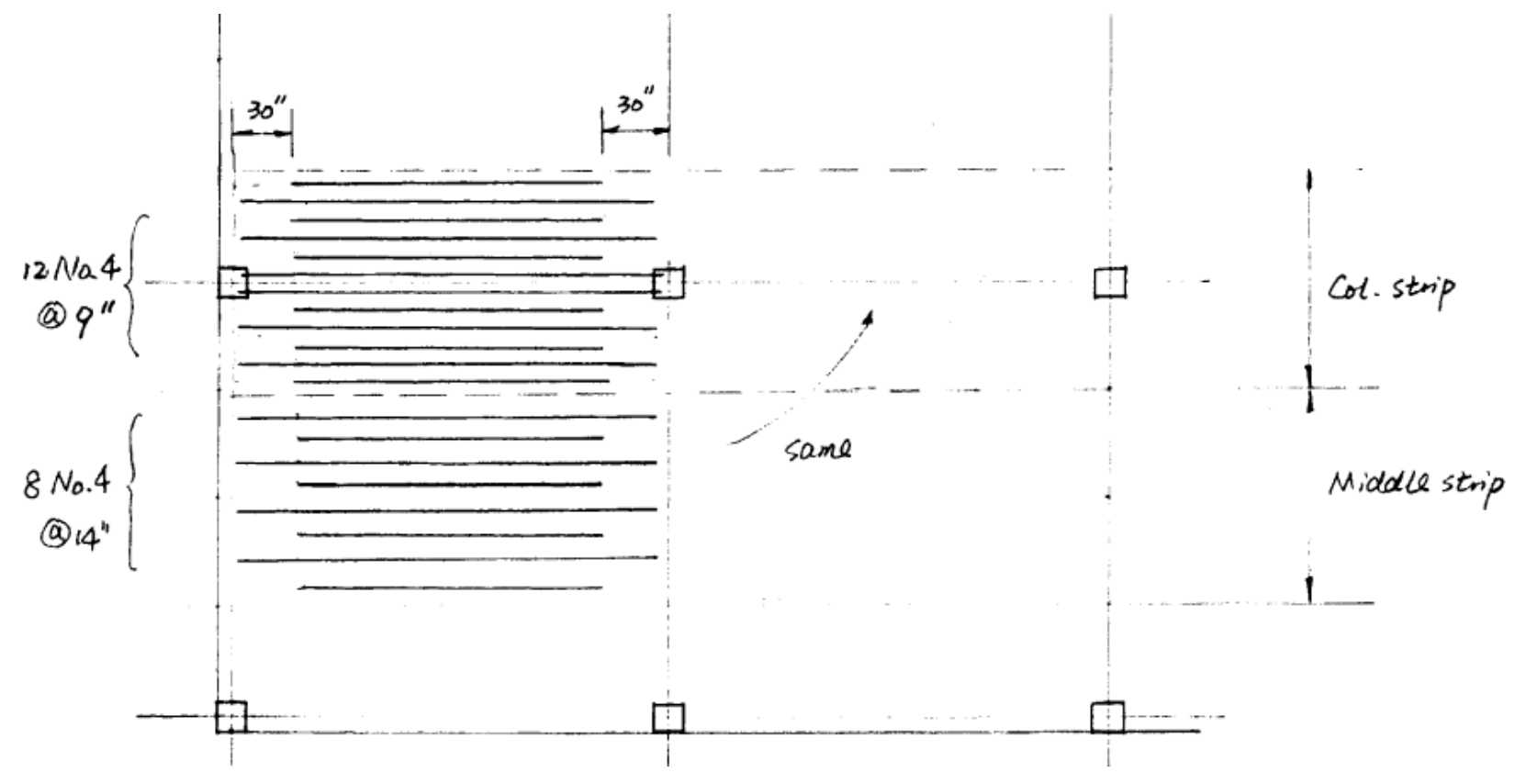

Figure 3.1.3 - Sketch of slab bottom reinforcement layout.

\section{2 - Slab Specimen Design}

The slab column specimens tested are designed to simulate one of the interior slab column connections, the relation of the specimens to the overall prototype structure can be seen in Figure 3.2.1. The slab specimens that were designed are at a 0.73 scale such that we could test them within the constraints of our testing facility. 

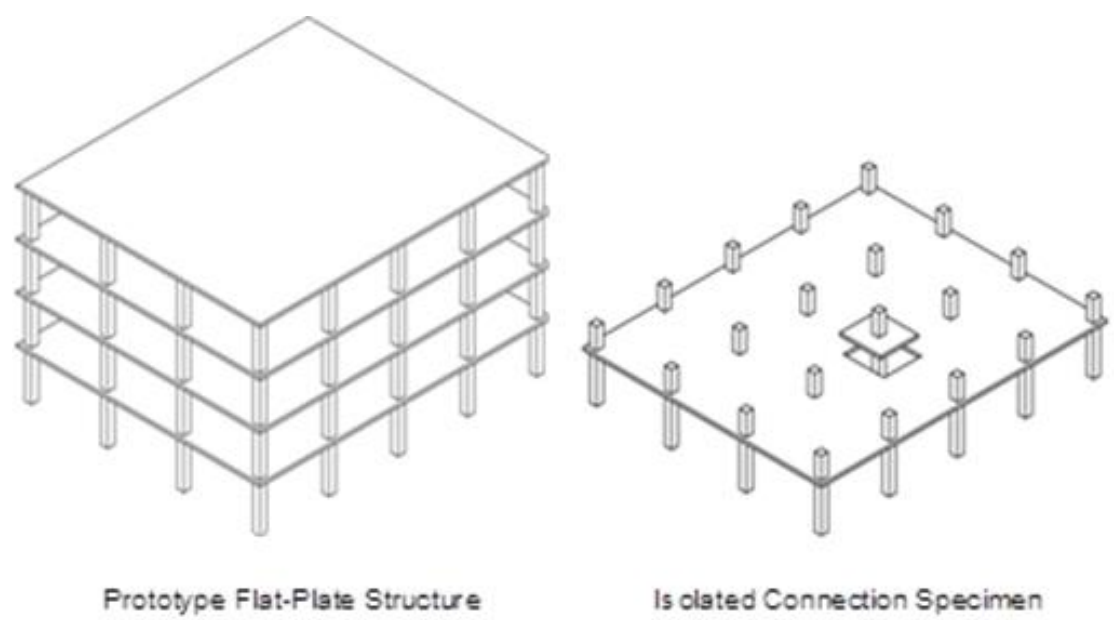

Figure 3.2.1 - Isolated slab column specimen in relation to overall prototype structure.

The specimens were designed to be 70 inch by 70 inch squares with a thickness of 5.5 inches. The 70 inch by 70 inch dimension was used in because this allowed the slab to extend to the inflection points in the moment diagram. The column stub on both sides of the slab was designed to be an 11 inch square with a height of 8 inches. The overall dimensions of the specimens are the same for all four test the differences are in the reinforcement ratio and test setup configuration. The slabs were designed using concrete with an assumed compressive strength of 4000psi. The steel reinforcement was assumed to be grade 60 with a yield strength of $60 \mathrm{ksi}$.

The slab specimens that were designed with a $1 \%$ reinforcement ratio used \# 4 bars spaced at 4.5 inches center to center for the tensile reinforcement and \# 3 bars spaced at 4.5 inches center to center for the compression reinforcement. The reinforcement layouts for the $1 \%$ reinforced slabs can be seen in Figures 3.2.2 and 3.2.3 (embedded anchors are shown as blue lines at the edges of the slab). 


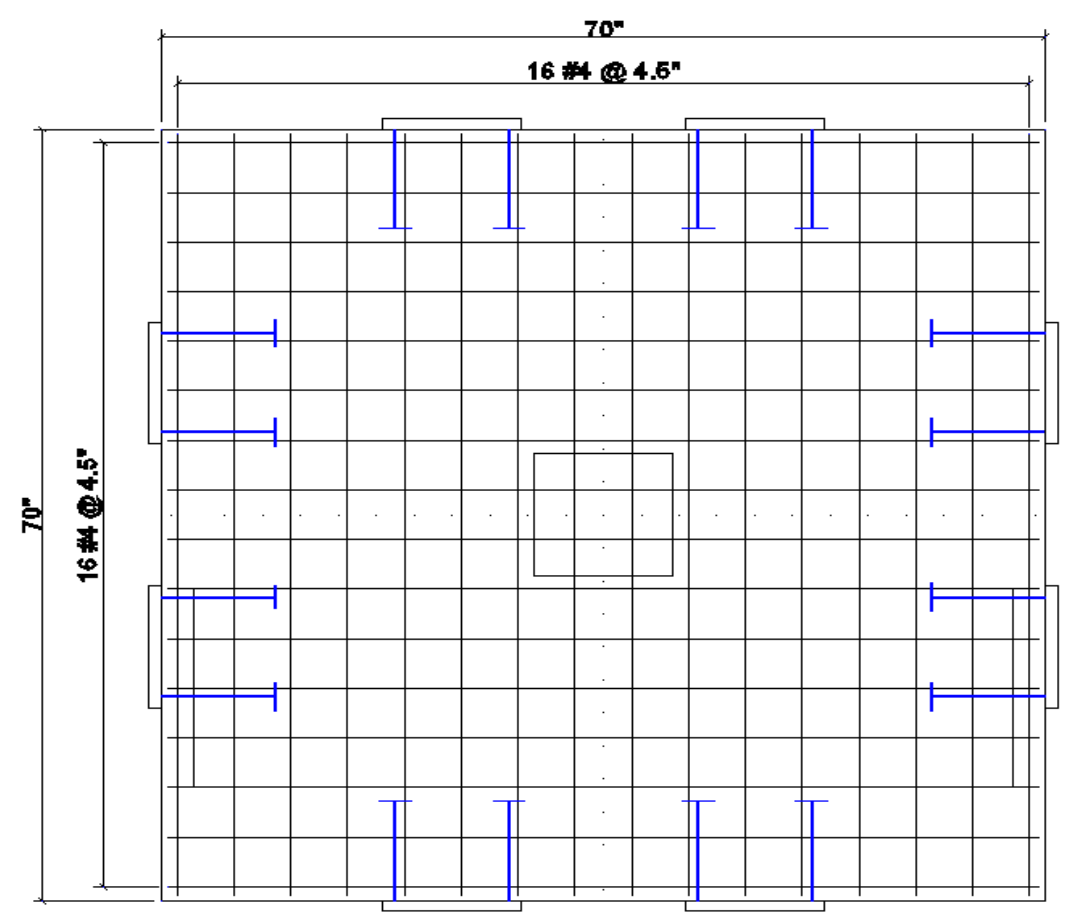

Figure 3.2.2 - Tension reinforcement layout for $1 \%$ reinforcement ratio slabs.

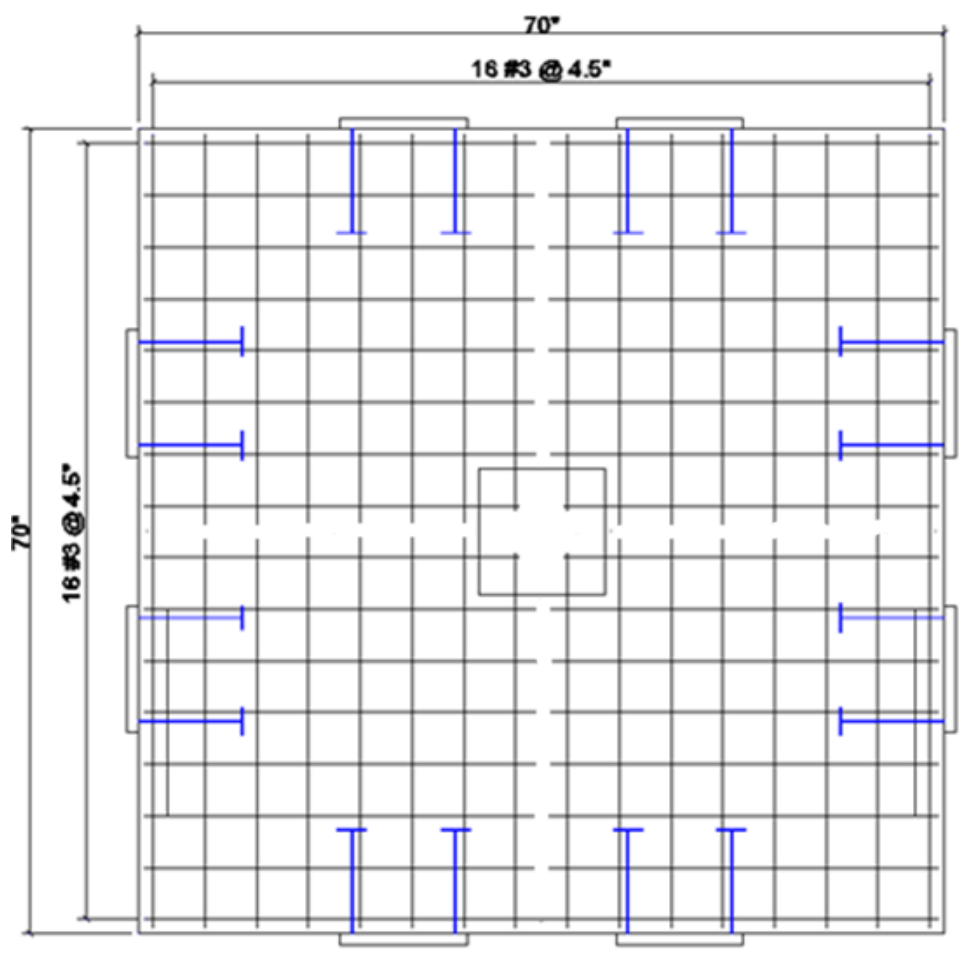

Figure 3.2.3 - Compression reinforcement layout for $1 \%$ reinforcement ratio slabs. 
The slab specimens designed with a $0.5 \%$ reinforcement ratio used \#4 bars spaced at 7 inches center to center for the tensile reinforcement and \#3 bars spaced at 7 inches center to center for the compressive reinforcement. The reinforcement layouts for the $0.5 \%$ reinforced slabs can be seen in Figures 3.2.4 and 3.2.5.

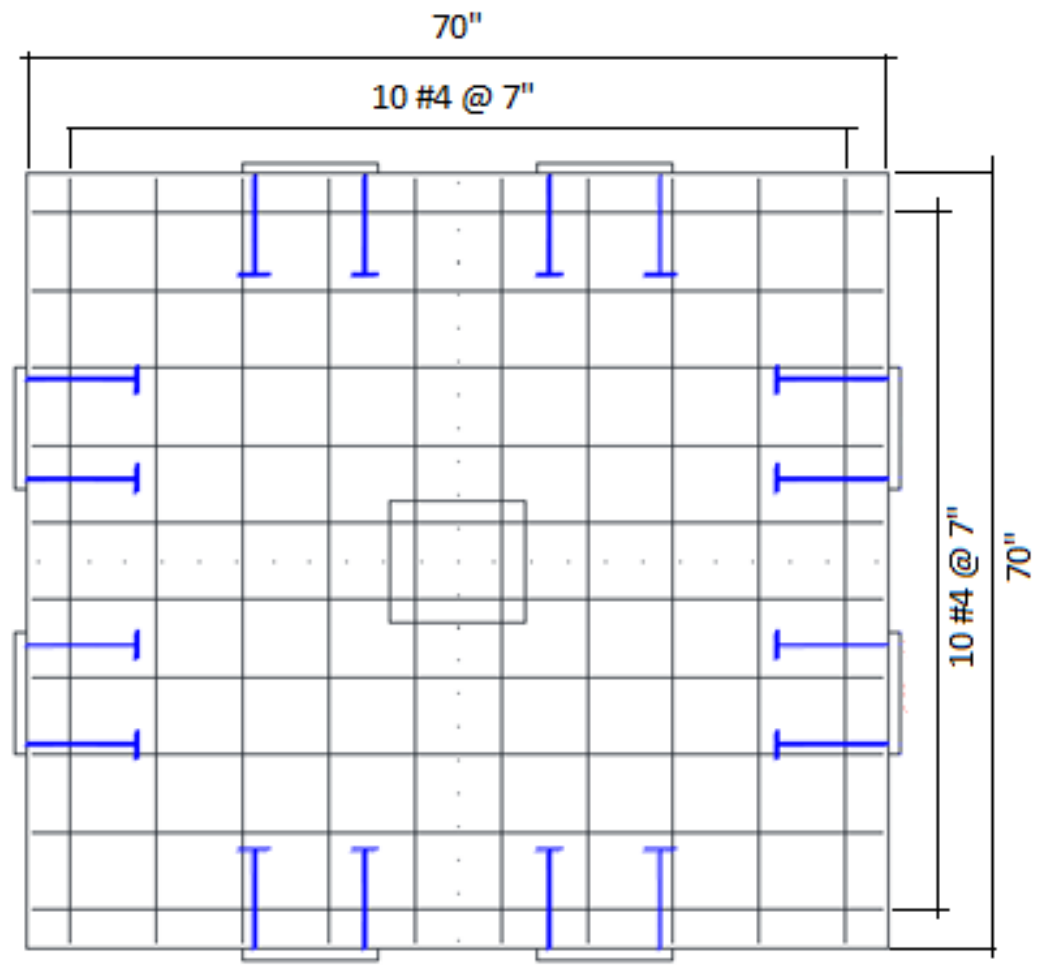

Figure 2.3.4 - Tension reinforcement layout for the $0.5 \%$ reinforcement ratio slabs. 


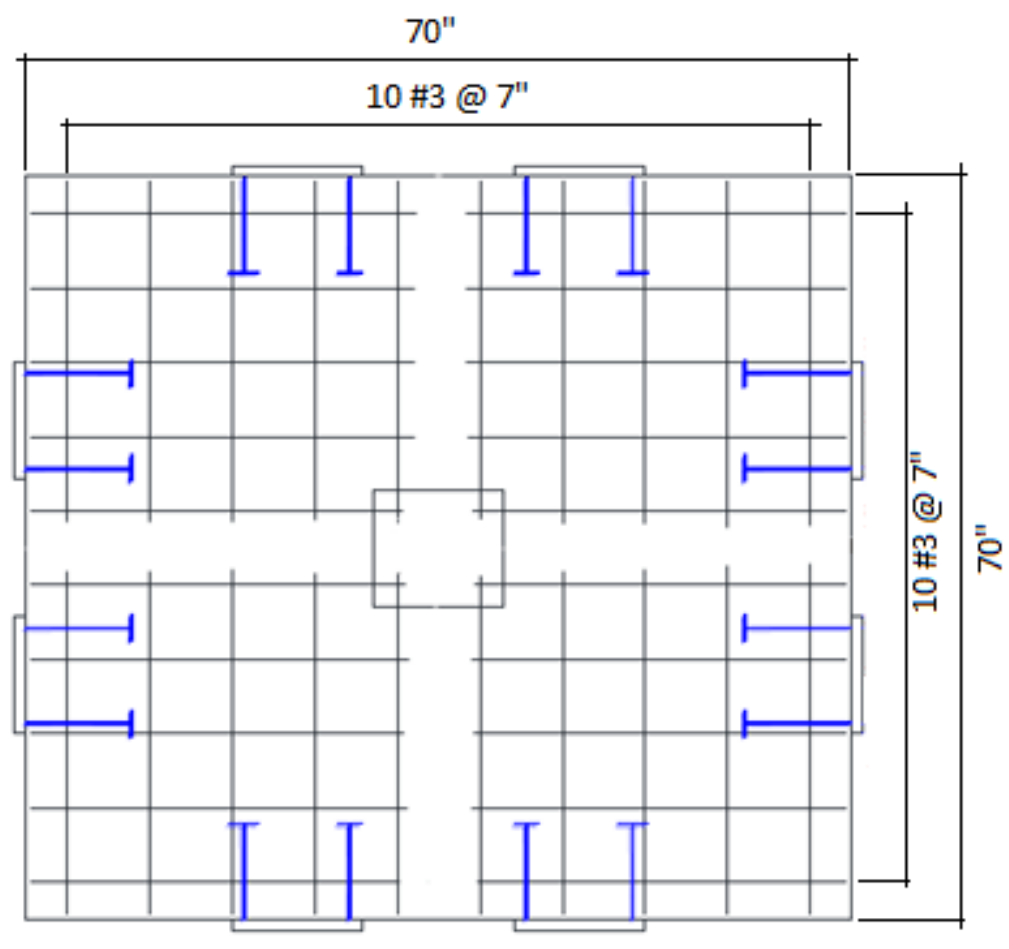

Figure 3.2.5 - Compression reinforcement layout for the $0.5 \%$ reinforcement ratio slabs.

The column stub on both sides of the slab was reinforced with four \#6 longitudinal bars and \#3 ties spaced at 3 inches. An elevation view of the slab specimens and a cross section of the column can be seen in Figures 3.2.6 and 3.2.7 respectively. 


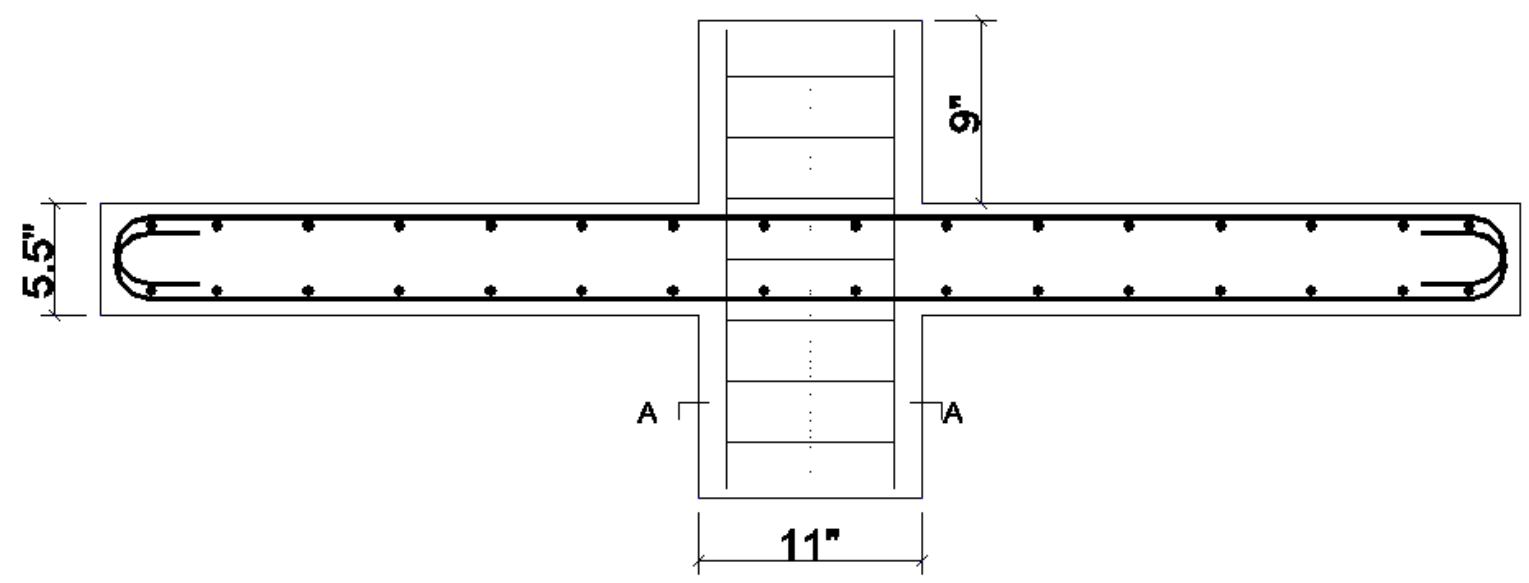

Figure 3.2.6 - Elevation view of slab column specimens.

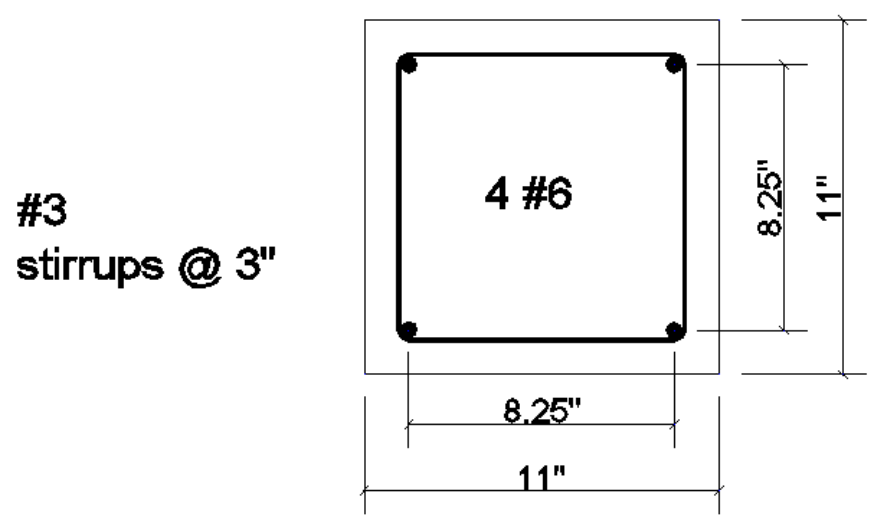

Figure 3.2.7 - Cross section view of column section.

All four slabs were designed with the tensile reinforcement continuous through the column while the compressive reinforcement was not in order to comply with the ACI code from 1971 (American Concrete Institute). Also, all of the specimens were designed with the reinforcing bars bent to 180 degree hooks at the edges of the slab. This was done to make up for the lack of space to allow for the required development length of the reinforcement. The hooks 
allowed for the bars to develop their full stress within the slab although the reinforcement did not extend as far from the column as would have been required with straight bars.

\section{3 - Slab Specimen Construction}

The slab specimen construction made up the majority of the man-hour work for this research. First the formwork for the concrete was constructed. In order to accommodate to column stub underneath the slab the formwork needed to be raised at least eight inches off of the ground. This was accomplished by creating a grid of $2 \times 4$ 's and $2 \times 6$ 's stacked on top of each other to create a solid base for the slab formwork. To create a flat bottom of the slab the formwork base was leveled and then $3 / 4$ inch plywood was screwed down to the base with a hole cut in the plywood to allow for the column stub to be cast. The sides of the slab formwork were created using 2 x 6's standing on edge. This worked perfectly for our slab since the $2 \times 6$ 's actually have a width of 5.5 inches and the design thickness of the slab was 5.5 inches. The vertical $2 \times 6$ 's were braced to avoid bending under the weight of the wet concrete. In order to cast the column stub pieces we created two plywood boxes one of which fit underneath the slab formwork and the other was suspended above the slab at the proper height using boards that ran from one side of the form to the other. The completed formwork can be seen in Figure 3.3.1. 


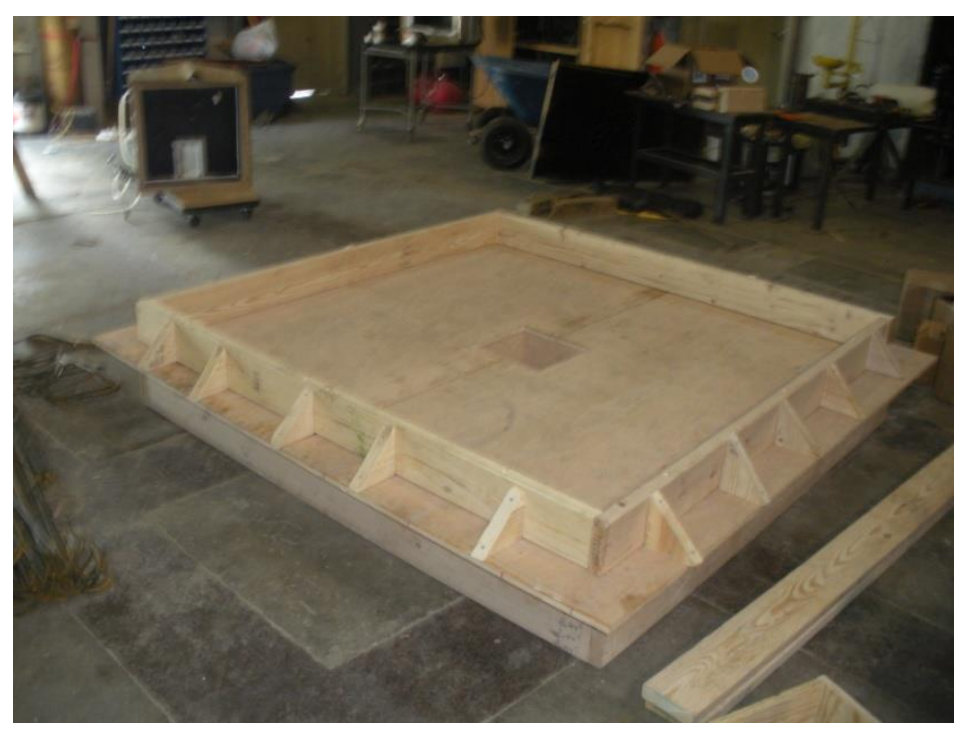

Figure 3.3.1 - Formwork for the slab specimens without top column stub formwork in place.

In order to connect the slab specimens to the test setup anchors were cast integrally with the slab. To accommodate the anchors that would extend out from the concrete and the hardware that would be attached during testing we drilled holes in the slab formwork. There were holes in the base of the formwork to allow us to insert PVC pipes such that we could cast the slab with vertical holes that would also be used to attach the slab to the test setup. In addition to connecting the slab specimens to the test setup the anchors were used as lifting points for the slab.

Prior to constructing the reinforcing cages strain gages were applied to the bars following the manufactures recommended procedure. Once all of the gages were applied and checked the reinforcing bars were then tied into cages. Care was taken to ensure that the cages were tied such that the strain gages were in the specified. The layout of the reinforcing bars as well as strain gages differed based on the reinforcement ratio of the slab being constructed. 
The anchors that extend out from the sides of the slab also had to be fabricated. These anchors consist of two pieces, the first being a 12 inch length of 5/8 inch threaded rod and the second being a 2.5 inch square of $3 / 4$ inch thick steel plate. The plates were cut to size, then a threaded hole was tapped in the center to allow the rod to be connected. The end of the rod with the plate on it was cast inside the slab to act as an anchor. The opposite end of the rod extended out of the slab through the holes in the vertical sides of the formwork that were drilled earlier. Once all of the parts were fabricated we were ready to assemble the slab for pouring.

Prior to pouring the slab the reinforcing cages were placed into the formwork along with the column reinforcement and the anchors. Measurements were made to ensure that the correct concrete cover would be provided. The spacing between the tension and compression reinforcement was also measured to ensure accuracy. A photo showing reinforcement spacing and slab depth can be seen in Figure 3.3.2. 


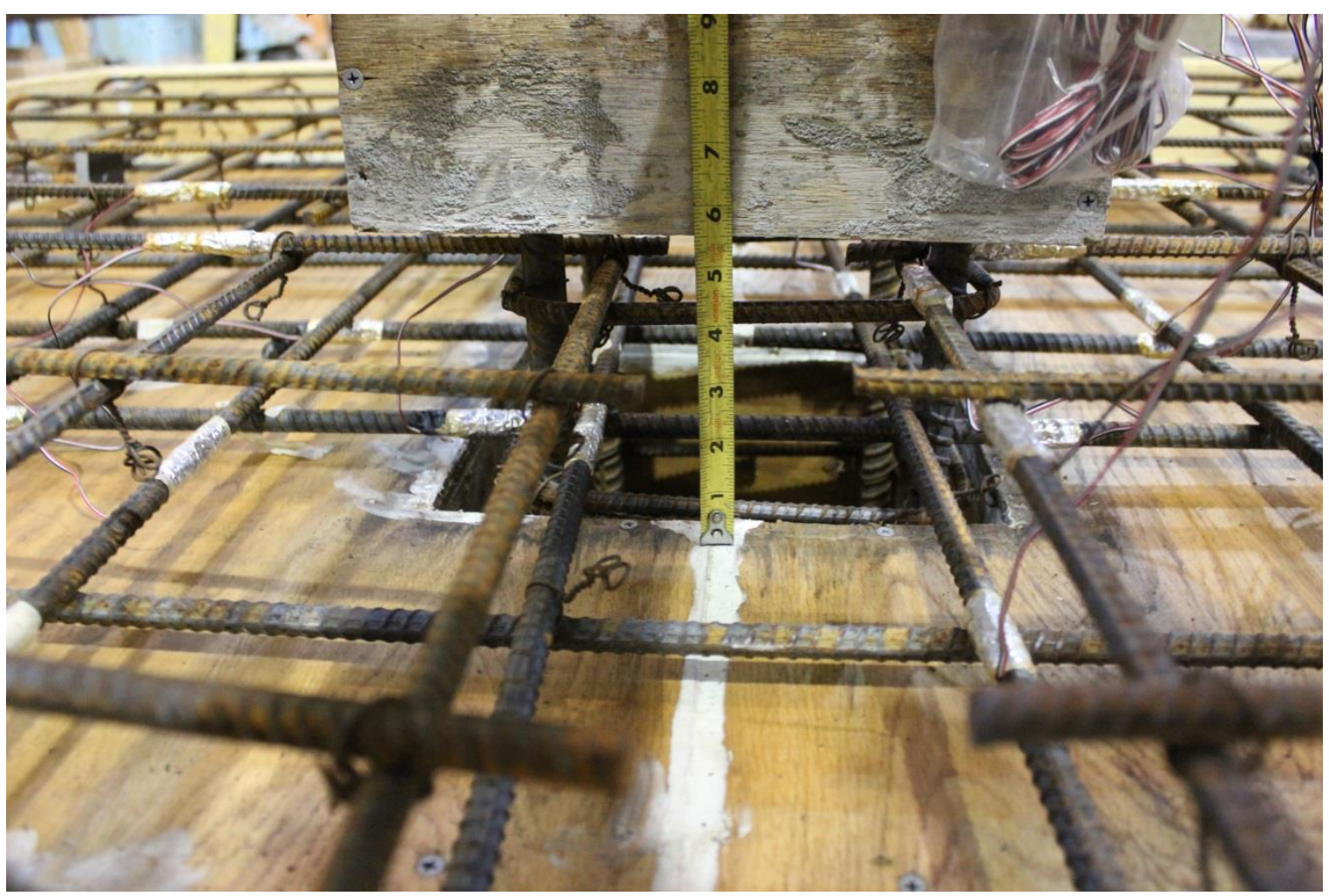

Figure 3.3.2 - Picture of slab formwork showing slab depth and reinforcement depths.

Once this was completed the top portion of the column stub reinforcement was tied and then the top column stub formwork was put into place. Finally the vertical PVC pipes were put in place, then the pipes as well as the anchors were tied in place using steel wire to prevent movement during the pour. The completed formwork in its ready to pour state can be seen in Figure 3.3.2. 


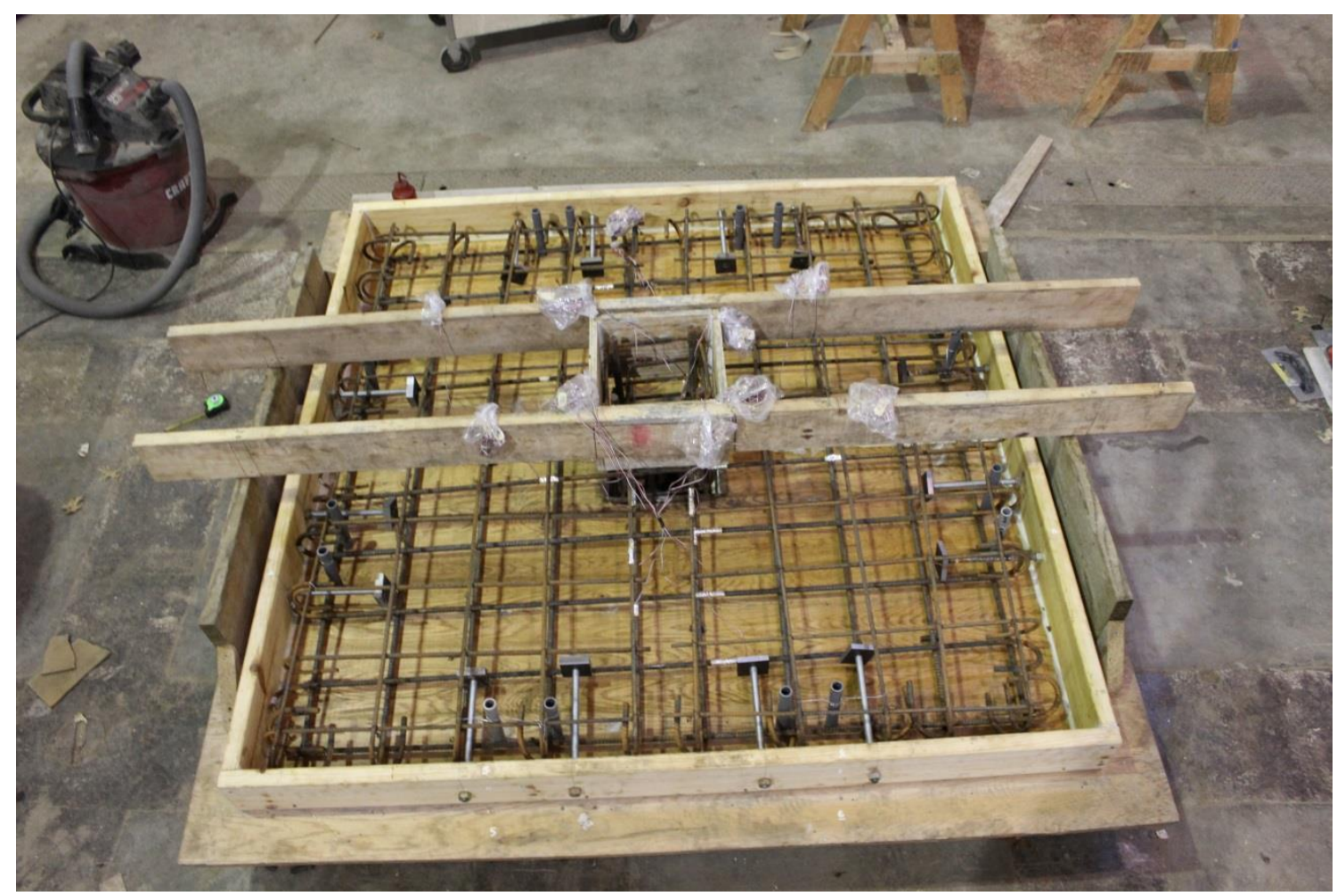

Figure 3.3.3 - Slab specimen ready to pour.

Once the formwork and the reinforcement was in place we were ready to pour the slab.

We moved concrete into the form using shovels as opposed to dumping it directly from the truck to avoid damaging any of the instrumentation or losing wires in the concrete. As the form was filled we used a concrete vibrator to help consolidate the concrete and remove unwanted voids. Care was taken to ensure that the concrete was not over vibrated such that it began to segregate. While pouring the slab we made efforts to ensure that the slab thickness was maintained at 5.5 inches especially in the area where the punching failure would occur as the slab thickness in this region directly affects the punching strength. Once the slab was poured we placed wet canvas over the slab followed by a plastic sheet to help prevent shrinkage due to evaporation during the curing process, the canvas was kept wet for the first week of curing. The slab just after pouring was completed can be seen in Figure 3.3.4. 


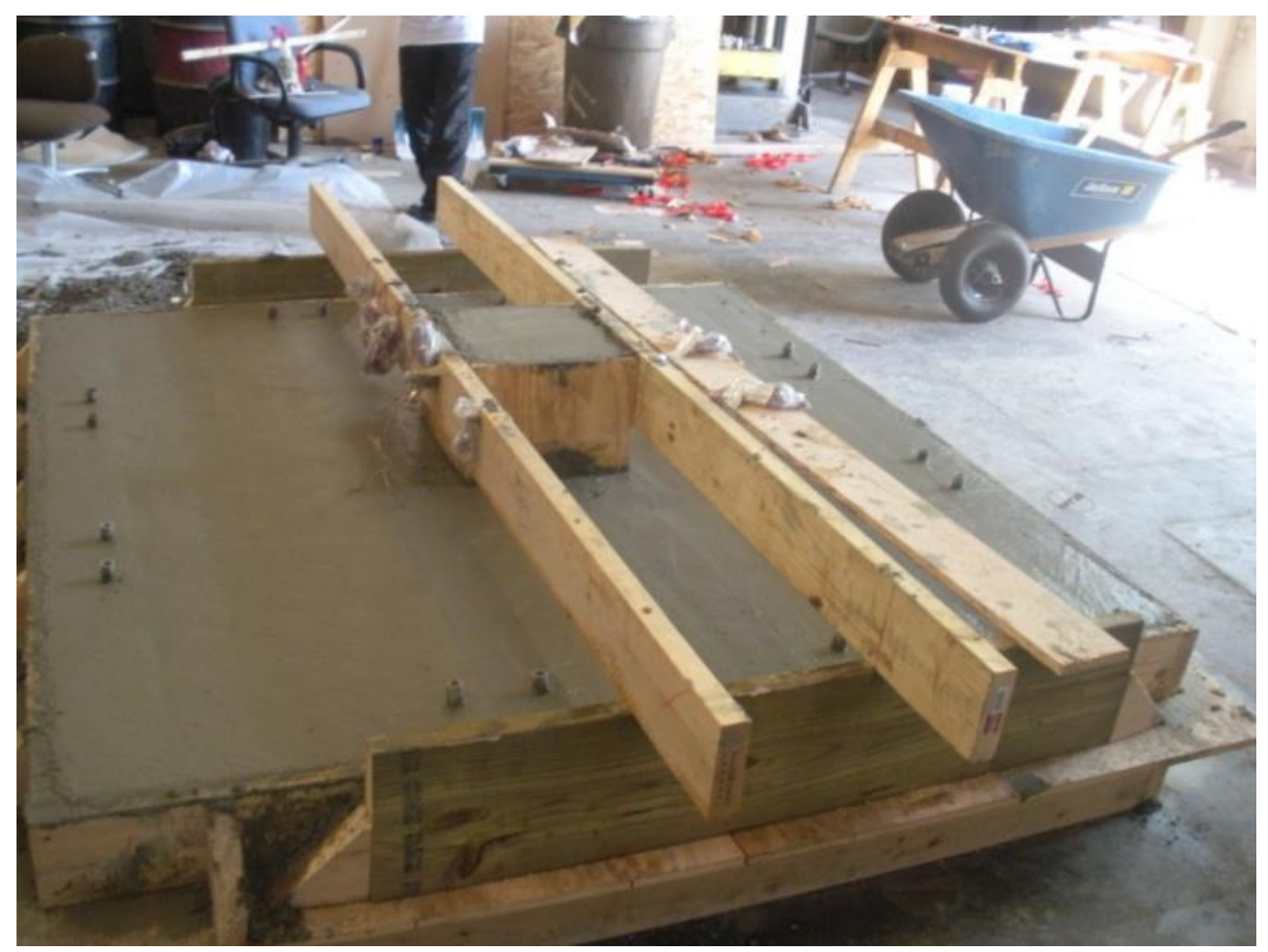

Figure 3.3.4 - Slab specimen just after pouring was completed.

\section{4 - Test Setup Design}

This section of the report will detail the designs of the test setup with and without lateral restraint. First, the test setup without lateral restraint (unrestrained setup) will be discussed and then the differences between that and the test setup with lateral restraint (restrained setup) will be discussed. An overall view of the unrestrained test setup can be seen in Figure 3.4.1. 


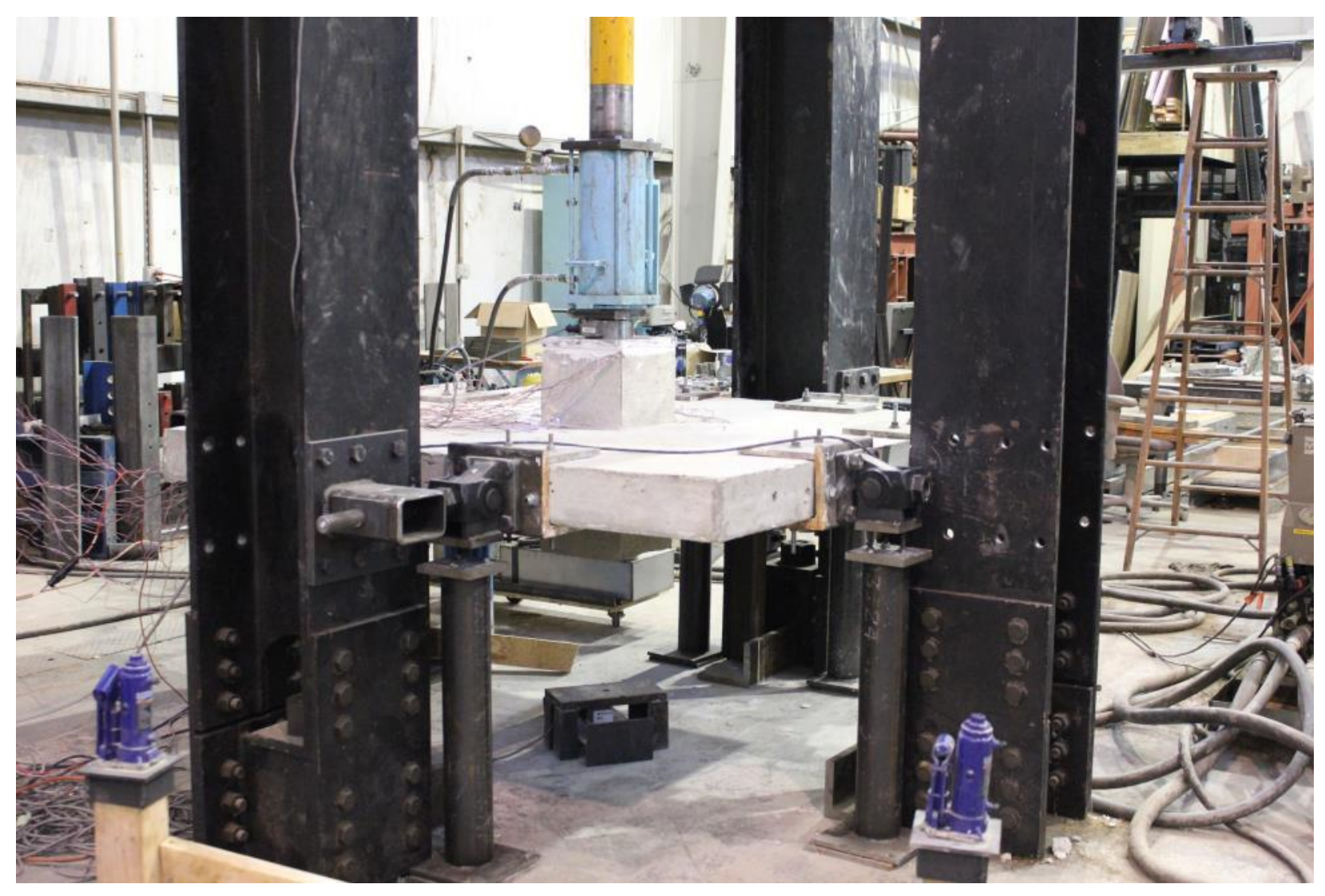

Figure 3.4.1 - Unrestrained test setup with slab specimen ready for testing.

The first two slabs that were to be tested were designed to be tested in the unrestrained setup because there has been much previous research in the area of punching shear in unrestrained slabs. These first two test would allow us to compare our results with past research to see what differences occur because of our slab design or test setup design. The unrestrained test setup's goal is to provide vertical support for the slab specimen while it is being loaded without providing any type of lateral restraint which would cause in plane forces. This is accomplished by supporting the slab at eight locations along its perimeter using adjustable height columns manufactured from a 4 inch steel pipe section with plates welded to either end to serve as bearing surfaces for the column. The slab was supported at eight locations in order to best simulate realistic support conditions, supporting slabs in this manner has been seen in previous 
research in the area of punching shear. The adjustability of the columns is provided by three $1 / 2$ inch bolts extending from welded nuts on the plate on the top of the column, the adjustable support can be seen in Figure 3.4.2.

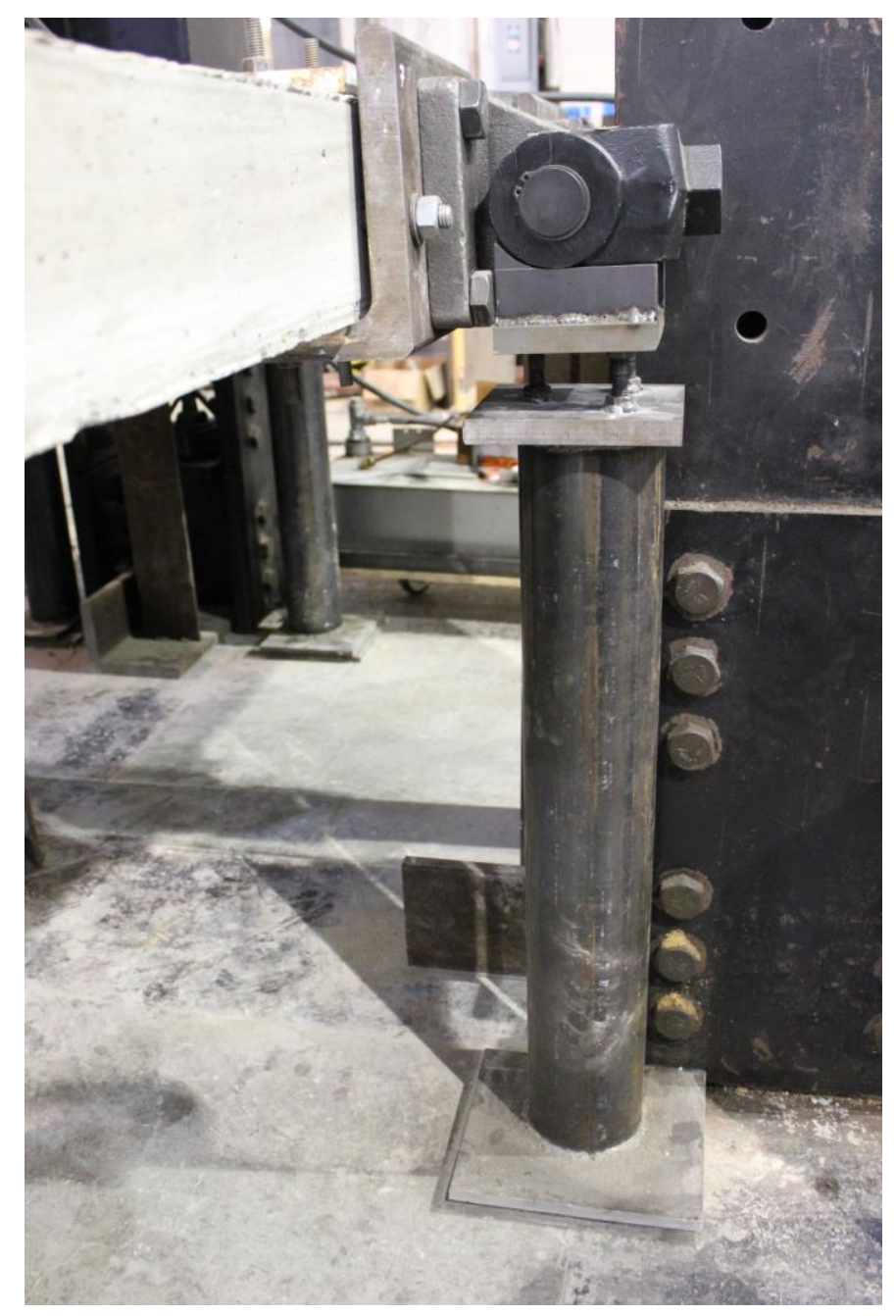

Figure 3.4.2 - Picture of one of the eight adjustable vertical supports.

The columns were designed to be adjustable so the slab height could be altered while the slab was still supported on all eight columns also the adjustability allows us to ensure that the slab is level prior to testing. In order to ensure that lateral forces could not build up the base of the column is seated on a set of rollers to reduce resistance to lateral movement. The slab is 
connected to the test setup support column using bolted steel parts. The part that actually connects to the slab its self is an $8 \times 8 \times 1$ inch angle section. The angle has been cut down to a length of 12 inches so that it can be moved and connected to the slabs without too much difficulty. Both legs of the angle have holes drilled in them to allow for connection to the slab. This is accomplished by connecting to the $5 / 8$ inch anchor rods that were cast in the slab such that they extend out of the sides and the $1 / 2$ inch threaded rods were run through the vertical holes that we cast into the slab around the anchor locations. Both were secured with nuts and washers against the angle. Also, a $1 / 2$ inch steel plate positioned on the top of the slab to provide confinement around the anchor areas was put in place and secured with the vertical threaded rods. A schematic of the anchorage as well as a picture of the anchorage area prior to casting the slab can be seen in Figures 3.4.3 and 3.4.4 respectively.

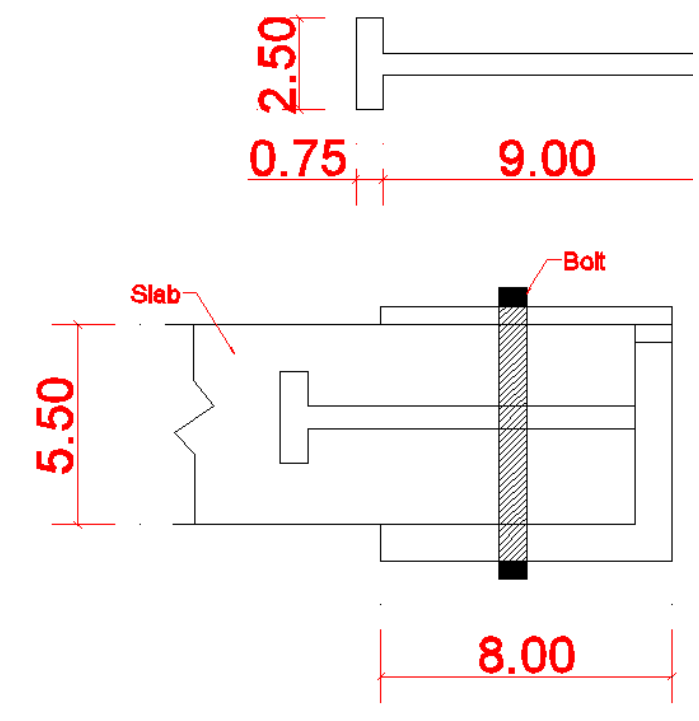

Figure 3.4.3 - Detail of anchorage design. 


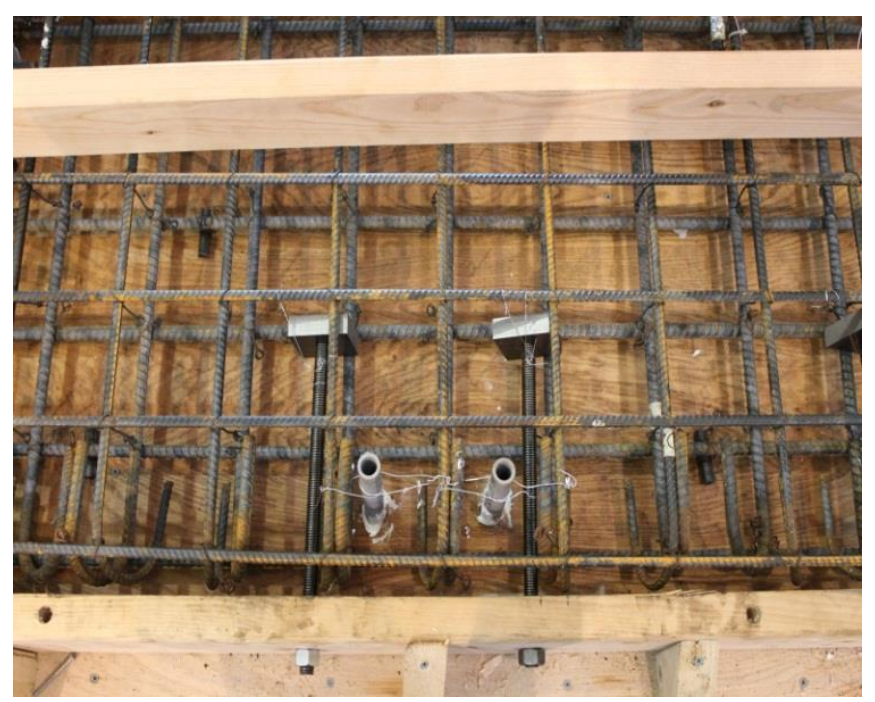

Figure 3.4.4 - Anchorage area prior to casting slab.

Extending off of the back of the angle section is a steel clevis. This clevis allows the slab to rotate about its supports, it also provides us with a location to attach the column support. The connection to the column support is made of two plates which matched the contour of the base of the clevis, then the clevis was simply seated on the plates which were welded to a base that rested on the adjustable column support. There are two of these vertical supports on each side of the slab specimen, each of the supports was designed to carry 20 kips of vertical load to ensure that we would not damage any of our supports during the testing. For the isolated slab specimen test the loading was accomplished using a hydraulic ram mounted to an extension that is in turn mounted to a steel cross bar about 5 feet above the top of the slab specimen.

The restrained test setup is designed to simulate the loading of the slab column connection within a real structure, the goal is to apply lateral restraint to the slab while it is being loaded vertically. All of the test setup parts that were used for the unrestrained setup are used 
again here the difference comes from the way that the lateral stiffness was provided. In the unrestrained test setup the clevis was only supported vertically by the adjustable column. In the restrained setup the clevis now has a 1.5 inch threaded rod extending from the back. This rod allows us to attach the clevis to the W14x144 columns that are mounted to the structural floor at the testing facility. This is accomplished by sliding an HSS $6 \times 4 \times 3 / 8$ inch which is welded to a plate over the back of the threaded rod. The threaded rod is then secured to the HSS using a nut on either side. The HSS - plate assembly is then bolted to the W section using $6-7 / 8$ inch bolts, this completes the restrained test setup which is designed to provide a lateral stiffness of 1600kips/in.

After a preliminary slab test in the restrained setup if was found that the current setup was not providing the lateral stiffness that was desired. In order to increase the stiffness of our test setup a few modifications were made. The columns were initially held in place by friction between the base of the column and the floor, it was found that this frictional force was overcome fairly easily when the column was loaded laterally so some form of restraint for the columns to prevent this sliding was needed. The first of these modifications was the addition of a steel angle welded to the structural floor just behind the base of the $\mathrm{W}$ sections this angle has two 1 inch adjustable bolts that allow us to provide some restraint to the back of the column. The angles are welded to the floor and the bolts are tightened to the back of the column to prevent the column from sliding on the floor when it is loaded laterally, this can be seen in Figure 3.4.5. 


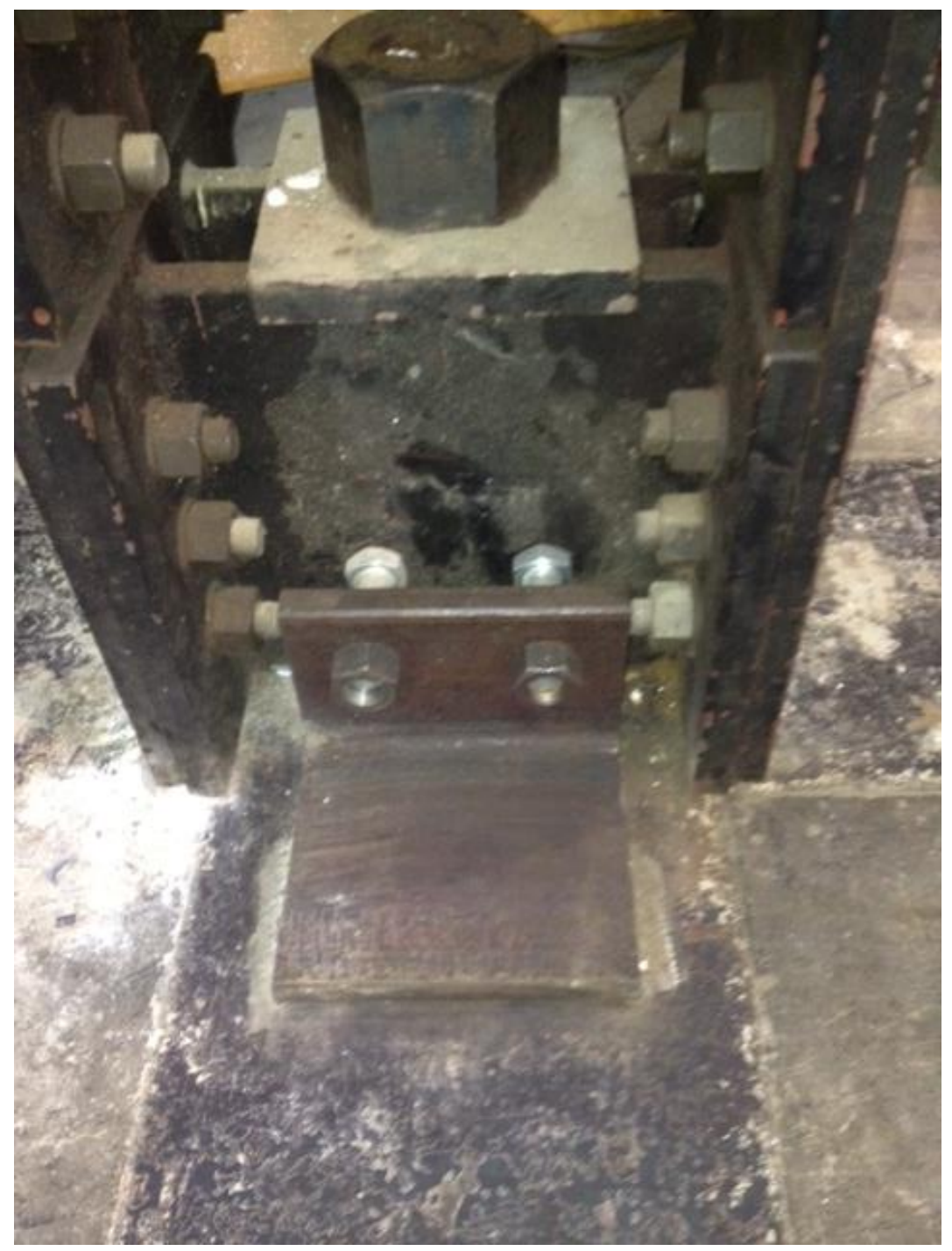

Figure 3.4.5 - Added bracing to prevent the support columns from sliding during restrained testing.

The next modification that was made was to stiffen webs of the $\mathrm{W}$ sections. It was found through physical test and FE models that the flanges of the column were twisting when the lateral load was applied and this movement was leading to the lateral stiffness being too small. Since the flanges of the $\mathrm{W}$ section were being spread apart on one side and pushed together on the other side we decided to provide a compression brace as well as a tension brace to provide the maximum stiffness. The compression brace consist of an HSS section welded in between the 
flanges at the height where the lateral load is applied. The tension bracing is provided by $2 \mathrm{high}$ strength $7 / 8$ inch threaded rods. These rods are run through the holes that are used to attach the plate that extends off of the clevis to the $\mathrm{W}$ section. The compression bracing can be seen in Figure 3.4.6.

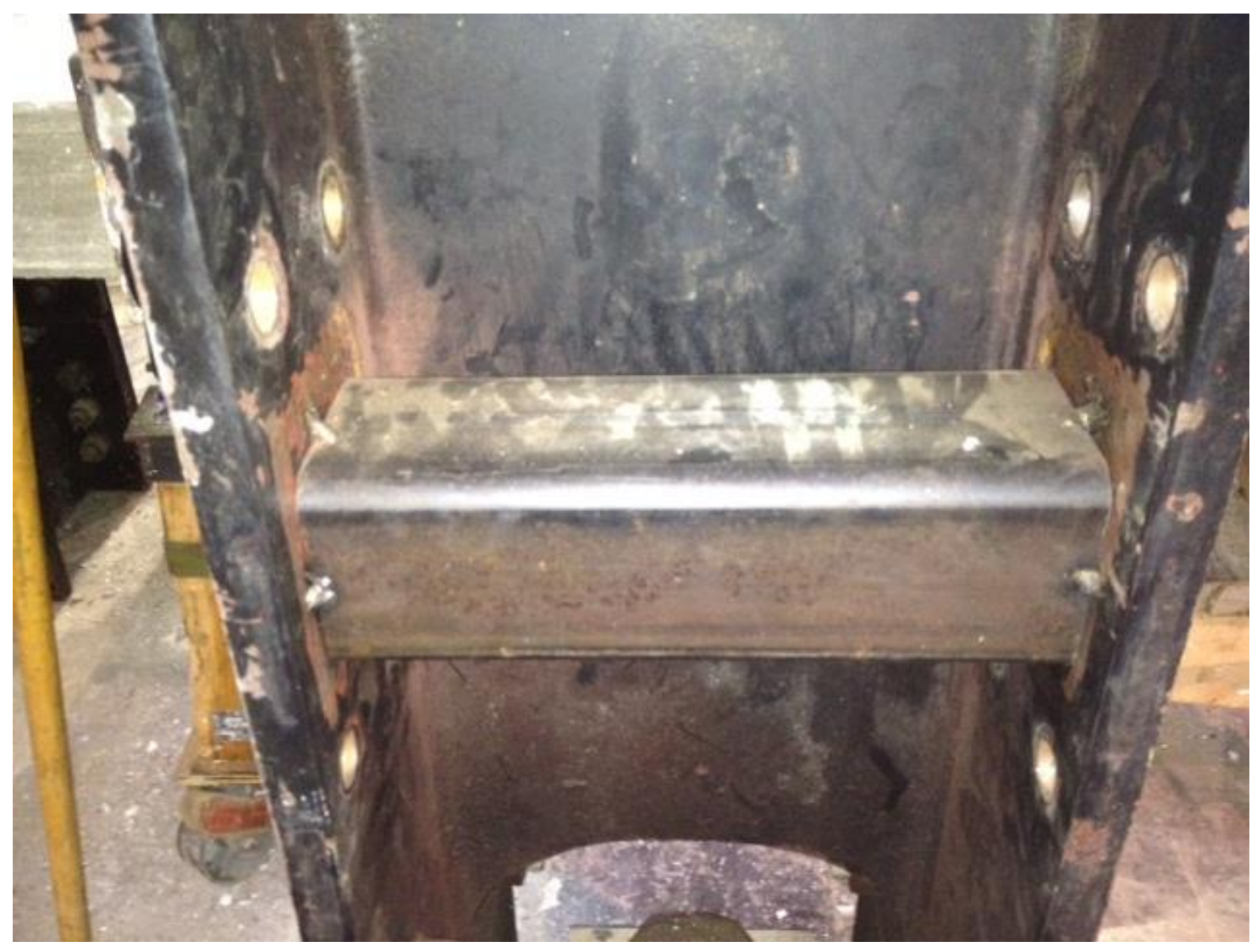

Figure 3.4.6 - Welded compression brace to stiffen the flanges of the support columns for the restrained test setup.

\section{5 - Instrumentation}

In order to record data instruments were attached to the test specimens during the testing. These instruments included two types of strain gages (steel strain gages and concrete strain gages), two types of load cells (tension and compression), String pots and LVDT's (linearly 
varying displacement transducers) to measure displacements. This section will detail the manner in which these instruments were used for both the unrestrained and restrained test's.

For both tests (unrestrained and restrained) strain gages were attached to the rebar at locations that were chosen to be significant prior to constructing the slab. The overall layout of the gages is the same between restrained and unrestrained but there are some slight differences in the layout between the $0.5 \%$ reinforcement ratio slabs and the $1 \%$ reinforcement ratio slabs. These differences result from the fact that there are more reinforcing bars in the slabs with higher reinforcement ratios which provided us with more possible locations to instrument. When placing the strain gages we chose locations that would allow us to see the manner in which the reinforcement strain varied as you moved closer to or farther away from the column slab interface and the failure surface. One consideration that needed to be made was the number of gages that could be placed on a single bar since the gages had to be heavily protected against damage during construction there would be some loss of cohesion between the bar and the concrete at the gage location. The layout of the reinforcement strain gages for the $0.5 \%$ reinforcement ratio specimens can be seen in Figures 3.5.1 and 3.5.2. 


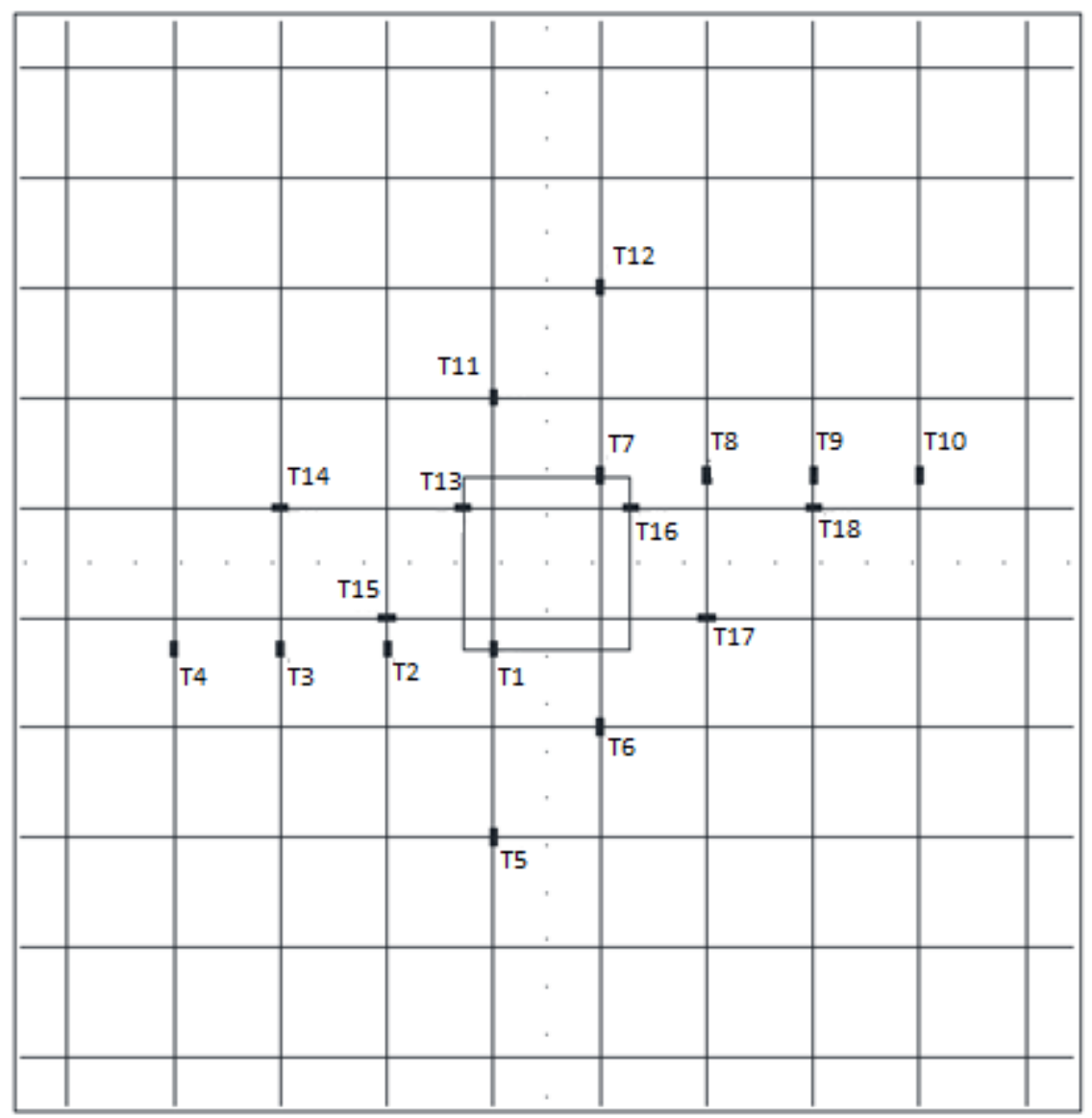

Figure 3.5.1 - Layout of tension reinforcement strain gages for $0.5 \%$ reinforcement ratio slabs. 


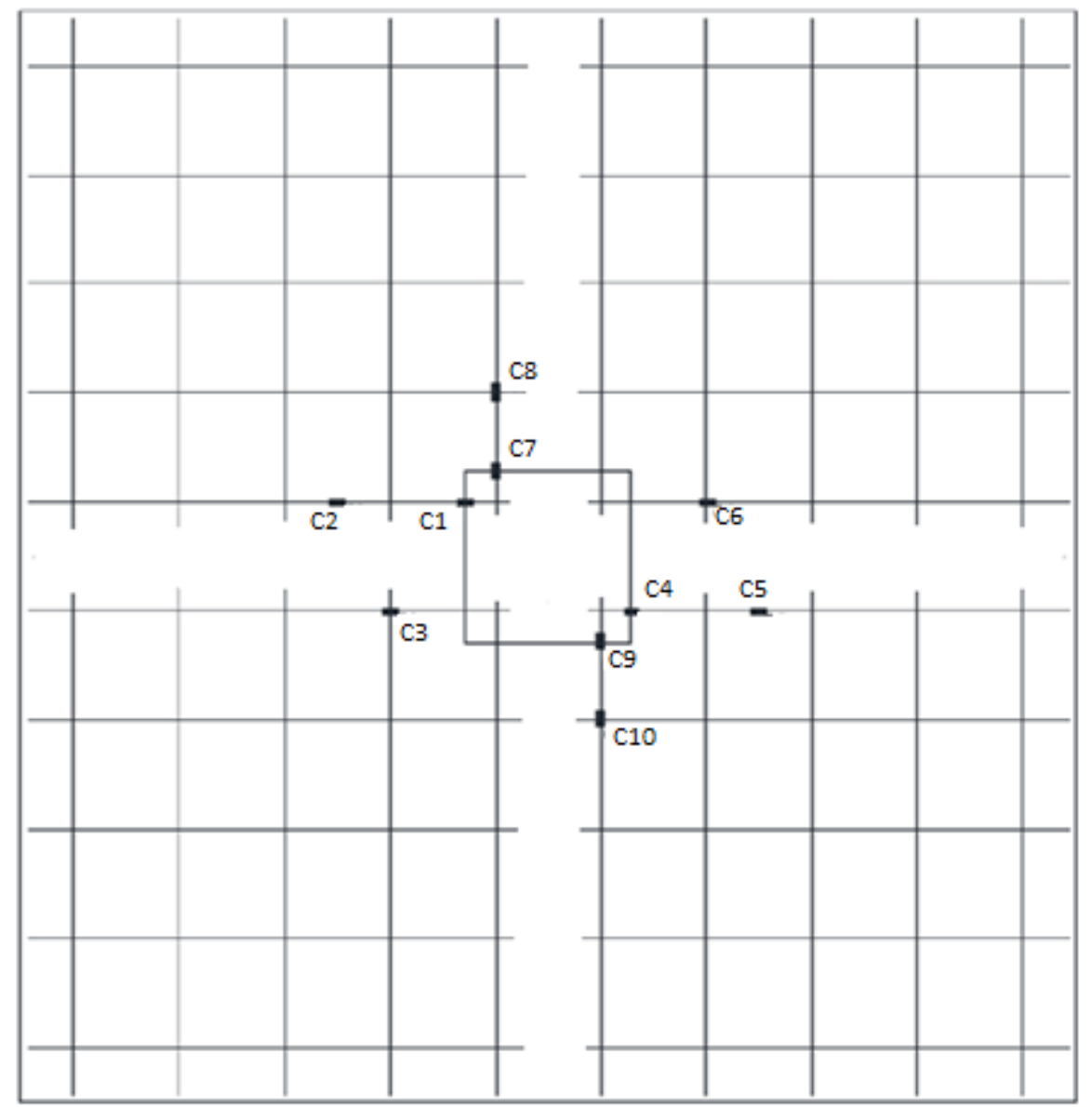

Figure 3.5.2 - Layout of compression reinforcement strain gages for $0.5 \%$ reinforcement ratio slabs.

For the slab specimens reinforced at a ratio of $0.5 \%$ there were 18 strain gages applied to the tension reinforcement cage and 10 strain gages applied to the compression reinforcement cage. It can be seen in Figure 3.5.1 (above) that there are two sets of gages on the tension reinforcement (gages T1-T4 and T7-T10) that are designed to show how the strain in the reinforcement varied as you move away from the column slab interface. Also, there is a set of gages $(\mathrm{T} 13,14,16,18)$ that are positioned along one of the bars that is continuous through the column such that the variation in the strain as you pass through the column could be determined. As for the compression reinforcement strain gages, four of the 10 are positioned at the slab 
column interface. The other six gages are positioned at locations slightly farther away from the column but still within the area where the largest deformations will occur during testing.

The strain gage layout for the slab specimens that were reinforced at a ratio of $1 \%$ differed slightly from the slabs that were reinforced at $0.5 \%$. The slabs with more reinforcement had 21 strain gages applied to the tension reinforcement cage and 10 applied to the compression reinforcement cage. The gages were positioned such that the same trends could be determined however there were more possible locations within the same areas due to the fact that the reinforcement spacing was smaller for the slabs with more reinforcement. The reinforcement strain gage layout for the slabs with a $1 \%$ reinforcement ratio can be seen in Figures 3.5.3 and 3.5.4. 


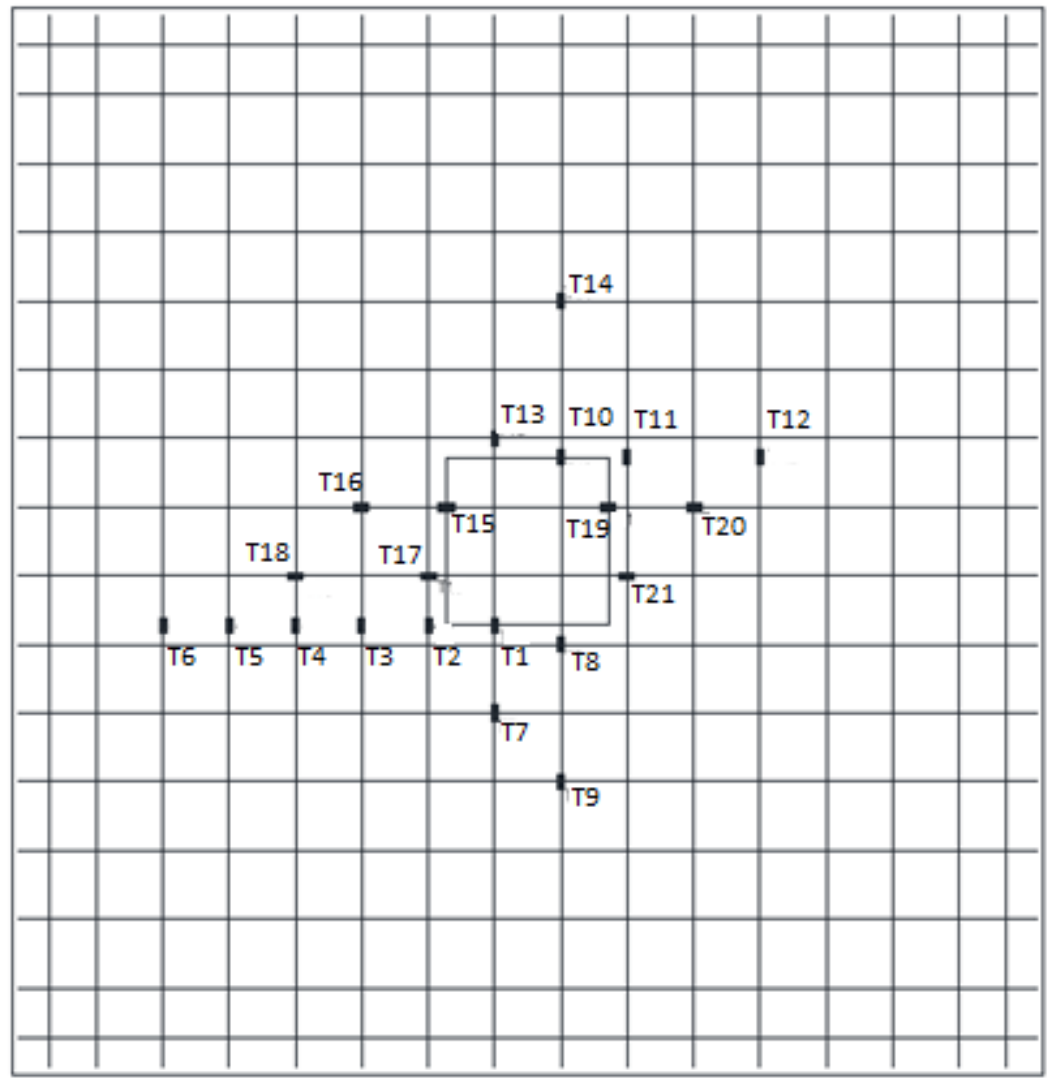

Figure 3.5.3 - Tension reinforcement strain gage layout for $1 \%$ reinforcement ratio slabs. 


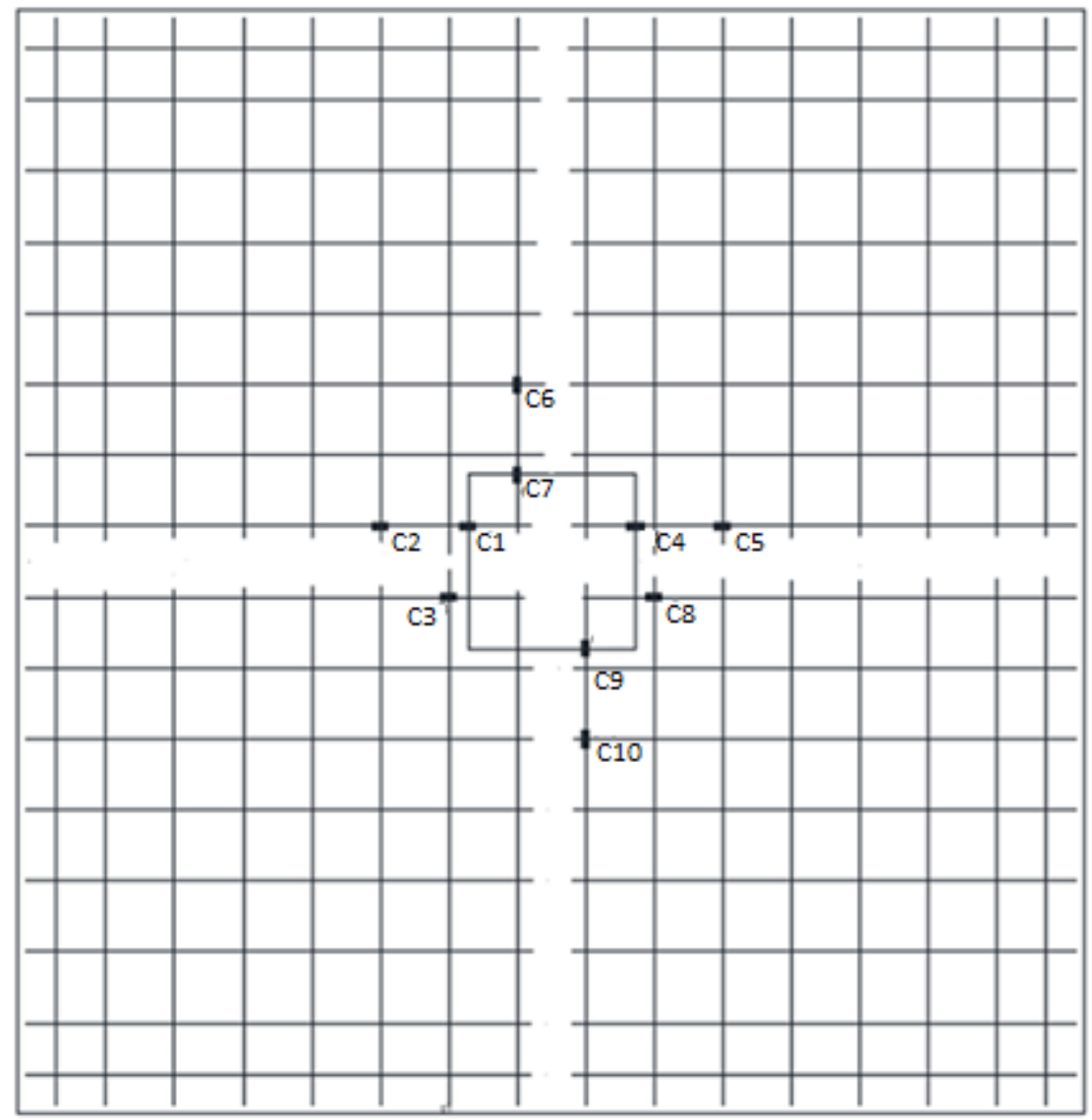

Figure 3.5.4 - Compression reinforcement strain gage layout for $1 \%$ reinforcement ratio slabs.

Strain gages were also applied to the concrete slabs surface against the center of the faces of the column. These gages allowed us to record the strain in the concrete itself during the testing. For each test there were four concrete gages placed around the column two each on two adjacent sides of the column. On each of the two sides one of the gages was placed such that is was measuring the strain parallel to the face of the column and one gage was placed such that it was measuring the strain perpendicular to the face of the column. There was no difference in the placement of the concrete strain gages between the various test setups. The concrete gage positions on one face of the column can be seen in Figure 3.5.5. 


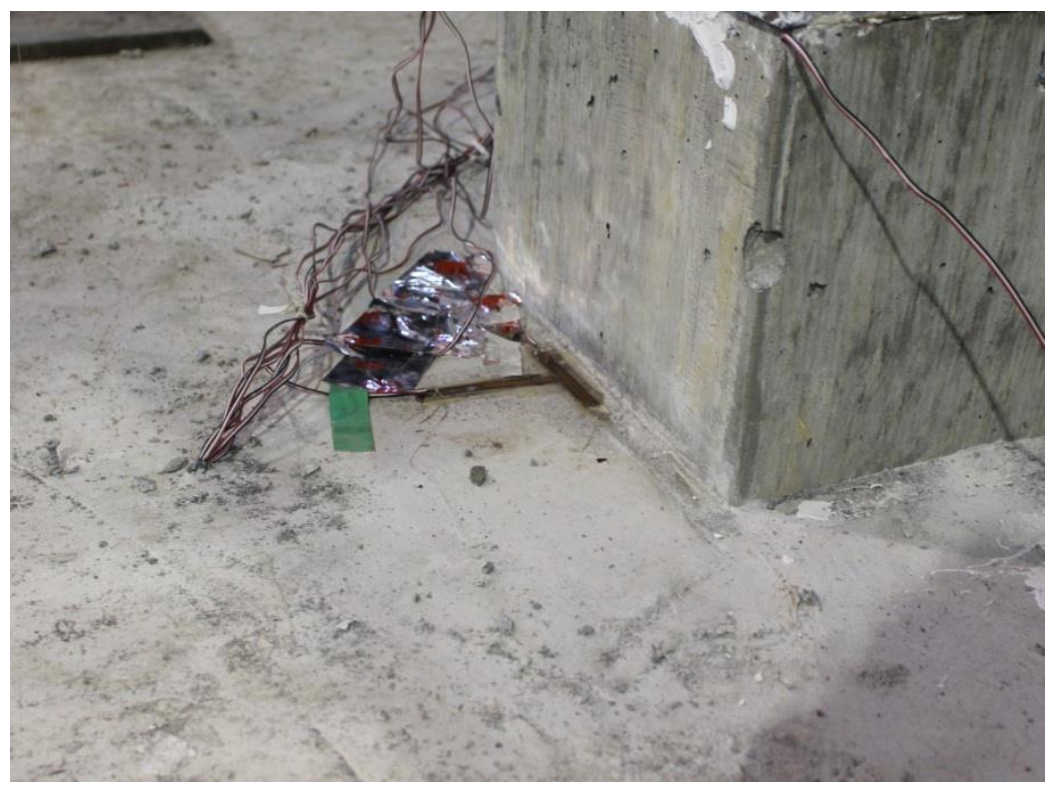

Figure 3.5.5 - Picture of concrete gages in position on the slab against the face of the column.

During the testing lateral movements as well as any expansion of the slab due to the loading was recorded, this was done by placing 4 LVDT's (one on each edge of the slab) at specified locations on the slab. The general locations of the LVDT's can be seen in Figure 3.5.6.

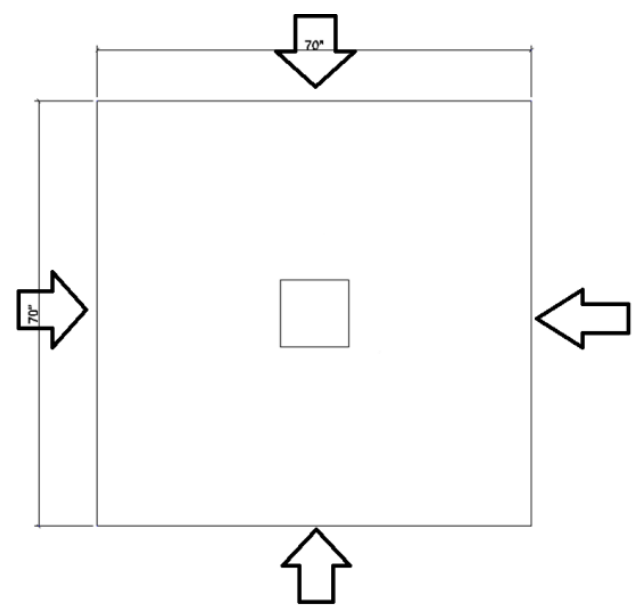

Figure 3.5.6 - Arrows denote the locations of the LVDT's used to measure horizontal displacements. 
The LVDT's were measuring from the vertical outer edge of the slab, they were placed along the edge in the center of the slab measured from top to bottom as well as end to end. Measurements were made in all four directions to determine if the slab was translating in any direction as well as expanding or contracting. There was no difference in the setup of the LVDT's that were measuring lateral movements between the different test setups. A photo of one of the LVDT's used to measure lateral movements can be seen in Figure 3.5.7.

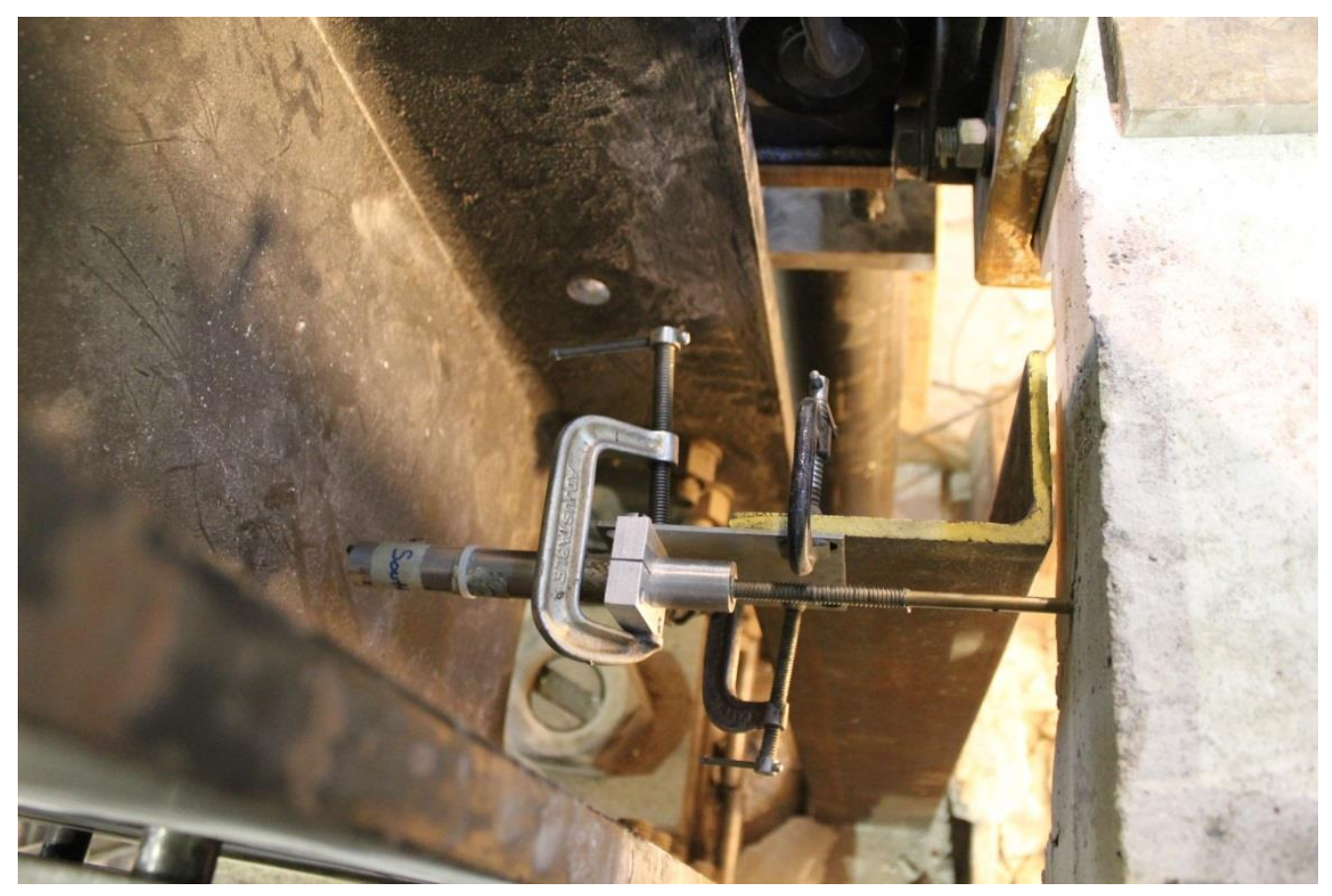

Figure 3.5.7 - Picture from above showing an LVDT positioned along the outer edge of the slab in order to measure the horizontal displacements.

During all four of the test vertical movements were measured at various locations on the specimen. The primary location of interest was the center of the column stub, measurements were made to know how far it moved vertically during the test. These measurements were made using a string pot attached to a small threaded rod that was imbedded in the concrete at the base of the column. A string pot was used for this measurement because an instrument that had a 
range up to 8 " was needed to measure the vertical movement of the column during both the pre and post punching regions of the test. The setup of the primary string pot can be seen in Figure 3.5.8.

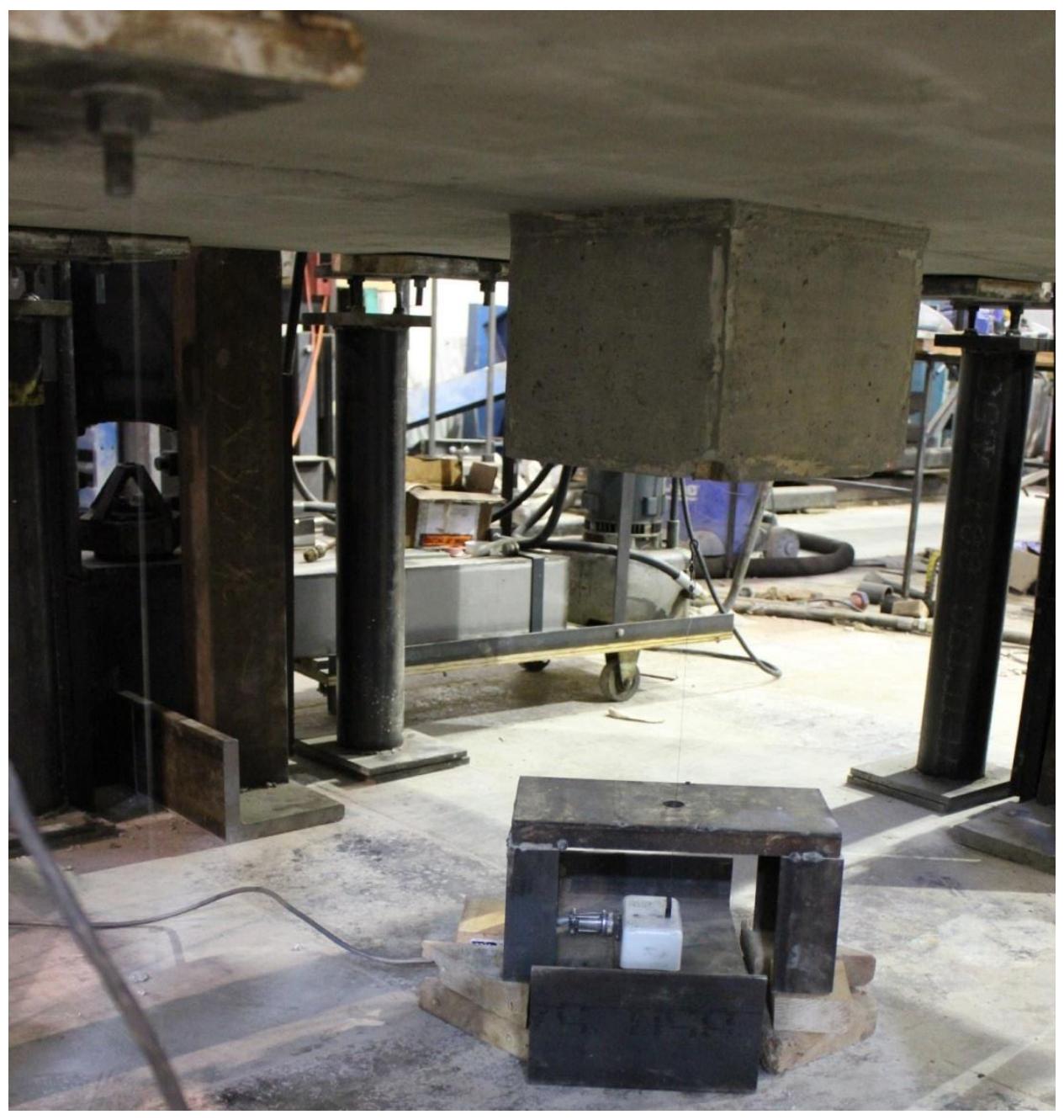

Figure 3.5.8 - Picture of center vertical string pot positioned directly under the bottom column stub (the string pot is covered to prevent damage from falling concrete).

Vertical displacements were also measured at other locations on the slabs during the test. These locations include two mid-slab locations on the top of the slab 10" out from the column centered along adjacent faces of the column, as well as points at the edge of the slab near the 
supports. These measurements were used to calculate the rotation of the slab during the test as well as to determine the vertical translation of the slab due to the applied load. There was no difference in the setup for measuring vertical displacements between the test types.

During each of the test a load cell was used to record forces that were applied on the column. The center load cell was a 200 kip compression load cell that was positioned directly under the hydraulic jack. This provided the ability to record the load applied to the slab during the test. This center load cell can be seen in Figure 3.5.10.

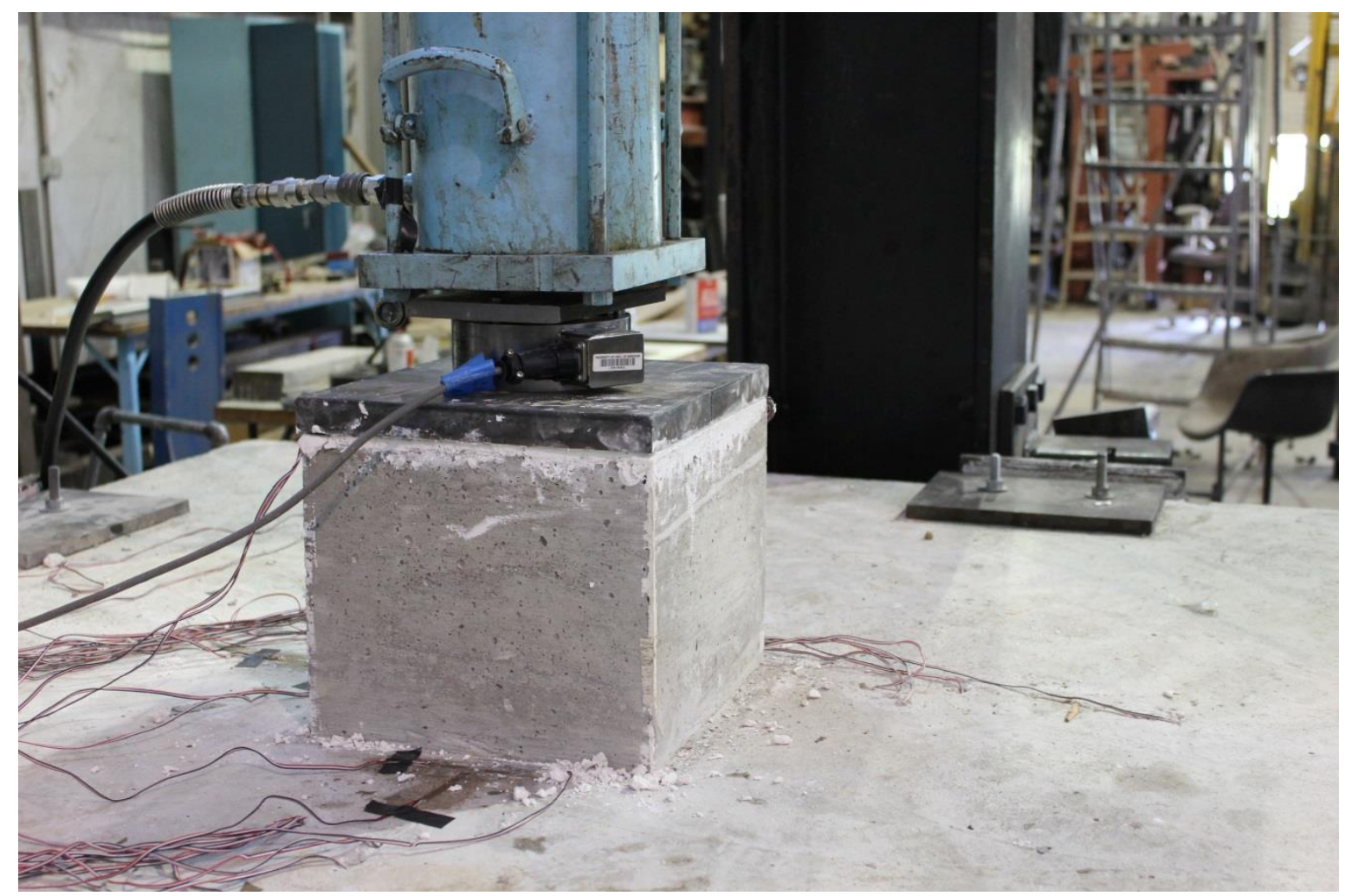

Figure 3.5.10 - Picture of center compression load cell in position on top column stub.

For the unrestrained test the center load cell is the only load cell used. When testing specimens in the restrained setup the center load cell as well as four other load cells were used. There were two tension load cells and two compression load cells. The additional load cells 
were placed on the 1.5 inch threaded rods that extended from the clevis, these load cells provided the ability to record any lateral forces that developed as the slab was loaded. An example of the locations of the additional load cells can be seen in Figure 3.5.11.

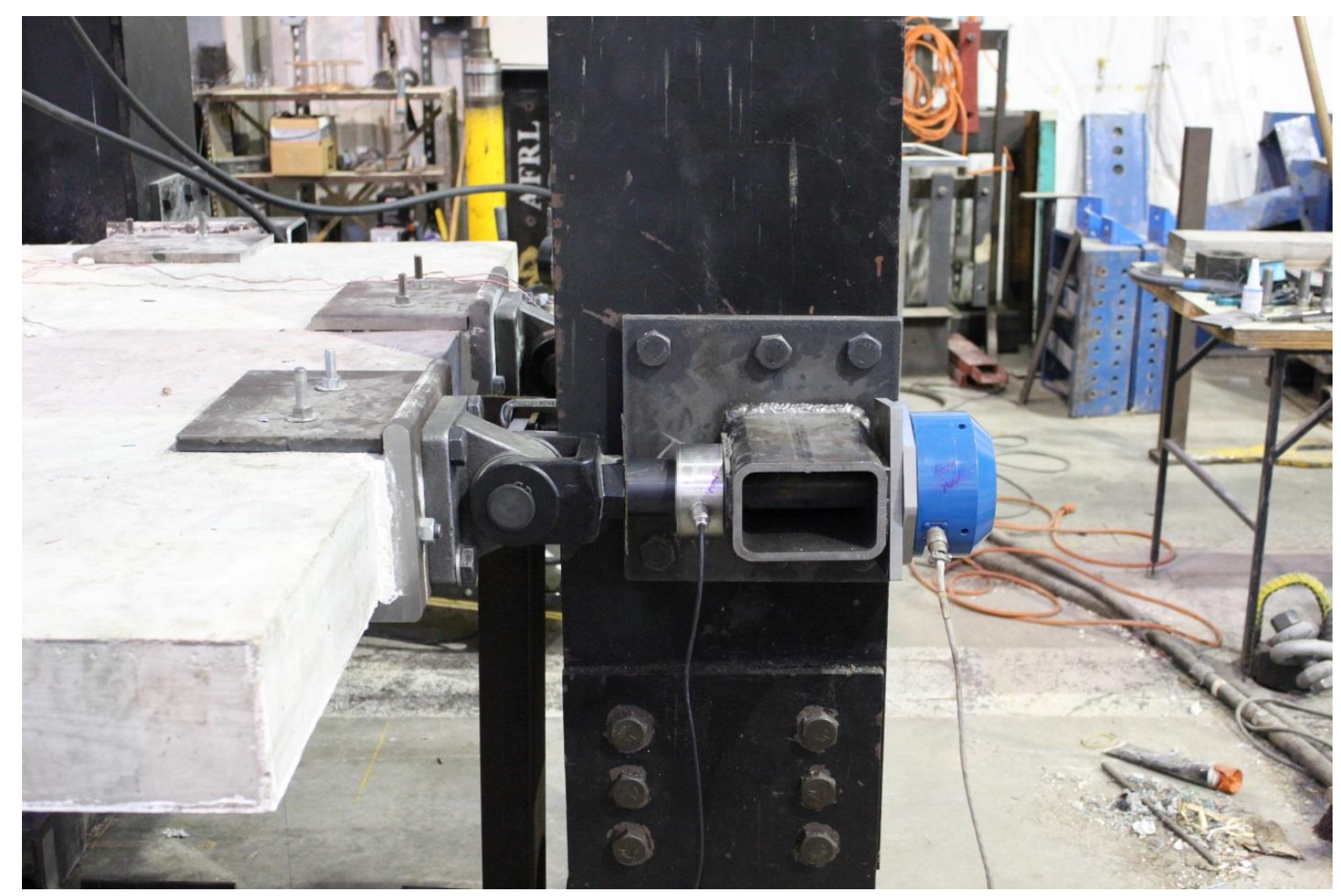

Figure 3.5.11 - Picture of tension (blue) and compression (silver) load cells in position for the restrained test setup.

The compression load cells were slid over the end of the rod prior to placing the rod through HSS that is attached to the column. The compression load cell is held in place by a washer and nut that forces it against the HSS. The tension load cells threaded on the ends of the same rods that the compression cells were on and were tightened down such that there was no slack in the system. The load cells were placed on rods that were on adjacent columns such that they were not measuring directly across from each other. 


\section{6 - Material Properties}

The slab specimens were designed using a target concrete compressive strength of 4,000psi and a design reinforcement yield strength of $60,000 \mathrm{psi}$. In order to conduct a more accurate analysis of results, testing was done to determine more exact material properties for all of the slab specimens. The actual concrete compressive strength at the time of the slab test was determined from compression test of concrete cylinders. The uniaxial compression test were conducted in accordance with ASTM (American Society for Testing and Materials). The concrete strengths of the slab specimens tested can be seen in Table 3.6.1.

Table 3.6.1 - Summary of concrete compressive strengths for all slab specimens.

\begin{tabular}{|c|c|}
\hline Slab Specimen & Concrete compressive strength (psi) \\
\hline $0.5 \%$ Unrestrained & $4,705 \mathrm{psi}$ \\
\hline $1.0 \%$ Unrestrained & $4,842 \mathrm{psi}$ \\
\hline $0.5 \%$ Restrained & $6,418 \mathrm{psi}$ \\
\hline $1.0 \%$ Restrained & $5,281 \mathrm{psi}$ \\
\hline
\end{tabular}

The steel reinforcement used was also tested in a uniaxial tension test setup to determine its material properties such that they could be used in analysis as well as computer modeling of the slab specimens. For all four slab specimens \#3 rebar was used as the compression reinforcement and \#4 rebar was used as the tension reinforcement. For the \#3 rebar samples the yield stress was just over 60,000 psi with the corresponding yield strain of about 0.0022 in/in and the ultimate stress was about 100,900 psi. For the \#4 rebar samples the yield stress was slightly higher, about 62,000 psi with a corresponding yield strain of about $0.0025 \mathrm{in} / \mathrm{in}$ and the ultimate 
stress was about 98,900psi. More detailed results from the material testing can be seen in the Appendix. 


\section{Chapter 4 - Results}

This section will present the results obtained from the testing of four isolated slab column specimens. Two of the specimens were tested in the unrestrained test setup while the other two specimens were tested in the restrained test setup. One of the specimens tested in each test setup configuration was constructed using a reinforcement ratio of $0.5 \%$ while the other specimen was constructed using a reinforcement ratio of $1 \%$. The results of each test will be presented and discussed individually in two sections, prior to the punching failure (pre punching) and after the punching failure (post punching). Then comparisons will be made between the tests based on test setup configuration and reinforcement ratio. Photos from above and below the untested slab specimens can be seen in Figures 4.1 and 4.2 respectively.

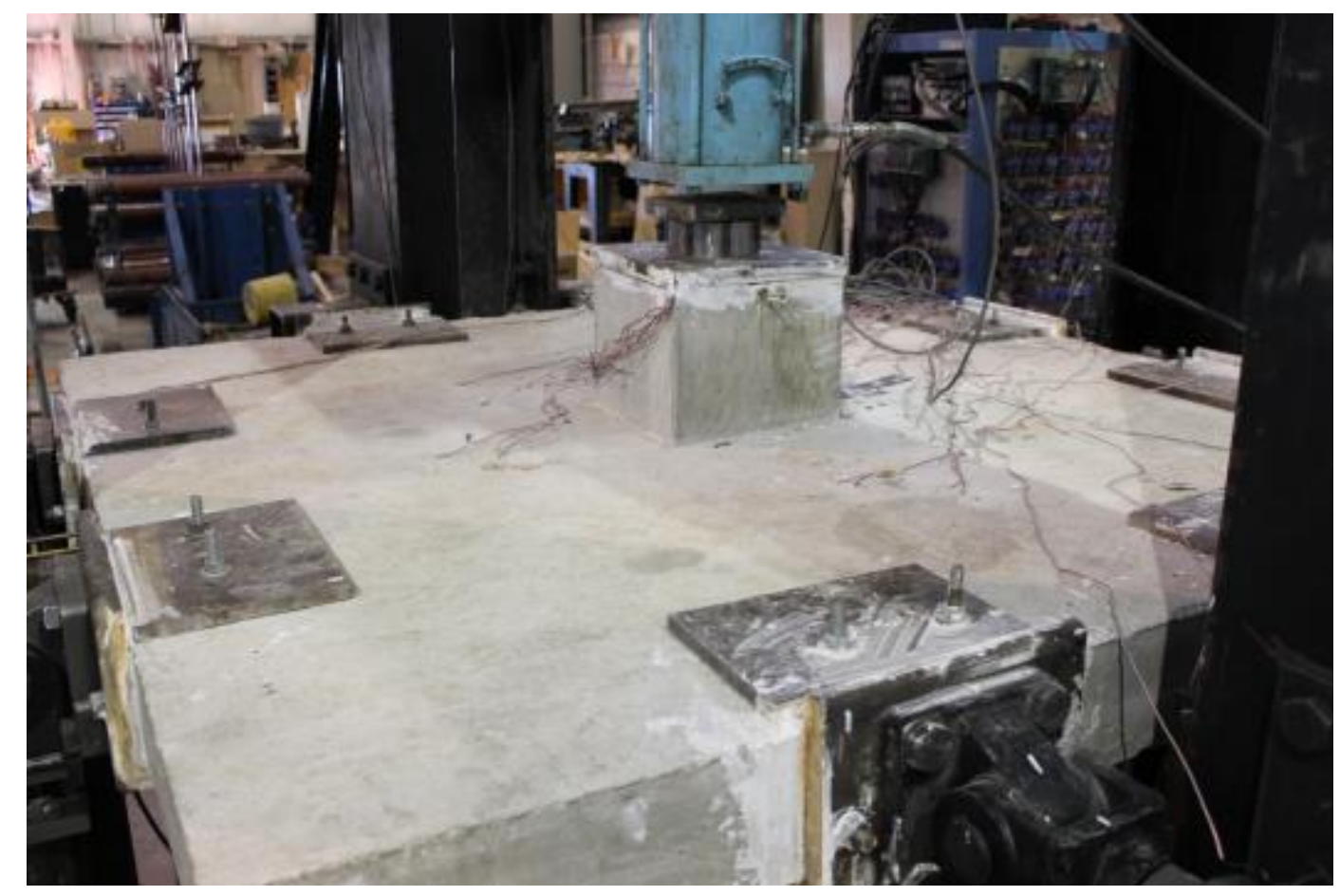

Figure 4.1 - Top view of slab specimen prior to testing. 


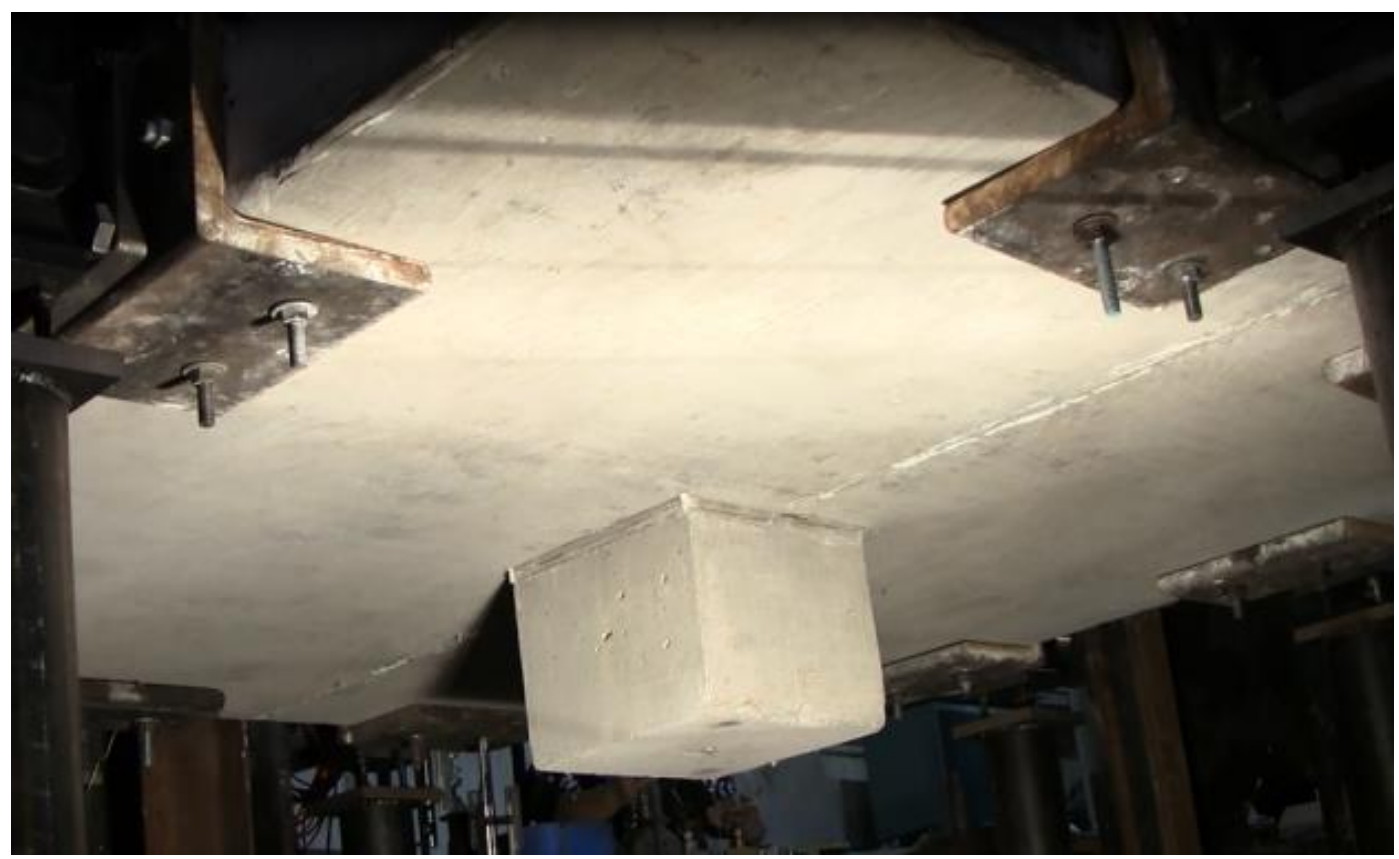

Figure 4.2 - Underside of slab prior to testing.

\section{1 - Unrestrained Slab Testing}

The results of the two slabs that were tested in the unrestrained test setup configuration will be discussed independently in this section.

\subsection{1 - 0.5\% Reinforcement Unrestrained Test Setup (Pre Punching)}

The slab specimen was loaded at a rate of 0.14 kips per second until the punching failure occurred. The hydraulic ram used to apply the loading is hand controlled so the operator was tasked with keeping the loading rate as constant as possible. The specimen resisted an applied load of 52 kips before the punching failure occurred at a corresponding center vertical displacement of 1.05 inches. The specimen behaved linearly until a displacement 0.01 inches and a load of about 10 kips was reached. At this point the shear cracking began in the slab which results in a reduced stiffness. As the loading increased from 10 kips to about 50 kips the slab 
again behaved almost linearly due to the resistance of the moment couple created between the conical compression shell and the tension reinforcement. The load deflection response of the slab specimen prior to the punching failure can be seen in Figure 4.1.1.1. A photo of the underside of the slab immediately following the punching failure can be seen in Figure 4.1.1.2.

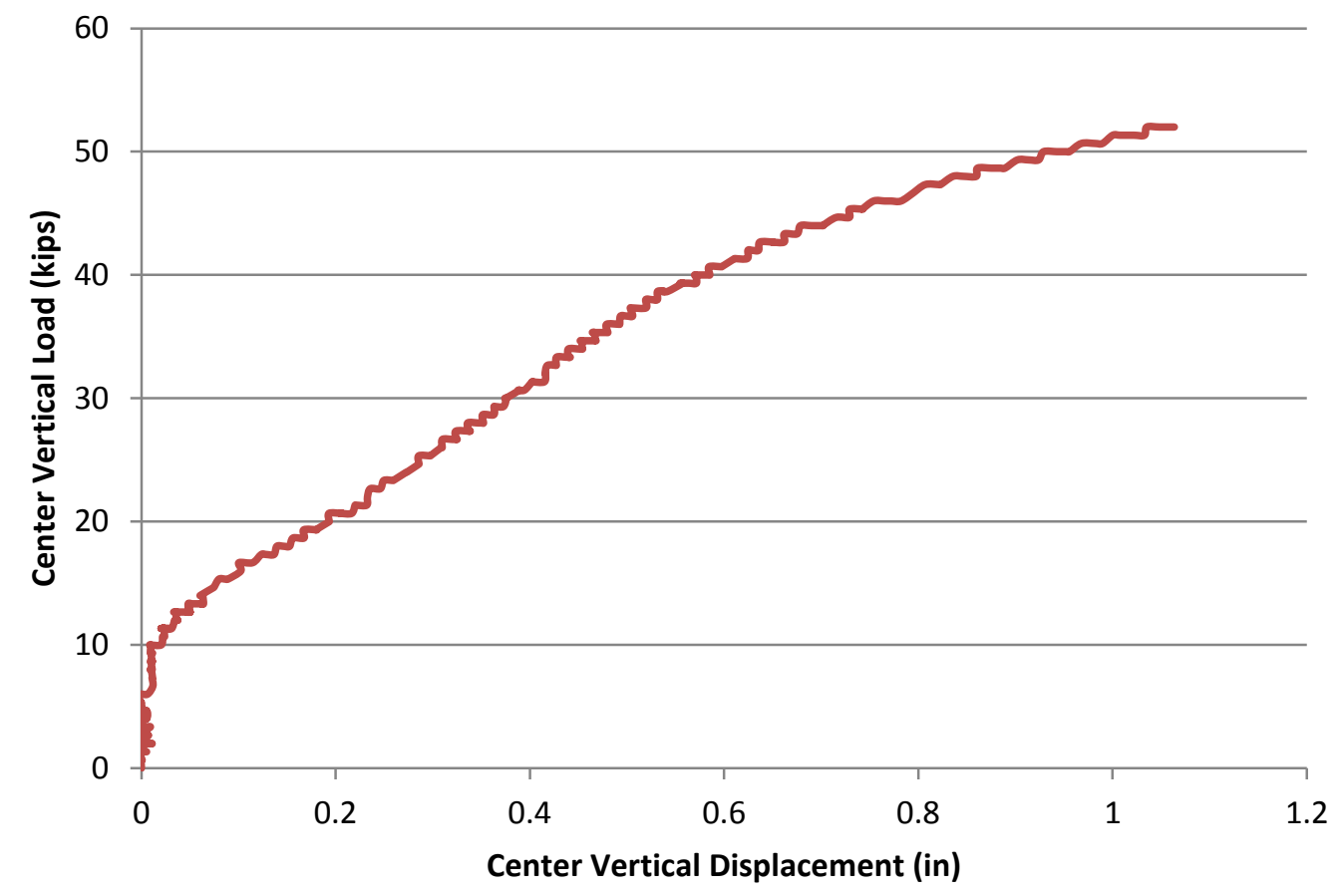

Figure 4.1.1.1 - Pre-punching vertical load vs. center vertical displacement for the $0.5 \%$ unrestrained specimen. 


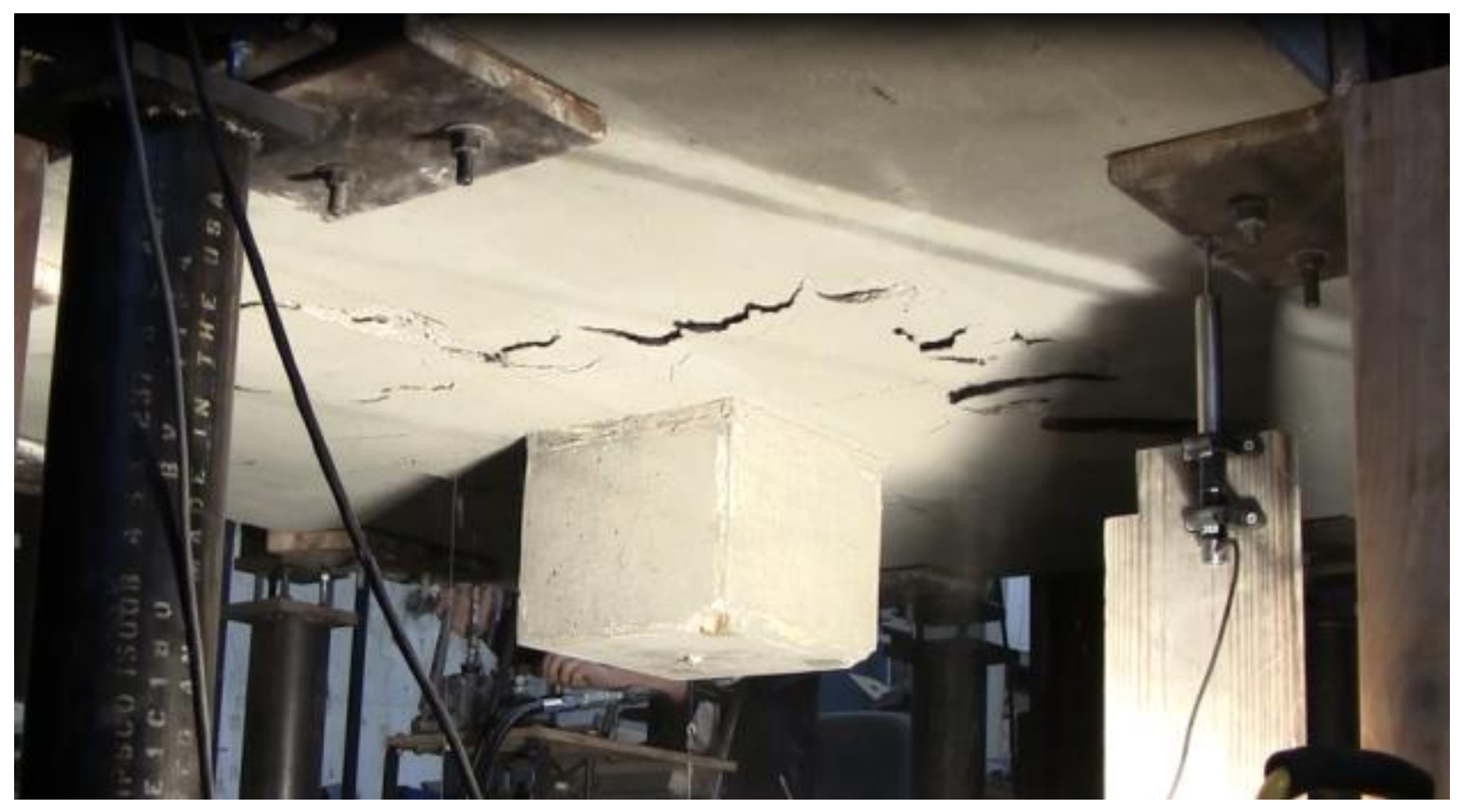

Figure 4.1.1.2 - Underside of the $0.5 \%$ unrestrained slab just after the punching failure.

During the testing process vertical displacements were measured at locations other than the center of the slab. Vertical displacement measurements were taken at the supports as well as at mid-slab locations which were 10 inches from the face of the column. The supports displaced 0.027 inches prior to the punching failure, this small displacement was subtracted from the other vertical displacements in order to find the actual displacement of the slab relative to its supports. Results showed that the mid slab locations displaced 0.52 inches prior to the punching failure which is $48 \%$ of the center displacement. The relative displacements of the slab at the center as well as the mid-slab locations can be seen in Figure 4.1.1.3. 


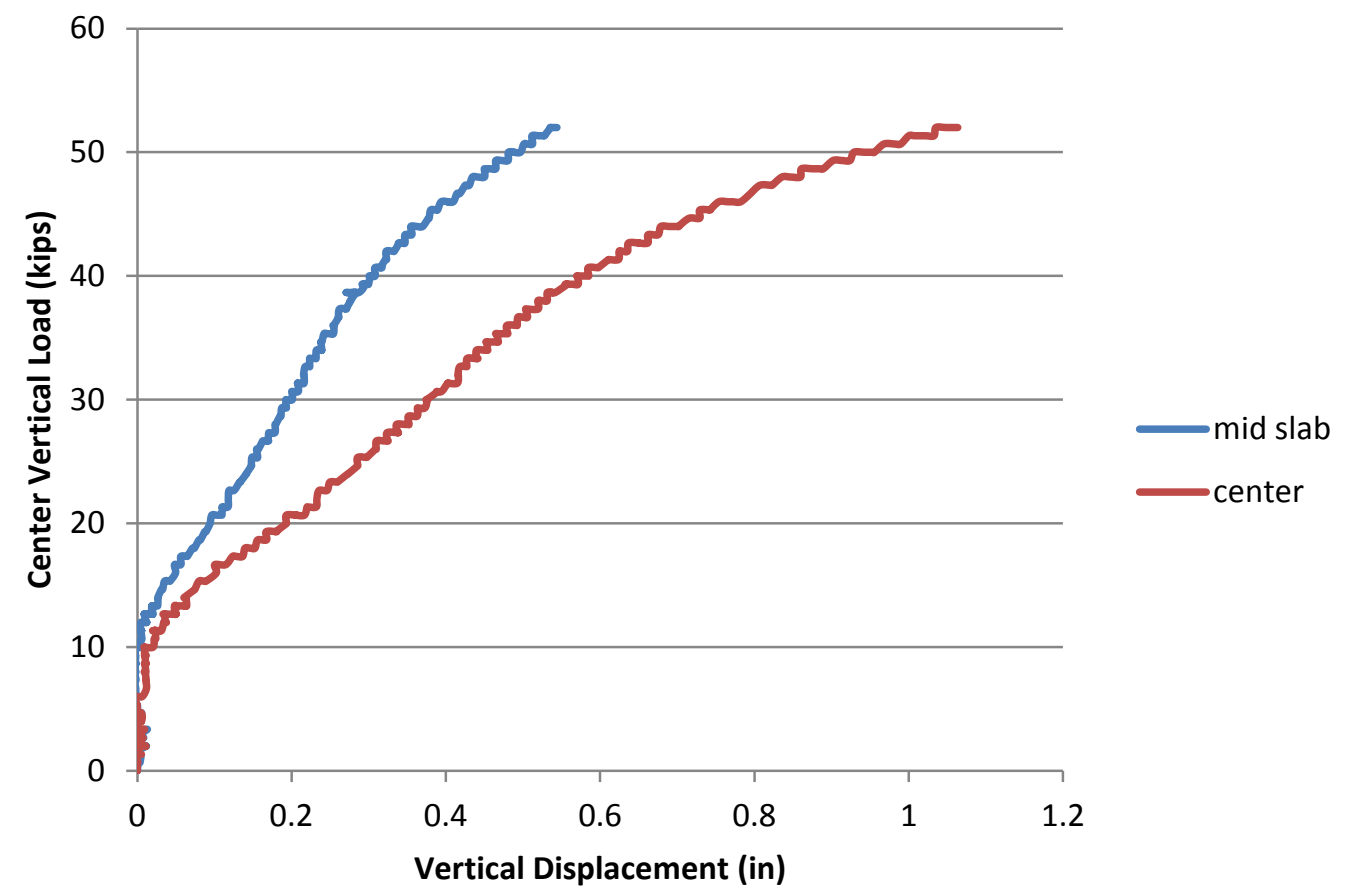

Figure 4.1.1.3 - Vertical displacements measured relative to the displacements of the supports $0.5 \%$ unrestrained slab specimen.

The mid-slab displacements were also used to determine the angle of rotation of the slab prior to failure since it has been shown in past research that the angle of rotation can be used as an indicator of punching failure. It was calculated that the slab specimen rotated 0.0243 radians prior to the punching failure occurring, rotations calculated from the work of Kinnunen and Nylander (1960) show that slabs of the same reinforcement ratio typically rotated about 0.04 radians prior to failure. Their plot of slab rotations prior to failure for various reinforcement ratios can be seen in Figure 2.4.2.

Since this slab specimen was tested in the unrestrained configuration there was nothing to stop the slab from expanding laterally when it was loaded vertically. The horizontal displacement of the slab was recorded along all four sides such that we could determine how 
much the slab expanded as well as how much the slab may have shifted horizontally during the testing. In order to determine the expansion of the slab we subtracted out the rigid movement in the slab from the displacement data that was recorded. It was determined that the slab expanded an average of 0.04 inches prior to the punching failure occurring. The relationship between applied load and expansion in the north - south and east - west directions can be seen in Figure

\subsubsection{4.}

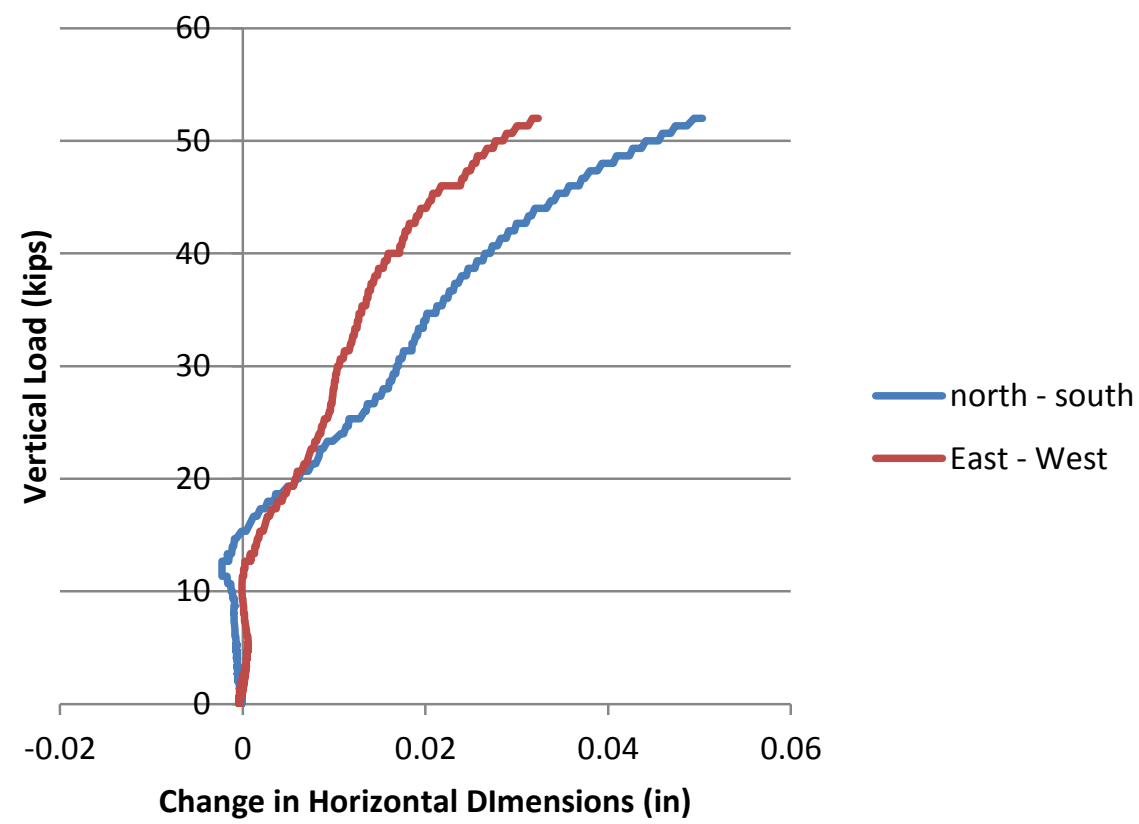

Figure 4.1.1.4 - Horizontal expansions of the $0.5 \%$ unrestrained slab as it relates to the applied loading prior to the punching failure.

It can be seen from past research in the area of punching shear that the compressive strain in the concrete parallel to the column face near the slab column connection can be an indicator that a punching failure is imminent. When the compressive strains reach $0.0008 \mathrm{in} / \mathrm{in}$ parallel to the column face microcracks begin to form, these can propagate through the connection initiating a punching failure (Broms, 1990). Concrete strains were measured perpendicular to the column 
face as well as parallel to the column face along two sides. Results showed that the compressive strains perpendicular to the column face reached a maximum value of $0.0018 \mathrm{in} / \mathrm{in}$ prior to the failure. However the strain measured parallel to one of the faces of the column was 0.00084 in/in just prior to the failure occurring which is consistent with past testing. The plot of applied vertical load vs. compressive strains in the concrete can be seen in Figure 4.1.1.5.

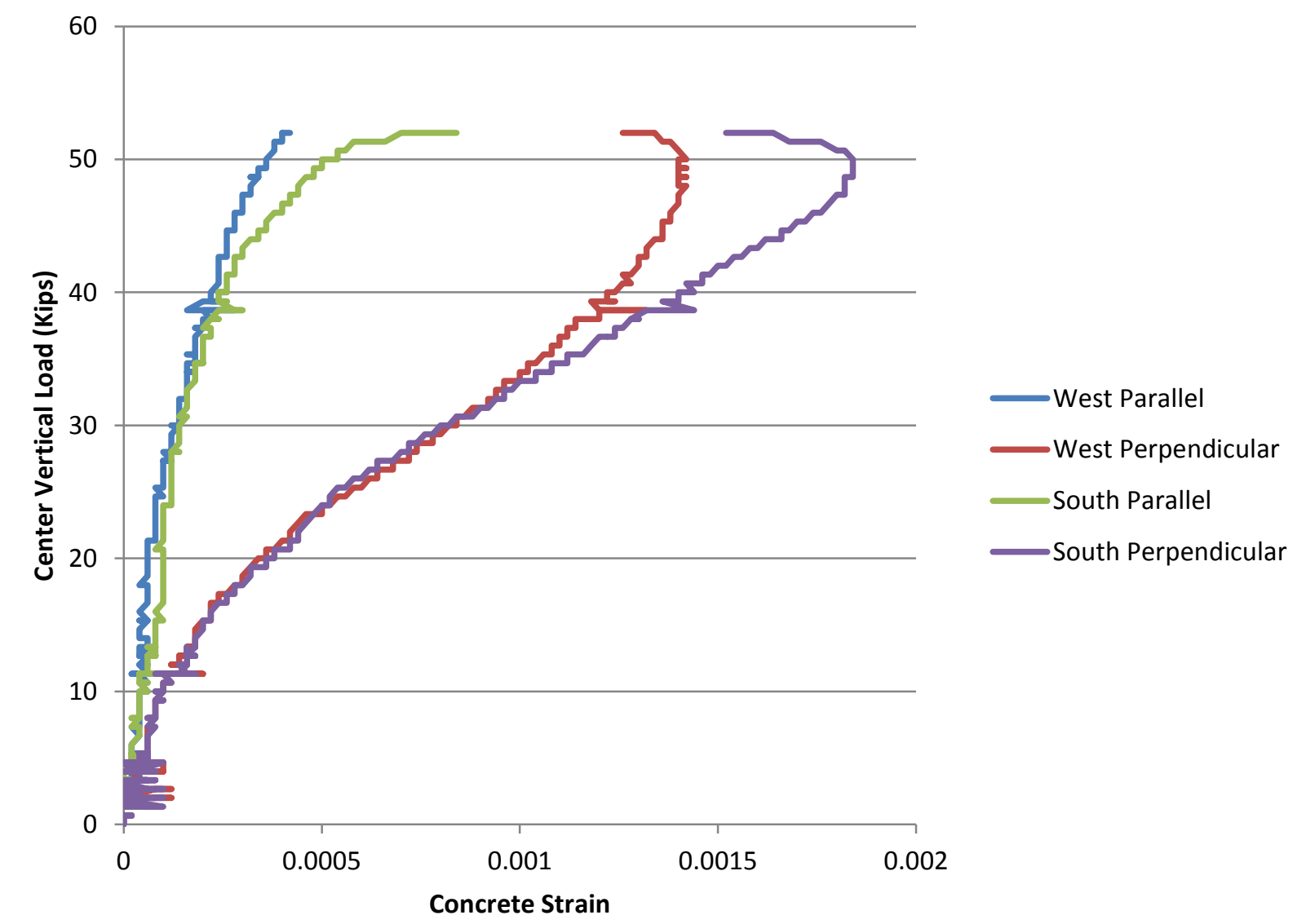

Figure 4.1.1.5 - Applied vertical load vs. concrete compressive strains measured along two of the faces of the column of the $0.5 \%$ unrestrained slab prior to the punching failure.

Along with all of the instrumentation on the exterior of the slab column specimen the tension and compression reinforcement cages were instrumented with strain gages. The layout of the gages was designed to allow us to determine how the strain varied as you move away from 
the slab column interface and the failure area. One of the major trends that can be seen for the $0.5 \%$ reinforcement slab specimen is that all of the tension reinforcement that was instrumented had reached the yield strain of $0.002 \mathrm{in} / \mathrm{in}$ at the time of the punching failure. The strains on the tension bars varied from $0.0026-0.009$ in/in prior to the failure. The instrumented compression reinforcement had not yielded prior to the failure occurring, the strains on the compression bars varied from $0.0002-0.0017 \mathrm{in} / \mathrm{in}$. In general the rebar strain was highest at the face of the column and it decreased farther away from the column. There were two set of four gages that were placed in a line on separate bars as you moved away from the column to show the strain distribution, the strain data from one of these sets this can be seen in Figure 4.1.1.6. It can be seen that the strain varied from $0.0026-0.0084 \mathrm{in} / \mathrm{in}$ as the measurements were made closer to the column face. It can also be seen that as the specimen was nearing punching failure the strains in the bars nearest to the column reduced. This is caused by redistribution in the load paths as the failure approaches.

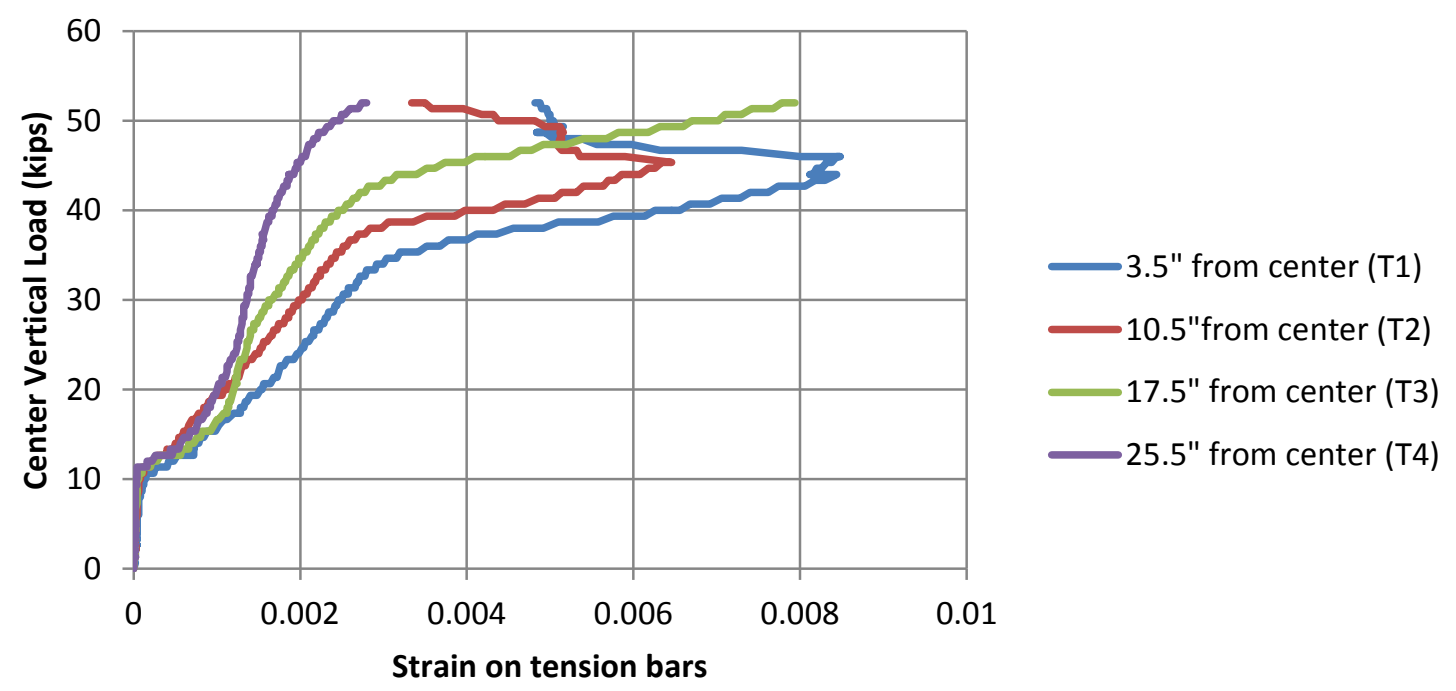

Figure 4.1.1.6 -Strain on the tension reinforcement vs. applied vertical load on the $0.5 \%$ unrestrained slab as you move away from the center of the slab specimen. 
Another set of gages (T13 - T18) was placed on the tension reinforcement cage such that the strain distribution as you pass from one side of the column through to the other side could be determined. It can be seen that the tension reinforcement within the punching cone in the center of the slab yields at an applied load between 22 and 25 kips whereas the reinforcement farther away from the center and outside of the failure area does not yield until an applied load between 36 and 40 kips. As in the other set of tension reinforcement gages it should be noted that the reinforcement develops almost no strain until the slab cracks at an applied load of 10 kips after which the tensile strains on the reinforcement increase quickly until just prior to the punching failure. A plot of the strain on the reinforcement as it passes through the column from one side to the other can be seen in Figure 4.1.1.7.

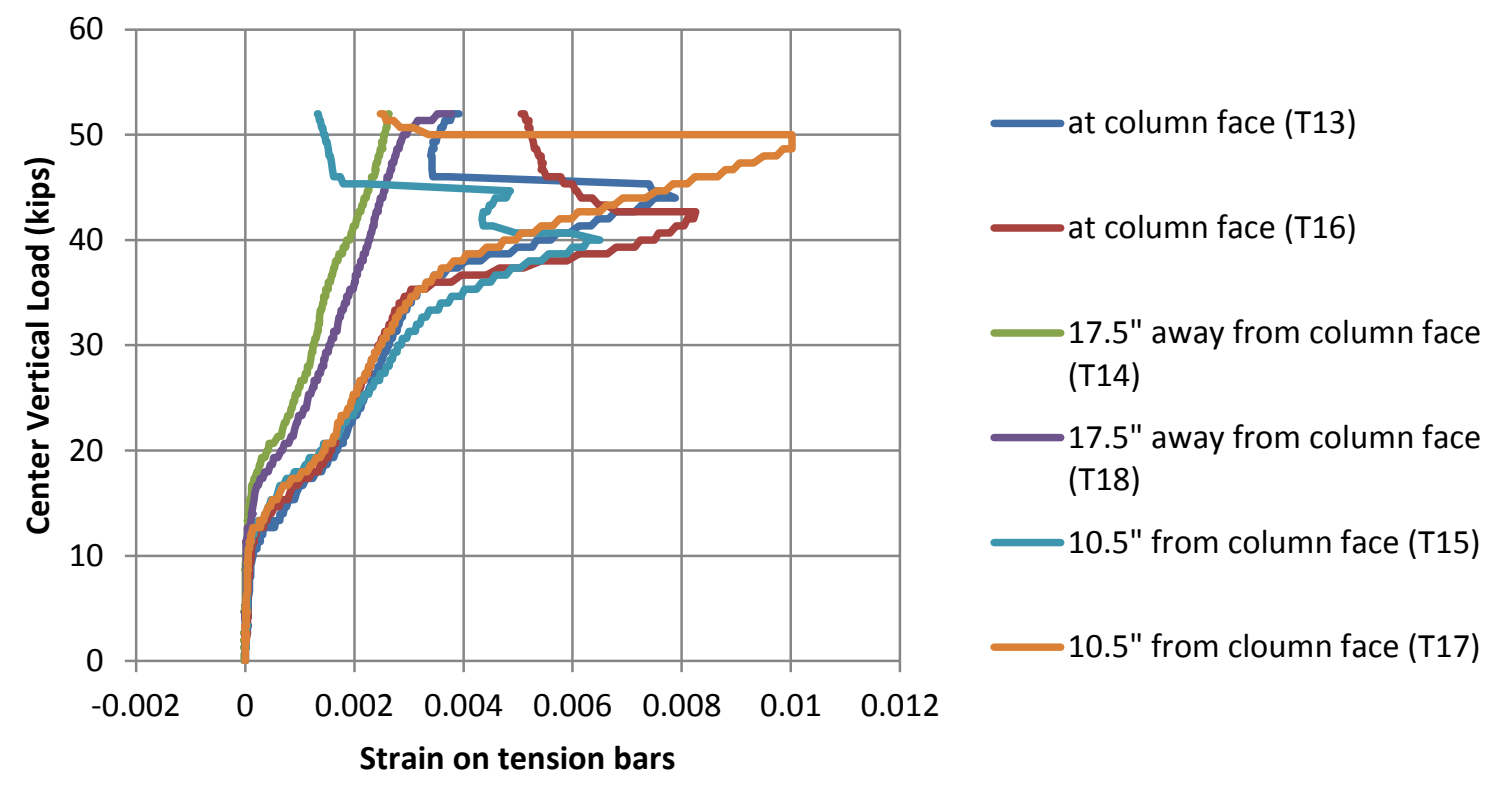

Figure 4.1.1.7 - Applied load on the 0.5\% unrestrained slab vs. strain on the tension reinforcing cage as the bars pass through the column and punching cone. 
From looking at a plot of the measured strains on the compression reinforcement bars it can be seen that all of the gages measured increasing compressive strains (shown as negative) from the start of the test until the slab began to crack at an applied load just over 10 kips. Once the slab cracked the shear dominated response of the slab specimen produced tensile strains in the bars. This is shown by the change in slope on the applied load vs. strain plot, which can be seen in Figure 4.1.1.8. As the applied loading reached 44 kips all of the instrumented bars saw tensile strains, strains were generally higher closer to the face of the column.

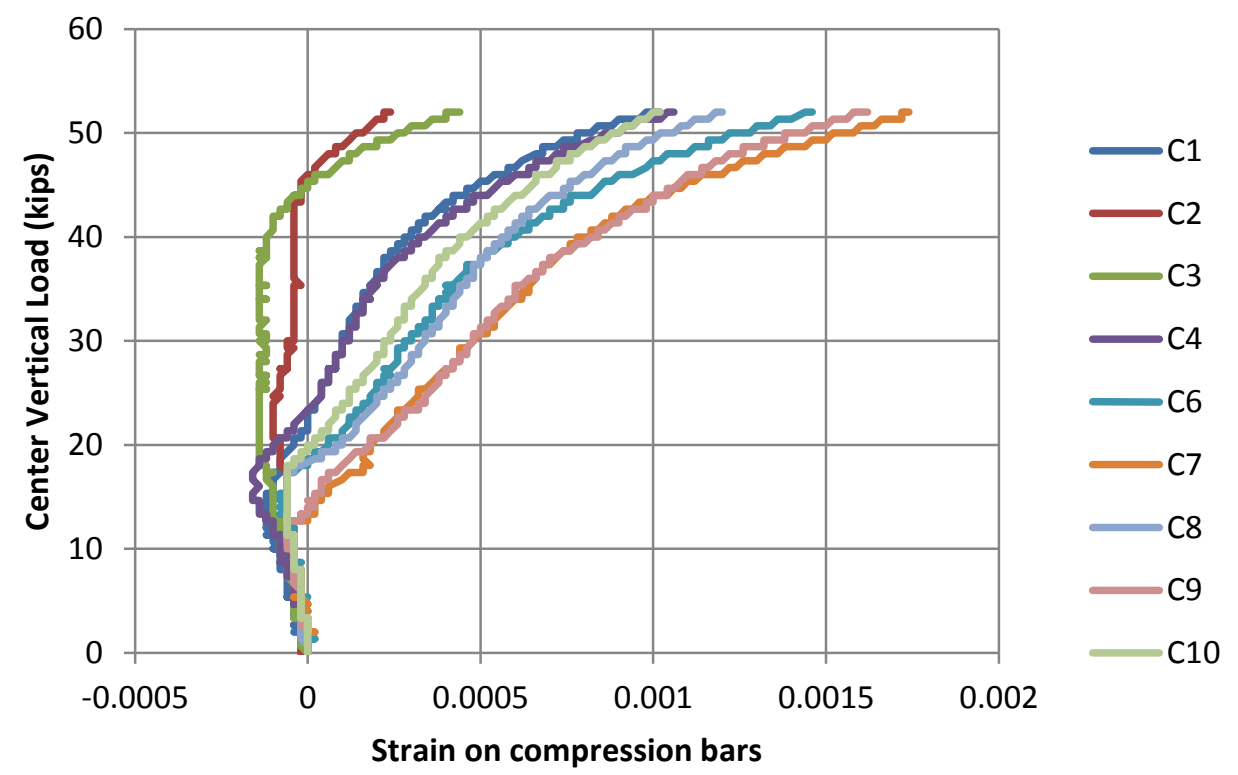

Figure 4.1.1.8 - Applied vertical load on the $0.5 \%$ unrestrained slab vs. strain on compression bars prior to the punching failure occurring. Compressive strains are shown as negative and tensile strains are shown as positive.

The plots in Figures 4.1.1.6 through 4.1.1.8 show some of the trends that developed in the reinforcement strain data. In order to gain a better understanding of the reinforcement strains throughout the slab specimen Figures 4.1.1.9 and 4.1.1.10 were created, showing the maximum 
strain values prior to failure listed at their corresponding locations within the slab. The gage locations can be referenced in Figures 3.5.1 and 3.5.2.

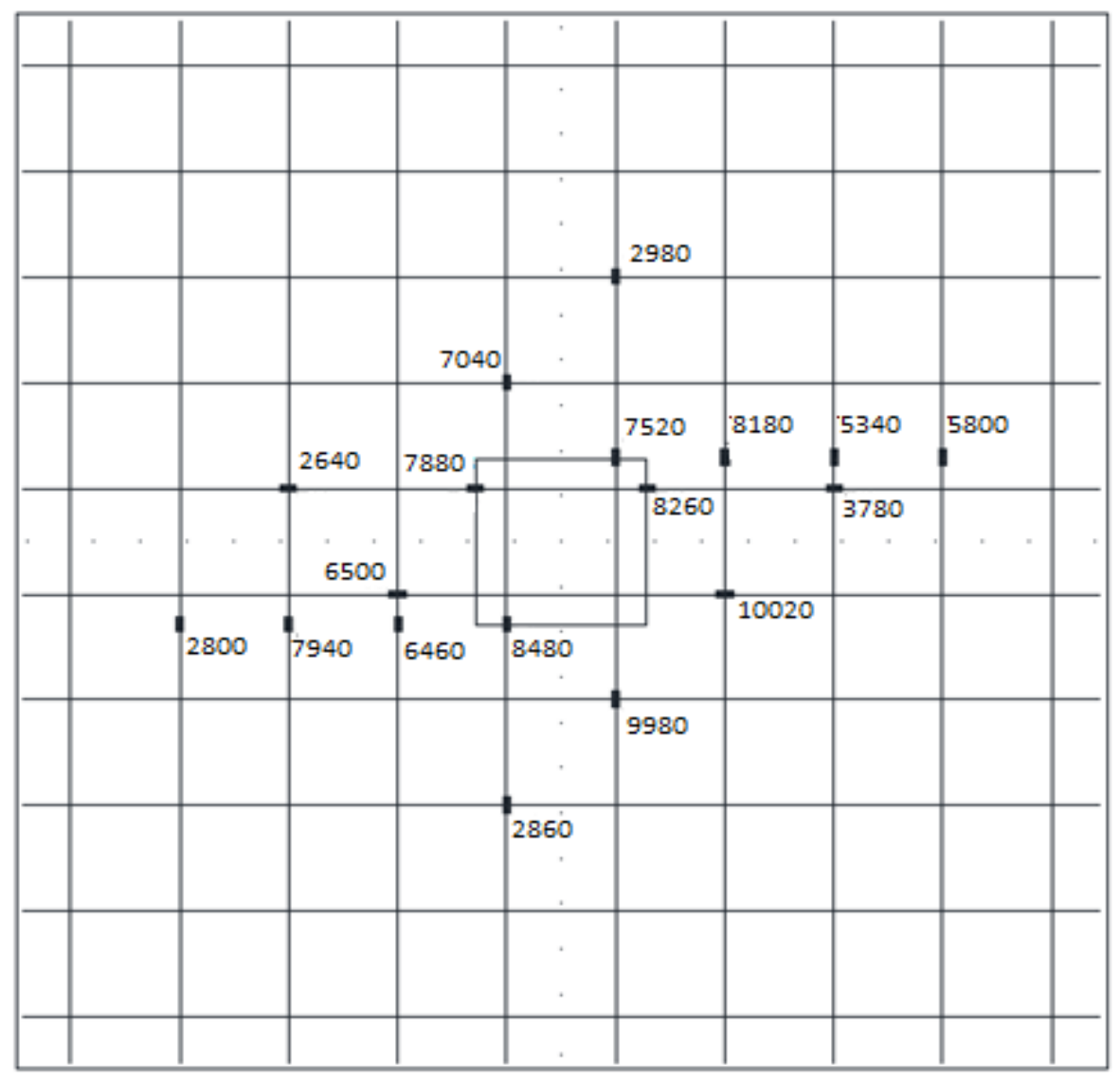

Figure 4.1.1.9 - Maximum strain values on the tension reinforcement prior to failure for the $0.5 \%$ unrestrained slab (strain values listed in microstrains). 


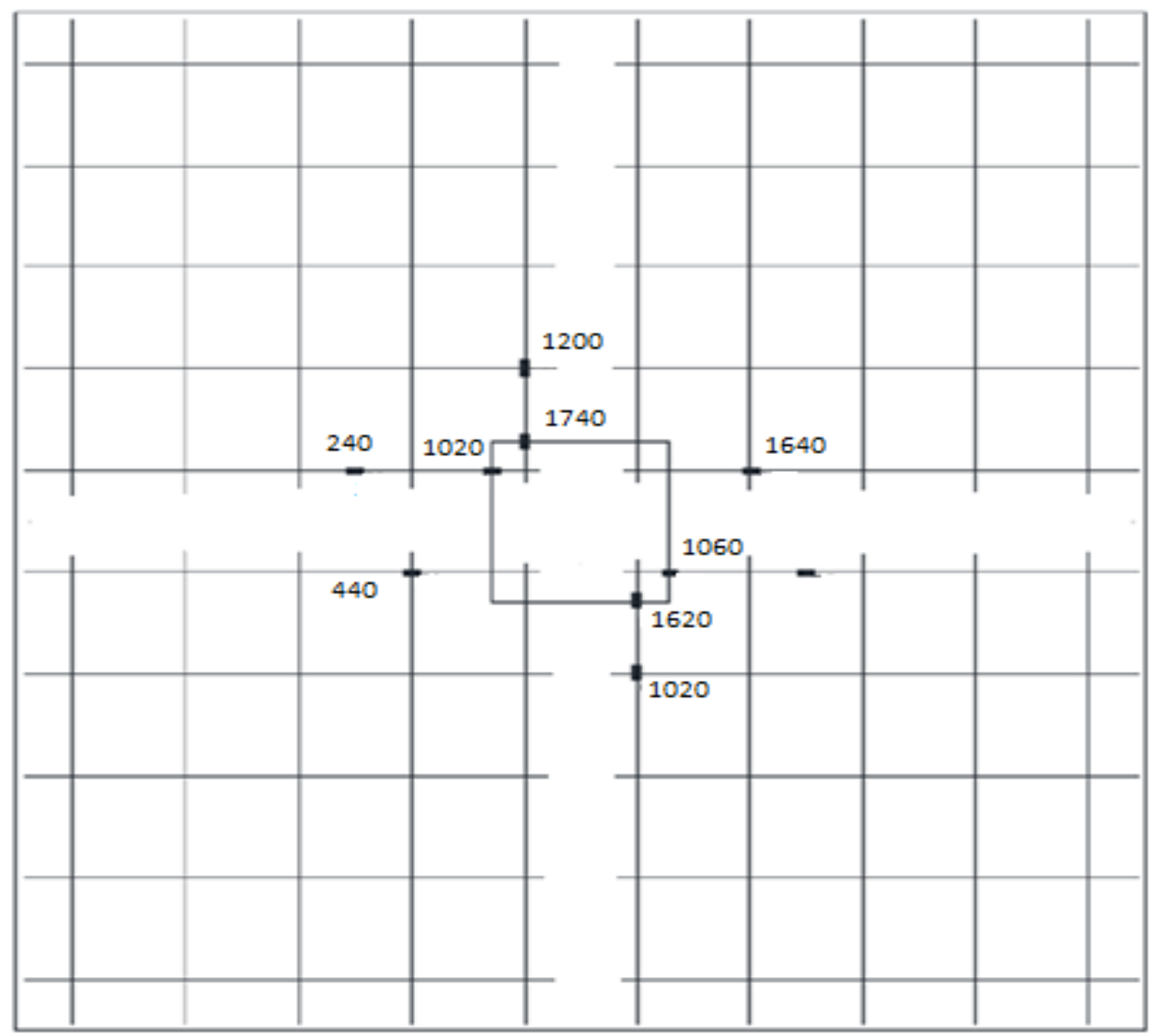

Figure 4.1.1.10 - Maximum tensile strain values on the discontinuous reinforcement prior to failure for the $0.5 \%$ unrestrained slab (strain values are listed in microstrains).

\subsection{2 - 0.5\% Reinforcement Unrestrained Test Setup (Post Punching)}

Testing did not stop immediately after the punching failure occurred, the slab was loaded further in order to determine the residual capacity of the slab column connection. The residual capacity of the connection is important because any load that can still be carried through the connection where the punching failure occurred does not need to be transferred to other connections. The transfer of load from one connection to the surrounding connections can result in overloading of the surrounding connections leading to a failure of those connections which 
can lead to a progressive collapse. The residual capacity of the connection is taken as the load that is still carried immediately after the punching failure has occurred. This can be seen as the point at the bottom of the large drop in load when looking at the load deflection plot which can be seen in Figure 4.1.2.1.

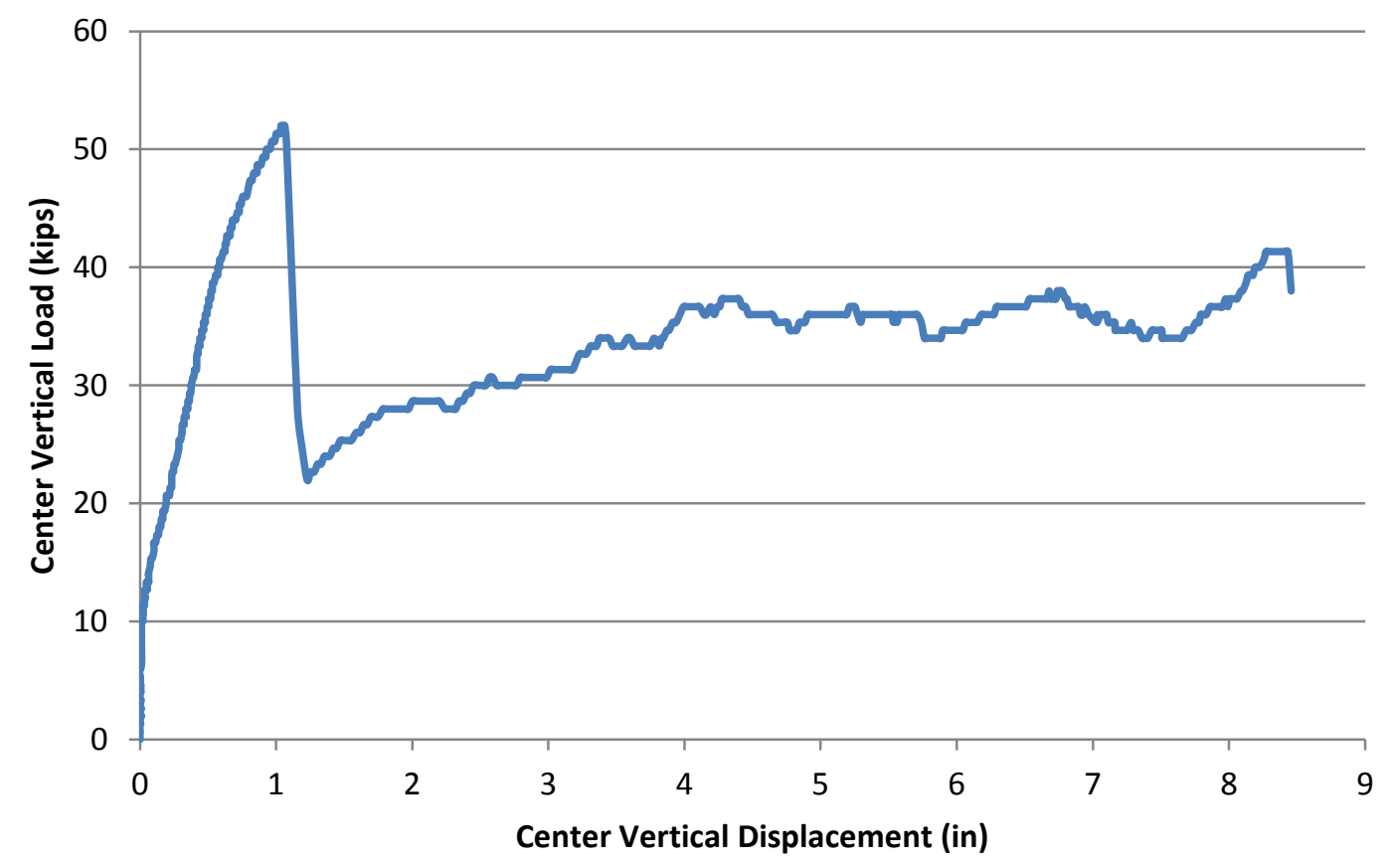

Figure 4.1.2.1 - Load Deflection plot including post punching response of the $0.5 \%$ unrestrained slab.

From Figure 4.1.2.1 it can be seen that the punching failure occurred at a load of 52kips at a deflection just over 1 inch. Following the failure the load drops rapidly and then starts to increase again as the reinforcement continuous through the column carries a significant load. The unrestrained slab with a reinforcement ratio of $0.5 \%$ had a peak residual capacity of 41.3 kips which is $79.5 \%$ of the punching load. This residual capacity is higher than the capacity predicted using Equation 7 from Habibi et al (2012). The ability of the connection to carry $79 \%$ of the 
total load after failure would be important in a structure because that may prevent the surrounding connections from being overloaded and failing themselves. The residual capacity of the connection is a result of the reinforcement that is continuous through the column as well as some dowel action from the discontinuous reinforcement that extends into the column. The slab was continually loaded until one of the reinforcing bars that were continuous through the column fractured. In this test the fracture occurred at a load of 41.3 kips and a corresponding center deflection of 8.3 inches. It is important to note that this slab specimen achieved its high residual capacity because the reinforcement was hooked at the ends which acted to anchor the reinforcement. In a real structure the reinforcement would not be hooked and would likely pull out of the slab thereby reducing the residual capacity. Future test are planned without hooked reinforcement such that the effects can be better determined. Photos from above and below the slab at the completion of the test can be seen in Figures 4.1.2.2 and 4.1.2.3 respectively.

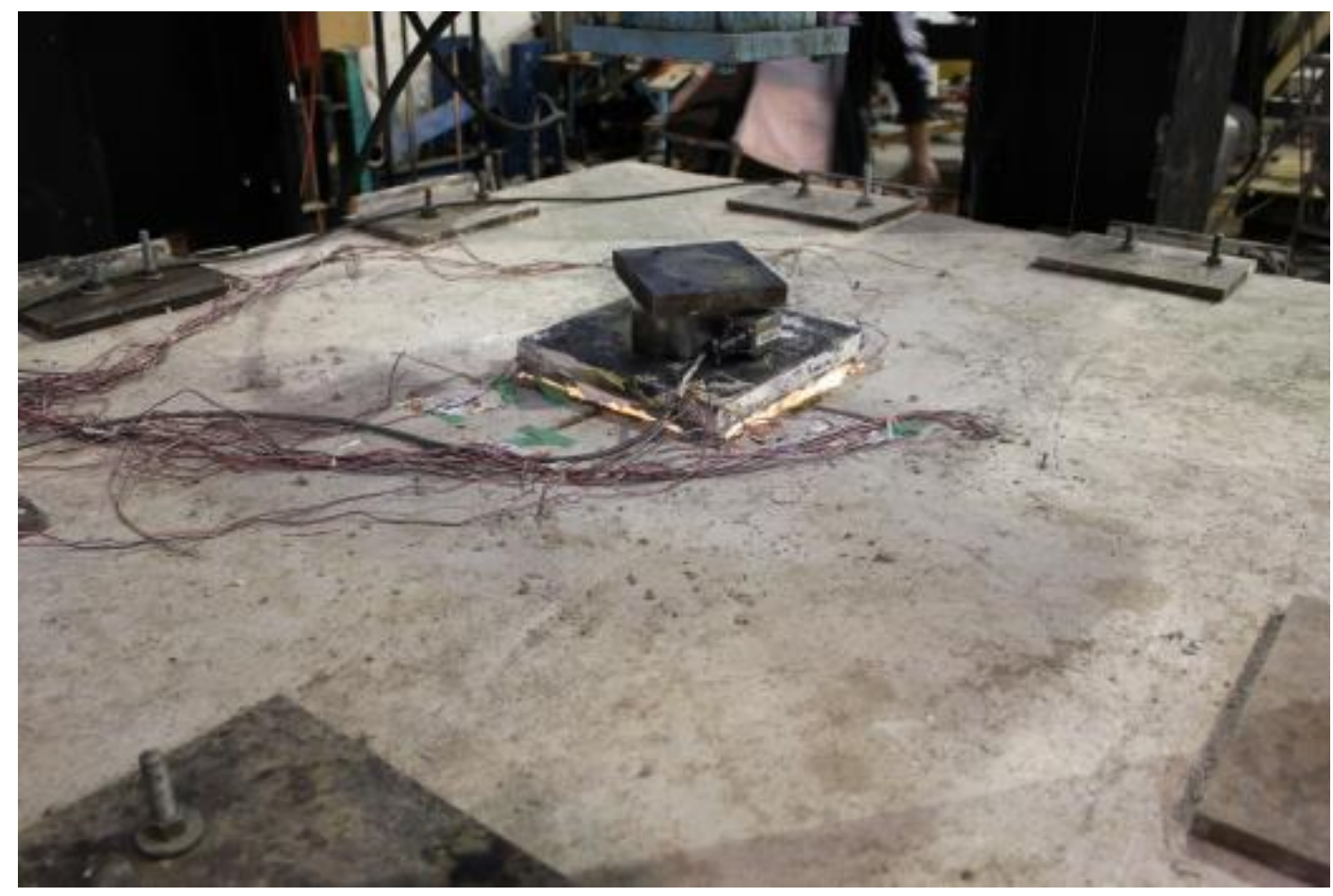

Figure 4.1.2.2 - 0.5\% unrestrained slab from above at the conclusion of the test. 


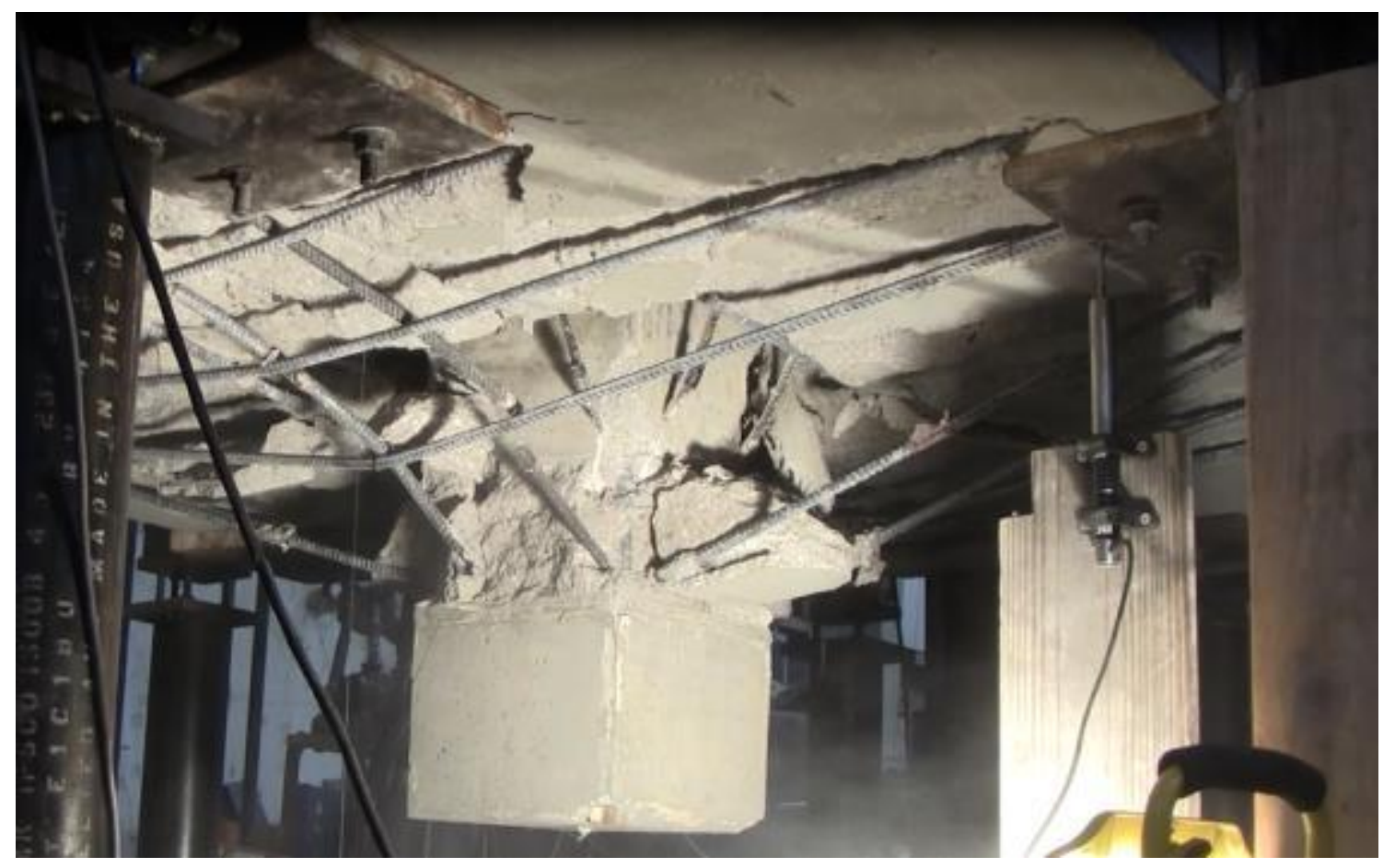

Figure 4.1.2.3 - Underside of the 0.5\% unrestrained slab at the conclusion of the test.

\subsection{3 - 1\% Reinforcement Unrestrained Test Setup (Pre Punching)}

The slab specimen was loaded at a rate of about $0.14 \mathrm{kips} / \mathrm{sec}$ from the beginning of the test until the punching failure occurred. The $1 \%$ reinforcement ratio slab resisted an applied vertical load of 69.1 kips prior to the failure occurring with a corresponding center vertical displacement of 0.83 inches. The load deflection response of the slab specimen was almost linear from the start of the test until an applied load of about 9.7 kips was reached with a corresponding center vertical displacement of 0.007 inches. At this point the shear cracking in the slab began slab which resulted in a reduced stiffness, this change in stiffness is represented in by the change in slope of the load deflection plot which can be seen in Figure 4.1.3.1. After the cracking occurred the slab specimen again behaved almost linearly until the punching failure occurred. 


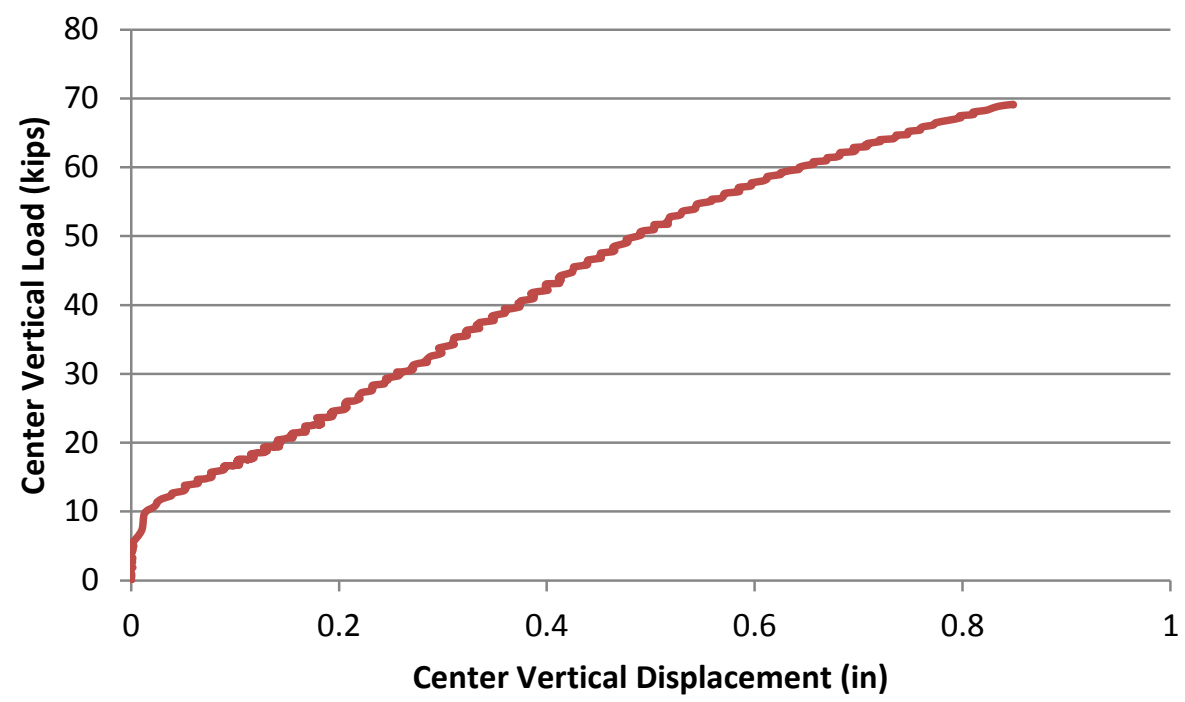

Figure 4.1.3.1 - Center load deflection response of the 1\% reinforcement unrestrained slab specimen prior to the punching failure occurring.

During the duration of the test vertical displacements were also measured at locations other than the center of the slab, these included mid-slab displacements located 10 inches away from the face of the column as well as support displacements located at the center of the vertical supports. Results showed that the supports displaced 0.035 inches vertically prior to the punching failure occurring. This support displacement was subtracted from the other vertical displacements to determine the actual displacement of the slab relative to its supports. The relative vertical displacements can be seen in Figure 4.1.3.2. 


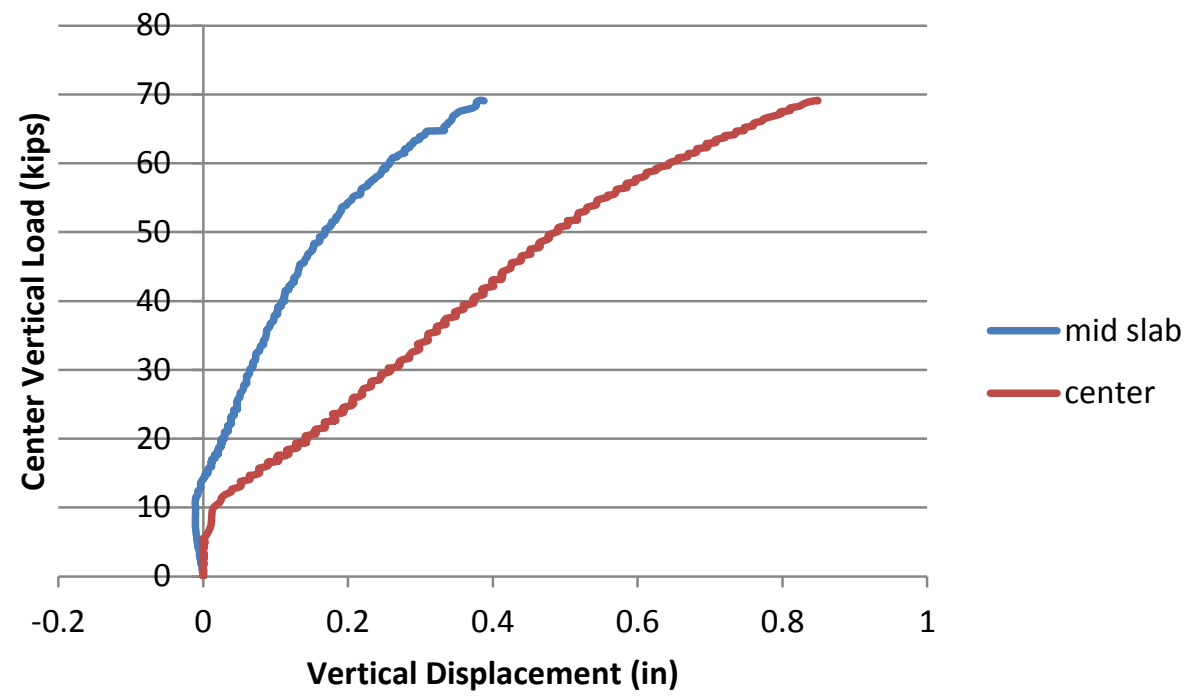

Figure 4.1.3.2 - Load displacement response for the center location as well as the mid slab location relative to the supports for the $1.0 \%$ unrestrained slab.

It can be seen that the mid slab locations displaced 0.37 inches prior to the punching failure which is $44 \%$ of the displacement measured at the center of the slab specimen. The midslab displacements were also used to calculate the angle of rotation of the slab prior to the failure occurring because past research by Kinnunen and Nylander (1960) showed that the slab rotation can be used as an indicator of punching failure. It was found that the slab specimen rotated 0.0173 radians prior to the punching failure occurring which is consistent with the results of the work by Kinnunen and Nylander (1960) which can be seen in Figure 2.4.2. It should be noted that this slab rotated less than the slab with a lower reinforcement ratio, this indicates that the increased reinforcement results in decreased ductility.

Since this slab specimen was tested in the unrestrained test setup configuration there was nothing to prevent the slab from expanding laterally when it was loaded vertically. Using LVDT's measuring along each of the four sides of the slab the expansion of the slab and any 
rigid body translation of the slab could be determined. It was calculated that the slab expanded about 0.025 inches prior to the punching failure.

It can be seen from past research in the area of punching shear that the compressive strain in the concrete around the slab column connection can be an indicator that a punching failure is imminent. When the compressive strains reach $0.0008 \mathrm{in} / \mathrm{in}$ microcracks begin to form, these can propagate through the connection initiating a punching failure (Broms, 1990). Concrete strains were measured perpendicular to the column face as well as parallel to the column face along two sides. Results showed that compressive strains measured parallel to the face of the column along one side reached 0.00078 in/in just prior to the punching failure occurring which is fairly consistent with the work of Broms. The compressive strains measured perpendicular to the face of the column reached maximum values of $0.001 \mathrm{in} /$ in along the same face of the column prior to the failure occurring. The relationship between applied load and measured concrete strains along both instrumented faces of the column can be seen in Figure 4.1.3.3. 


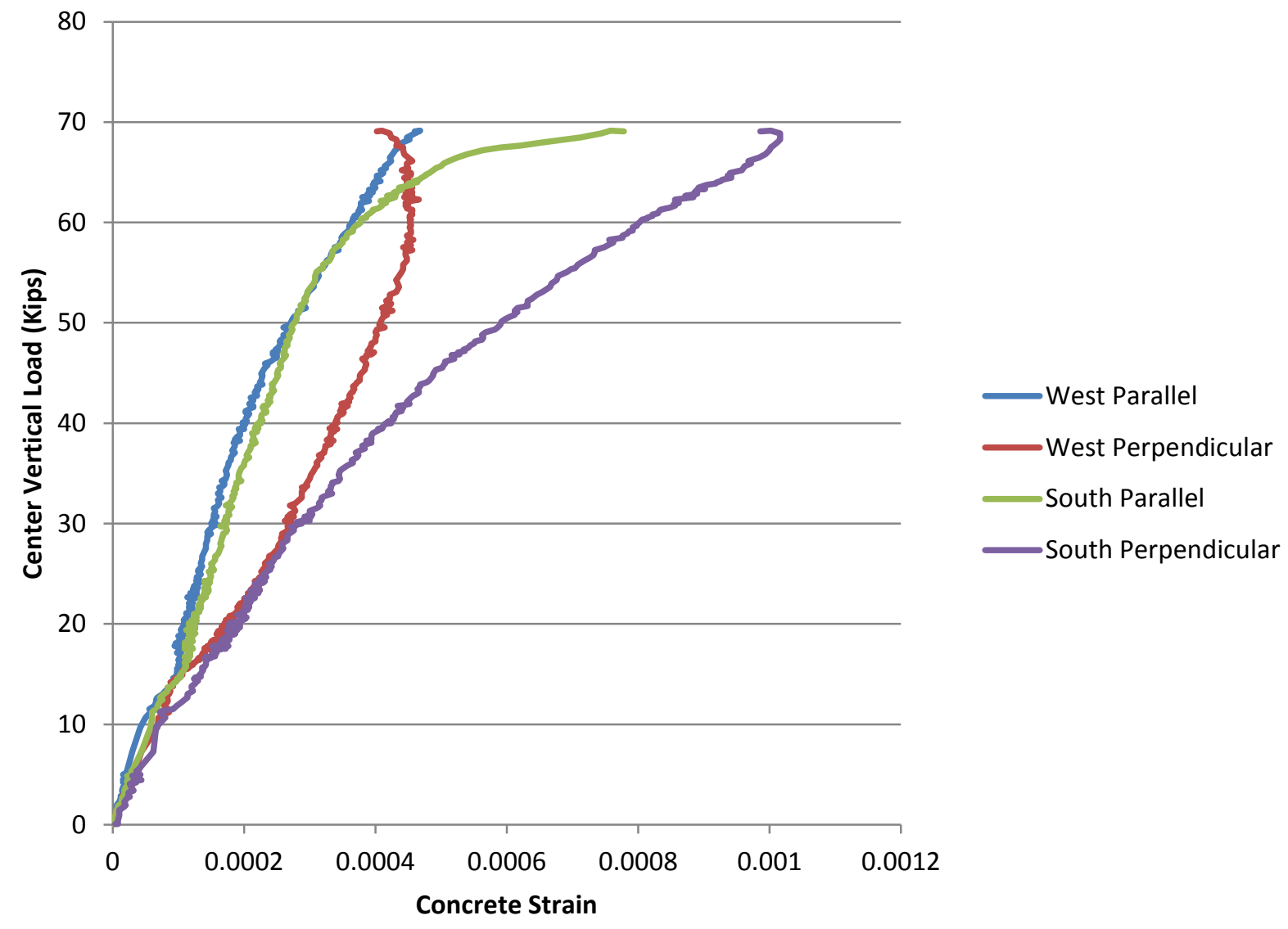

Figure 4.1.3.3 - Applied vertical load vs. compressive concrete strains for the $1 \%$ unrestrained slab specimen.

Along with the instrumentation on the exterior of the slab the tension and compression reinforcing cages were instrumented with strain gages. The layout of the gages for the $1 \%$ reinforcement ratio slabs which can be seen in Figures 3.5.3 and 3.5.4 were designed to show how the reinforcement strain varied as the measurement locations moved from the slab column interface to locations outside the failure area. Two sets of gages were placed on the tension reinforcement to show the change in strain moving away from the column face towards the edge of the slab. The data from one of these sets can be seen in Figure 4.1.3.4 the strains prior to the 
punching failure occurring on this set of bars ranged from 0.0059 in/in at a location 2 inches from the center of the slab to $0.0018 \mathrm{in} / \mathrm{in}$ at a location 22 inches from the center of the slab.

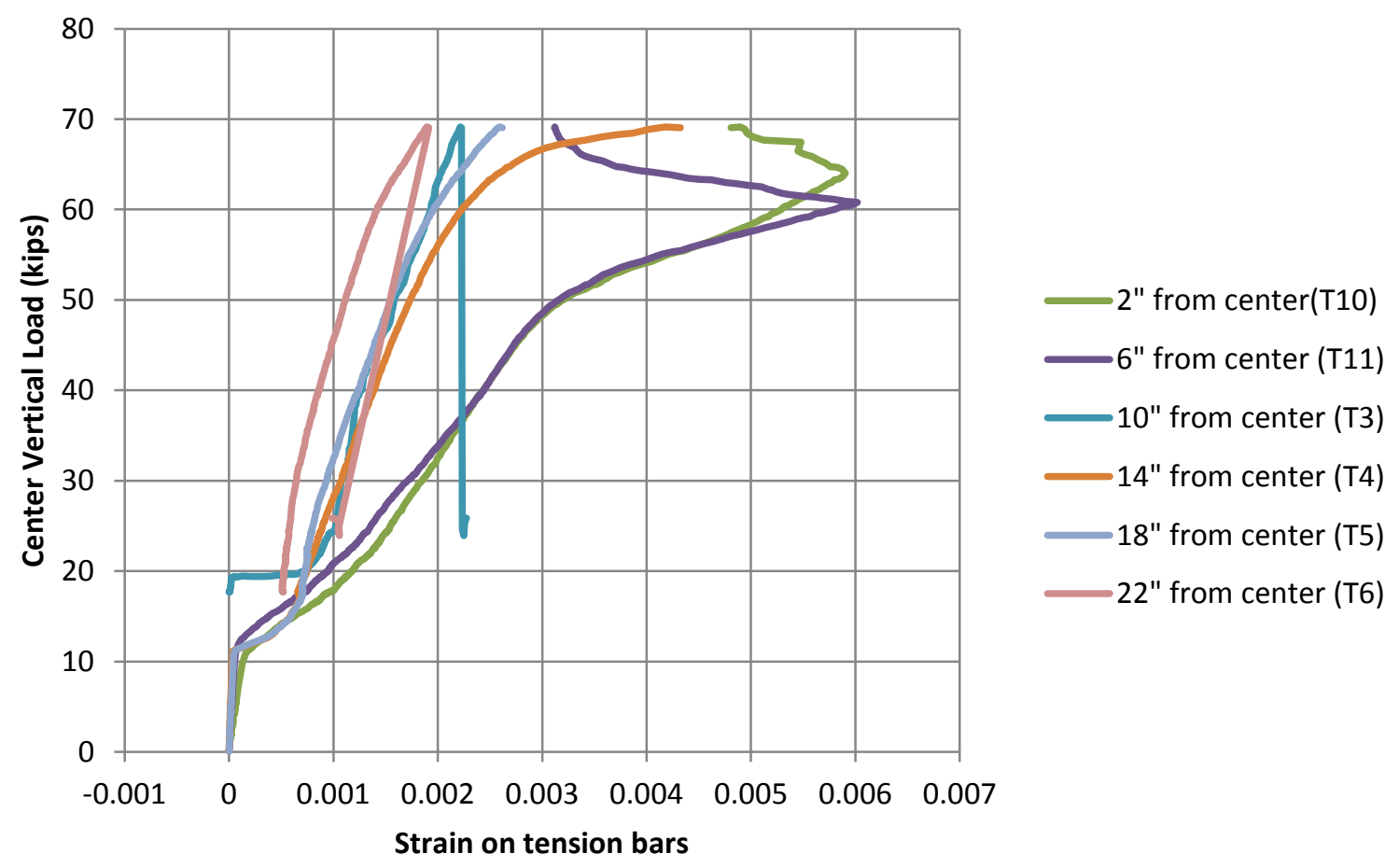

Figure 4.1.3.4 - Applied load on the 1.0\% unrestrained slab vs. tension reinforcement strains as measurement locations moved away from the center of the slab.

Another set of gages on the tension reinforcing cage was placed such that the distribution of strain as measuring location passed through the column could be determined. In general the strains were highest very near the column face with measured values up to $0.009 \mathrm{in} / \mathrm{in}$. With lower strains around $0.002 \mathrm{in} / \mathrm{in}$, measured at locations further away from the column on either side. A plot of the measured strains in relation to the applied load can be seen in Figure 4.1.3.5. 


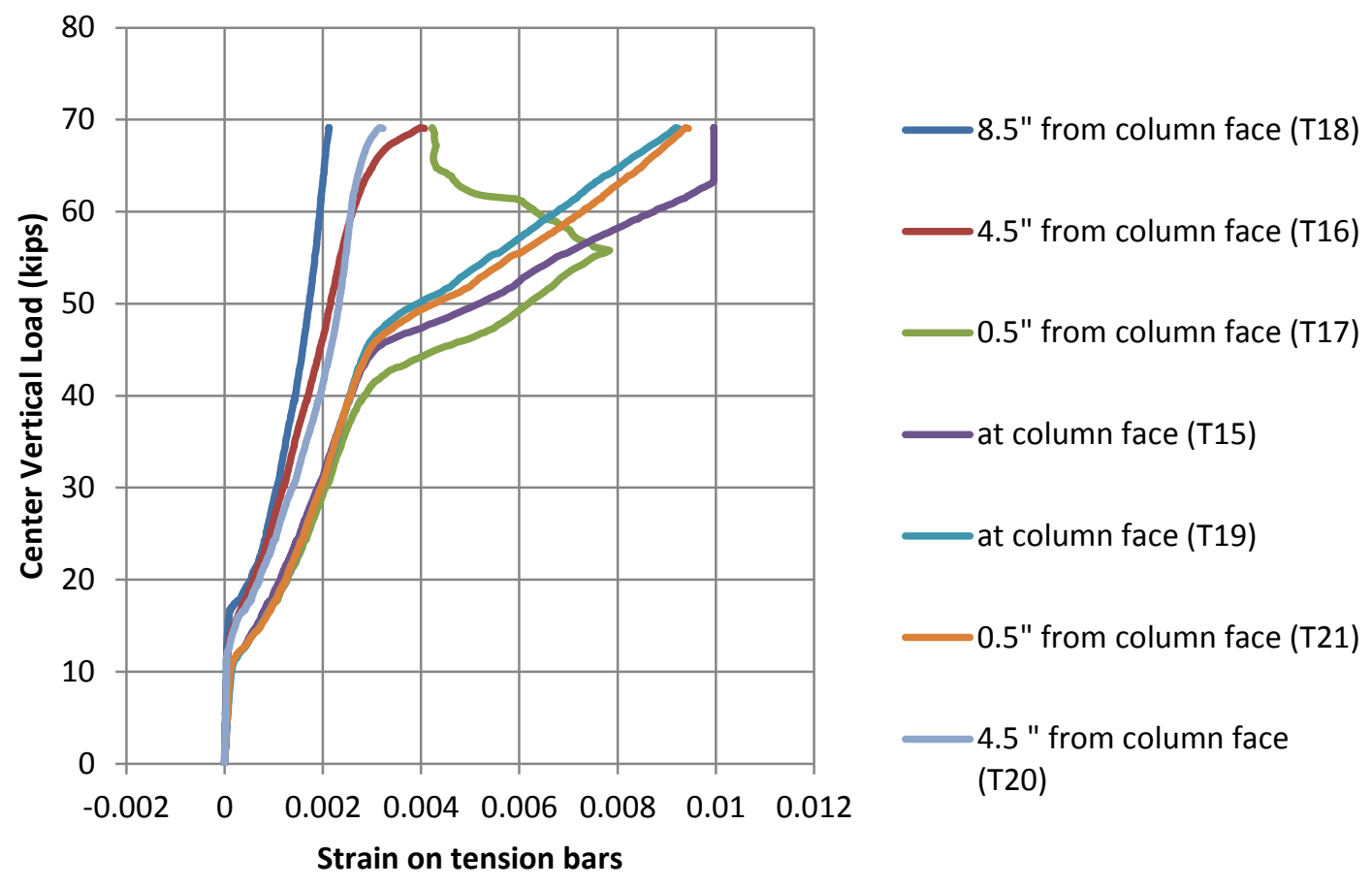

Figure 4.1.3.5 - Relationship between applied load on the 1.0\% unrestrained slab and measured strains on tension reinforcement as measuring locations moved through the column.

Overall it can be seen that strains on the tension reinforcement ranged from 0.0017 to $0.009 \mathrm{in} / \mathrm{in}$ prior to the punching failure occurring, with 16 of the 19 functional gages showing strains above the yield strain of $0.002 \mathrm{in} / \mathrm{in}$. The gages on the tension reinforcing cage showed almost no strain prior to the slab cracking at a load just under 10 kips, after the slab cracked the reinforcement was required to carry tensile loads resulting in strains increasing until the punching failure occurred.

The compression reinforcing cage was also instrumented with strain gages during the testing, looking at a plot of the measured strains prior to the punching failure it can be seen that none of the compression gages had reached the yield strain of $0.002 \mathrm{in} / \mathrm{in}$ prior to the failure occurring. When the loading began the gages initially showed increasing compressive strains 
(shown as negative) until the slab cracked at an applied load just under 10 kips. After the slab cracked in flexure the response of the specimen was dominated by shear which resulted in the bars beginning to stretch. This can be seen in Figure 4.1.3.6 when the slope of the load- strain response changes from negative to positive. At the time of the punching failure 6 of the 8 functional gages showed tensile strains ranging from $0.0003-0.001 \mathrm{in} / \mathrm{in}$. A photo of the underside of the slab just after the punching failure can be seen in Figure 4.1.3.9.

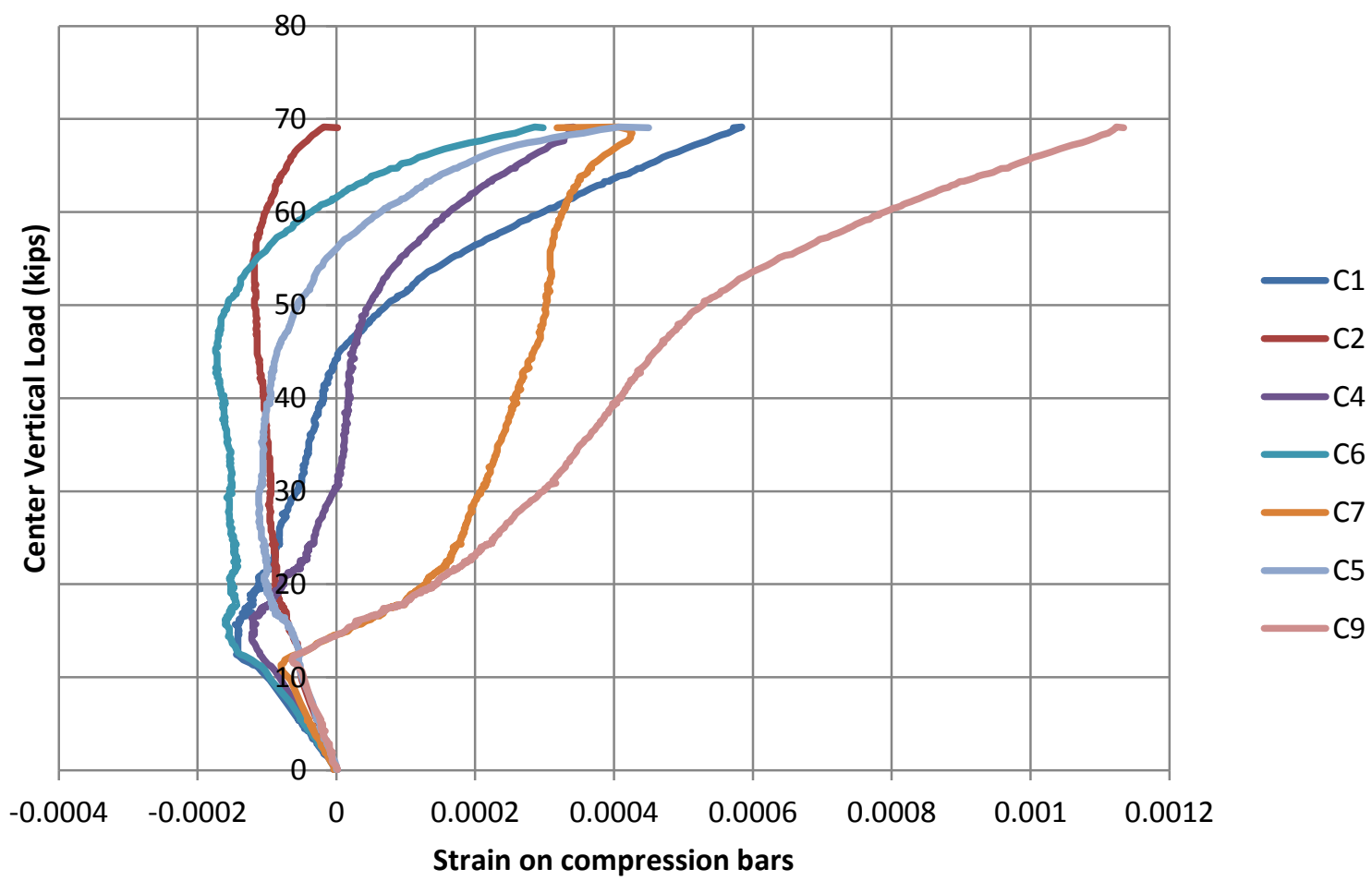

Figure 4.1.3.6 - Relationship between applied load on the 1.0\% unrestrained slab and measured strain on the compression reinforcing cage. Compressive strains are shown as negative while tensile strains are shown as positive.

The plots in Figures 4.1.3.4 through 4.1.3.6 show some of the trends that developed in the reinforcement strain data. In order to gain a better understanding of the reinforcement strains 
throughout the slab specimen Figures 4.1.3.7 and 4.1.3.8 were created, showing the maximum strain values prior to failure listed at their corresponding locations within the slab. The gage locations can be referenced in Figures 3.5.3and 3.5.4.

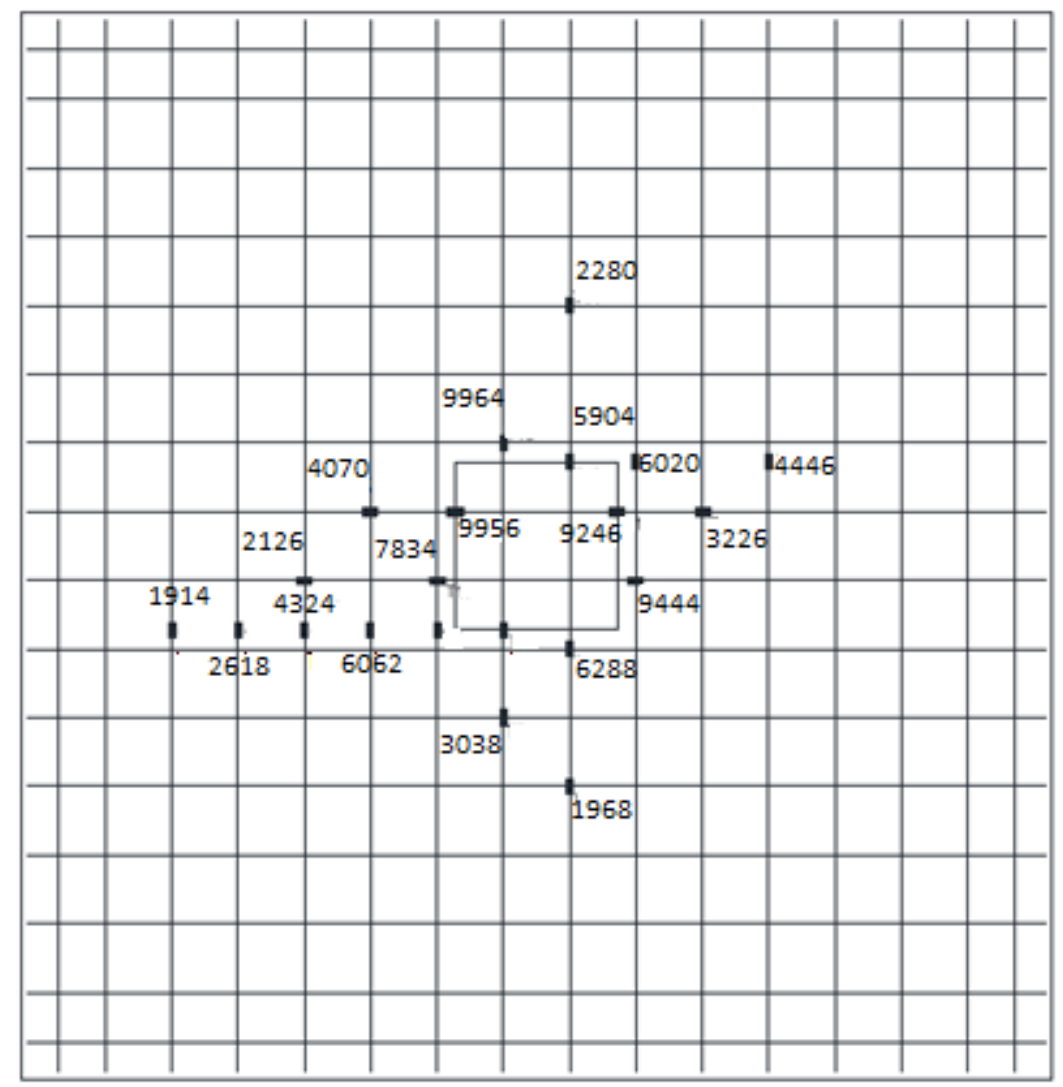

Figure 4.1.3.7 - Maximum strains on the tension reinforcement prior to the punching failure for the $1.0 \%$ unrestrained slab (strain values listed in microstrains). 


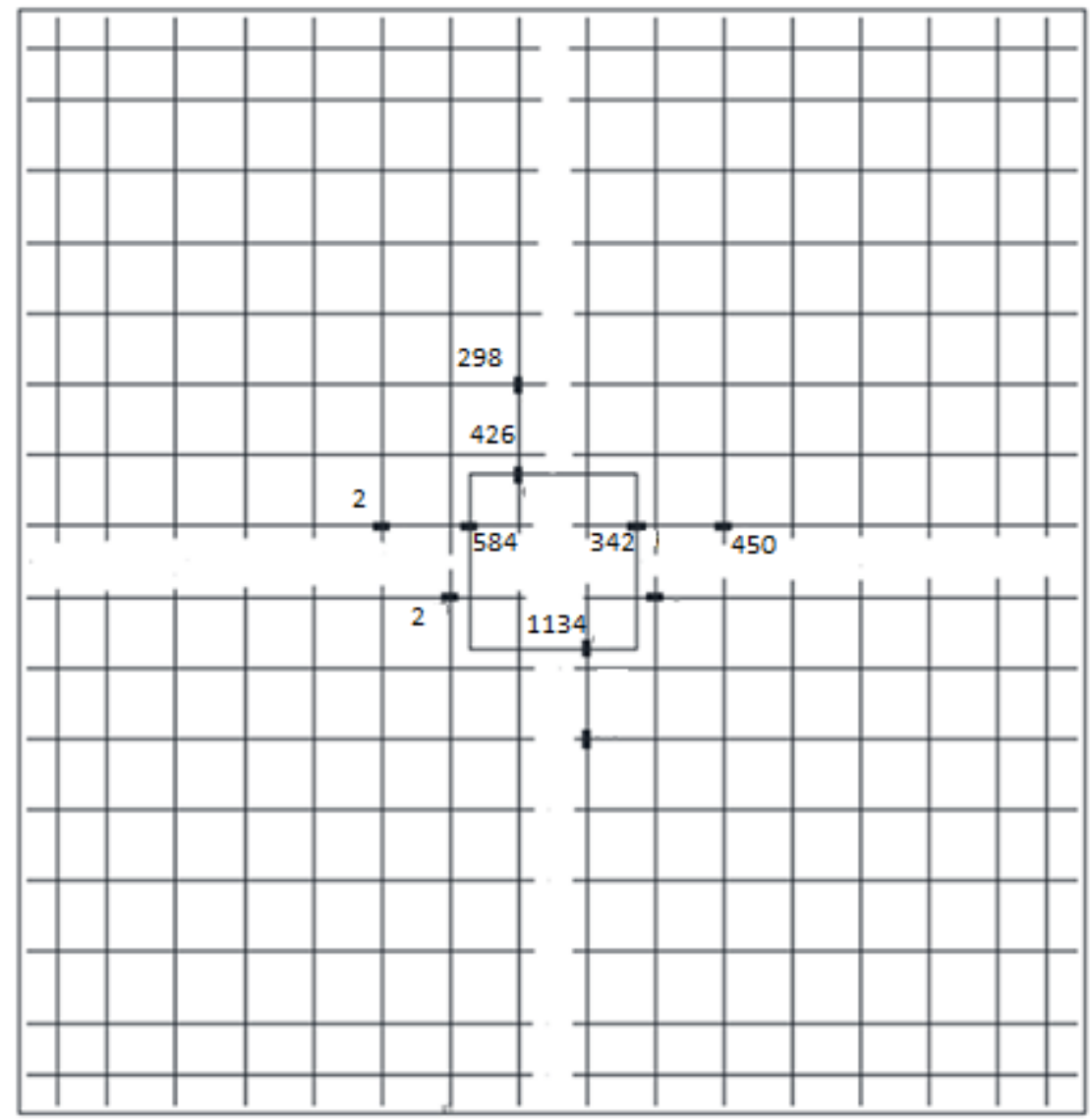

Figure 4.1.3.8 - Maximum strains on the discontinuous reinforcement prior to failure for the $1.0 \%$ unrestrained slab (strain values listed in microstrains). 


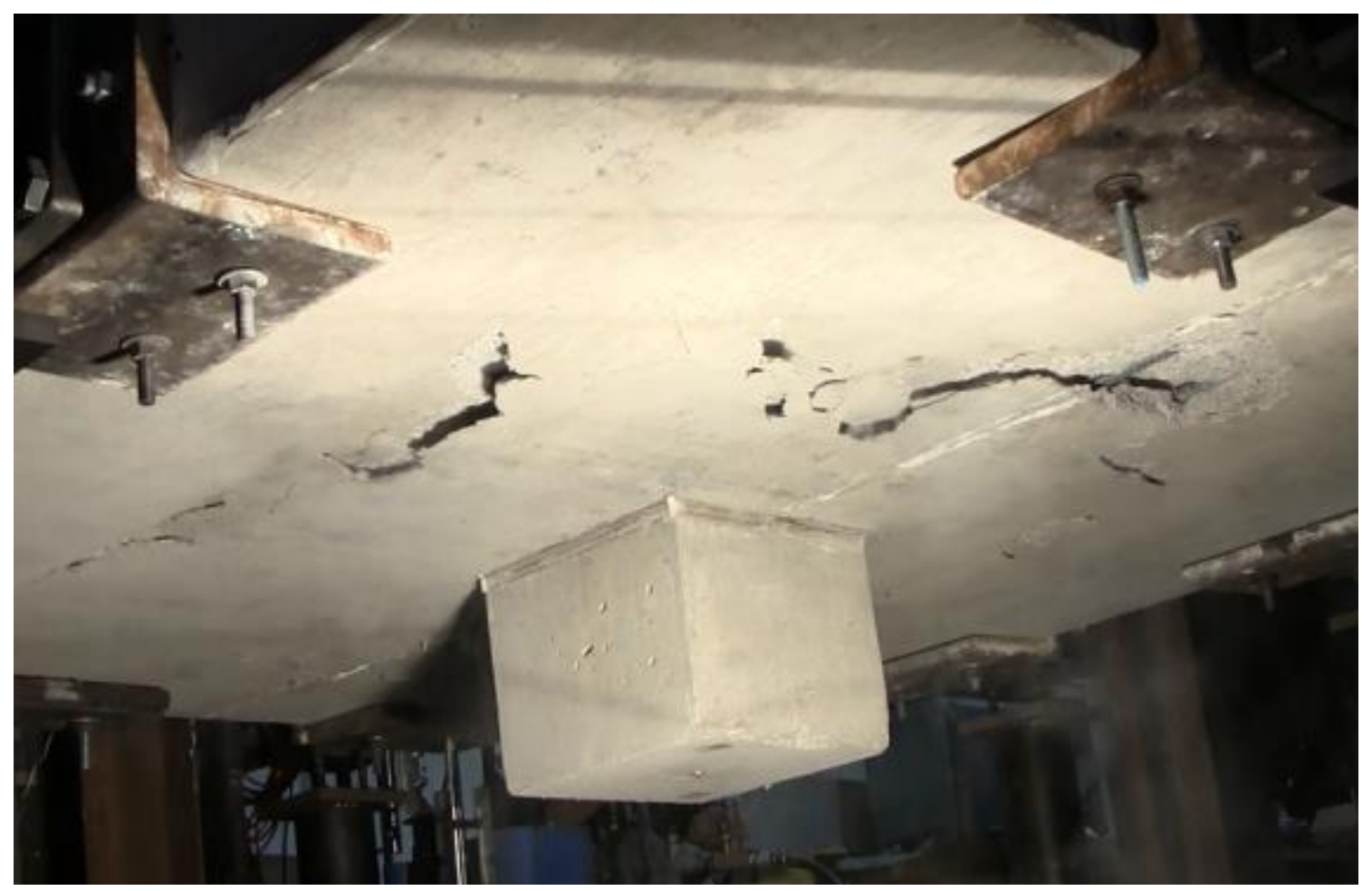

Figure 4.1.3.9 - Underside of the 1.0\% unrestrained slab just after the punching failure.

\subsection{4 - 1\% Reinforcement Unrestrained Test Setup (Post Punching)}

After the punching failure occurred the loading of the slab column specimen was continued in order to determine the residual capacity of the connection. The residual capacity of the connection is taken as the load that is still carried through the connection after the punching failure occurs. The load deflection plot including the post punching response of the slab column specimen can be seen in Figure 4.1.4.1. 


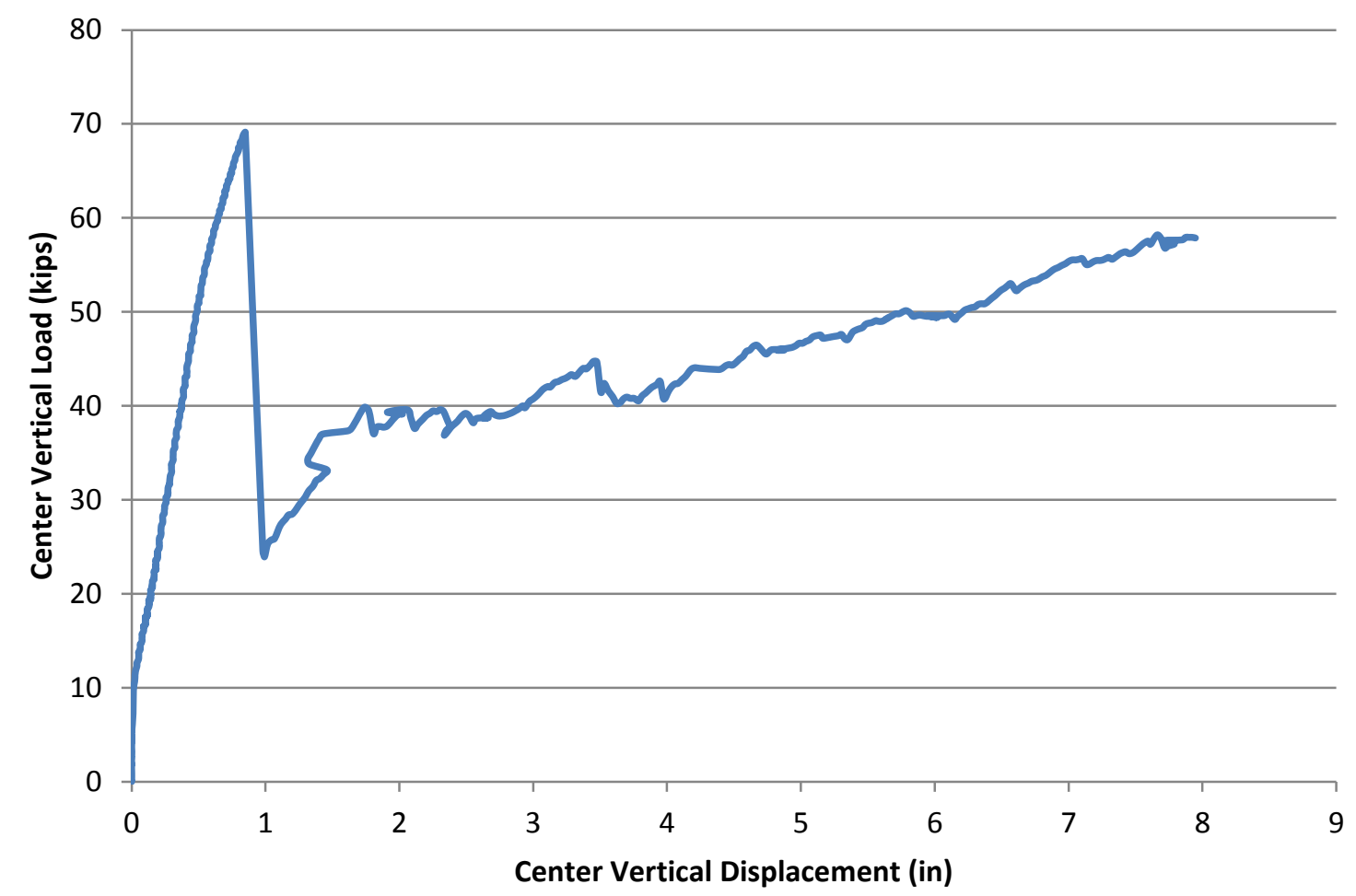

Figure 4.1.4.1 - Load Deflection plot including post punching behavior for the 1.0\% unrestrained slab.

It can be seen from the load deflection plot that the punching failure occurred at a load of 69.1 kips and a corresponding center deflection of 0.84 inches. For the unrestrained slab with a $1.0 \%$ reinforcement ratio the peak residual capacity was 57.6 kips which is $83.3 \%$ of the punching capacity of the slab specimen. This residual capacity was again higher than the predicted residual capacity form Equation 7 (Habibi et al 2012). This ability of the connection to continue to carry $83 \%$ of its failure load would be very important in a structure because that portion of the load would not need to be distributed to the surrounding connections. This residual capacity is a result of the reinforcement that is continuous through the column as well as some dowel action from the discontinuous reinforcement that extends just into the column. The slab was loaded until one of the reinforcing bars that was continuous through the column 
fractured. For this particular test the fracture occurred at a load of 57.6 kips and a center deflection of 7.94 inches. A photo of the underside of the slab at the conclusion of the test can be seen in Figure 4.1.4.2.

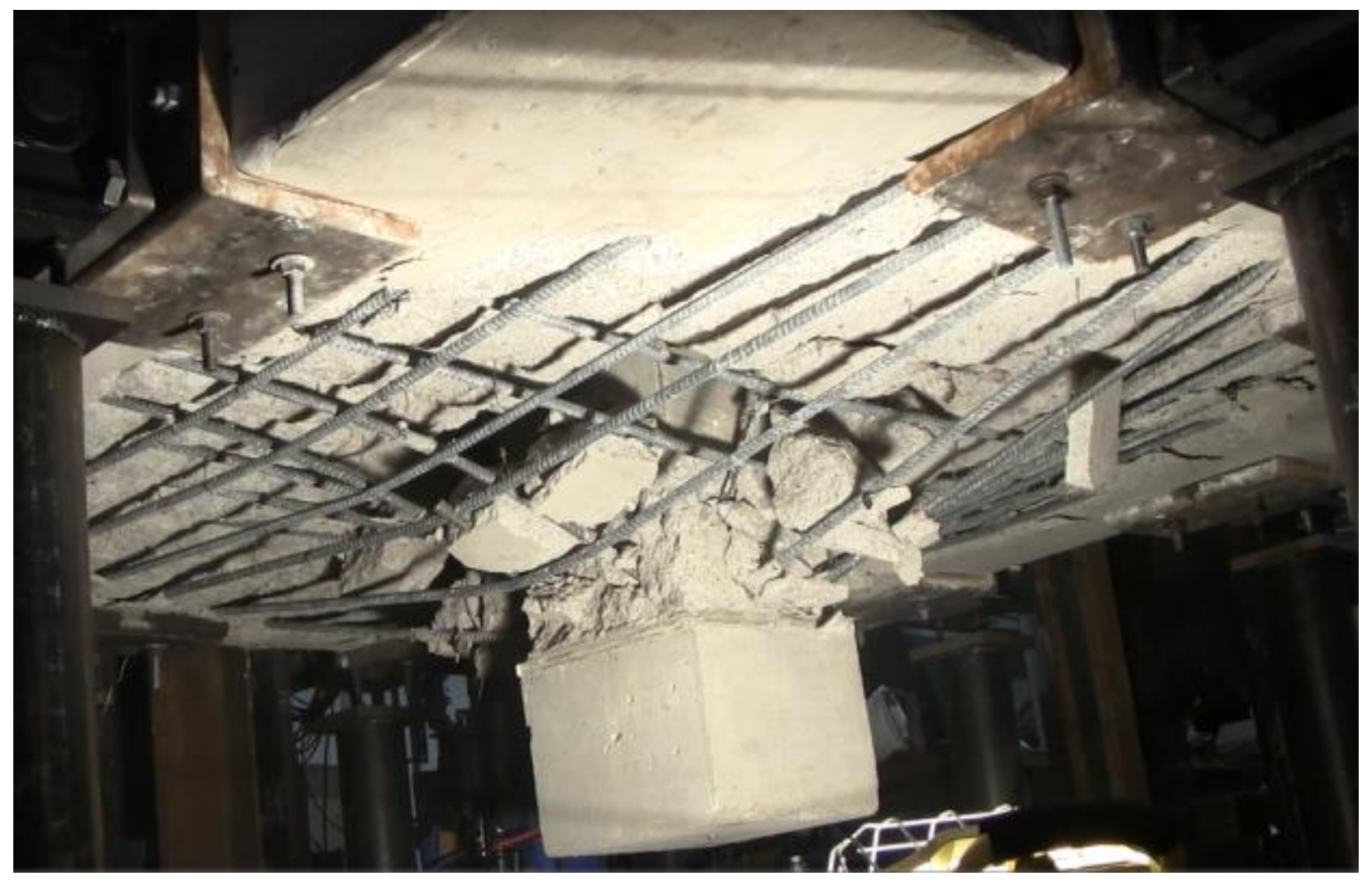

Figure 4.1.4.2 - Underside of the 1.0\% unrestrained slab at the conclusion of the testing.

\section{2 - Restrained Slab Testing}

The results of the two slabs that were tested in the restrained test setup configuration will be discussed individually in this section.

\subsection{1 - 0.5\% Reinforcement Restrained Test Setup (Pre Punching)}

The slab specimen was loaded at a rate of about $0.12 \mathrm{kips} / \mathrm{sec}$ from the beginning of the test until the punching failure occurred. The $0.5 \%$ reinforcement ratio slab held an applied load 
of 54.3 kips prior to the punching failure occurring. The slab specimen behaved in a linear fashion until an applied load of about 14 kips at which point the shear cracking in the slab began at a corresponding deflection of 0.023 inches. After the initial cracking of the slab the overall stiffness was reduced this resulted in a change in slope of the load deflection plot which can be seen in Figure 4.2.1.1. The slab specimen again behaved almost linearly from when flexural cracking occurred until the punching failure occurred at a load of $54.3 \mathrm{kips}$ and a corresponding deflection of 0.93 inches.

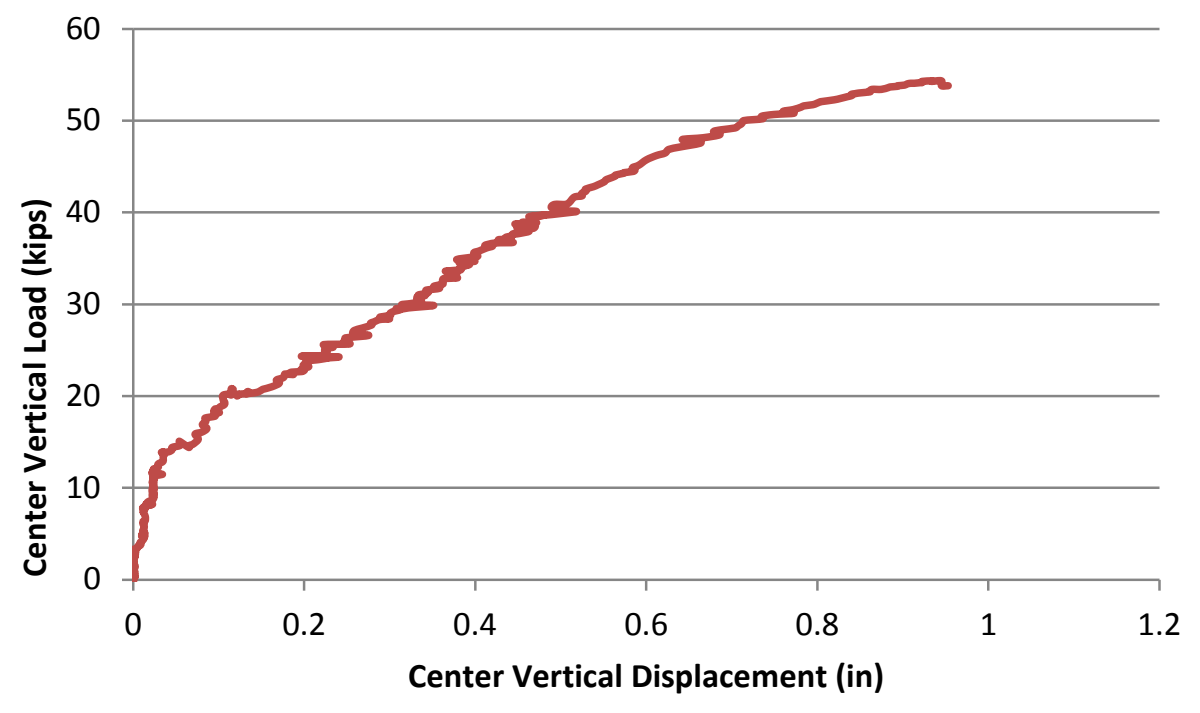

Figure 4.2.1.1 - Center load-deflection plot for the $0.5 \%$ restrained slab prior to the punching failure.

During the testing vertical displacements were also measured at the supports and at midslab locations which were 10 inches away from the face of the column. The displacements at the supports were subtracted out from the other vertical displacements in order to determine how much the slab specimen displaced relative to its supports. The relative displacements of the slab 
prior to the punching failure can be seen in Figure 4.2.1.2. The mid-slab locations displaced 0.7 inches prior to the failure which is $75 \%$ of the displacement of the center of the slab specimen. The mid-slab displacements were used to calculate the angle of rotation of the slab prior to the punching failure occurring because past research by Kinnunen and Nylander has shown that slab rotation can be used as an indicator of punching failure. It was calculated that the slab rotated 0.0328 radians prior to the punching failure occurring which fairly consistent with the results from Kinnunen and Nylander (1960) for 0.5\% reinforced slabs which can be seen in Figure 2.4.2.

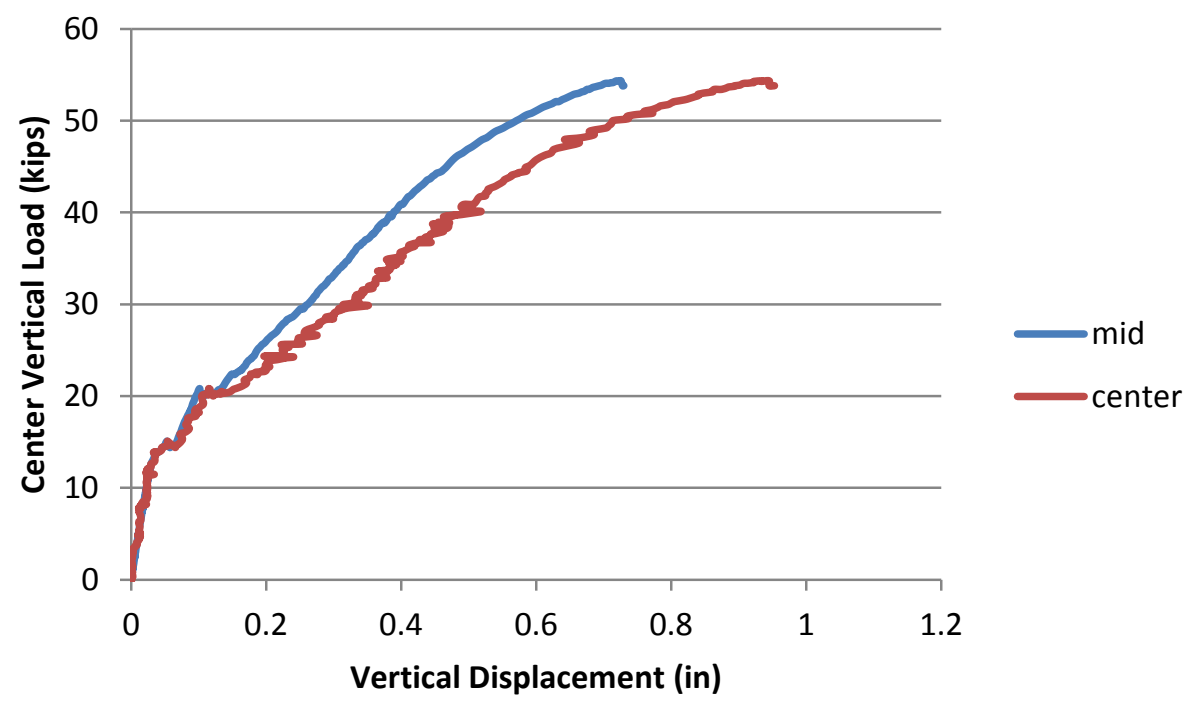

Figure 4.2.1.2 - Load displacement plot for the $0.5 \%$ restrained slab prior to the punching failure.

For the slabs tested in the restrained test setup there was some resistance to lateral expansion because of the manner in which the slab was connected to the reaction frame. As a part of the connection, load cells were put in place to measure the horizontal forces that built up as the slab was loaded vertically and attempted to expand laterally. As in the unrestrained tests 
changes in the horizontal dimensions of the slab were also recorded. The horizontal displacements on opposite sides of the slab were used to determine the horizontal expansion of the slab due to the applied loading. It was determined that the slab expanded a maximum of 0.03 inches prior to the punching failure occurring. This is only slightly less than the expansion of 0.04 inches in the unrestrained tests. The plot of applied load and corresponding horizontal expansion can be seen in Figure 4.2.1.3.

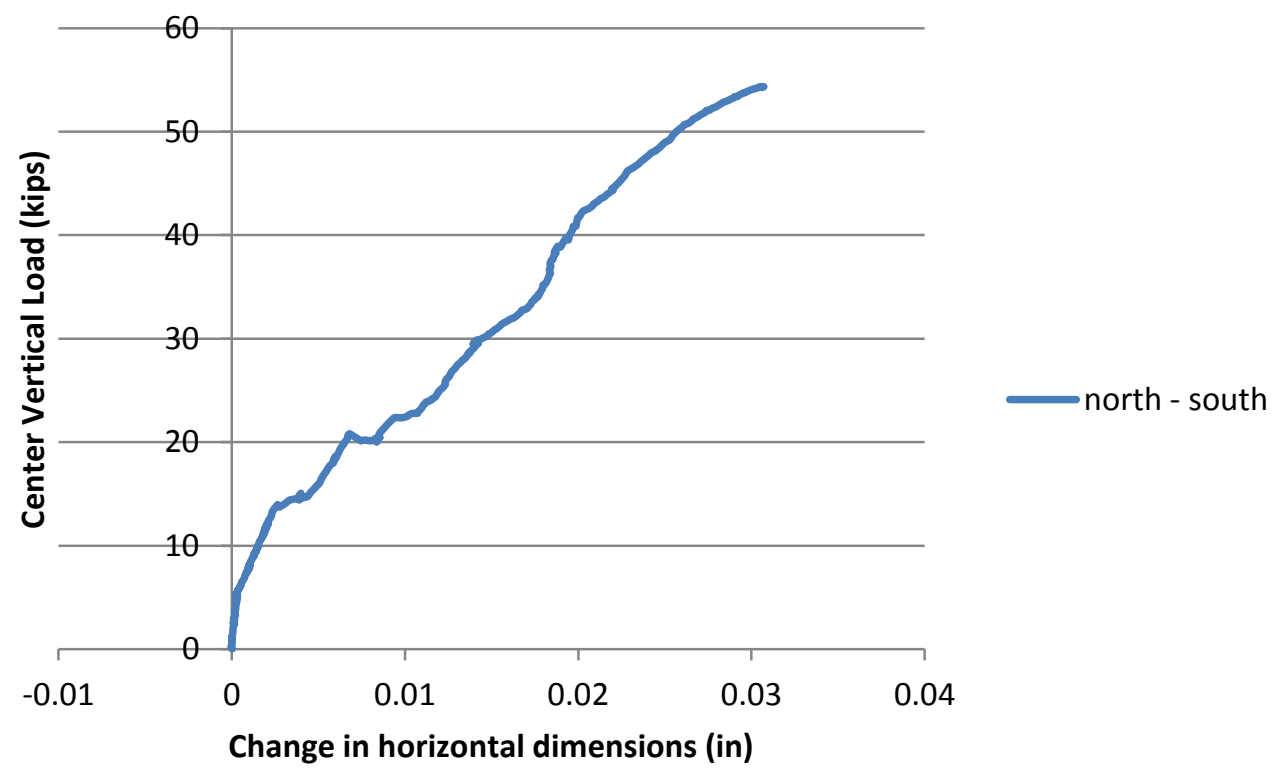

Figure 4.2.1.3 - Change in horizontal dimensions of the $0.5 \%$ restrained slab and the corresponding applied vertical load.

The load cells that were used to measure the horizontal loads that built up as the slab attempted to expand were washer type compression load cells which fit over the 1.5 " threaded rods that were used to connect the slab to the reaction frame. There were load cells on two of the eight connections between the slab and the reaction frame, they were positioned on adjacent sides of the slab such that they were measuring in opposite directions. It was seen that the lateral 
compressive loads increased from the start of the test until the punching failure occurred in the East - West direction. However in the North -South direction there was a brief unloading of the load cell at the start of the test prior to the compressive load increasing. A plot of the horizontal compressive loads in relation to the center vertical displacement can be seen in Figure 4.2.1.4. Considering that the horizontal loads were only measured at one of the four connections in either direction (north-south or east-west) the plotted loads are assumed to be four times the load recorded by the load cells. It can be seen that the total lateral compressive load in one direction is between 8.5 and 10.5 kips.

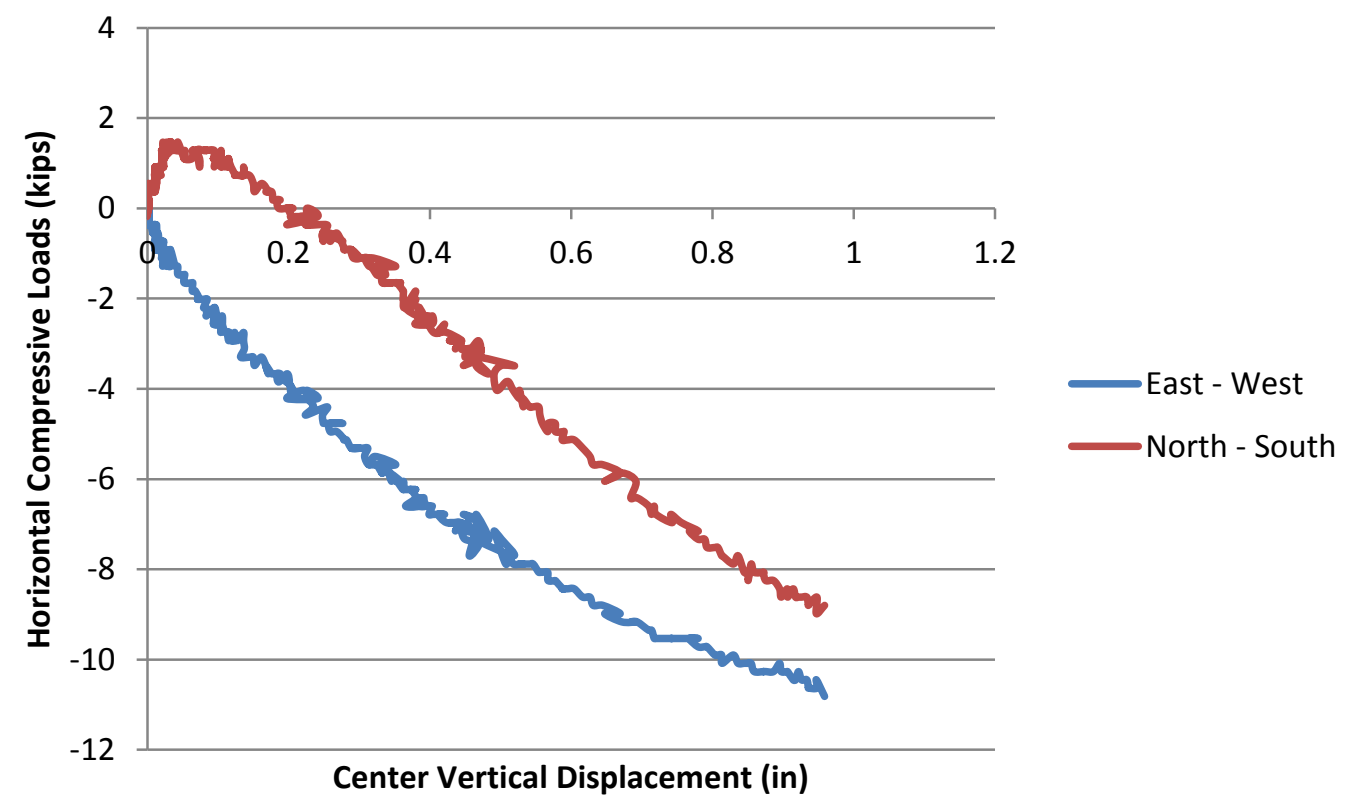

Figure 4.2.1.4 - Horizontal compressive loads measured by load cells in relation to the center vertical displacement for the $0.5 \%$ restrained slab.

The loads calculated from the load cell data are lower than expected, it is believed that this is due to bending in the threaded rods caused by rigid movement of the slab. The movement causes the load cells to be loaded unevenly which in turn produces inaccurate load data. To 
account for this the threaded rods themselves were instrumented with strain gages positioned on opposite sides such that readings could be averaged to remove any effects from bending in the rod. The strain data was used along with material and geometric properties to calculate the loads on the threaded rods. One of the two rods on each side of the slab was instrumented with strain gages in order to collect more data than the load cells. Using the data collected from the threaded rods it was found that the lateral compressive loads reached maximum values around 15.6 kips prior to the punching failure occurring. A plot of the load calculated from the threaded rods as it relates to the center vertical displacement of the slab can be seen in Figure 4.2.1.5.

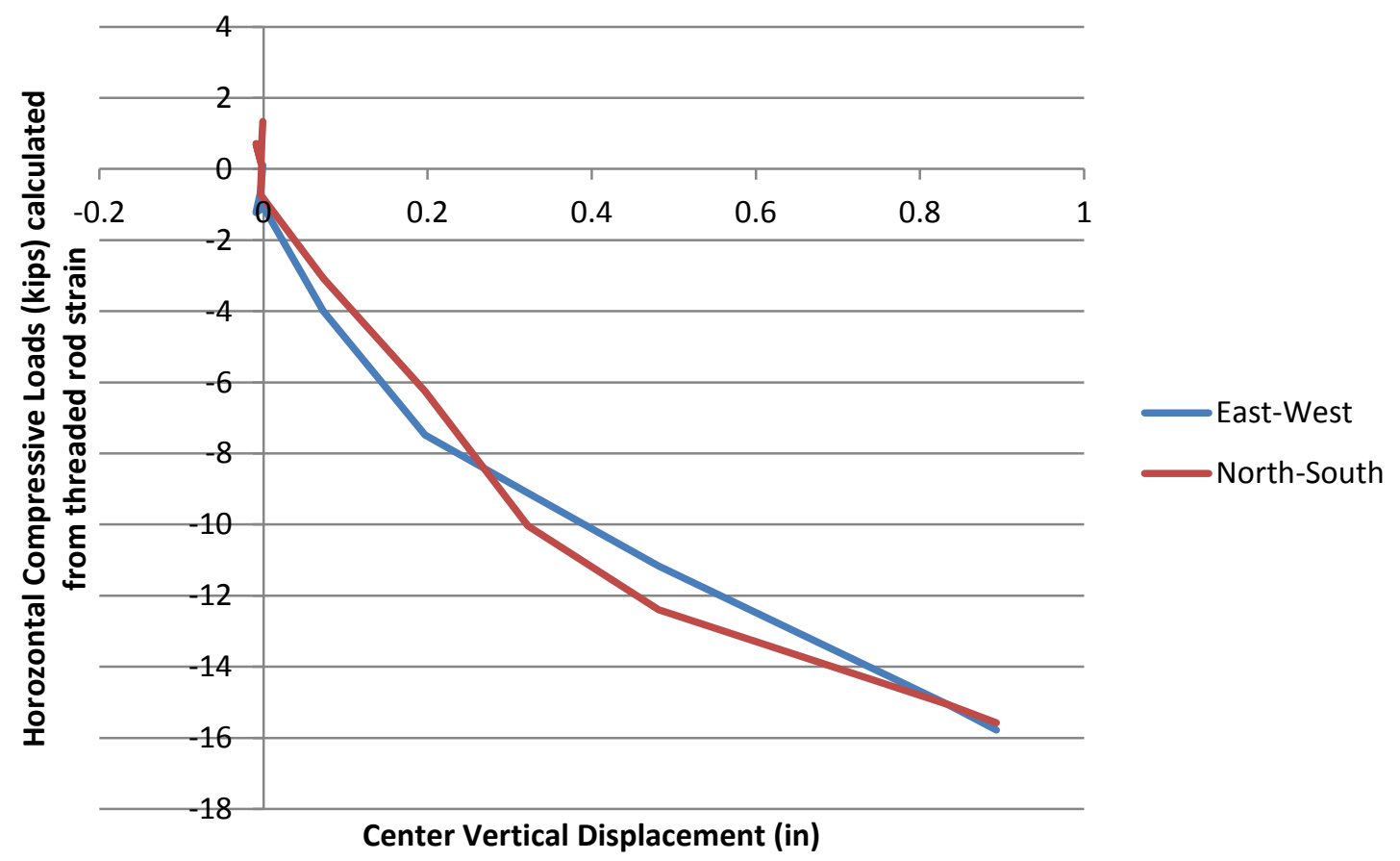

Figure 4.2.1.5 - Horizontal compressive loads calculated from threaded rod strains for the $0.5 \%$ restrained slab.

Using the horizontal load data in conjunction with the horizontal movement data the lateral stiffness of the test setup could be calculated. The slab expanded a maximum of 0.03 
inches in the north south direction prior to the punching failure occurring at a corresponding horizontal compressive load of 15.57 kips. Using these values a lateral stiffness of 525 kips/in was calculated. The design lateral stiffness for the test setup was 1600 kips/in, it was believed that a high lateral stiffness was needed to accurately represent connection of the slab to its surroundings in a real structure. The lack of stiffness in our actual testing was the result of slight movements in the reaction frame that were not anticipated. Although the lateral stiffness was not as high as anticipated the provided stiffness should still have had some effect on the capacity of the slab.

Past research in the area of punching shear has shown that the compressive strains in the concrete can be used to predict when a punching failure is about to occur. During testing concrete strains were measured parallel and perpendicular to the face of the column along two of the four faces. A plot of the applied vertical load and the corresponding compressive strains in the concrete can be seen in Figure 4.2.1.6. Research by Broms (1990) shows that strains measured parallel to the face of the column should reach $0.0008 \mathrm{in} / \mathrm{in}$ prior to the failure occurring. In this particular test the maximum strain measured parallel to the face of the column was $0.0004 \mathrm{in} / \mathrm{in}$ however the maximum strain measured perpendicular to the face of the column was 0.0015 in/in prior to the punching failure occurring. The strains measured parallel to the column face were only about half of what was predicted by Broms (1990) and half of what was measured in the unrestrained testing. It may be that the effect of the in-plane lateral restraint reduced this value. 


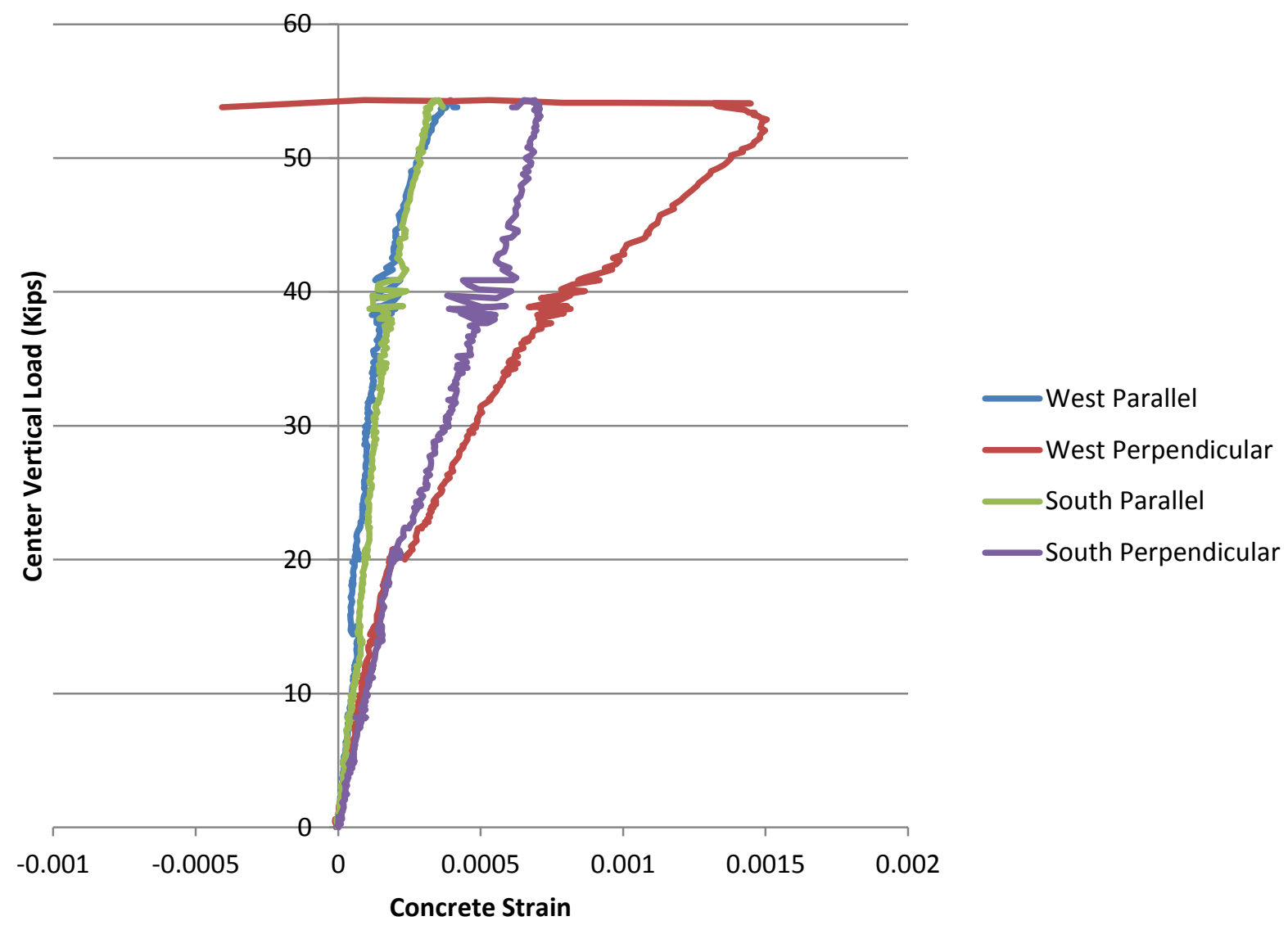

Figure 4.2.1.6 - Applied vertical load and strain in the concrete measured on the slab at the face of the column for the $0.5 \%$ restrained slab.

In addition to the instrumentation on the exterior of the slab specimen the reinforcing cages were again instrumented with strain gages. For the slab specimen with the $0.5 \%$ reinforcement ratio there was a total of 28 strain gages applied to the reinforcement 18 of which were on the tension reinforcement and the other 10 were on the compression reinforcement. The layouts of the gages on the tension and compression reinforcement cages can be seen in Figures 3.5.1 and 3.5.2 respectively. The layout of the gages on the tension reinforcement was designed such that the distribution of strain could be seen around the failure area in the center of the slab. One set of gages was placed such that the distribution of strain moving from the center of the 
slab outwards to outside of the failure area could be seen these gages are denoted as T7-T10 in Figure 3.5.1. Looking at a plot of the applied load and the resulting strain on the reinforcement it can be seen that the strain is largest near the center of the slab specimen, with strain readings reaching values of $0.009 \mathrm{in} / \mathrm{in}$ measured 3.5 inches from the center of the slab, prior to the failure occurring. As strain measurements were made farther from the center of the slab the strain readings prior to the punching failure were significantly smaller, down to 0.005 in/in at a distance of 25 inches from the center of the slab. A plot of the applied load and the resulting strain values can be seen in Figure 4.2.1.7.

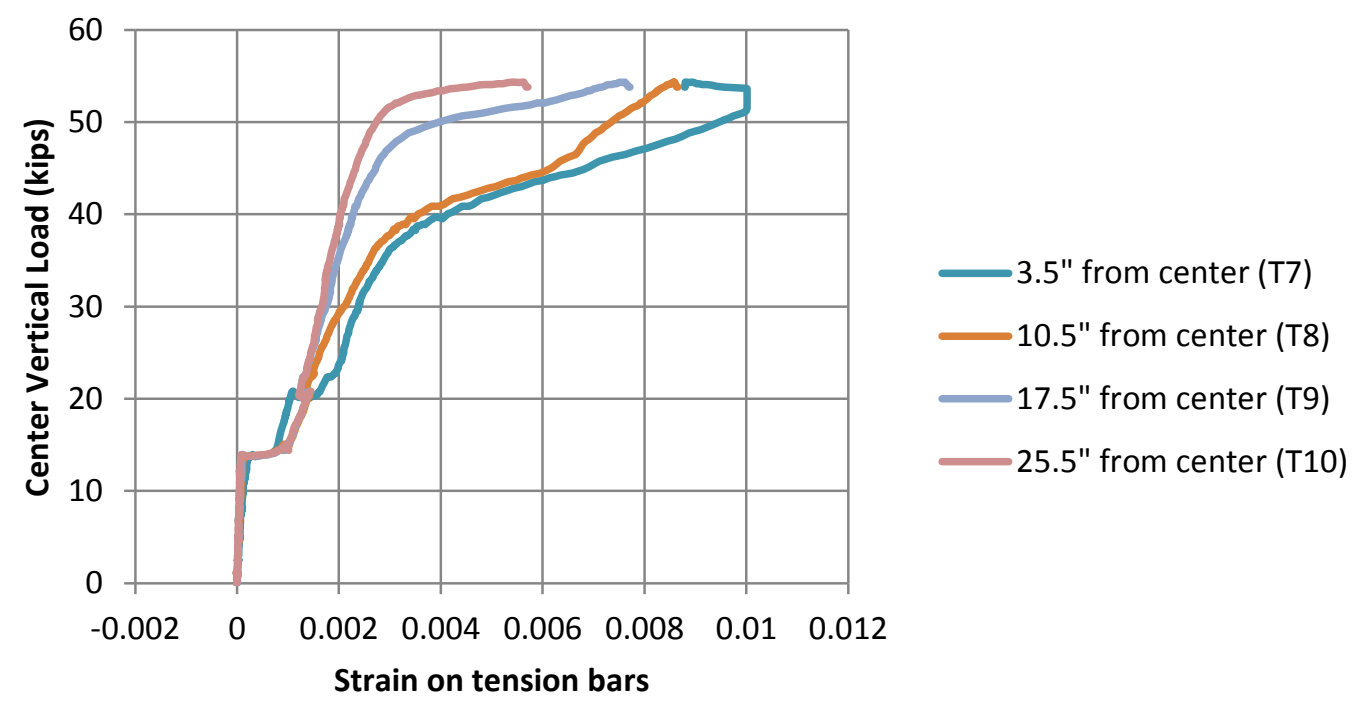

Figure 4.2.1.7 - Applied load and resulting strain on tension reinforcement as measurements were made farther from the center of the $0.5 \%$ restrained slab.

A second set of gages placed on the tension reinforcement was designed such that the distribution of strain along the bars that are continuous through the column could be seen. These gages are denoted as T13 - T18 in Figure 3.5.1. Looking at a plot of the reinforcement strain corresponding to the applied load it can be seen that all of the instrumented locations had yielded 
prior to the punching failure occurring. The strain values were smallest, around $0.0025 \mathrm{in} / \mathrm{in}$ at the locations farthest from the center while the values were significantly larger, up to $0.01 \mathrm{in} / \mathrm{in}$ near the center of the slab specimen. A plot of the applied load and the resulting strain on the reinforcement can be seen in Figure 4.2.1.8.

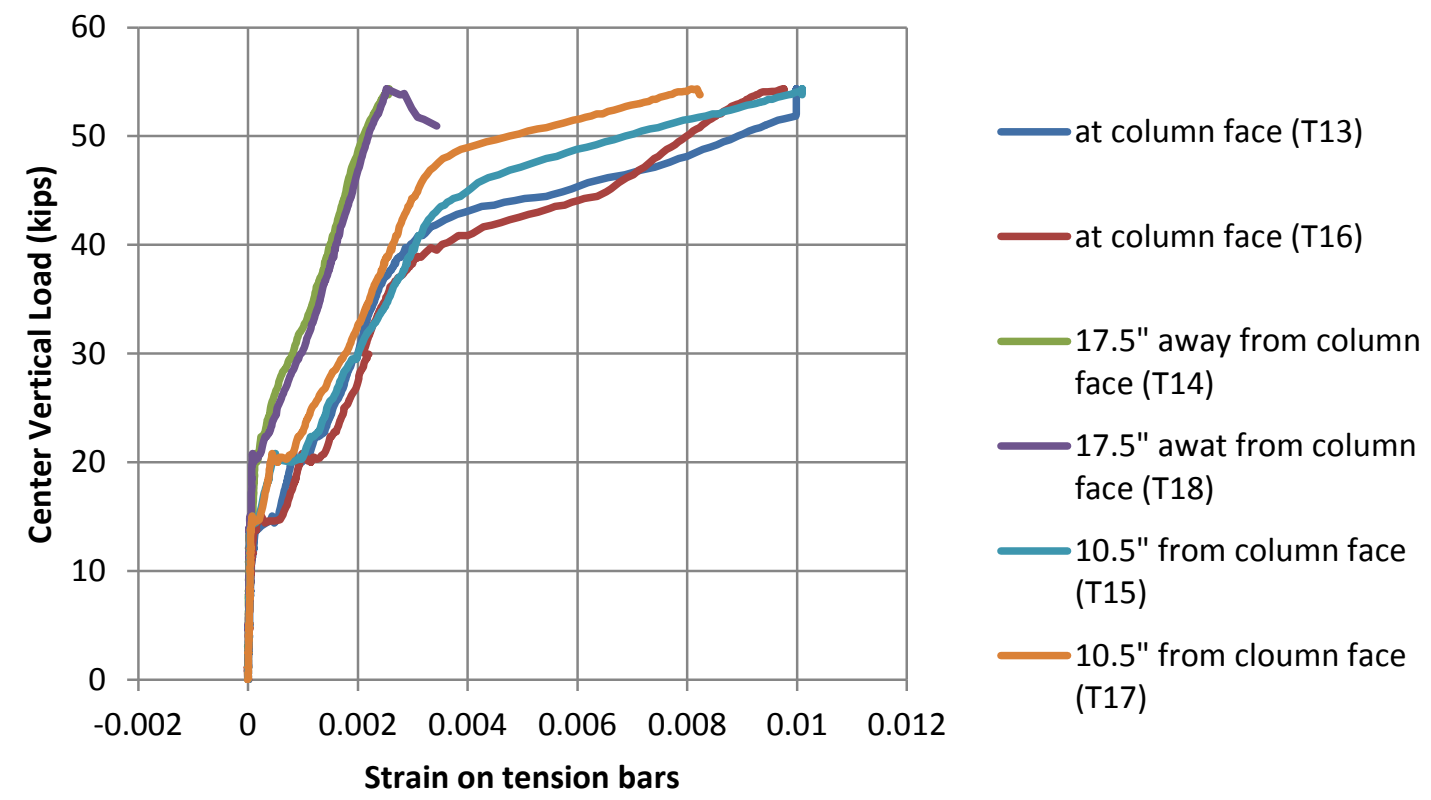

Figure 4.2.1.8 - Applied load and resulting tensile strains on the reinforcement that is continuous through the column of the $0.5 \%$ restrained slab.

In general the strains on the tension reinforcement were highest near the face of the column with strain values decreasing the farther from the center measurements were made. All 18 gages on the tension reinforcement showed readings above the yield strain of 0.002 in/in prior to the punching failure occurring with the values ranging from 0.0025 to $0.01 \mathrm{in} / \mathrm{in}$. Looking at Figures 4.2.1.7 and 4.2.1.8 it can be seen that the reinforcement sees almost no strain prior to the slab beginning to crack in flexure at a load of about 14 kips, after cracking occurs the strain on the reinforcement increases quickly until the punching failure occurs. 
The compression reinforcement strain measurements follow some different trends than the tension reinforcement. From the beginning of the test until the shear cracking begins in the slab all 9 of the functional gages showed increasing compressive strains which are shown as negative. Once the slab cracked at an applied load of about 14 kips the response of the slab specimen resulted in the compression reinforcement beginning to stretch, this can be seen as the change in slope on the plot of applied load and resulting strains. This occurs because the conical compression zone is in the concrete cover which results in the compression steel being in tension. Once the applied load reached 20 kips some of the strain gages began to read tensile strains, by the time that the load reached 30 kips 7 of the 9 functional gages on the compression reinforcement showed tensile strains. The remaining two gages C2 and C5 showed strains that had returned very close to zero at the time of the punching failure, these two gages are located farthest from the center on the compression reinforcement cage as can be seen in Figure 3.5.2. Of the 9 gages only one had reached the yield strain at the time of the punching failure with strain values ranging from -0.00008 to 0.0022 in/in. A plot of the applied load and the resulting strain on the compression reinforcement can be seen in Figure 4.2.1.9. A photo of the underside of the slab just after the punching failure occurred can be seen in Figure 4.2.1.12. 


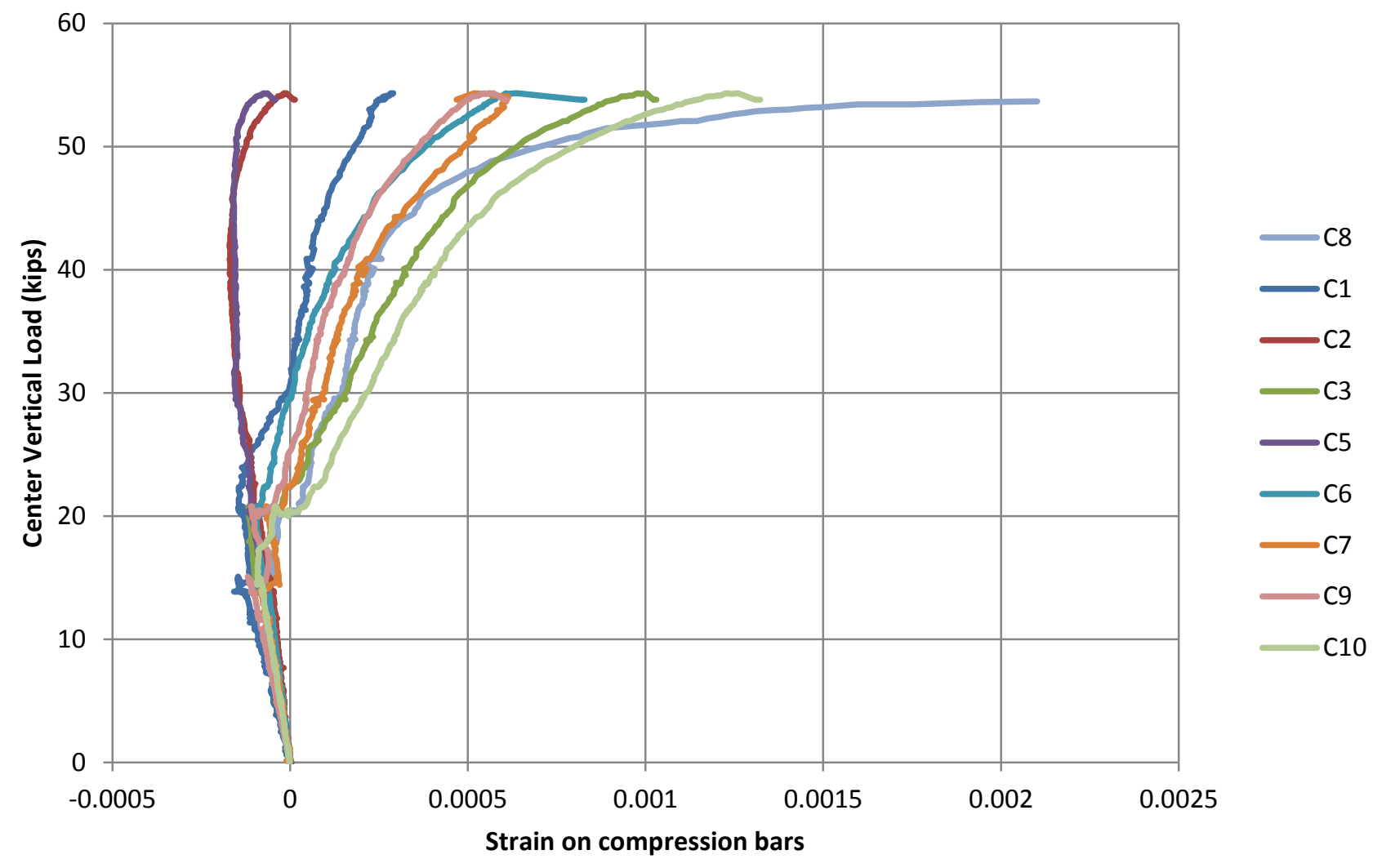

4.2.1.9 - Applied load and resulting strain on the compression reinforcement prior to the punching failure for the $0.5 \%$ restrained slab. Compressive strains are shown as negative and tensile strains are shown as positive.

The plots in Figures 4.2.1.7 through 4.2.1.9 show some of the trends that developed in the reinforcement strain data. In order to gain a better understanding of the reinforcement strains throughout the slab specimen Figures 4.2.1.10 and 4.2.1.11 were created, showing the maximum strain values prior to failure listed at their corresponding locations within the slab. The gage locations can be referenced in Figures 3.5.1 and 3.5.2. 


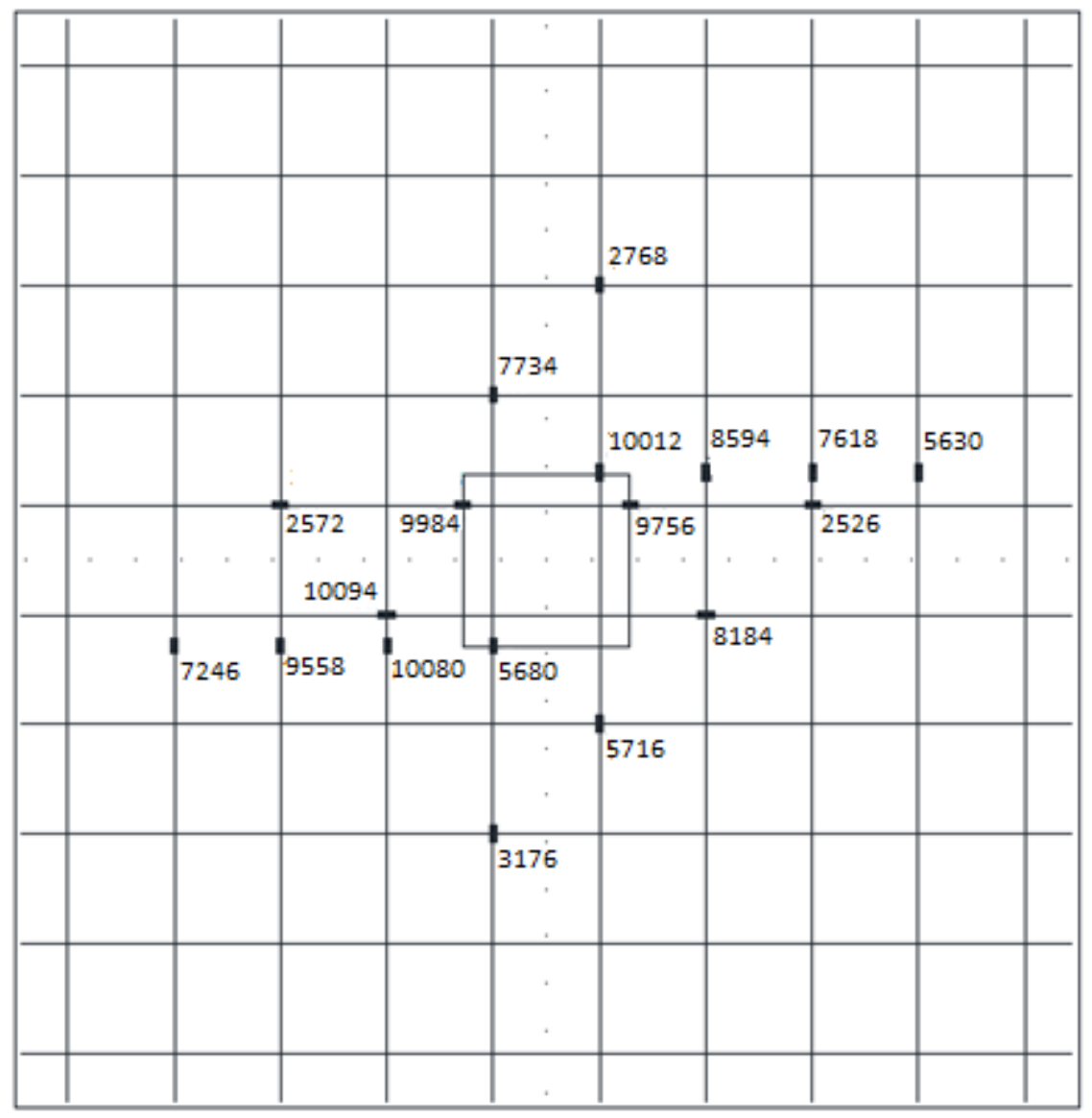

Figure 4.2.1.10 - Maximum strains on the tension reinforcement prior to failure for the $0.5 \%$ restrained slab (strain values listed in microstrains). 


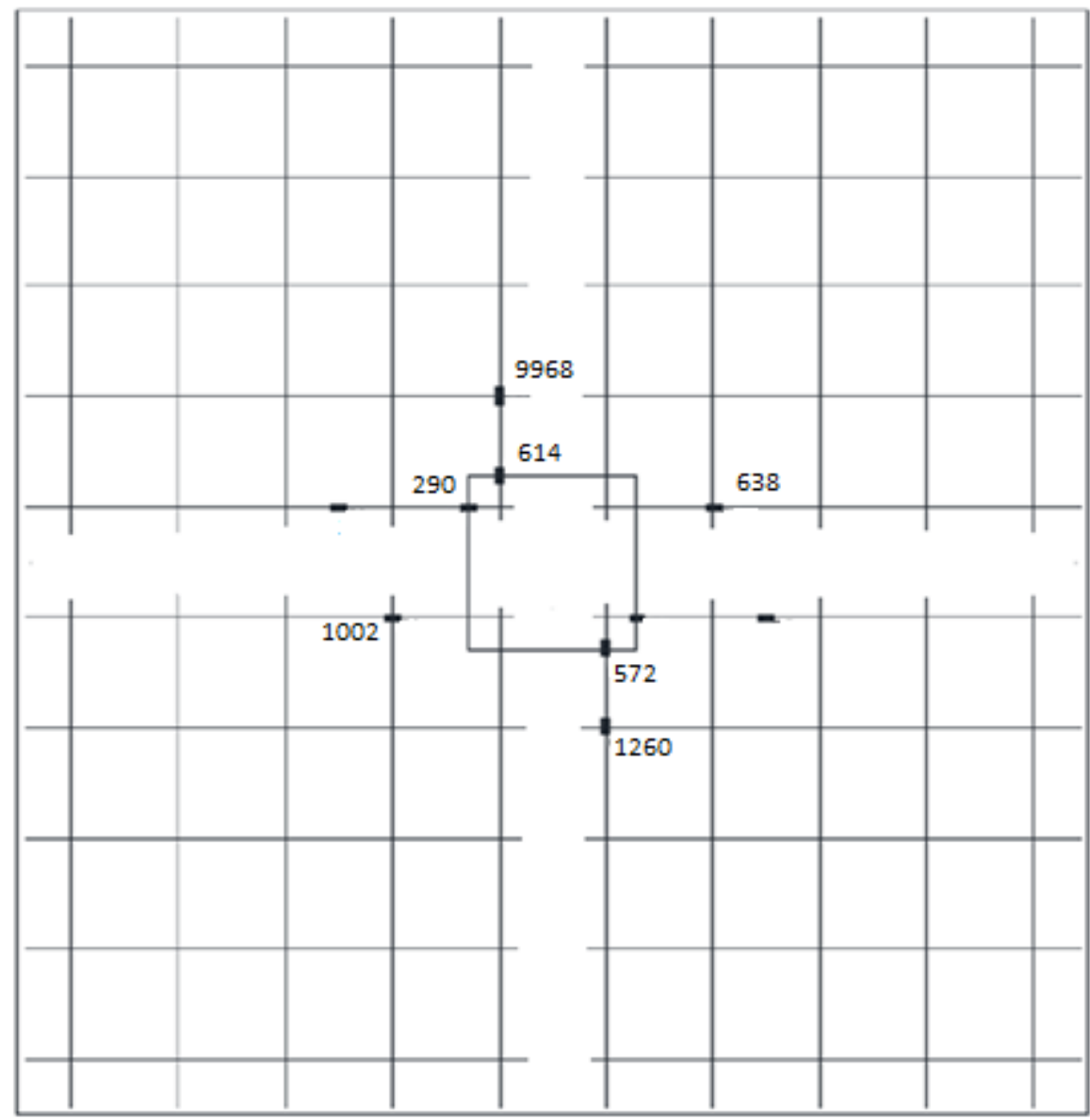

Figure 4.2.1.11 - Maximum strain values on the discontinuous reinforcement prior to failure for the $0.5 \%$ restrained slab (strain values listed in microstrains). 


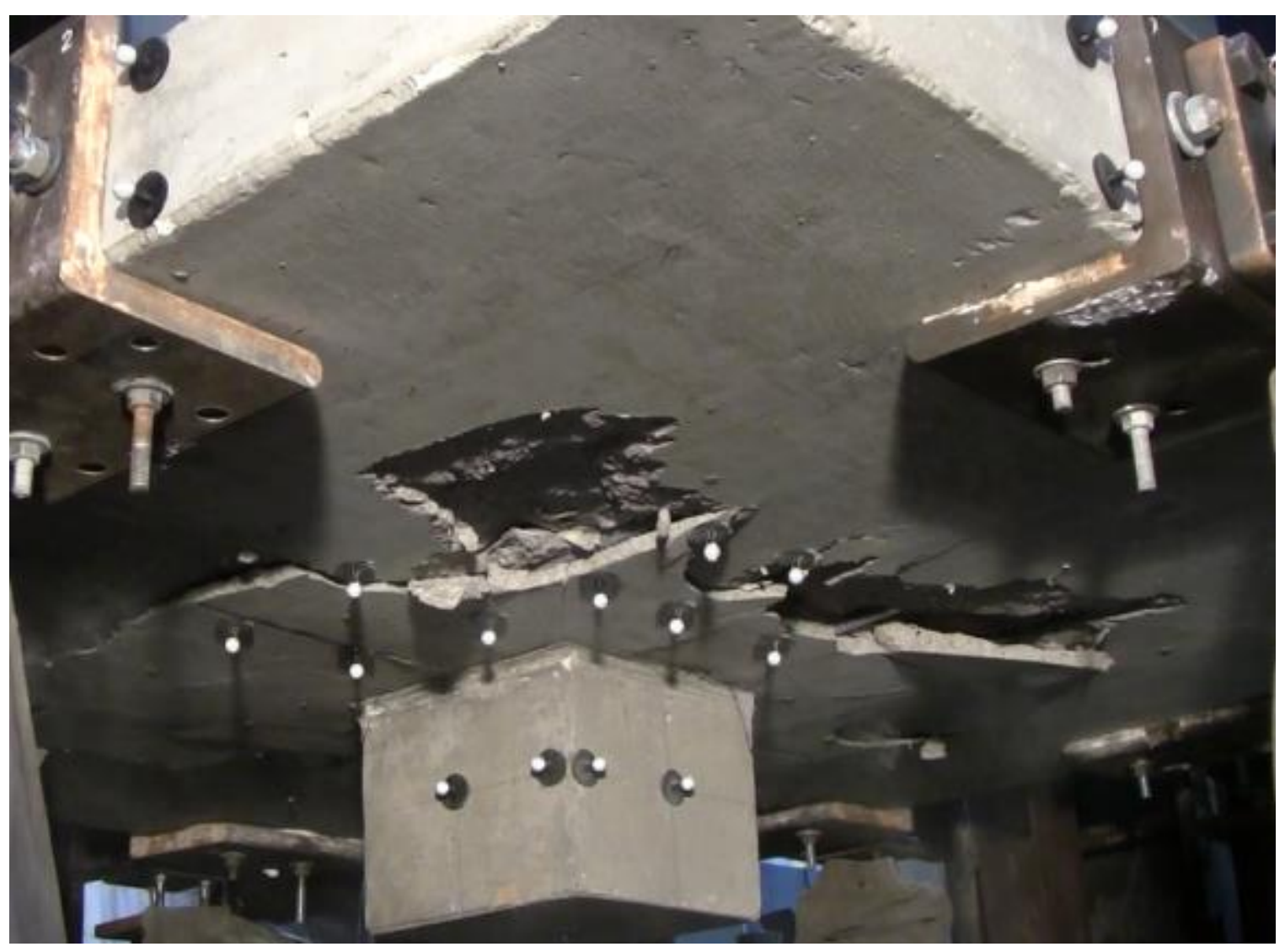

Figure 4.2.1.12 - Underside of the $0.5 \%$ restrained slab just after the punching failure. The slab bottom was instrumented with markers to record displacements via video.

\subsection{2 - 0.5\% Reinforcement Restrained Test Setup (Post Punching)}

Loading of the slab column specimen was continued after the punching failure occurred in order to determine the residual capacity of the connection. The residual capacity of the slab is important because any load that can still be carried through the partially failed connection does not need to be distributed to surrounding connections in a structure. If too much load is redistributed some of the surrounding connections can be overloaded in turn causing them to fail which can lead to a progressive collapse. The load deflection plot including the post punching behavior of the slab column connection can be seen in Figure 4.2.2.1. 


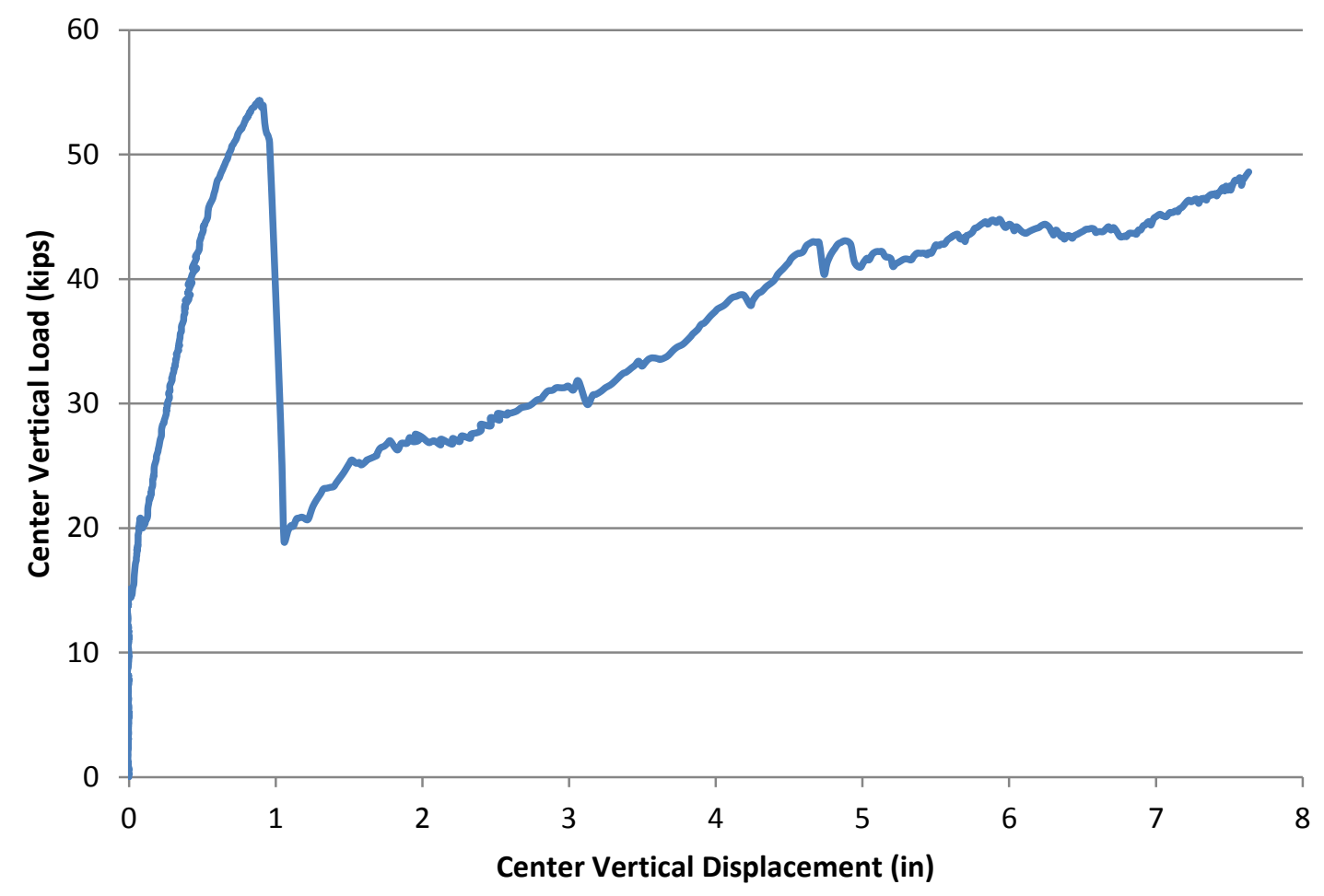

Figure 4.2.2.1 - Load Deflection plot including post punching response for the 0.5\% restrained slab.

It can be seen from the load deflection plot that the punching failure occurred at a load of 54 kips and a center deflection of 0.87 inches. For the restrained slab with a $0.5 \%$ reinforcement ratio the residual capacity was 48 kips which was $88.9 \%$ of the punching capacity of the connection. This residual capacity was again higher than the capacity predicted from Equation 7 (Habibi et al 2012). The ability of the connection to carry $88 \%$ of its failure load would be significant in a structure where the loading would need to be redistributed to the surrounding parts of the structure. The residual capacity of the connection is a result of the reinforcement that is continuous through the column as well as some dowel action that is produced by the discontinuous reinforcement that extends just into the column. The slab specimen was loaded continually until one of the reinforcing bars continuous through the column fractured. For this 
test the fracture occurred at a load of 48 kips and a corresponding center deflection of 7.6 inches. A photo of the underside of the slab at the conclusion of the testing can be seen in Figure 4.2.2.2.

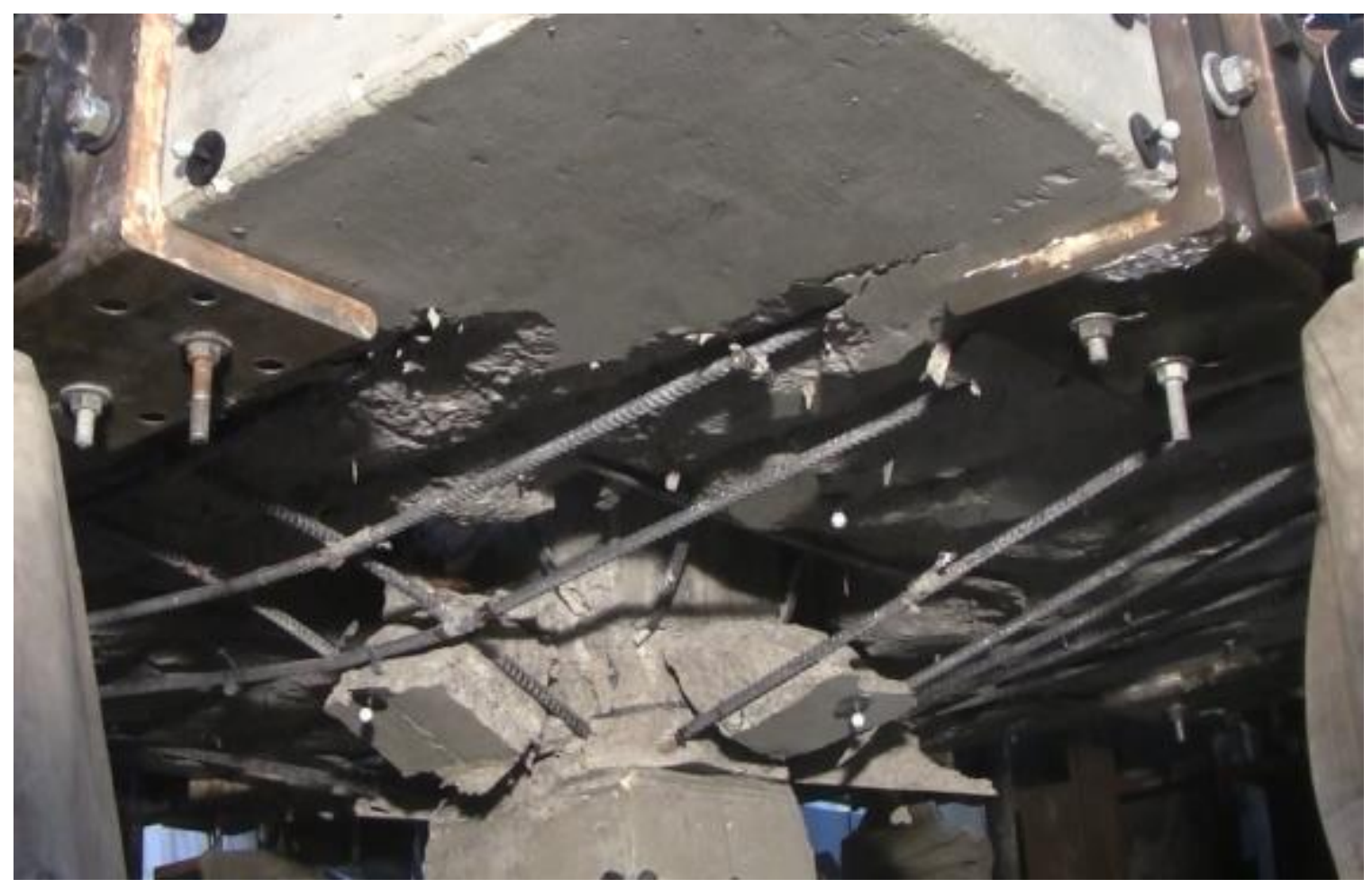

Figure 4.2.2.2 - Underside of the $0.5 \%$ restrained slab at the conclusion of the testing.

\subsection{3 - 1.0\% Reinforcement Restrained Test Setup (Pre Punching)}

The slab specimen was loaded at a rate of about $0.17 \mathrm{kips} / \mathrm{sec}$ from the beginning of the test until the punching failure occurred. The $1 \%$ reinforcement ratio slab specimen held a load of 74 kips prior to the failure occurring. The slab behaved linearly from the start of the test until the slab cracked in flexure at a load of about 12 kips and a corresponding center deflection of 0.02 inches. The shear cracking of the slab resulted in a reduced stiffness which can be seen as the change in slope of the load deflection plot in Figure 4.2.3.1. After flexural cracking the slab 
specimen again behaved almost linearly up until the punching failure occurred at an applied load of 74 kips and a corresponding center deflection of 0.79 inches.

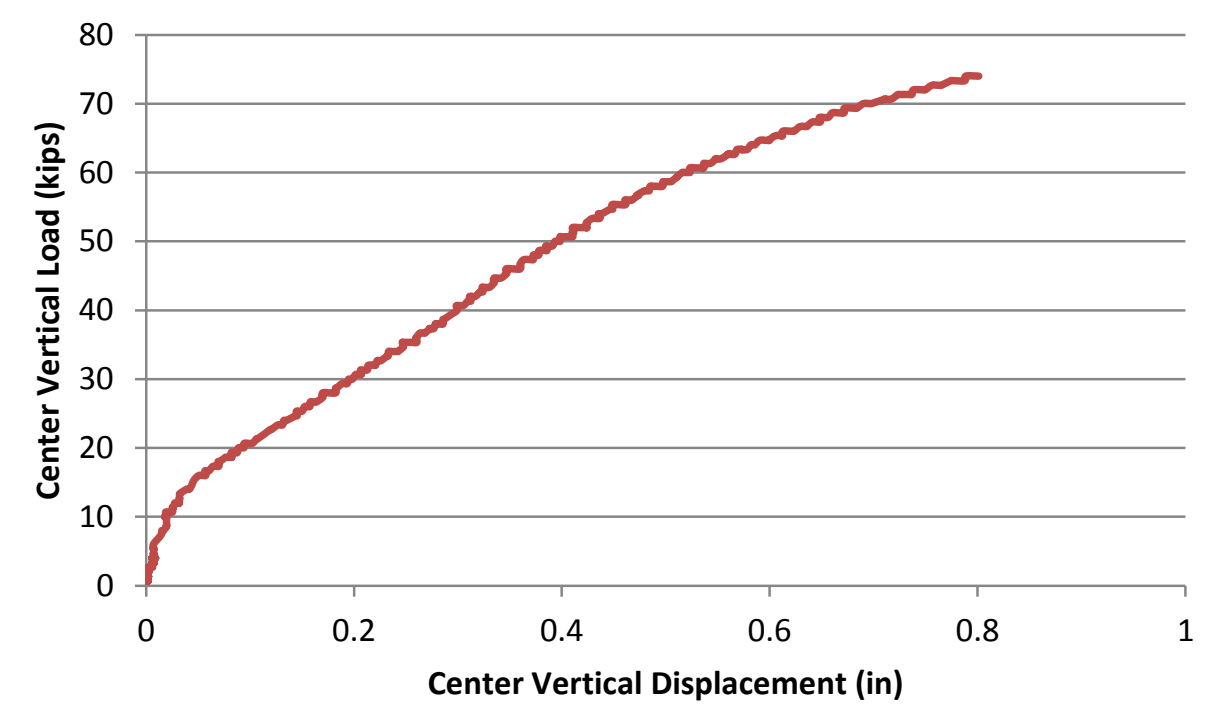

Figure 4.2.3.1 - Center load deflection plot for the $1 \%$ restrained slab prior to the punching failure.

During the test vertical displacements were recorded at the supports, at mid-slab locations ten inches from the face of the column as well as at the center of the slab. The displacement of the supports was subtracted out from the center and mid-slab displacements such that the displacement of the slab relative to the supports could be determined. The stringpots used to measure the mid-slab displacements did not seem to function properly at the start of the test because they showed no displacement from the start of the test until an applied load just over 20 kips was reached. The data shows that the mid-slab locations displaced a maximum of 0.28 inches just prior to the punching failure occurring which is $35 \%$ of the measured deflection at the center of the slab. The load deflection plot showing the center as well as mid-slab displacements can be seen in Figure 4.2.3.2. 


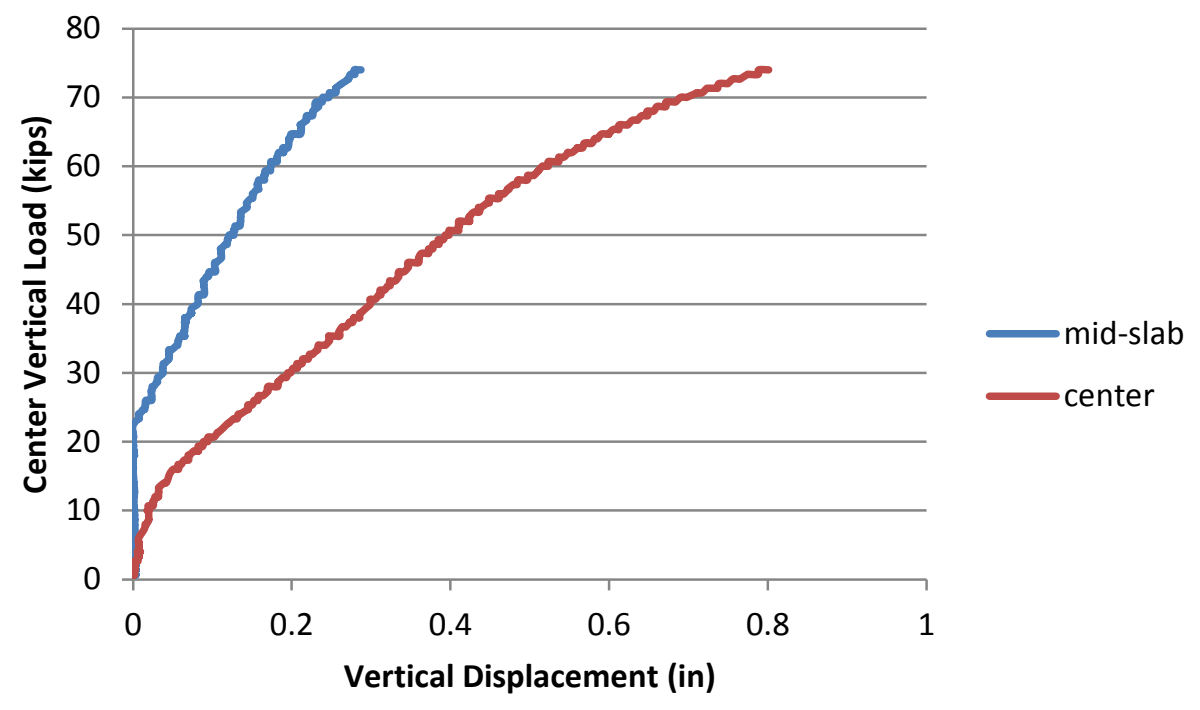

Figure 4.2.3.2 - Load deflection plot showing displacements relative to the supports prior to the punching failure for the $1.0 \%$ restrained slab.

The mid-slab displacements were also used to calculate the angle of rotation of the slab prior to the punching failure occurring. Past research by Kinnunen and Nylander (1960) has shown that the angle of rotation can be a predictor of punching failures for slabs of different reinforcement ratios. From the mid-slab displacement data it was calculated that the slab rotated 0.0126 radians which is fairly consistent with the findings of Kinnunen and Nylander (1960) for slabs with a reinforcement ratio of $1 \%$, which can be seen in Figure 2.4.2.

In the restrained test setup the slab was not allowed to expand freely in the lateral directions as it was loaded vertically because of the manner in which the slab was connected to the reaction frame. As part of the connection between the slab and the reaction frame load cells were put in place to record the lateral forces that built up due to the slab attempting to expand. As in the unrestrained test setup the lateral displacements at the edges of the slab were also recorded. The lateral displacements were used to calculate the expansion of the slab during the 
testing process. Calculations show that the slab expanded a maximum of 0.0298 inches prior to the punching failure occurring. The plot of applied vertical load and the resulting change in horizontal dimensions of the slab can be seen in Figure 4.3.2.3.

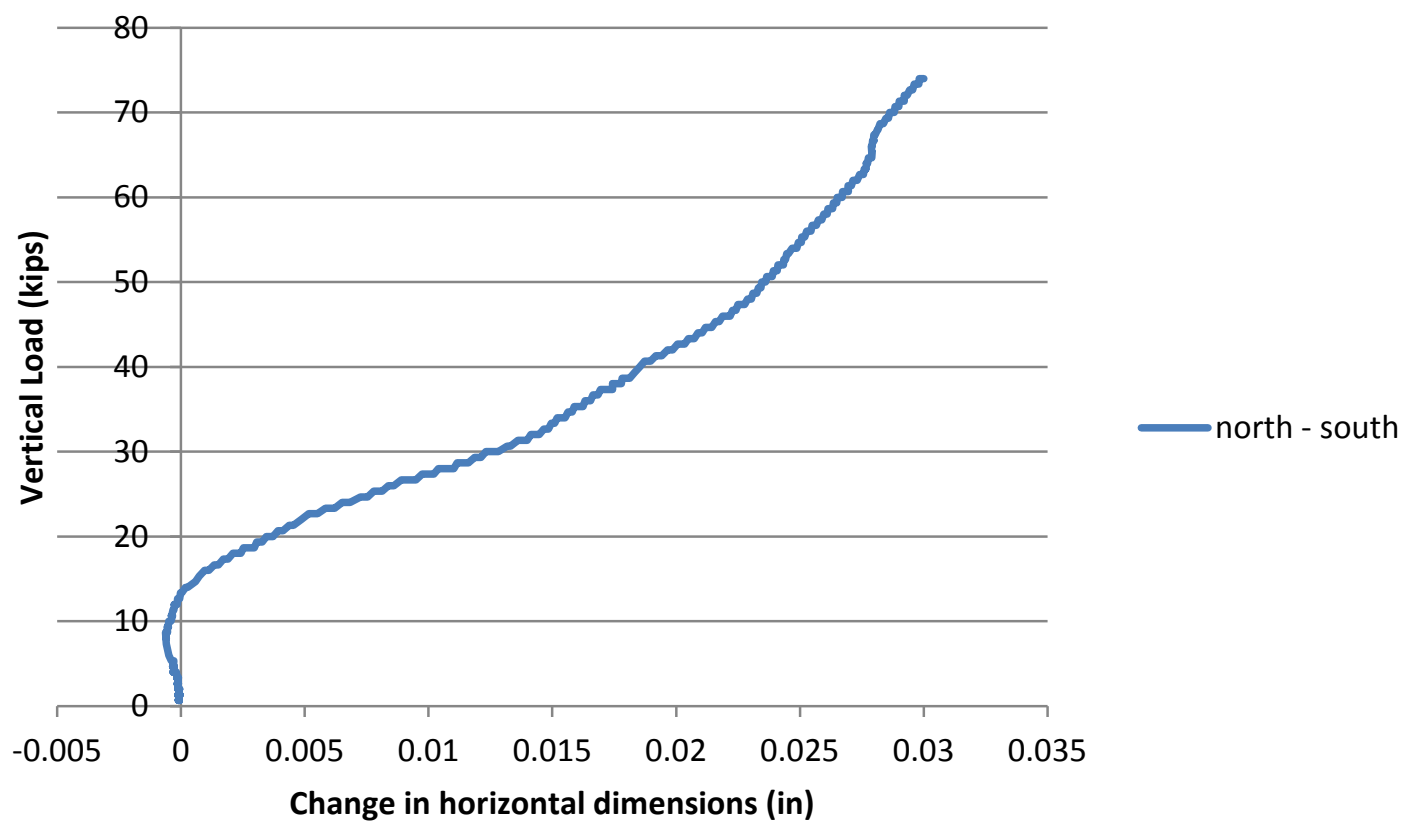

Figure 4.2.3.3 - Applied vertical load and resulting change in horizontal dimensions of the $1.0 \%$ restrained slab specimen.

The load cells that were put in place to measure the lateral compressive forces that built up as the slab attempted to expand were washer type compression load cells that fit over the 1.5 inch threaded rods that connect the slab to the reaction frame. Load cells were positioned on two of the eight connections between the slab and the reaction frame the cells were positioned on adjacent sides of the slab such that they were not recording directly across from one another as that would create redundant readings. During this particular test the recorded load cell data is more coarse, this occurred because the DAQ system was not setup to record enough significant digits in turn making the data appear coarser. The total compressive load in the North - South 
direction was only 3.6 kips which was significantly smaller than the 9.1 kip compressive load developed in the East - West direction. The total horizontal compressive loads calculated from the load cell data can be seen in Figure 4.2.3.4.

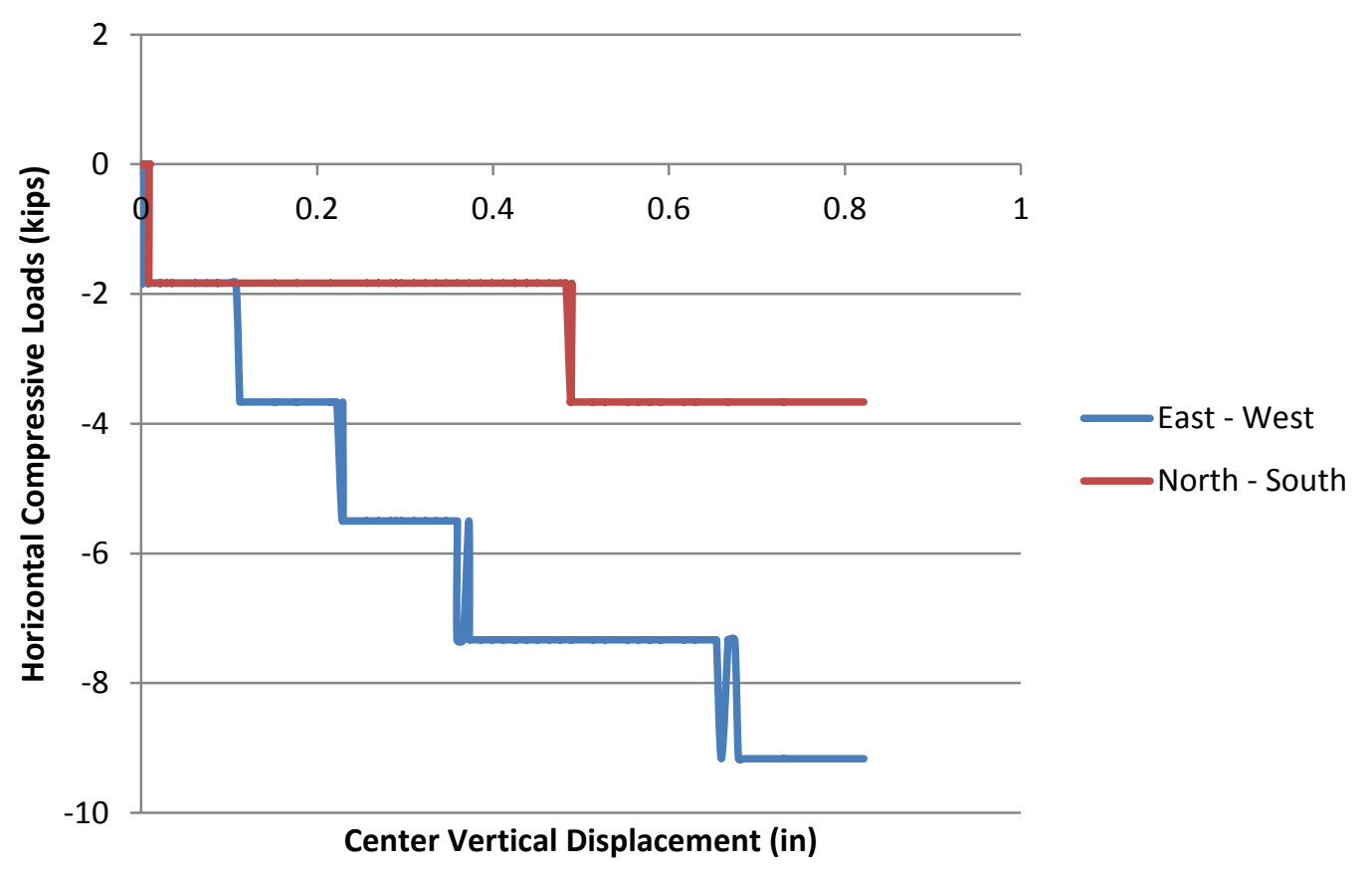

Figure 4.2.3.4 - Total horizontal compressive loads calculated from compression load cell data for the $1.0 \%$ restrained slab.

The lateral compressive loads measured by load cells in both directions were smaller than expected, it is believed that this is due to some bending in the threaded rods that the load cells were positioned on. This bending resulted in the load cells being unevenly loaded which in turn creates inaccurate results. In order to determine the lateral loads that developed without being dependent on the load cells the threaded rods were instrumented with strain gages positioned on opposite sides of the rod such that any bending effects could be removed when the strain readings were averaged. One of the two threaded rods on each side of the slab was instrumented 
in this manner to record additional data. Using the strain data from the threaded rods along with geometric and material properties the lateral loads on the threaded rods could be calculated. As with the load cell data the loads in the North -South direction were much smaller than in the East - West direction. Using the threaded rod strain data a lateral load of 3.1 kips was calculated in the North - South direction while a load of 16.4 kips was calculated in the East - West direction. The lateral load reached in the East - West direction is similar to the load reached in the $0.5 \%$ test, however it appears that there is a lack of restraint in the North - South direction resulting in a much smaller lateral load. A plot of the lateral compressive loads calculated from the threaded rod strain data can be seen in Figure 4.2.3.5.

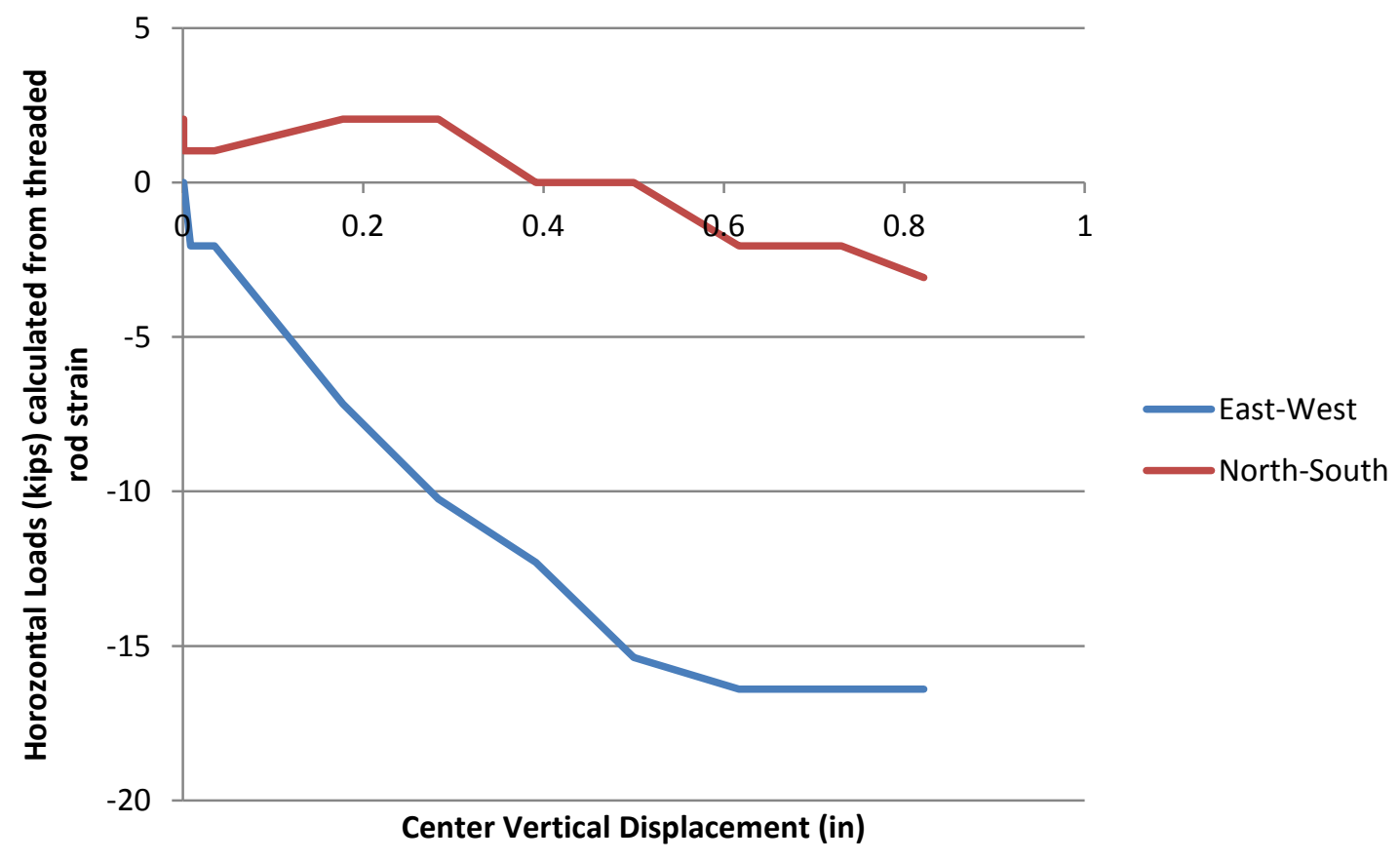

Figure 4.2.3.5 - Total lateral compressive loads calculated from the strain in the threaded rods used to connect the $1.0 \%$ restrained slab to the reaction frame. 
Using the lateral load data in conjunction with the lateral displacement data the lateral stiffness of the test setup can be calculated. The lateral stiffness is important for the restrained test setup because the application of restraint is intended to alter the performance of the slab specimens. The maximum expansion of the slab was found to be 0.0298 inches prior to the punching failure with a maximum lateral compressive load of 16.4 kips. Using these values a lateral stiffness of $550 \mathrm{kips} / \mathrm{in}$ was calculated for the East-West direction. For the North-South direction the lateral load was significantly less resulting in a significantly lower lateral stiffness of $103 \mathrm{kips} / \mathrm{in}$. The design stiffness for the restrained test setup was $1600 \mathrm{kips} / \mathrm{in}$ so the actual stiffness was lower than anticipated which was a result of some movement in the reaction frame which was not anticipated.

Past research in the area of punching shear by Broms (1990) has shown that the compressive strains in the concrete can be used as an indicator that a punching failure is imminent. Broms (1990) concluded that compressive strains of 0.0008 in/in measured parallel to the face of the column indicated that the slab was close to failure. During testing concrete strains were measured on the slab along two of the faces of the column, strains were measured perpendicular as well as parallel to the column face. A plot of applied load and the resulting strain in the concrete can be seen in Figure 4.2.3.6. The compressive strains measured perpendicular to the column face reached values between 0.003 and $0.0058 \mathrm{in} / \mathrm{in}$ prior to the punching failure occurring which is significantly smaller than the values measured in previous test. The strains measured parallel to the face of the column reached values between 0.00074 and $0.001 \mathrm{in} / \mathrm{in}$ just prior to the punching failure occurring which is fairly consistent with the results presented by Broms (1990). 


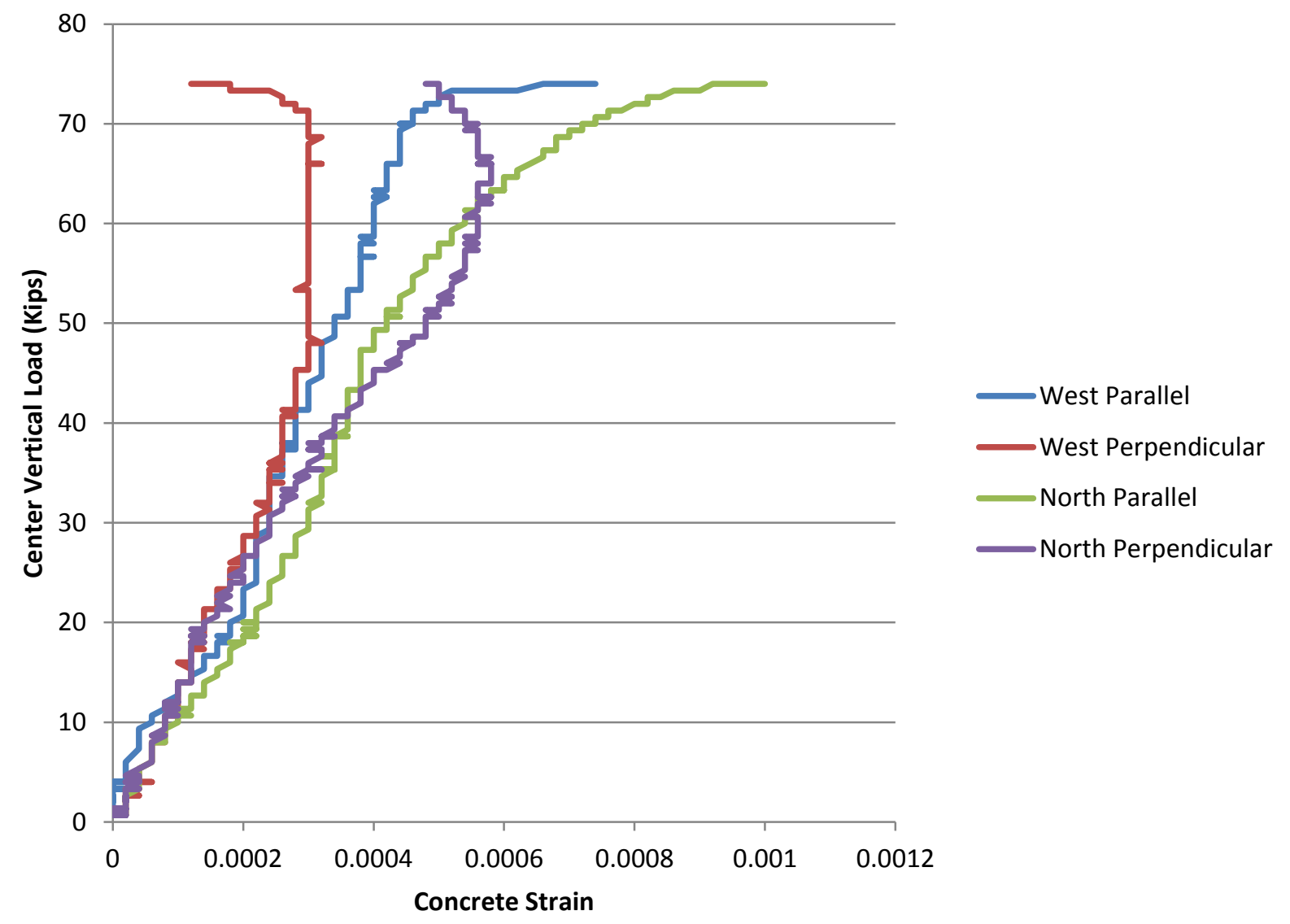

Figure 4.2.3.6 - Applied load and corresponding compressive strain in the concrete prior to the punching failure for the $1.0 \%$ restrained slab.

In addition to all of the external instrumentation the reinforcing cages were instrumented with strain gages. For the $1 \%$ reinforcement ratio slab there was a total of 31 strain gages, 21 were applied to the tension reinforcement and 10 were applied to the compression reinforcement cage. The layouts of the strain gages for the tension and compression reinforcement cages can be seen in Figures 3.5.3 and 3.5.4 respectively. The layout of the strain gages on the tension reinforcement cage was designed such that the variance in strain in and around the failure zone could be determined. One set of strain gages on the tension reinforcement was designed to show the variance in strain as measurements were taken from the center of the slab towards the outside 
edge of the slab. In our other tests the strain values were highest near the center of the slab and decreased as measurement locations moved away from the center. In this test the strain distribution did not follow the same pattern, one of the gages in the set, T5 showed significantly higher strain readings than would have been expected based on its location. This is shown in a plot of applied load and the corresponding strain on the tension reinforcement which can be seen in Figure 4.2.3.7.

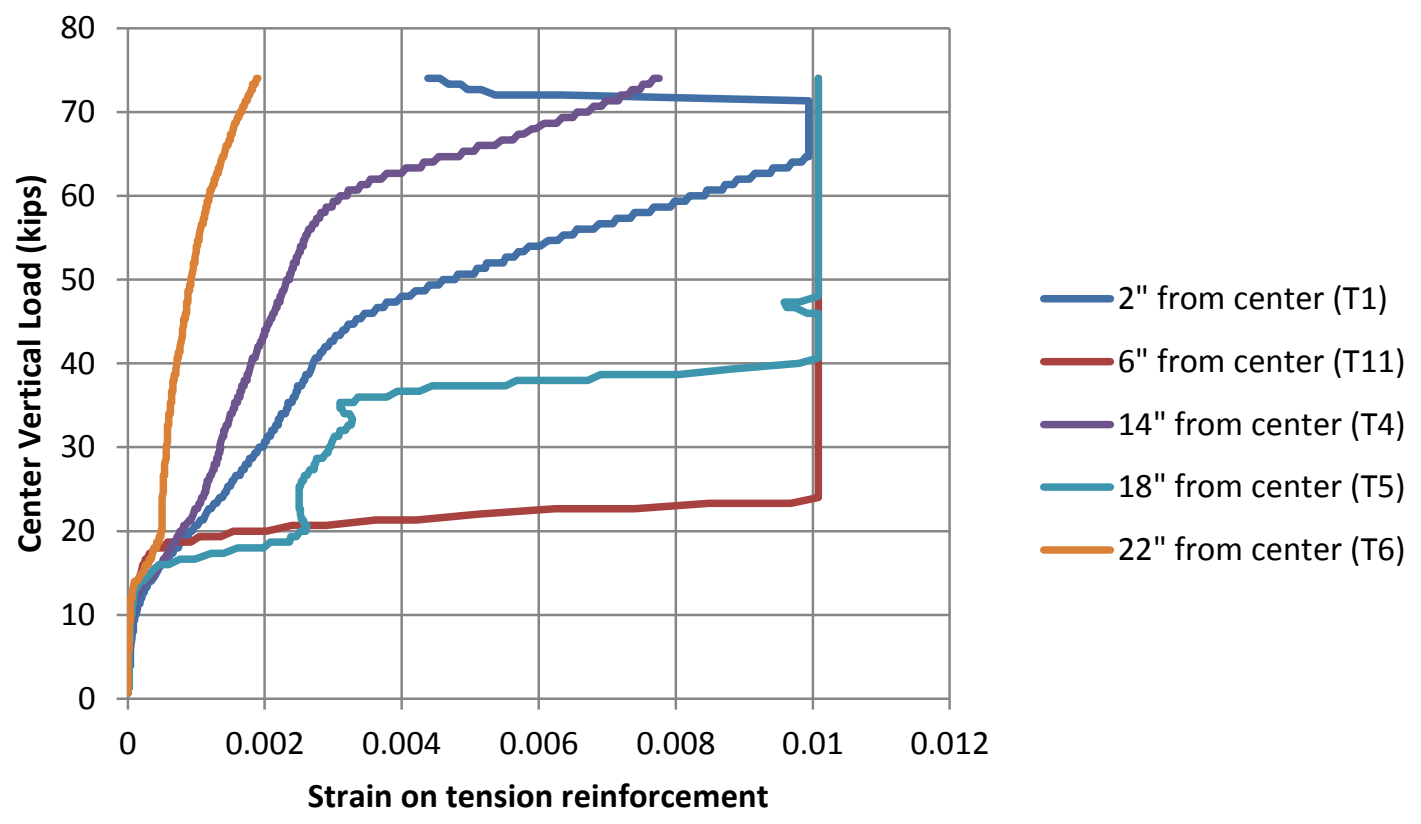

Figure 4.2.3.7 - Applied load and the corresponding tensile strains on the reinforcement for the $1.0 \%$ restrained slab.

Another set of gages on the tension reinforcement cage was designed to show the variance in strain as measurement locations moved along the rebar that was continuous through the column from one side to the other. In general the strains were higher near the column and values were lower farther from the column with values ranging from $0.0025-0.0065$ in/in just 
before the punching failure occurred. A plot of the applied load and the corresponding strain on the bars continuous through the column can be seen in Figure 4.2.3.8.

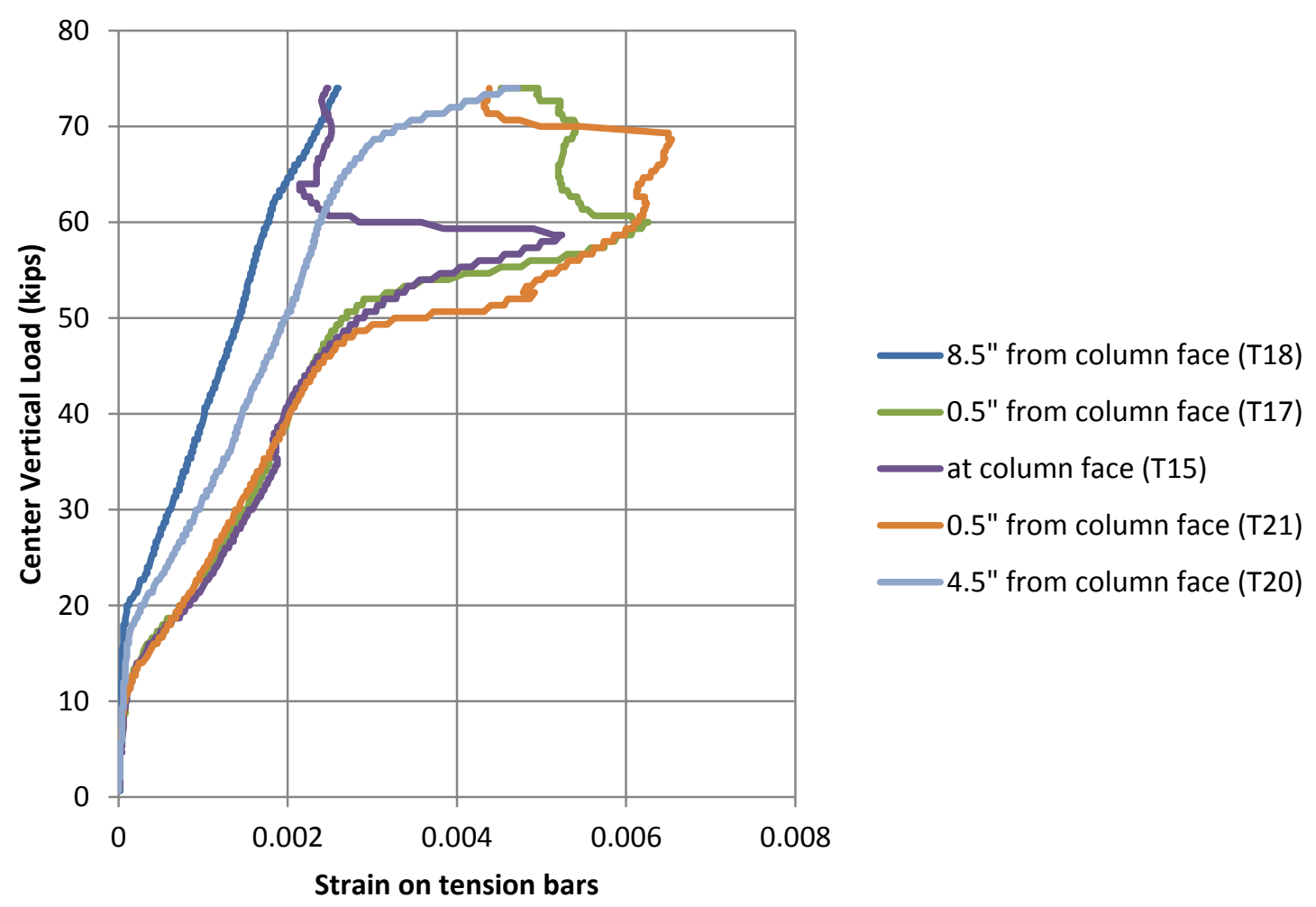

Figure 4.2.3.8 - Applied vertical load and the corresponding tensile strains on the bars continuous through the column for the $1.0 \%$ restrained slab.

In general the strains measured on the tension reinforcement cage were highest near the column and decreased as measurements were made farther from the center of the slab and outside the failure area. At the time of the punching failure 14 of the 16 functional gages on the tension reinforcement cage measured strains above the yield strain of $0.002 \mathrm{in} / \mathrm{in}$. Looking at Figures 4.2.3.7 and 4.2.3.8 it can be seen that the tension reinforcement develops almost no strain prior to the slab cracking in flexure at a load of about 12 kips. Once the slab begins to 
crack the tension reinforcement is required to carry the tensile stresses that the concrete cannot, therefore the strain increases quickly after cracking until the punching failure occurs.

The compression reinforcement follows some different trends from the tension reinforcement. In general the strains are still highest when measurements are made closer to the center of the slab but when looking at the data only one of the 6 functional gages measured strains higher than the yield strain of $0.002 \mathrm{in} / \mathrm{in}$ with values ranging from 0.0005 to $0.0022 \mathrm{in} / \mathrm{in}$. Also it should be noted that from the beginning of the test until the slab cracks in flexure at a load of about 12 kips the compression reinforcement gages measured compressive strains. After the slab cracks the stress distribution along the depth of the slab changes which causes the compression reinforcement to begin to stretch, this is represented by the change in slopes on the load- strain plot for the compression reinforcement which can be seen in Figure 4.2.3.9. When the applied load reached 30 kips all of the functional gages on the compression reinforcement measured tensile strains which continued to increase until the punching failure occurred. A photo of the underside of the slab just after the punching failure occurred can be seen in Figure 4.2.3.12. 


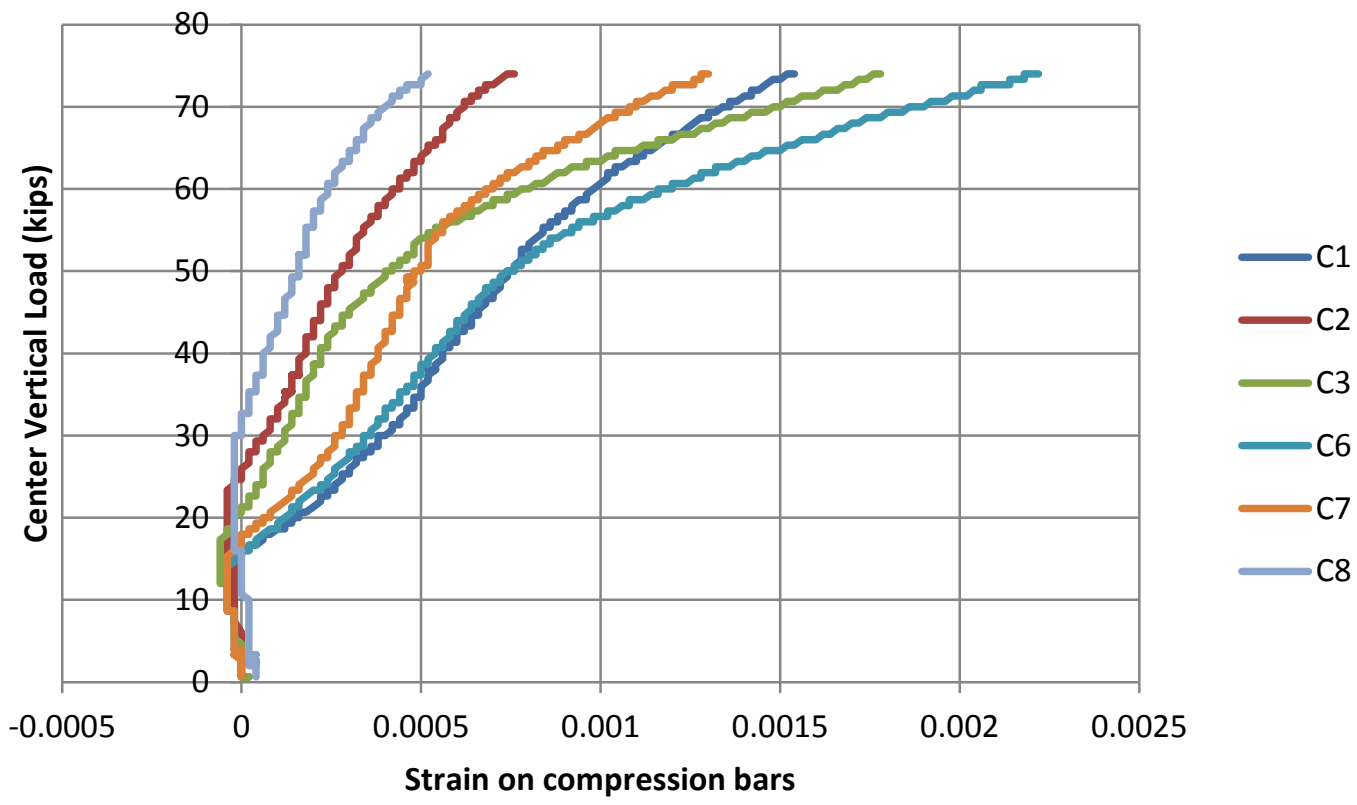

Figure 4.2.3.9 - Applied load and the resulting strain on the compression reinforcement prior to the punching failure for the $1.0 \%$ restrained slab. Compressive strains are shown as negative and tensile strains are shown as positive.

The plots in Figures 4.2.3.7 through 4.2.3.9 show some of the trends that developed in the reinforcement strain data. In order to gain a better understanding of the reinforcement strains throughout the slab specimen Figures 4.2.3.10 and 4.2.3.11 were created, showing the maximum strain values prior to failure listed at their corresponding locations within the slab. The gage locations can be referenced in Figures 3.5.3and 3.5.4. 


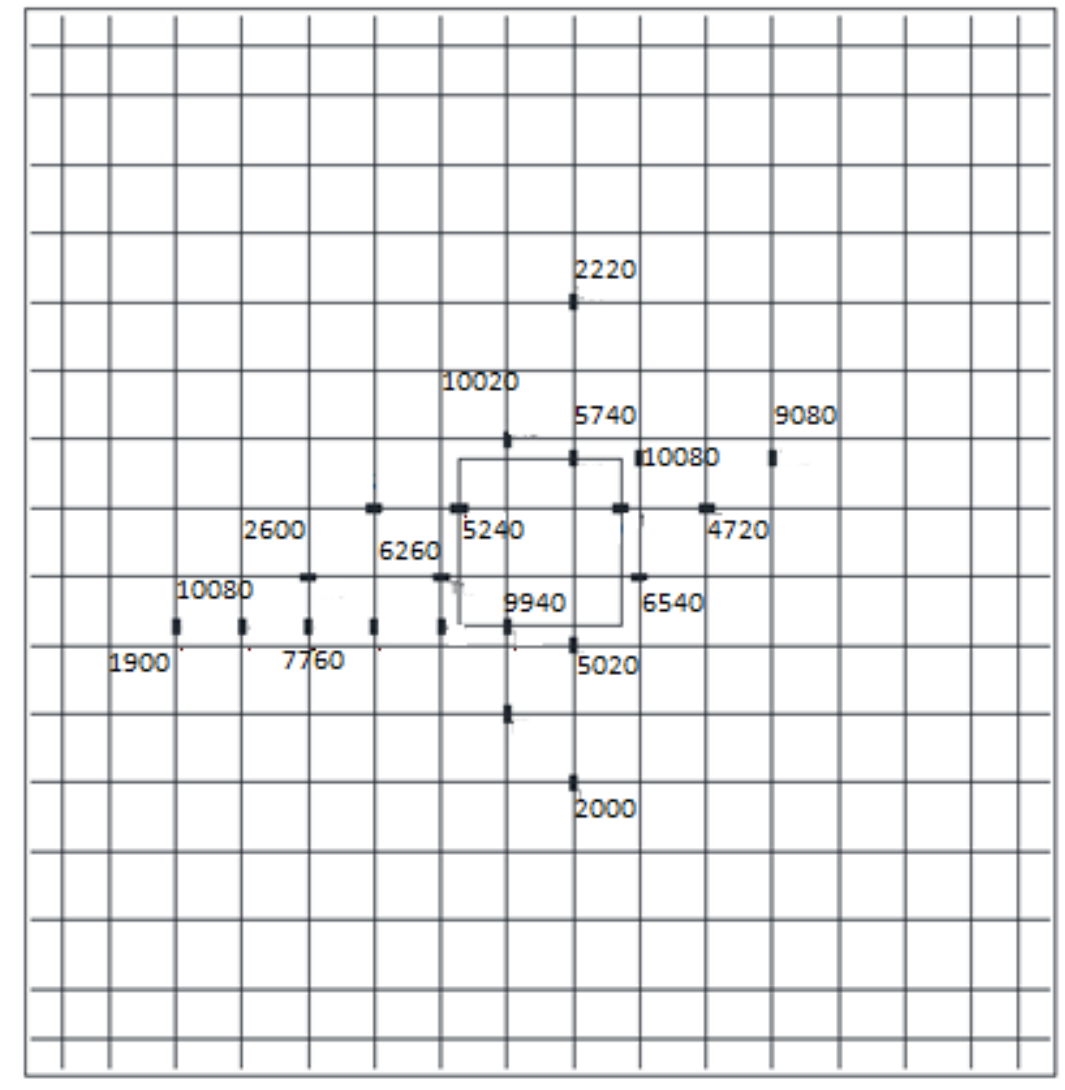

Figure 4.2.3.10 - Maximum strains on the tension reinforcement prior to failure for the $1.0 \%$ restrained slab (strain values listed in microstrains). 


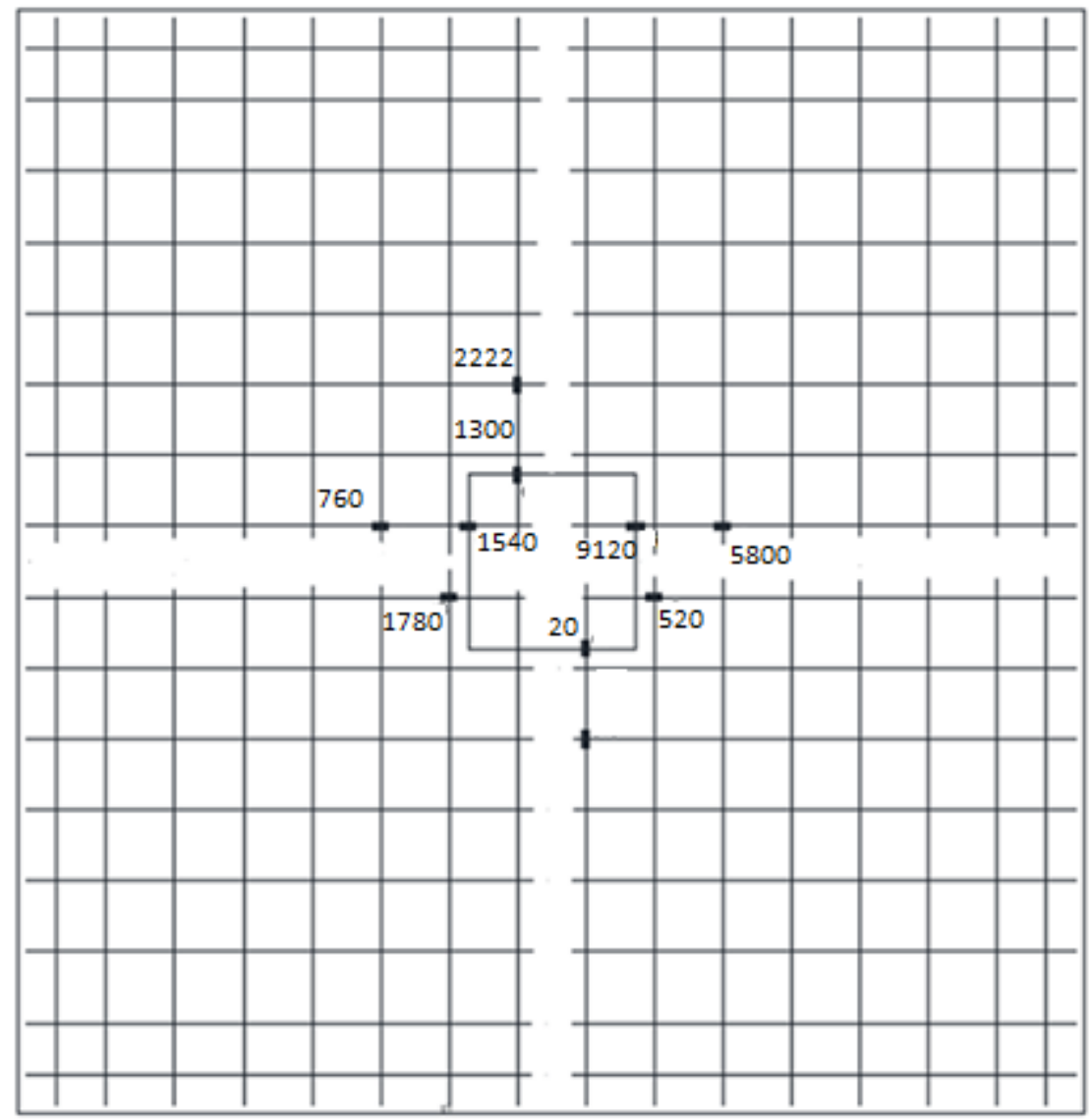

Figure 4.2.3.11 - Maximum strain values on the discontinuous reinforcement prior to failure for the $1.0 \%$ restrained slab (strain values listed in microstrains). 


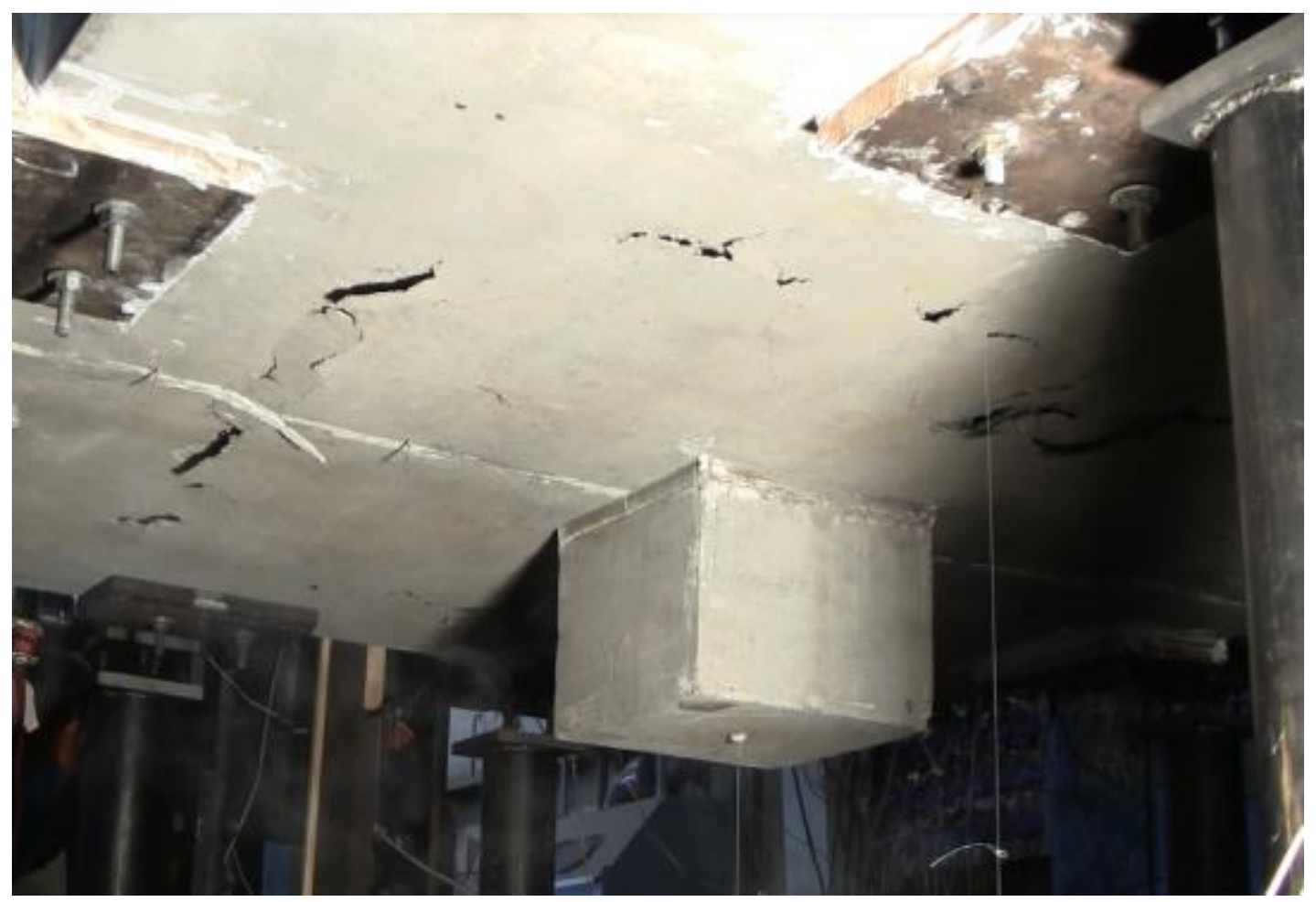

Figure 4.2.3.12 - Underside of the 1.0\% restrained slab just after the punching failure occurred.

\subsection{4 - 1.0\% Reinforcement Restrained Test Setup (Post Punching)}

After the punching failure occurs the slab column connection is still able to carry some load because of the reinforcement that is continuous through the column as well as dowel action provided by the discontinuous reinforcement. The residual capacity of the connection can be determined by reviewing a load deflection plot that includes the post punching behavior of the slab specimen, the load deflection plot can be seen in Figure 4.2.4.1. 


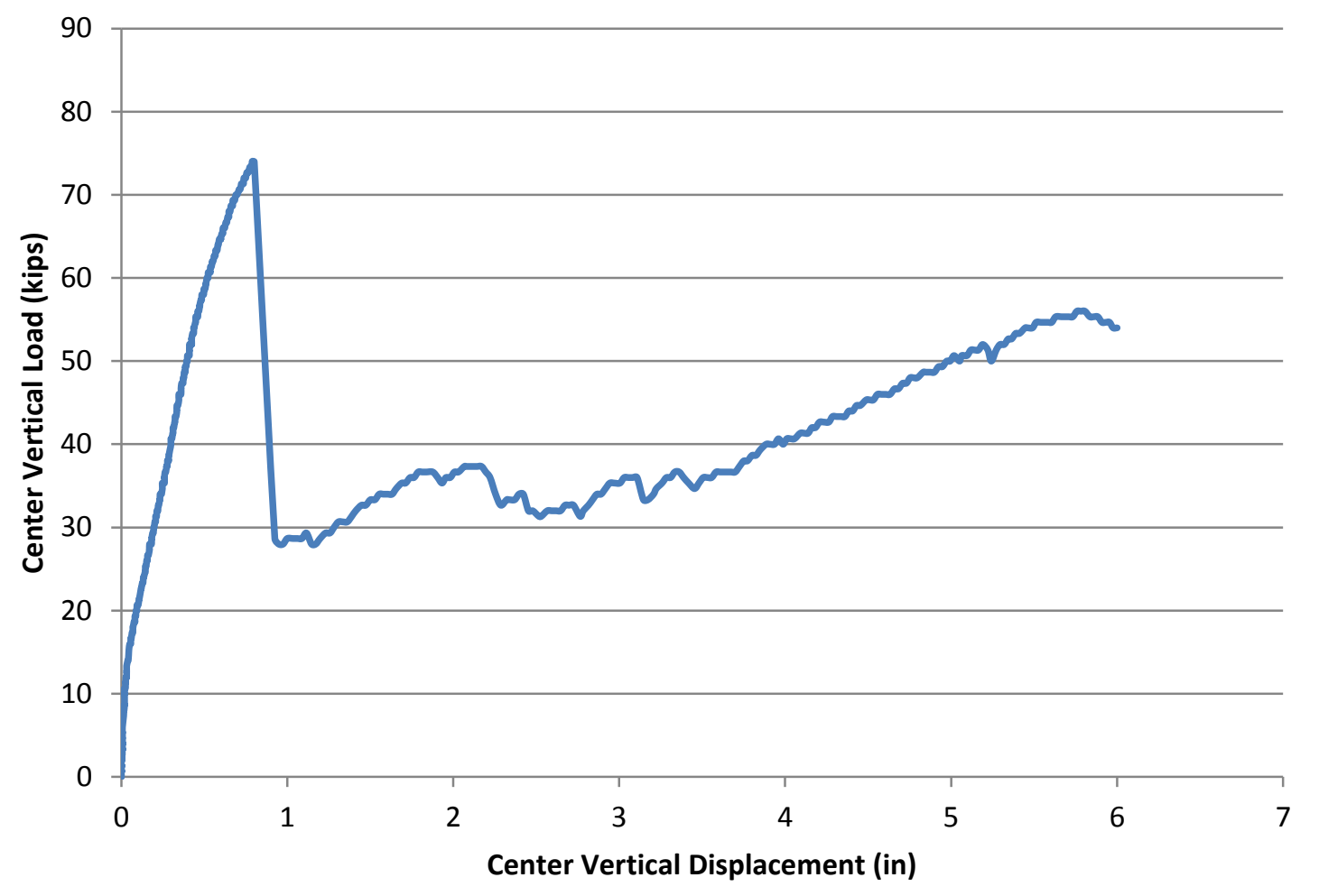

Figure 4.2.4.1 - Load deflection plot including post punching response for the $1.0 \%$ restrained slab.

From the plot in Figure 4.2.4.1 it can be seen that the punching failure occurred at a load of 73.99 kips and a center deflection of 0.78 inches. The peak residual capacity for the restrained slab with a reinforcement ratio of $1.0 \%$ was 55.3 kips which is $74.7 \%$ of the failure load. The ability of the connection to continue to carry $74 \%$ of its failure load would be important in a structure because that load would not need to be redistributed to the surrounding connections. This could keep surrounding connections from being overloaded and failing themselves, leading to a potential progressive collapse. The slab specimen was loaded after the punching failure until one of the reinforcing bars that was continuous through the column fractured. The fracture occurred at a load of 53.9 kips and a center displacement of 5.93 inches for the $1.0 \%$ reinforced 
slab tested in the restrained setup. A photo of the underside of the slab at the conclusion of the test can be seen in Figure 4.2.4.2.

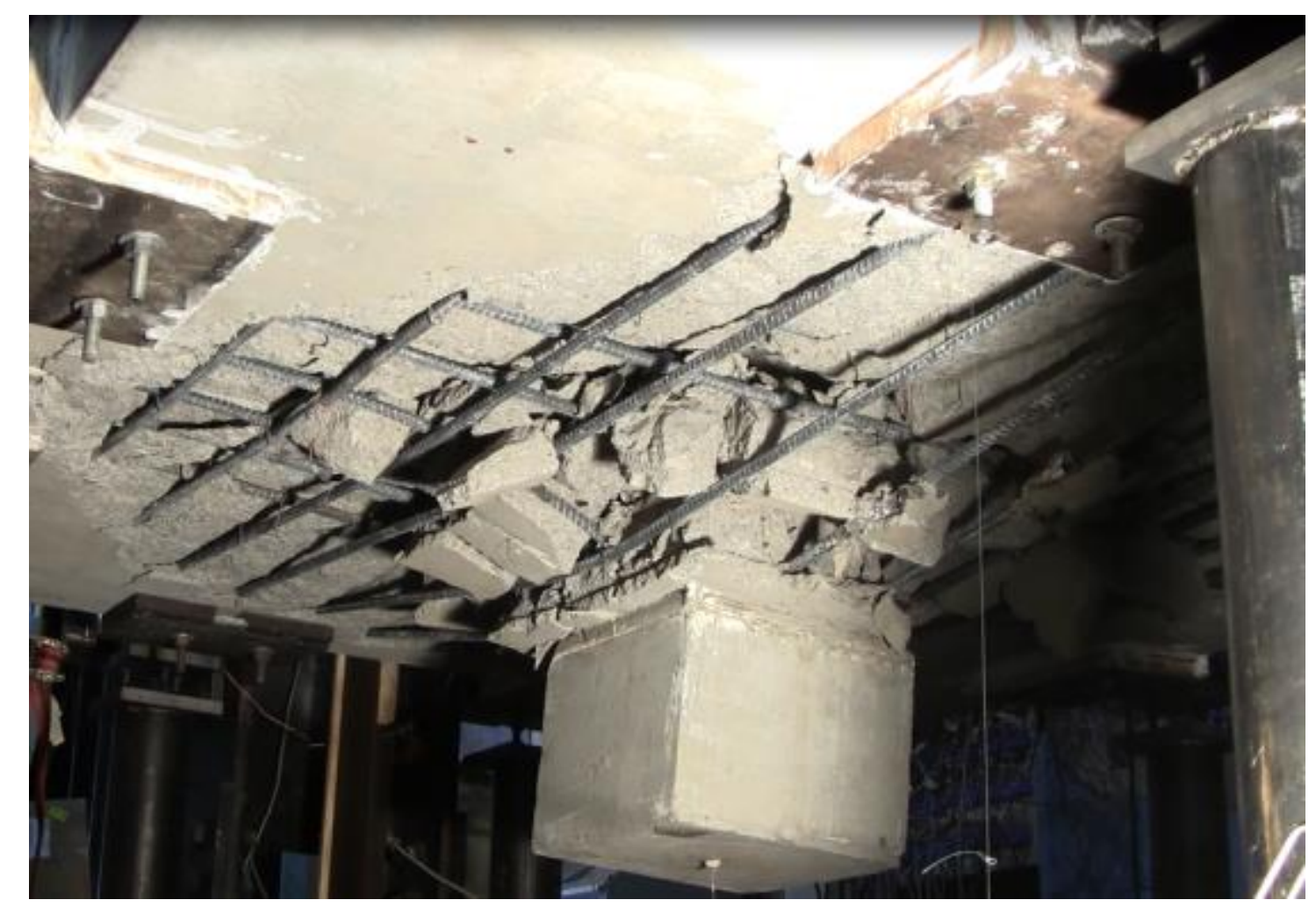

Figure 4.2.4.2 - Underside of the 1.0\% restrained slab at the conclusion of the testing.

\section{3 - Comparison of Test Results}

In these sections comparisons between the four specimen tests will be presented. Tests will be compared based on reinforcement ratio as well as test setup configuration.

\subsection{1 - Unrestrained Slab Tests}

Two slab specimens were tested in the unrestrained test setup configuration, one of which was constructed with a reinforcement ratio of $0.5 \%$ while the other specimen was constructed with a reinforcement ratio of $1.0 \%$. Constructing the slab specimens in this manner and testing 
both in the unrestrained test setup configuration provided a chance to determine the effects of reinforcement ratio on the punching shear capacity of isolated slab column specimens. The most notable difference in the results of these slab tests in the increased capacity of the slab with the $1 \%$ reinforcement ratio. The additional reinforcement resulted in an increase in punching capacity from 52kips for the $0.5 \%$ reinforced slab to $69.1 \mathrm{kips}$ for the $1.0 \%$ reinforced slab. The two slab specimens were poured at different times in the hope that they could be tested when the concrete had cured to similar strengths, considering the fact that the concrete compressive strengths is a major factor in the punching capacity of the slab. The concrete compressive strengths of these two slab specimens were only $2.8 \%$ different, with the $0.5 \%$ reinforcement slab having a compressive strength of $4705 \mathrm{psi}$ and the $1.0 \%$ reinforcement slab having a compressive strength of 4842 psi. With the compressive strengths being so similar the $24.7 \%$ increase in capacity can be attributed mostly to the increased reinforcement. The $1.0 \%$ reinforcement slab carried a higher load but showed less ductility than the $0.5 \%$ reinforced slab. The center deflection of the $1.0 \%$ reinforcement slab just prior to the punching failure was 0.848 inches which is $80 \%$ of the $0.5 \%$ reinforcement slabs deflection of 1.06 inches. The mid-slab displacements followed a similar trend, with the $1.0 \%$ reinforcement slab displacing only $71 \%$ as much as the $0.5 \%$ reinforcement slab. The combined load deflection plot for both slabs can be seen in Figure 4.3.1.1. 


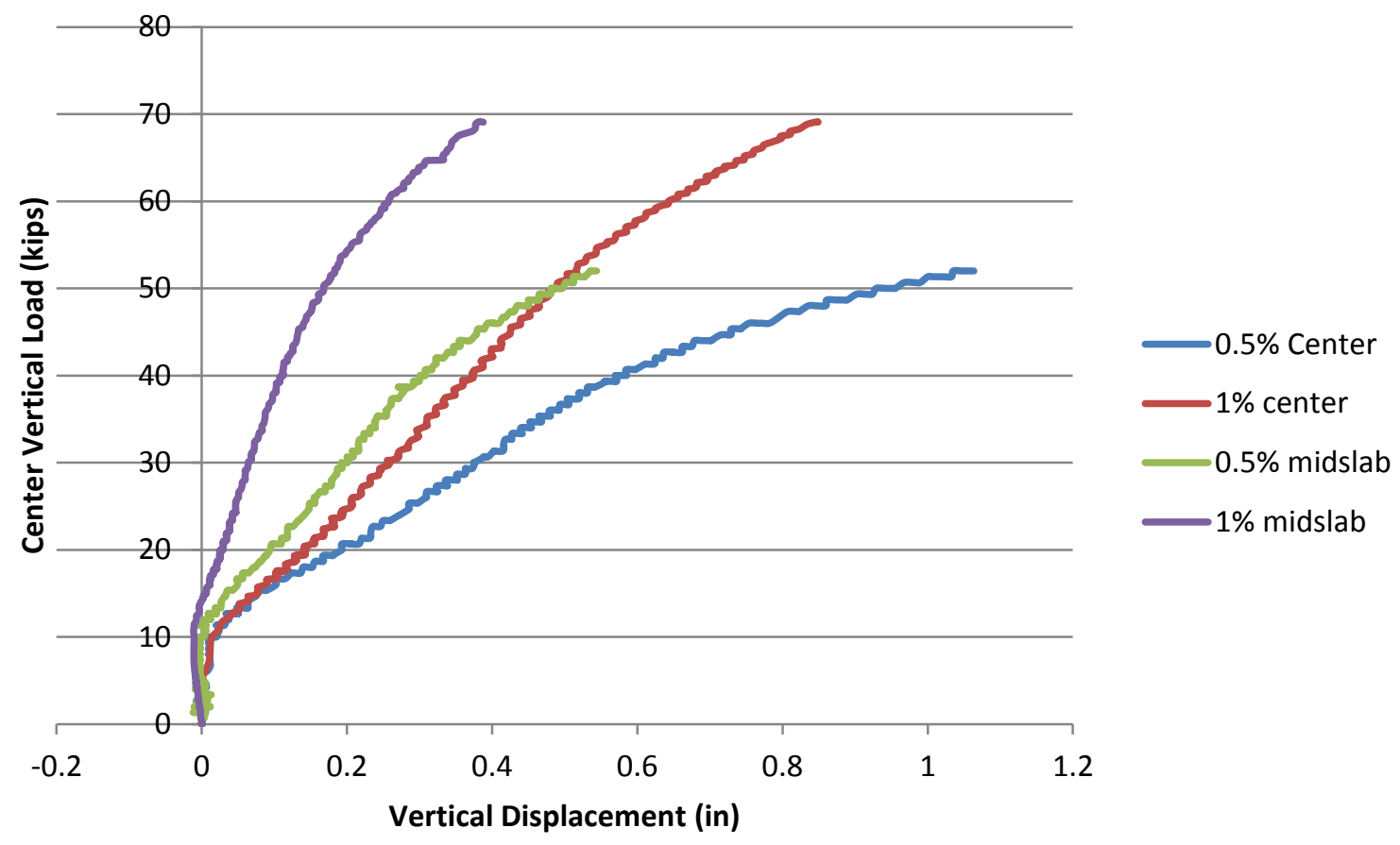

Figure 4.3.1.1 - Load Deflection plot showing center and mid-slab deflections for the $0.5 \%$ and $1.0 \%$ reinforced slabs tested in the unrestrained configuration.

The residual capacity of the two slabs tested in the unrestrained test setup was also examined. It was found that the slab with the $0.5 \%$ reinforcement ratio had a residual capacity of 41.3 kips which was $79 \%$ of the failure load for that slab specimen. The $1.0 \%$ reinforcement ratio slab had a residual capacity of 57.6 kips which was $83 \%$ of the failure load for that slab specimen. The residual capacities of the slabs are fairly similar in terms of the percentage of the total load carried because most of the residual capacity comes from the reinforcement that is continuous through the column. Although the slabs have different reinforcement ratios, both slabs have equal numbers of continuous bars through the column which results in fairly similar residual capacities. The ability of these connections to carry large percentages of their failure load is vital in helping to prevent further failures in a structure. The load deflection plots 
including the post punching behavior of the $0.5 \%$ and $1.0 \%$ reinforcement unrestrained slabs can be seen in Figures 4.1.2.1 and 4.1.4.1 respectively.

\subsection{2 - Restrained Slab Tests}

Two of the slab specimens that were constructed were tested in the restrained test setup, of these two slabs one was constructed with a reinforcement ratio of $0.5 \%$ while the other slab was constructed with a reinforcement ratio of $1.0 \%$. Constructing and testing the slabs in this manner provided the opportunity to determine the effects of differing reinforcement ratio when lateral restraint was present. Looking at the general load deflection data collected during testing the slab with the $1.0 \%$ reinforcement ratio demonstrated a higher capacity with less ductility which is similar to the results that were gathered during the unrestrained testing. The $1.0 \%$ reinforcement slab held a load of 74 kips which is a $36 \%$ increase in capacity compared to the slab constructed with a $0.5 \%$ reinforcement ratio which held 54.3 kips prior to the punching failure. The concrete compressive strengths of these two slabs were $21.5 \%$ different with the $0.5 \%$ reinforced slab having a measured compressive strength of 6418 psi while the measured compressive strength of the slab with $1.0 \%$ reinforcement was only 5281 psi. Since the compressive strength of the concrete is a determining factor in the punching shear capacity of the slab, the difference of over $20 \%$ could be a large factor. The punching capacity of slabs is generally related to the concrete compressive strength by a curve that resembles the square root of the compressive strength. Using this information the load deflection plot can be normalized to the compressive strength by dividing the applied load by the square root of the compressive strength. The normalized load deflection plot can be seen in Figure 4.3.2.1. Looking at the normalized data the slab with the $1.0 \%$ reinforcement ratio held a load that was $50 \%$ greater than the load held by the slab with less reinforcement prior to punching. Although the slab 
constructed with the $1.0 \%$ reinforcement ratio had a significantly higher capacity it deflected less prior to the punching failure occurring. The mid-slab deflections of the $1.0 \%$ reinforced slab were only $39 \%$ of the mid slab deflections of the $0.5 \%$ reinforced slab and the center deflections of the $1.0 \%$ reinforced slab were $84 \%$ of the deflections of the $0.5 \%$ reinforced slab.

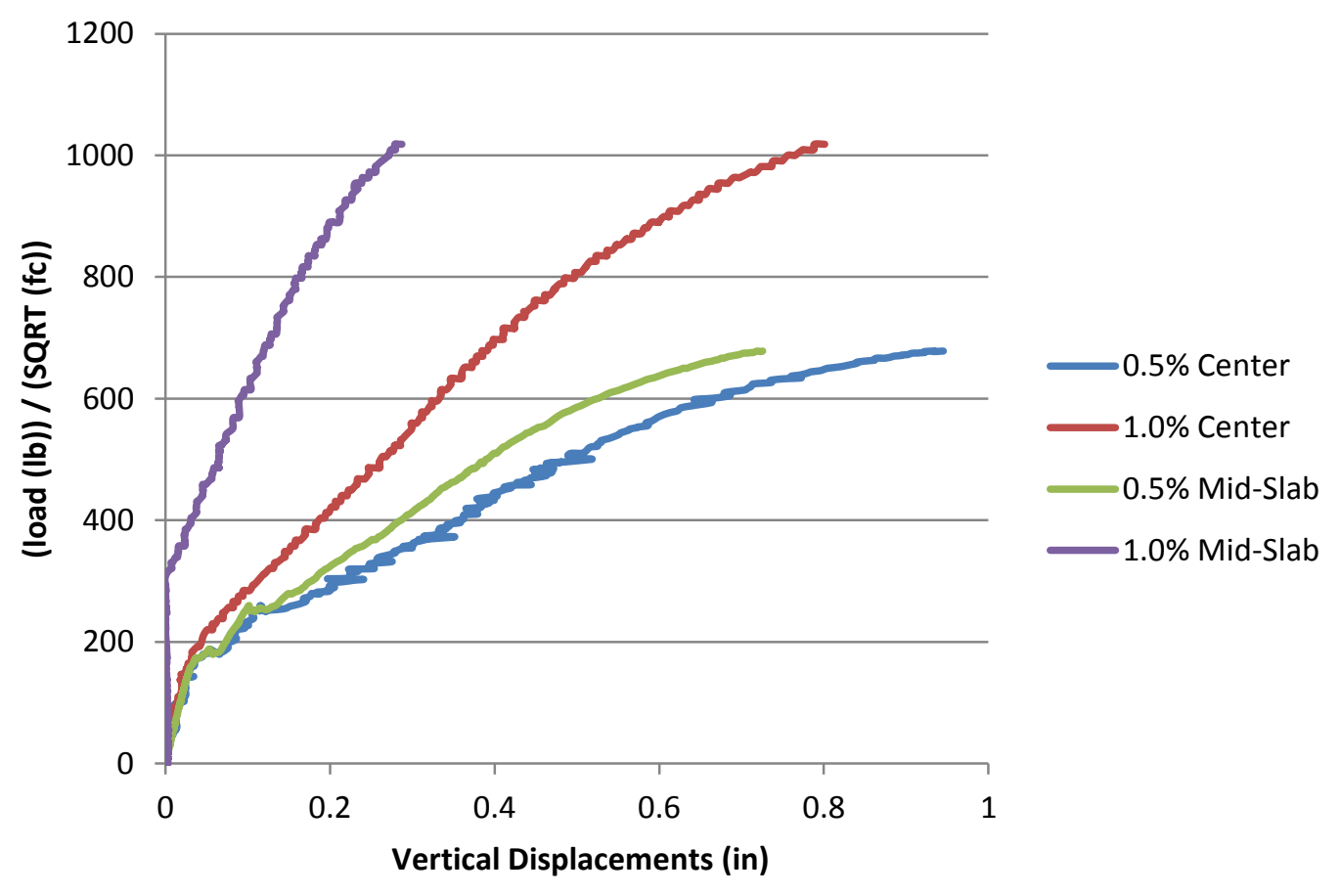

Figure 4.3.2.1 - Load deflection plot for the slabs tested in the restrained test setup with load values normalized to the concrete compressive strength.

The residual capacity of the restrained slabs after the punching failure had occurred was also examined to determine how much load could still be carried through the partially failed connection. From looking at load deflection plots that include the post punching behavior of the slab specimens it was determined that the $0.5 \%$ reinforcement slab column connection had a residual capacity of 48 kips which was $88.9 \%$ of the failure load for that slab specimen. The $1.0 \%$ reinforcement slab had a residual capacity of 55.3 kips which was $74.7 \%$ of the failure load 
for that slab. The slab specimen with the higher reinforcement ratio has a larger residual capacity when looking at total load, but the percentage of the failure load carried was smaller. In a structure any load that can no longer be carried through the failed connection needs to be redistributed to the surrounding connections. The ability of these connections to carry at least $74 \%$ of their failure load would very beneficial in a structure and may help to prevent damage to surrounding connections and ultimately a potential progressive collapse. The load deflection plots showing the post punching behavior of the $0.5 \%$ reinforcement and $1.0 \%$ reinforcement restrained specimens can be seen in Figures 4.2.2.1 and 4.2.4.1 respectively.

\subsection{3 - 0.5\% Reinforcement Ratio Slab Tests}

Two of the slab specimens were constructed with a reinforcement ratio of $0.5 \%$, of the two slabs one was tested in the restrained test setup while the other was tested in the unrestrained test setup. Testing slabs with the same reinforcement layout in different test setups provided the opportunity to determine the effects of lateral restraint on the punching capacity of the slabs. Looking at the general load deflection data that was collected during testing it can be seen that the slab tested in the restrained setup held a load of 54.3 kips while the unrestrained slab only held a load of 51.9 kips, so the restraint may have provided a $4.6 \%$ increase in capacity. However the concrete compressive strengths of these two slabs were significantly different with the restrained slab having a compressive strength of 6418 psi while the unrestrained slab only had a compressive strength of 4705 psi. This $36 \%$ difference in concrete compressive strength could have easily accounted for the $4.6 \%$ increase in punching capacity. If it is assumed that punching capacity varies with concrete compressive strength in a curve that resembles the square root of the concrete strength, a load deflection plot normalized to the concrete strength can be created. This allows us to view the results of the testing with some of the effects of the 
difference in concrete strength removed. The normalized load deflection plot for both slabs tested with a $0.5 \%$ reinforcement ratio can be seen in Figure 4.3.3.1. When looking at the normalized plot it can be seen that the restrained slab had $89 \%$ of the capacity of the unrestrained slab. This suggests that the lateral restraint that was provided was ineffective in terms of increasing the capacity of the slab. It should be noted that the slab tested in the restrained test setup deflected $89 \%$ as much at the center location and $133 \%$ as much at the mid-slab locations prior to punching when compared with the unrestrained slab. The decreased center deflection was expected however the increased mid slab displacement was not, however it may be attributed to differences in the size and shape of the failure area in the two test.

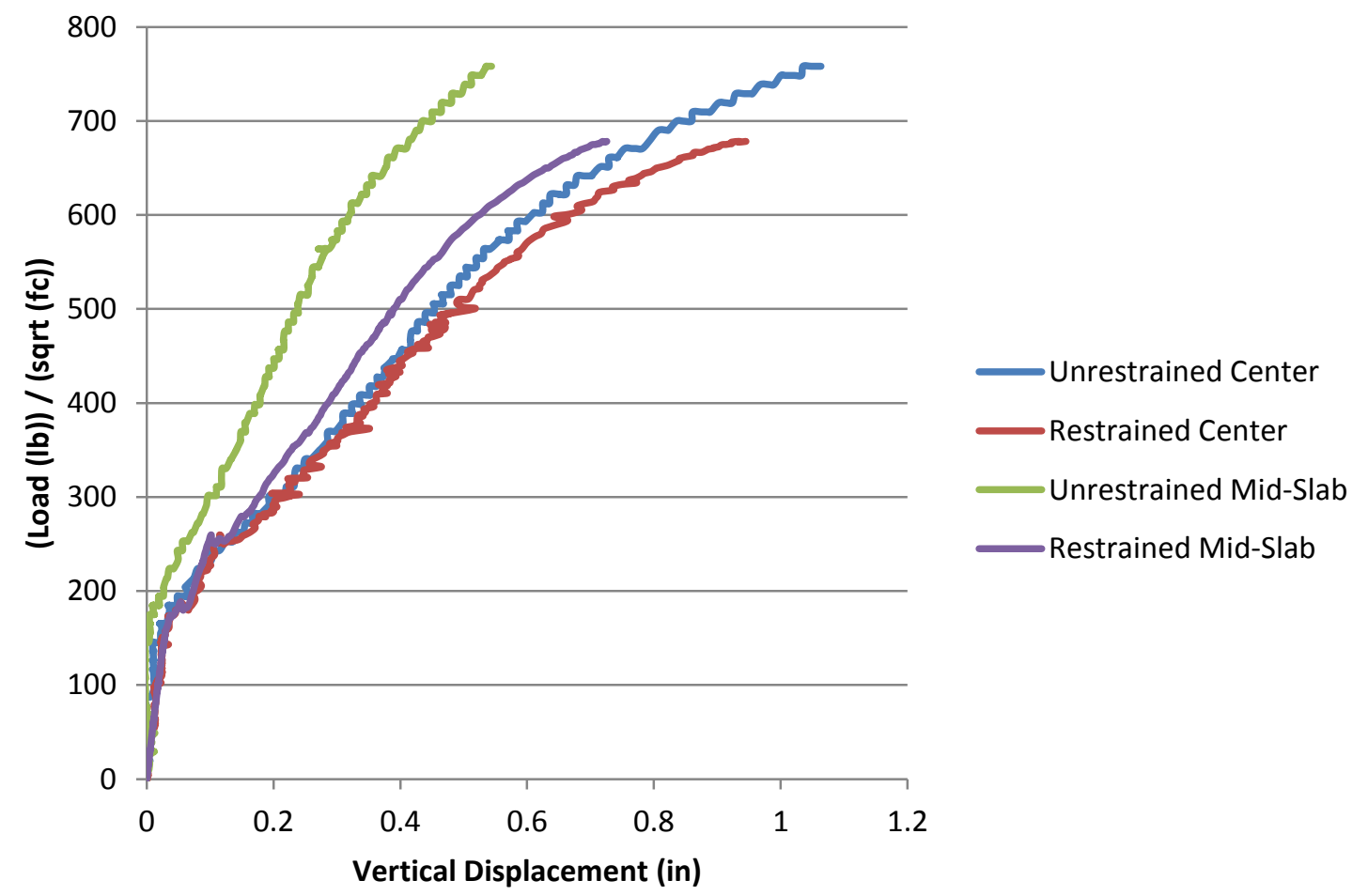

Figure 4.3.3.1 - Load deflection plot for the $0.5 \%$ reinforcement slabs with the applied load normalized to the concrete compressive strength. 
The residual capacities of the slab column connections after the punching failure occurred were also examined for the $0.5 \%$ reinforcement ratio slabs tested in both test setup configurations. Looking at load deflection plots that include the post punching behavior of the slab column specimens, the residual capacity can be determined. It was found that the $0.5 \%$ reinforcement slab tested in the unrestrained test setup had a residual capacity of 41.3 kips which was $79 \%$ of the failure load for that slab. The $0.5 \%$ reinforcement ratio slab tested in the restrained test setup had a residual capacity of 48 kips which was $88.9 \%$ of the failure load for that slab. The ability of these connections to carry a large portion of their pre punching load after the failure occurs is vital in the prevention of a potential progressive collapse. The load deflection plots showing the post punching behavior for the $0.5 \%$ reinforcement unrestrained and restrained slabs can be seen in Figures 4.1.2.1 and 4.2.2.1 respectively.

\subsection{4 - 1.0\% Reinforcement Ratio Slab Tests}

Two of the slab specimens were constructed with a reinforcement ratio of $1.0 \%$ of the two slabs one was tested in the restrained test setup while the other was tested in the unrestrained test setup. Testing two slabs with the same reinforcement layout in different test setups provided the opportunity to determine the effects of the addition of lateral restraint in the restrained test setup. Looking at the load deflection data that was recorded for each of the slabs it can be seen that the slab tested in the restrained showed a higher capacity with less ductility when compared with the slab tested in the unrestrained test setup. The restrained slab held a load of 73.9 kips while the unrestrained slab held a load of $69.1 \mathrm{kips}$, giving an increase in capacity of $6.9 \%$. The restrained slab deflected 5\% less at the center and 32\% less at the mid slab locations when compared to the unrestrained slab. The measured concrete compressive strengths in these two slabs were fairly similar with a difference of only $9 \%$. The restrained slab had the slightly higher 
compressive strength of 5281 psi while the unrestrained slab had a compressive strength of 4842 psi. Again a load deflection plot normalized to the concrete compressive strength was created to help remove the effects of the difference in concrete strength. The normalized load deflection plot can be seen in Figure 4.3.4.1. Looking at the plot it can be seen that the restrained slab still had a capacity that was $102.5 \%$ of the capacity of the unrestrained slab. This slight increase in capacity suggests that the lateral restraint that was present in the restrained test was not very effective in increasing the punching capacity of the slab.

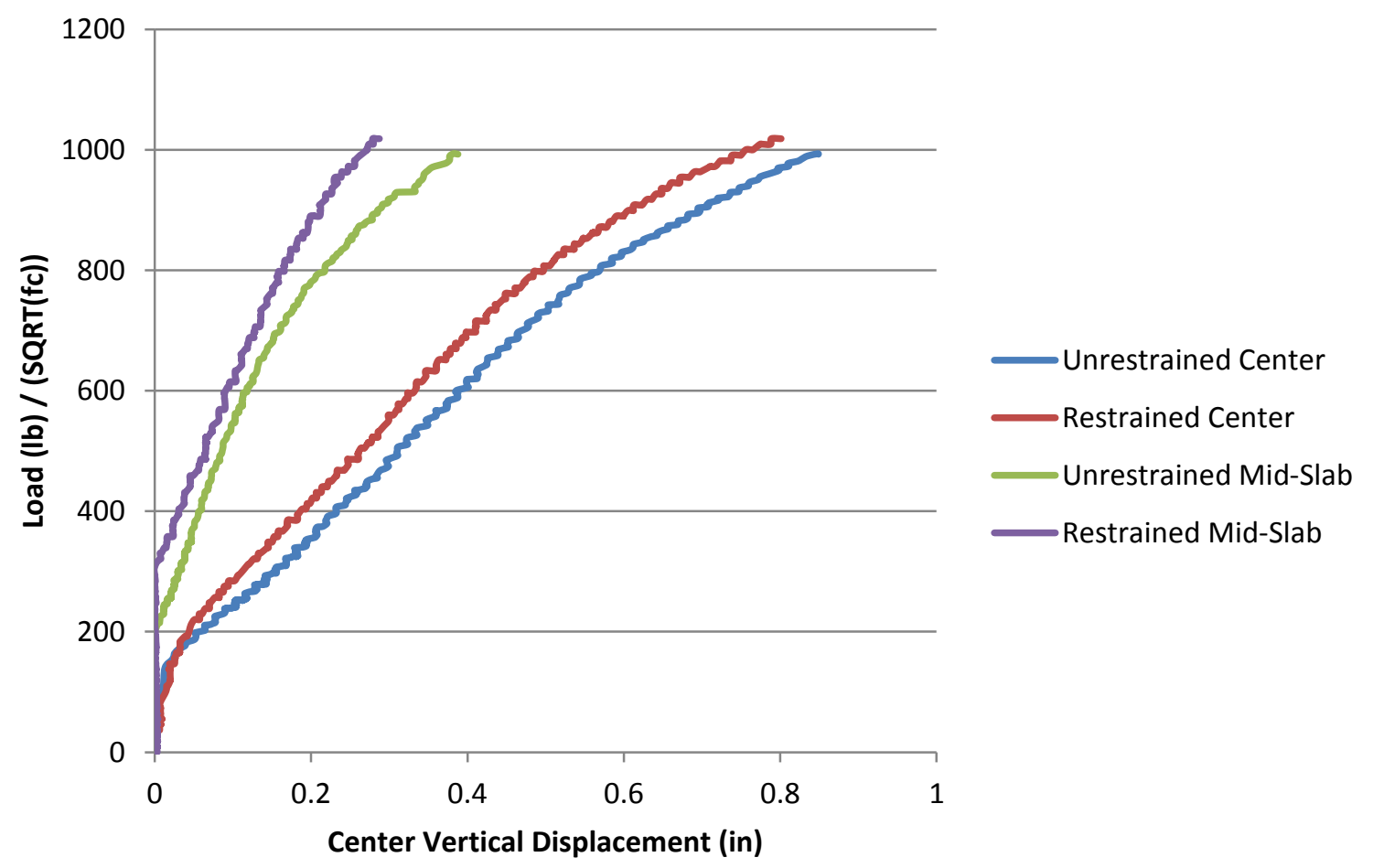

Figure 4.3.4.1 - Load deflection plot normalized to the concrete compressive strength for the slabs with a $1.0 \%$ reinforcement ratio.

The post punching residual capacity of the $1.0 \%$ reinforcement ratio slabs tested in both the unrestrained and restrained test setups was also examined. The residual capacity was determined from load deflection plots that included the post punching behavior of the slab 
column specimen. It was determined that the $1.0 \%$ reinforcement slab tested in the unrestrained tests setup had a residual capacity of 57.6 kips which was $83.3 \%$ of the punching failure load for that slab column specimen. The $1.0 \%$ reinforcement slab tested in the restrained test setup had a residual capacity of 55.3 kips which was $74.7 \%$ of the punching failure load for that slab column connection. The ability of these connections to carry a large portion of their ultimate load after the failure has occurred is vital in structures where the load would have to be redistributed to the surrounding connections. 


\section{Chapter 5 - Summary and Conclusions}

The goal of the research project is to evaluate the performance of flat plate reinforced concrete slab column connections in a scenario where a surrounding connection has failed. This results in increased stresses at the connection which can lead to a progressive collapse. There has been little research on the resistance of flat plates to progressive collapse; therefore the goal is to better understand the performance of these types of connections. The main goal of this portion of the research project was to evaluate the effects of in-plane lateral restraint on the punching shear capacity of flat plate reinforced concrete slab column specimens constructed at two different reinforcement ratios as well as evaluate the post punching residual capacity of these types of connections.

Equations provided by ACI predict that the punching shear capacity of the slab column specimens should have been about 70 kips. However these equations do not take into account the reinforcement that is included in the slab or the effects of in-plane lateral restraint. The ACI equations can provide a reasonable estimation of the capacity of the connection, however the effects of reinforcement ratio would need to be included in calculations to generate more accurate estimations of capacity for slab column connections.

The first two slab specimens tested were loaded without the addition of in-plane lateral restraint. These slabs were at constructed at different reinforcement ratios the first having a reinforcement ratio of $1.0 \%$ and the second having a reinforcement ratio of $0.5 \%$. It was found that the slab with the $1.0 \%$ reinforcement ratio had a punching capacity just over 69 kips which is very close to the $\mathrm{ACI}$ equations capacity estimation. The slab with the $0.5 \%$ reinforcement ratio had a punching capacity of just under $52 \mathrm{kips}$, which is significantly lower than the ACI 
estimation. This demonstrates the need for the inclusion of reinforcement ratio in equations designed to estimate the punching capacity of slab column connections. The slabs tested with the addition of in-plane lateral restraint were constructed with the same reinforcement ratios and showed a similar difference in capacity based on reinforcement ratio as the slabs tested without the lateral restraint. The capacities of the slabs tested can be seen in Figure 5.1.

Table 5.1 - Slab specimen failure loads and peak residual capacities.

\begin{tabular}{|c|c|c|}
\hline $\begin{array}{c}\text { Slab reinforcement / } \\
\text { Test setup configuration }\end{array}$ & Punching Failure Load (kips) & Peak Residual Capacity (kips) \\
\hline $1.0 \%$ Restrained & $73.9 \mathrm{kips}$ & $55.3 \mathrm{kips}$ \\
\hline $0.5 \%$ Restrained & $54.3 \mathrm{kips}$ & $48 \mathrm{kips}$ \\
\hline $1.0 \%$ Unrestrained & $69.1 \mathrm{kips}$ & $57.6 \mathrm{kips}$ \\
\hline $0.5 \%$ Unrestrained & $51.9 \mathrm{kips}$ & $41.3 \mathrm{kips}$ \\
\hline
\end{tabular}

In order to investigate the effects of the in-plane restraint the slabs tested in the different configurations with the same reinforcement ratio must be compared. Looking at the results of the testing of the slabs with a reinforcement ratio of $0.5 \%$ it can be seen that the slab tested with the effects of in-plane lateral restraint only achieved $89 \%$ of the capacity of the slab tested without the effects of in-plane lateral restraint. These results are the inverse of what was expected prior to the testing however it was determined that the test setup designed to provide lateral restraint did not perform as designed. It was determined that a lateral stiffness of about $525 \mathrm{kips} / \mathrm{in}$ was achieved during the testing unfortunately this was only $32 \%$ of the designed lateral stiffness of $1600 \mathrm{kips} / \mathrm{in}$. This lack of lateral stiffness did not allow the full effects of 
compressive membrane action to develop which was anticipated to increase the punching capacity of the slab. When looking at the results of the testing of the slabs with a reinforcement ratio of $1.0 \%$ it was seen that the slab tested with the effects of in-plane lateral restraint reached a capacity equal to $102.5 \%$ of the capacity of the slab tested without lateral restraint present. As in the testing of the slabs with the lower reinforcement ratio the lateral stiffness was less than $35 \%$ of the designed stiffness. Again it is believed that this lack of stiffness did not allow for the full benefits of compressive membrane action to develop.

The slab specimens were continually loaded after the punching failure occurred in order to examine their post punching behavior. The post punching residual capacity of the connections is of interest because the connections ability to carry load after the punching failure occurs can help to prevent failures in surrounding connections. It was determined that all four of the slabs tested had a peak residual capacity equal to at least $74 \%$ of their failure loads. The high residual capacities of these slab specimens would be essential in a real structure because the residual capacity would help to prevent damage to the surrounding connections as the load is redistributed after the punching failure.

Table 5.2 displays the calculated angle of rotation of the slab specimens prior to failure. It should be noted that the slabs tested at the higher reinforcement ratio of $1.0 \%$ rotated less prior to failure than the slabs tested at the lower reinforcement ration of $0.5 \%$. This demonstrates the loss of ductility of the slabs when additional reinforcement is added. 
Table 5.2 - Slab specimen rotations prior to failure.

\begin{tabular}{|c|c|}
\hline $\begin{array}{c}\text { Slab reinforcement / } \\
\text { Test setup configuration }\end{array}$ & $\begin{array}{c}\text { Slab specimen rotation prior to punching } \\
\text { failure (radians) }\end{array}$ \\
\hline $1.0 \%$ Restrained & 0.0126 \\
\hline $0.5 \%$ Restrained & 0.0328 \\
\hline $1.0 \%$ Unrestrained & 0.0173 \\
\hline $0.5 \%$ Unrestrained & 0.0243 \\
\hline
\end{tabular}

Table 5.3 displays the maximum measured concrete strains parallel and perpendicular to the face of the column prior to the punching failure. It should be noted that three of the four slabs tested reached concrete strains parallel to the column of at least $0.0008 \mathrm{in} / \mathrm{in}$ prior to the failure which is consistent with the findings of Broms (1990).

Table 5.3 - Slab specimen concrete strains prior to failure.

\begin{tabular}{|c|c|c|}
\hline $\begin{array}{c}\text { Slab reinforcement / } \\
\text { Test setup configuration }\end{array}$ & $\begin{array}{c}\text { Concrete strain parallel to } \\
\text { column face (in/in) }\end{array}$ & $\begin{array}{c}\text { Concrete Strain perpendicular } \\
\text { to column face (in/in) }\end{array}$ \\
\hline $1.0 \%$ Restrained & 0.001 & 0.0058 \\
\hline $0.5 \%$ Restrained & 0.0004 & 0.0015 \\
\hline $1.0 \%$ Unrestrained & 0.00078 & 0.001 \\
\hline $0.5 \%$ Unrestrained & 0.00084 & 0.0018 \\
\hline
\end{tabular}


Table 5.4 displays the horizontal expansions of the slabs prior to the failure. It can be seen that the slabs tested with the lower reinforcement ratio of $0.5 \%$ expanded slightly more than the slabs tested with the higher reinforcement ratio of $1.0 \%$.

Table 5.4 - Slab specimen horizontal loads and expansions

\begin{tabular}{|c|c|c|}
\hline $\begin{array}{c}\text { Slab reinforcement / } \\
\text { Test setup configuration }\end{array}$ & Slab horizontal expansion (in) & Slab horizontal load (kips) \\
\hline $1.0 \%$ Restrained & 0.0298 & 16.4 \\
\hline $0.5 \%$ Restrained & 0.03 & 15.6 \\
\hline $1.0 \%$ Unrestrained & 0.025 & --- \\
\hline $0.5 \%$ Unrestrained & 0.04 & -- \\
\hline
\end{tabular}

The conclusions that can be drawn from the results of this portion of the research are.

1. Increasing the reinforcement ratio of a flat slab is an effective method of increasing the punching capacity of the slab, however this increase in capacity results in a decrease in ductility.

2. The presence of in-plane lateral restraint reduces the ductility of flat slabs prior to a punching failure occurring because of the additional stresses on the concrete due to the in-plane forces.

3. Isolated slab column specimens constructed with the tension reinforcement continuous through the column and hooked at the edges of the slab can achieve post-punching residual capacities greater than $70 \%$ of the punching capacity of the slab. 
4. The level of in-plane lateral restraint that was achieved during this portion of the testing which was less than designed, was not enough to produce increases in the punching strength of flat slabs.

The results and conclusions drawn from this portion of the research highlight the need for the following future research.

During the remainder of this research project slab specimens will be tested without the reinforcement hooked at the ends to determine the effects on the residual capacity with the reinforcement laid out in a manner more similar to a real structure.

During the remainder of this research project slab specimens will be tested under dynamic loading conditions to evaluate their performance.

The lateral stiffness of the restrained test setup must be improved in order to better evaluate the effects of in-plane lateral forces on the punching behavior of flat slabs.

This research project will conclude with tests of multi panel slab column specimens as opposed to the isolated slab column tests discussed in this thesis to determine the effects of the loss of a supporting column in a real structure. 


\section{REFERENCES}

Aberdeen Group, The. (1956). "Construction Failure at Jackson, Michigan." Jackson, MI. 1956.

A.K.M. Jahangir Alam , Khan Mahmud Amanat \& Salek M. Seraj (2009): Experimental investigation of edge restraint on punching shear behavior of RC slabs, The IES Journal Part A: Civil \& Structural Engineering, 2:1, 35-46

American Concrete Institute. (1971). "Building Code Requirements for Reinforced Concrete (318-71).” Detroit, MI.

American Concrete Institute. (2008). "Building Code Requirements for Structural Concrete (318-08).” Farmington Hills, MI.

Bailey, Colin G. (2000). "Membrane action of unrestrained lightly reinforced concrete slabs at large displacements." Engineering Structures 23, 470-483.

Broms, Carl E. (1990). "Punching of Flat Plates - A Question of Concrete Properties in Biaxial Compression and Size Effect." ACI Structural Journal, No. 87-S30, June 1990.

Calavera, J. (2001). "Comparison of Eurocode 2, Model Code 90 and ACI 318-99 with regard to shear and punching provisions for footings." Structural Concrete, Vol. 2 (4), December 2001, pp. 183-186.

Crowder, Brian. (2005). "Progressive Collapse - Historical Perspective." Naval Facilities Engineering Command. Power-point presentation, 2005.

Dat PX, Hai TK. Membrane actions of RC slabs in mitigating progressive collapse of building structures. Eng Struct (2011)

Elstner, Richard C. and Hognestad, Eivind. (1956). "Shearing Strength of Reinforced Concrete Slabs." ACI Journal, July 1956.

Gardner, N.J. (2011). "Verification of Punching Shear Provisions for Reinforced Concrete Flat Slabs." ACI Structural Journal, No. 108-S54, October 2011.

Gardner, N.J., Chung, Lan, and Huh, Jungsuck. (2002). "Lessons from the Sampoong department store collapse." Cement \& Concrete Composites 24, 523-529.

Gardner, N.J. and Shao, Xiao-yun. (1996). "Punching Shear of Continuous Flat Reinforced Concrete Slabs." ACI Structural Journal, No. 93-S20, April 1996. 
Guice, Leslie K. and Rhomberg, Edward J. (1988). "Membrane Action in Partially Restrained Slabs." ACI Structural Journal, No. 85-S34, August 1988.

Guice, Leslie K., Rhomberg, Edward J., and Slawson, Thomas R. (1989). "Membrane Analysis of Flat Plate Slabs." ACI Structural Journal, No. 85-S10, February 1989.

Habibi, F. Cook W.D. and Mitchell D. (2012). "Assessment of CSA A23.3 Structural Integrity Requirements for 2-Way Slabs.” Can. J. Civ. Eng. Vol. 39, 2012

Harris, Devin K. (2004). "Characterization of Punching Shear Capacity of Thin UHPC Plates." Masters Thesis, 2004.

International Federation for Structural Concrete. (2010). "Model Code 2010". Lausanne, Switzerland.

King, S. and Delatte, N. (2004). "Collapse of 2000 Commonwealth Avenue: Punching Shear Case Study." J. Perform. Constr. Facil., 18(1), 54-61.

Kinnunen, S., and Nylander, H., "Punching of Concrete Slabs Without Shear Reinforcement," Transactions of the Royal Institute of Technology, No. 158, Stockholm, Sweden, 1960, 112 pp.

Muttoni, Aurelio. (2008). "Punching Shear Strength of Reinforced Concrete Slabs without Transverse Reinforcement." ACI Structural Journal, No. 105-S42, August 2008 .

Salim, W., Sebastian W.M. (2002). "Punching Shear Failure in Reinforced Concrete Slabs with Compressive Membrane Action.” ACI Structural Journal, V. 100, No. 4, August 2003.

Tian, Ying, Jirsa, James O., Bayrak, Oguzhan, Widianto, and Argudo, Jaime F. (2008). "Behavior of Slab-Column Connections of Existing Flat-Plate Structures." ACI Structural Journal, No. 105-S52, October 2008.

Vecchio, F.J. and Tang, K. (1989). "Membrane action in reinforced concrete slabs." Toronto, Ont., Canada. 1989.

Wight J. and MacGregor, J. (2005). "Reinforced Concrete Mechanics and Design." Upper Saddle River. New Jersey, 2005.

Xuan Dat P, Hai TK. Experimental study of beam-slab substructures subjected to a penultimate-internal column loss. EngStruct (2013) 


\section{APPENDIX}

Detailed summary of concrete compressive strength testing.

\begin{tabular}{|c|c|c|c|c|}
\hline $\begin{array}{c}\text { Slab } \\
\text { Specimen }\end{array}$ & $1 \%$ Restrained & $\begin{array}{c}1 \% \\
\text { Unrestrained }\end{array}$ & $\begin{array}{c}0.5 \% \\
\text { Unrestrained }\end{array}$ & $\begin{array}{c}0.5 \% \\
\text { Restrained }\end{array}$ \\
\hline Cylinder \#1 $\mathrm{f}_{\mathrm{c}}$ & $4944 \mathrm{psi}$ & $4476 \mathrm{psi}$ & $4793 \mathrm{psi}$ & $6450 \mathrm{psi}$ \\
\hline Cylinder \#2 $\mathrm{f}_{\mathrm{c}}$ & $5327 \mathrm{psi}$ & $4410 \mathrm{psi}$ & $4631 \mathrm{psi}$ & $6412 \mathrm{psi}$ \\
\hline Cylinder $\# 3 \mathrm{f}_{\mathrm{c}}$ & $5302 \mathrm{psi}$ & $4981 \mathrm{psi}$ & $4449 \mathrm{psi}$ & $6481 \mathrm{psi}$ \\
\hline Cylinder $\# 4 \mathrm{f}_{\mathrm{c}}$ & $5723 \mathrm{psi}$ & $5042 \mathrm{psi}$ & $4748 \mathrm{psi}$ & $6332 \mathrm{psi}$ \\
\hline Cylinder $\# 5 \mathrm{f}_{\mathrm{c}}$ & $5384 \mathrm{psi}$ & $4922 \mathrm{psi}$ & $4789 \mathrm{psi}$ & - \\
\hline Cylinder $\# 6 \mathrm{f}_{\mathrm{c}}$ & $5007 \mathrm{psi}$ & $5221 \mathrm{psi}$ & $4818 \mathrm{psi}$ & - \\
\hline Average $\mathrm{f}_{\mathrm{c}}$ & $5281 \mathrm{psi}$ & $4842 \mathrm{psi}$ & $4705 \mathrm{psi}$ & $6418 \mathrm{psi}$ \\
\hline
\end{tabular}

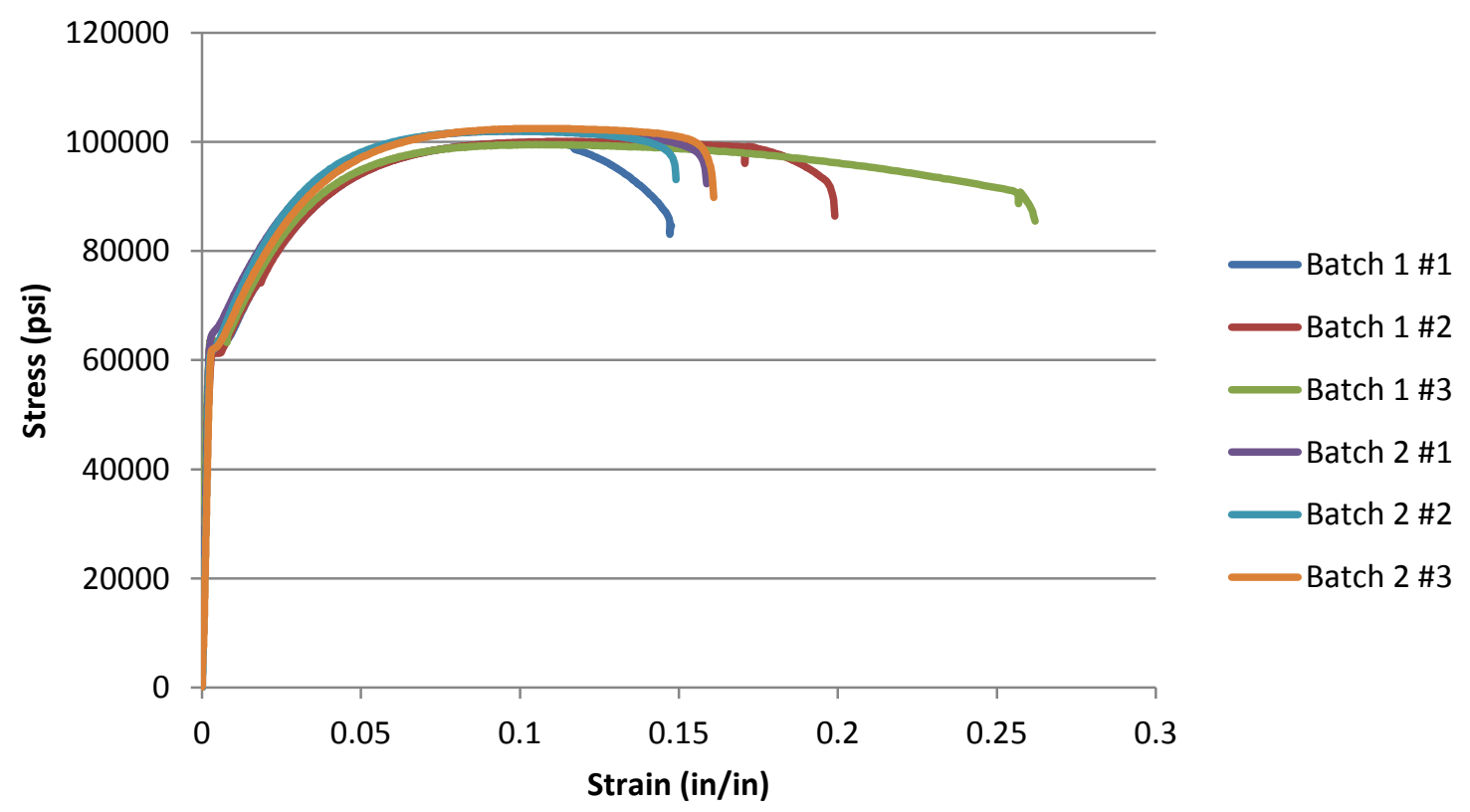

Stress Strain plot recorded during tensile testing of \#3 Rebar samples. 


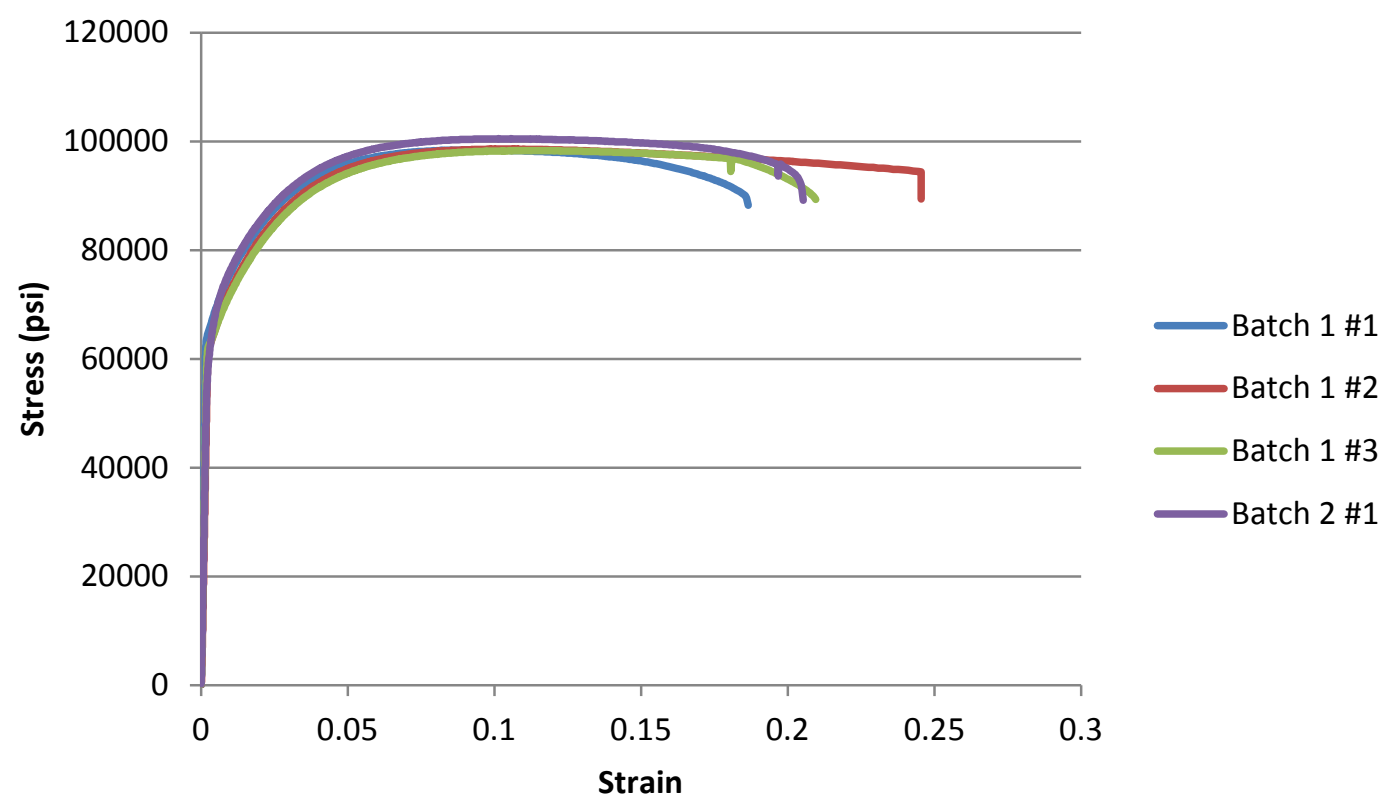

Stress Strain plots recorded during tensile testing of \#4 rebar samples.

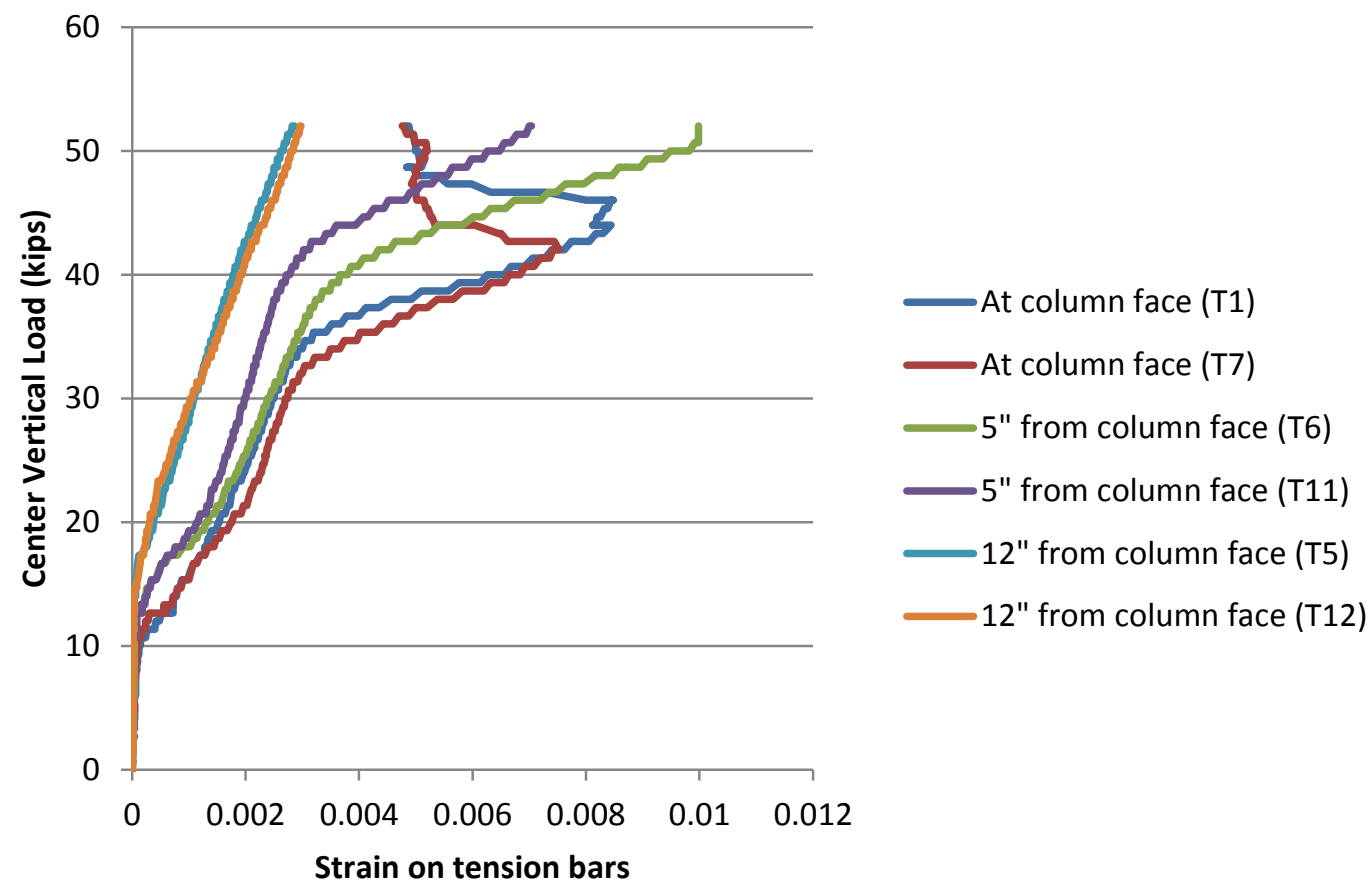

$0.5 \%$ unrestrained, strains on integrity reinforcement (opposite direction of section 4.1.1). 


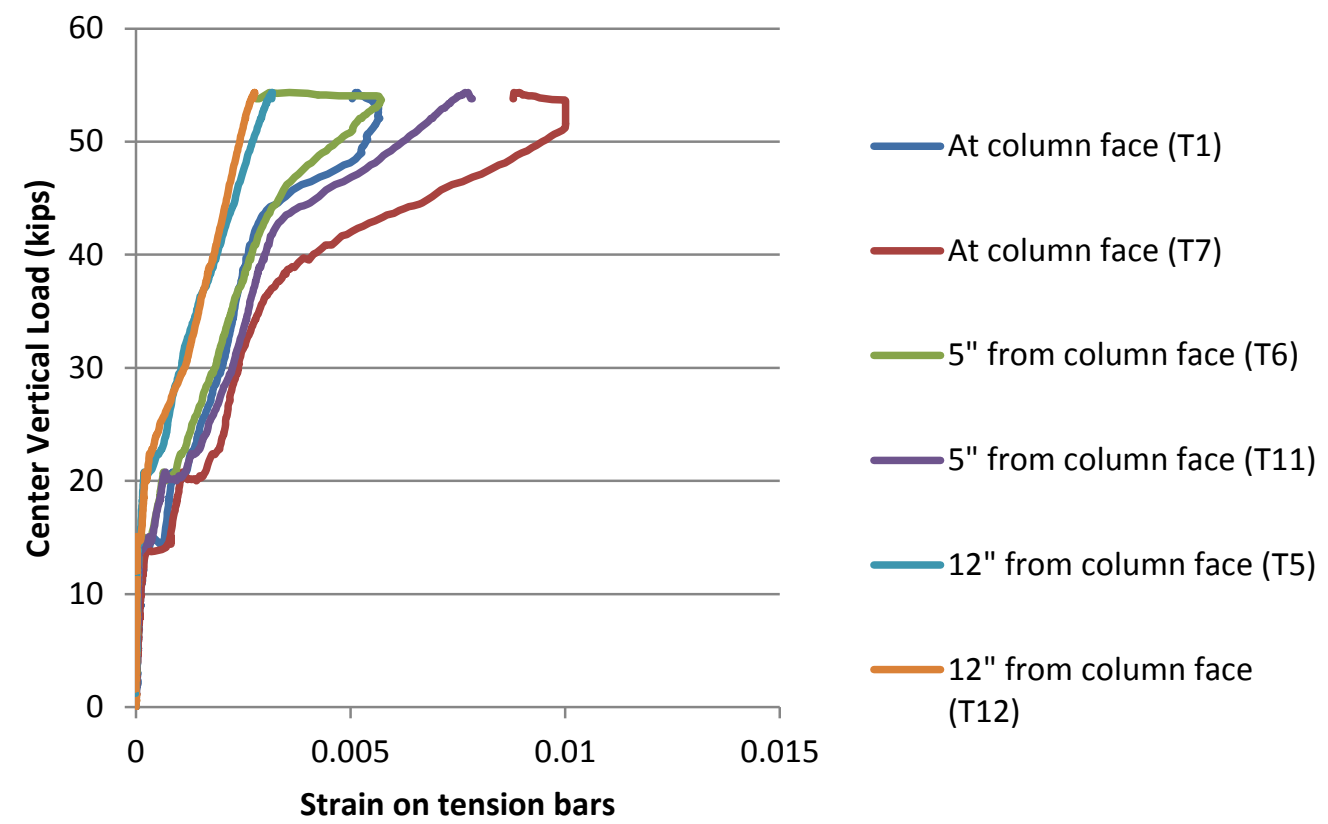

$0.5 \%$ restrained, strains on integrity reinforcement (opposite direction of section 4.2.1).

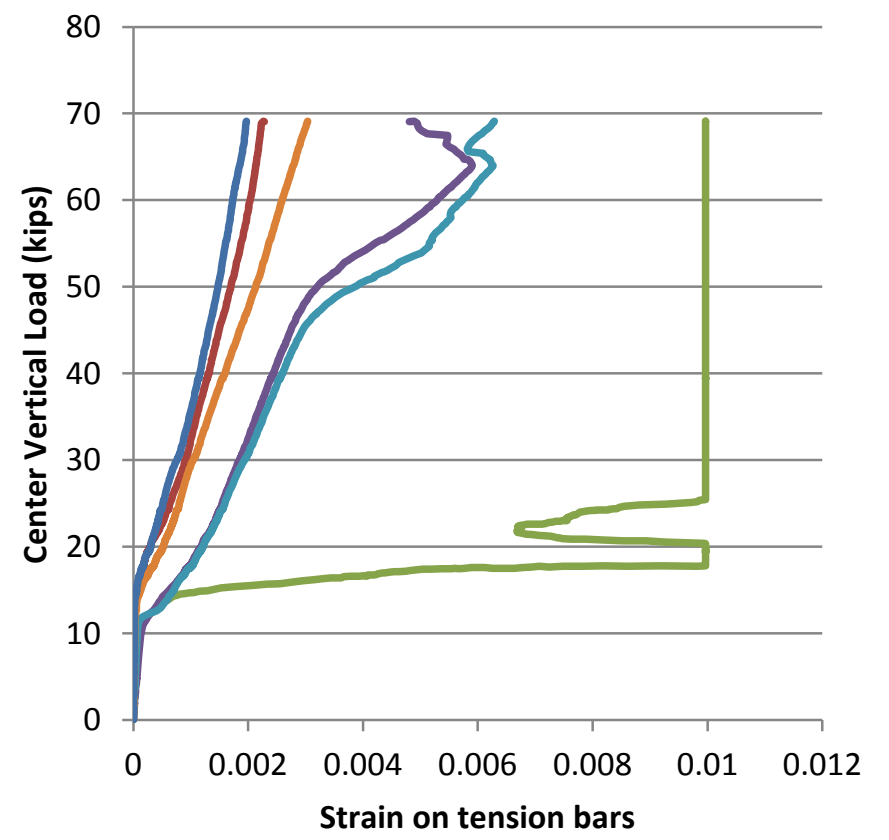

8.5" from column face (T14)

$0.5^{\text {" from column face }}$ (T13)

at column face (T10)

$0.5^{\prime \prime}$ from column face (T8)

4.5 " from column face (T7)

8.5" from column face (T9)

1.0\% unrestrained, strains on integrity reinforcement (opposite direction of section 4.1.3). 


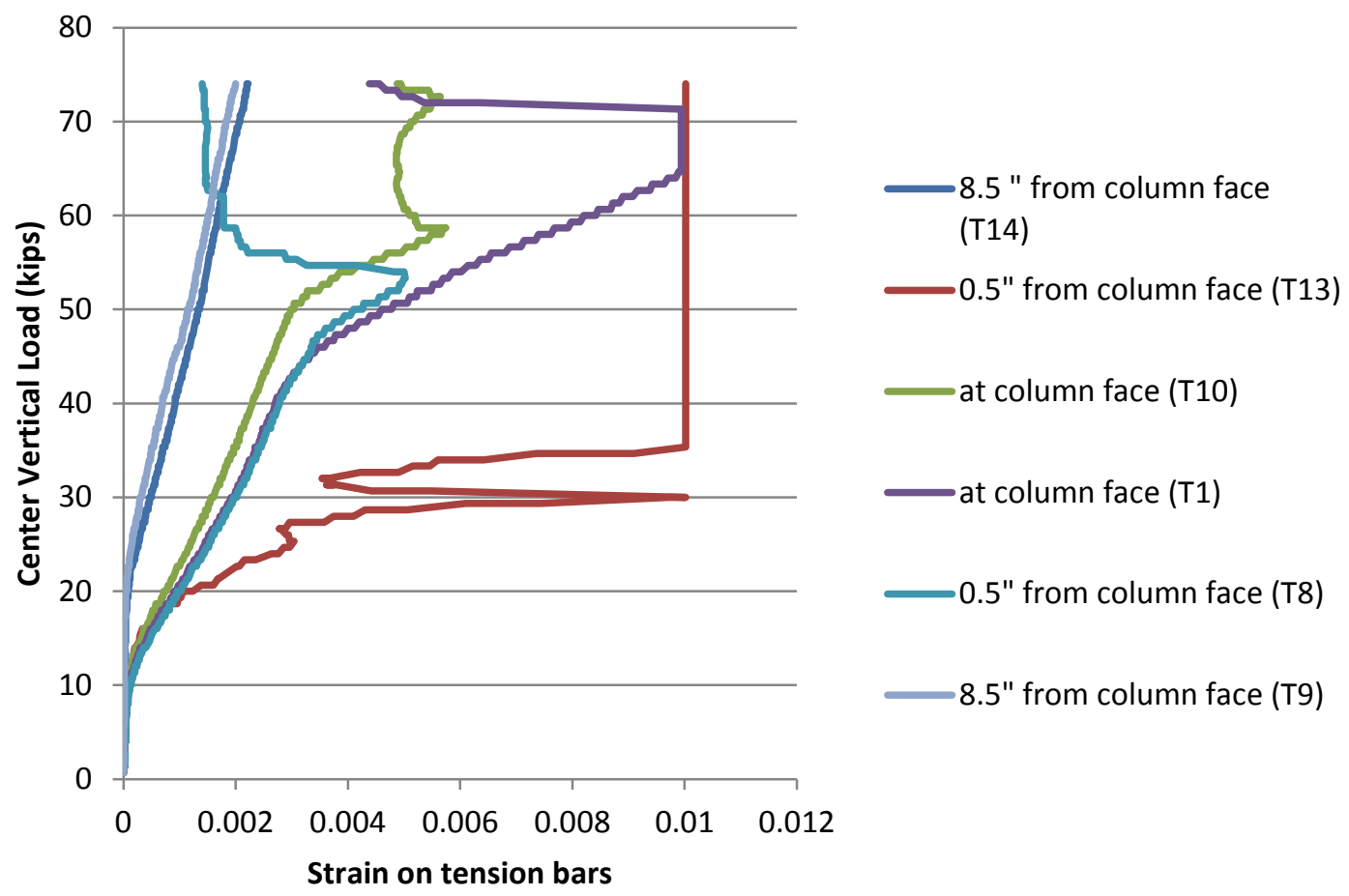

$1.0 \%$ restrained, strains on integrity reinforcement (opposite direction of section 4.2.3).

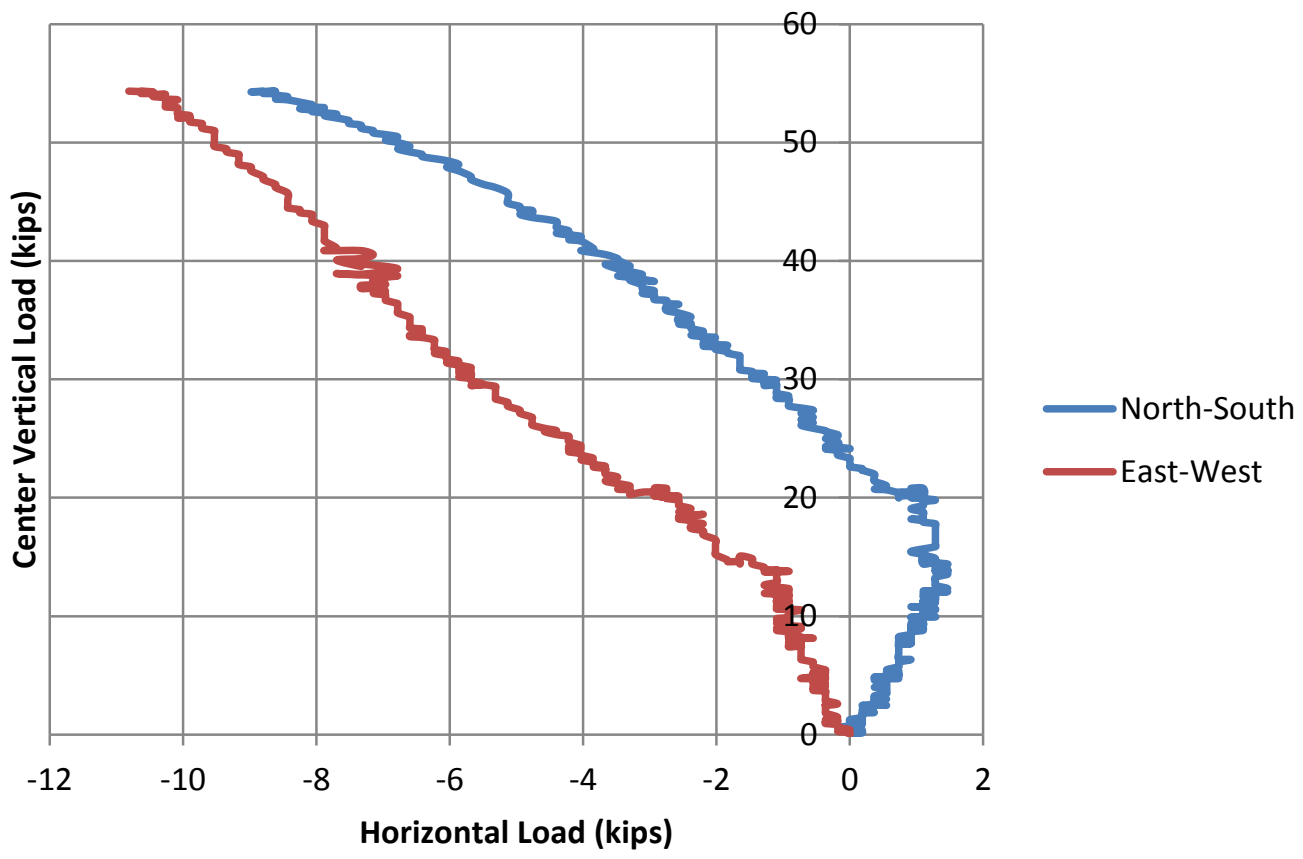

$0.5 \%$ restrained, center vertical load vs. horizontal compressive loads. 


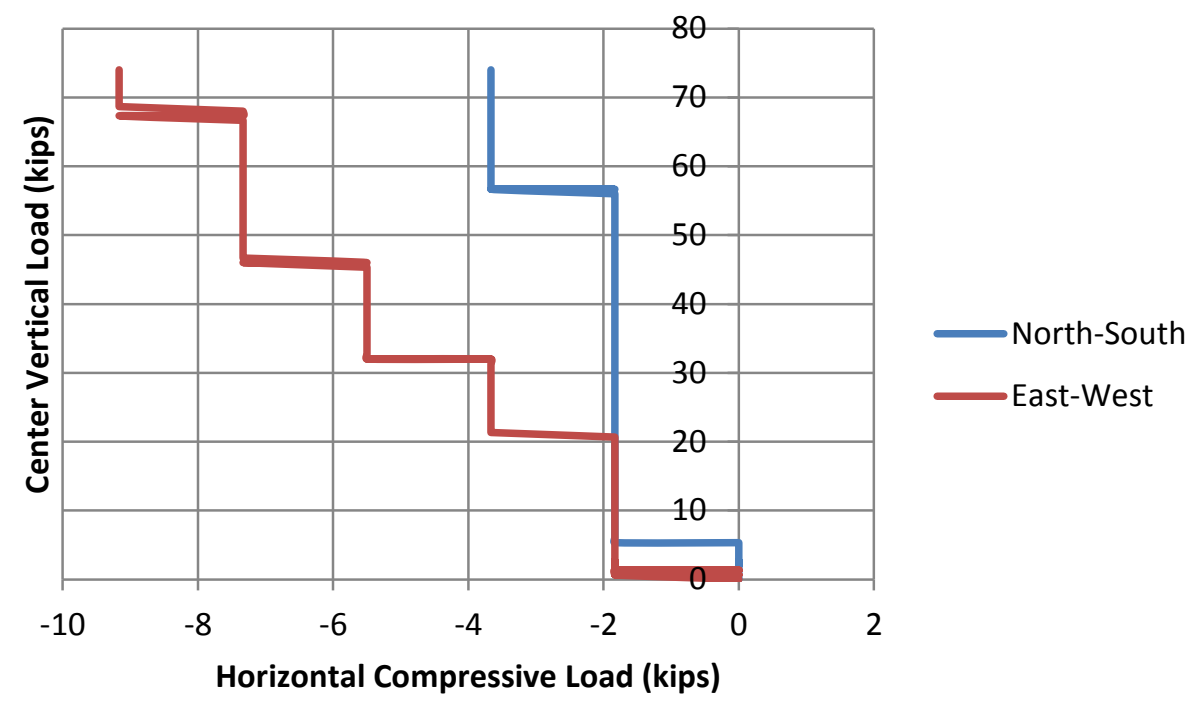

$1.0 \%$ restrained, center vertical load vs. horizontal compressive loads.

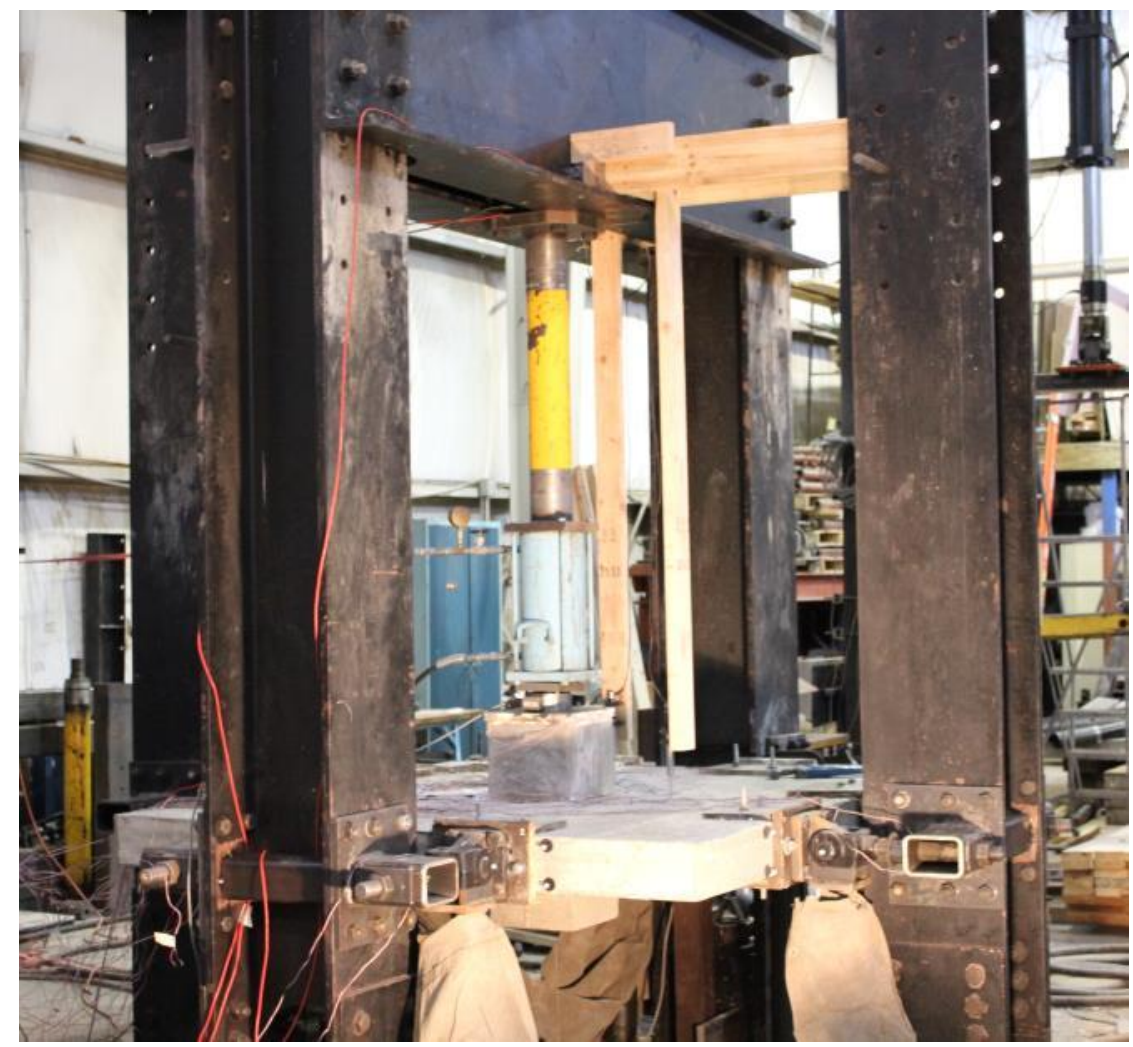

Photo of overall test setup 